\author{
UNIVERSIDADE DE SÃO PAULO \\ INSTITUTO DE PSICOLOGIA
}

\title{
DIFUSÃO EXPERIMENTALMENTE INDUZIDA DO USO DE FERRAMENTAS DE SONDA EM UM GRUPO SEMI-LIVRE DE MACACOS-PREGO (SAPAJUS SP.)
}

HENRIQUE PEREIRA RUFO

BACHAREL EM CIÊNCIAS BIOLÓGICAS

SÃO PAULO

2019 


\author{
UNIVERSIDADE DE SÃO PAULO \\ INSTITUTO DE PSICOLOGIA
}

\title{
DIFUSÃO EXPERIMENTALMENTE INDUZIDA DO USO DE FERRAMENTAS DE SONDA EM UM GRUPO SEMI-LIVRE DE MACACOS-PREGO (SAPAJUS SP.)
}

(Versão corrigida)

\author{
HENRIQUE PEREIRA RUFO \\ BACHAREL EM CIÊNCIAS BIOLÓGICAS
}

\begin{abstract}
Dissertação apresentada ao Instituto de Psicologia da Universidade de São Paulo como parte dos requisitos necessários para a obtenção do título de Mestre em Psicologia.
\end{abstract}

Área de Concentração: Psicologia Experimental

Orientador: Prof. Dr. Eduardo B. Ottoni

\section{SÃO PAULO}

2019 
AUTORIZO A REPRODUÇÃO E DIVULGAÇÃO TOTAL OU PARCIAL DESTE TRABALHO, POR QUALQUER MEIO CONVENCIONAL OU ELETRONICO,

PARA FINS DE ESTUDO E PESQUISA, DESDE QUE CITADA A FONTE.

Catalogação na publicação Biblioteca Dante Moreira Leite

Instituto de Psicologia da Universidade de São Paulo

Dados fornecidos pelo(a) autor(a)

Rufo, Henrique Pereira

Difusão experimentalmente induzida do uso de ferramentas de sonda em um grupo semi-livre de macacos-prego (Sapajus sp.) / Henrique Pereira Rufo;

orientador Eduardo Benedicto Ottoni. -- São Paulo, 2019.

$179 \mathrm{f}$.

Dissertação (Mestrado - Programa de Pós-Graduação em Psicologia Experimental) - Instituto de Psicologia, Universidade de São Paulo, 2019

1. Macacos-prego. 2. Aprendizagem social. 3. Uso de ferramentas. 4. Sonda. 5. Difusão. I. Ottoni, Eduardo Benedicto, orient. II. Título. 
“O Universo é um lugar desconcertantemente grande, um fato que, para continuar levando uma vida tranquila, a maioria das pessoas tende a ignorar." (O guia do mochileiro das galáxias) 


\section{DEDICATÓRIA}

Dedico essa dissertação a minha mãe, Maria Angela, por todo apoio nos momentos difíceis e pelo seu suporte em cada batalha diária, sem a sua força a conclusão desse trabalho não seria 
possível. Te amo. 


\section{AGRADECIMENTOS}

Ao meu orientador Prof. Dr. Eduardo Ottoni por me abrir as portas do mundo acadêmico, por todo conhecimento compartilhado, pela sabedoria e pela paciência.

A minha namorada e parceira, Tainah Fonseca, por todo apoio, incentivo, amor e compressão durante essa jornada.

Ao meu pai, Edson Rufo, que sempre me apoiou.

Aos meus colegas de laboratório e departamento Tiago Falótico, Paulo Henrique, Denize Ezaki, Carolina Bueno, Natália Biscassi, Naila Fukimoto, Natália Albuquerque, Rafael Rodrigues, Jani Pereira, Tati Valença, Graziela Abe, Carolina Wood, Marie Caroline e Josiane Marques.

Aos professores e professoras do Instituto de Psicologia, Briseida Resende, Michele Verderane, Nicolas Chaline, Patrícia Izar, Marceli Rossi, Emma Otta e Ronara Chaline.

Ao Parque Ecológico do Tiete e funcionários por me receber e permitir a realização da minha pesquisa nesse lugar maravilhoso.

Aos familiares que acreditaram nessa conquista.

Aos meus amigos, Antônio Carlos, Fabiano Menegidio, Cynthia Ramos, Loren Nakano, Leonardo Cruz, Aline Gonçalves, Armando Serra, Fred, Bruno Soares, Allan Marin, Thamara Regis, Aline e Rodrigo Merlin, entre tantos outros, agradeçoos pelos momentos de descontração.

Aos macacos-prego do Parque por todo esse tempo em que passamos juntos e que sem eles não haveria pesquisa. 


\section{SUMÁRIO}

DEDICATÓRIA ................................................................................ 5

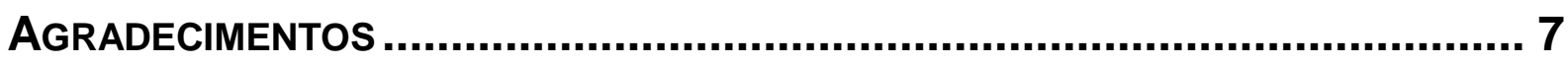

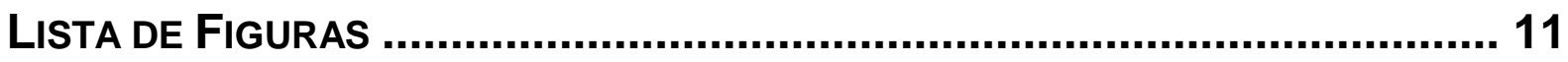

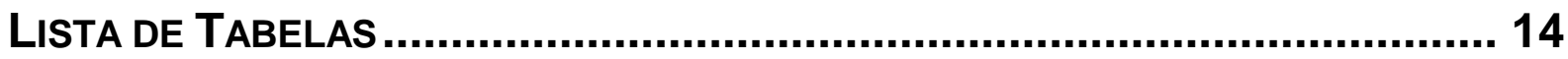

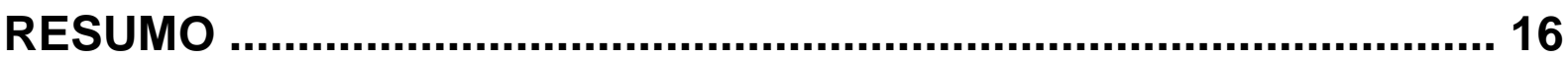

ABSTRACT ...................................................................................... 17

1. INTRODUÇÃO ........................................................................... 18

1.1. Uso de ferramentas percussivas por macacos-prego .................................21

1.2. Uso de ferramentas de sondas por macacos-prego .....................................24

1.3. Aprendizagem Socialmente Mediada ......................................................26

1.4. Tradições Comportamentais e Cultura em animais não-humanos .............29

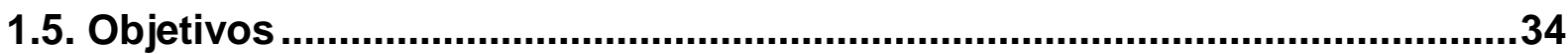

2. MATERIAIS E METÓDOS ............................................................... 36

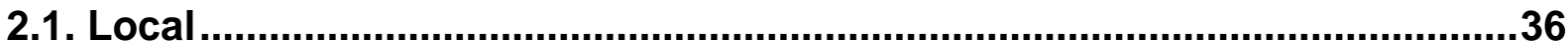

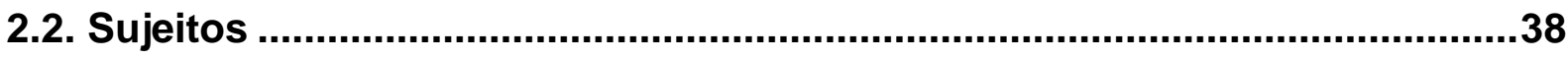

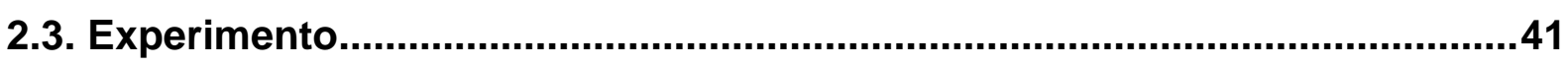

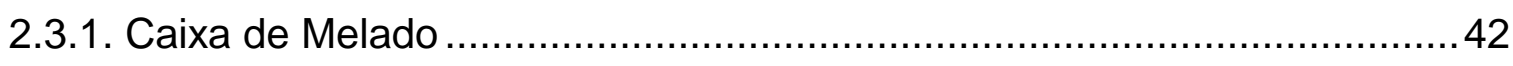

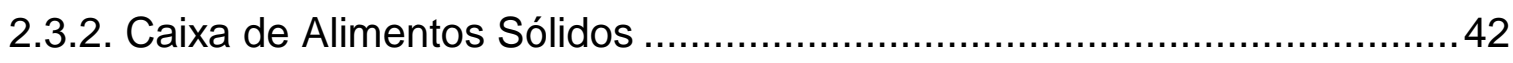

2.3.3. Disponibilização de ferramentas (Facilitações)......................................... 43

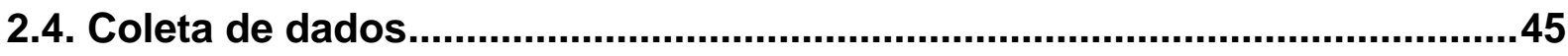

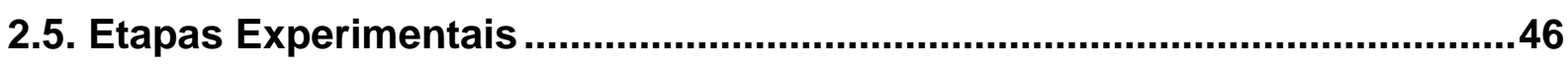

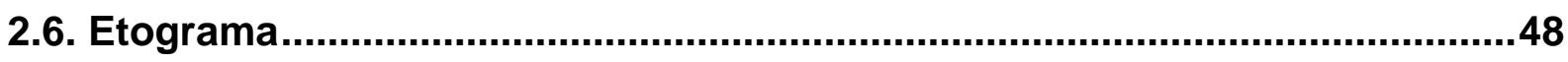

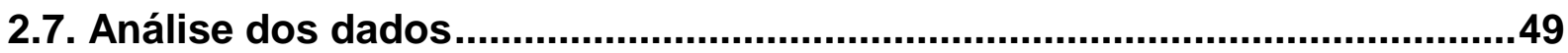

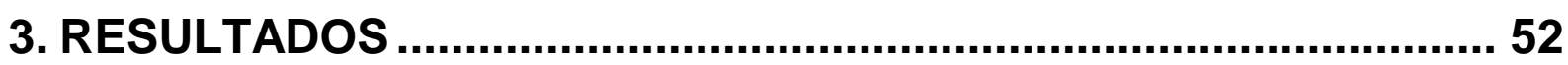

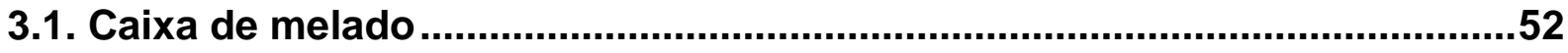

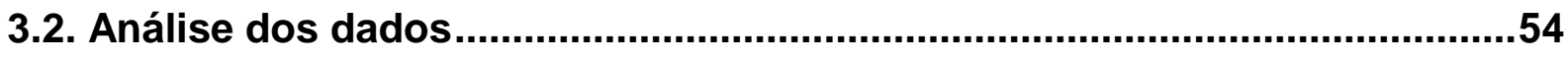

3.3. Investigação das variáveis entre os bem-sucedidos ...................................57

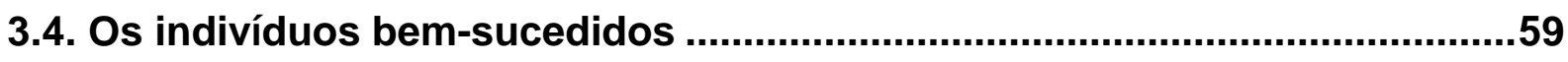

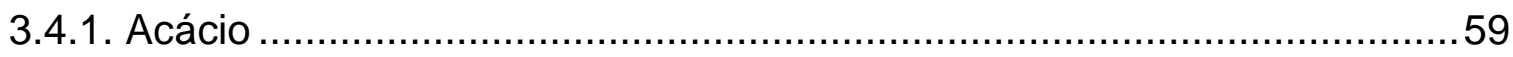

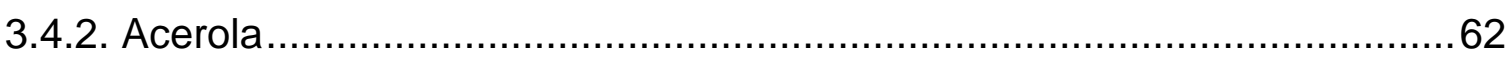




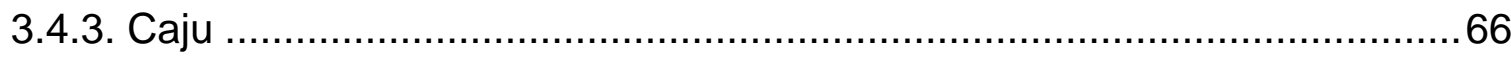

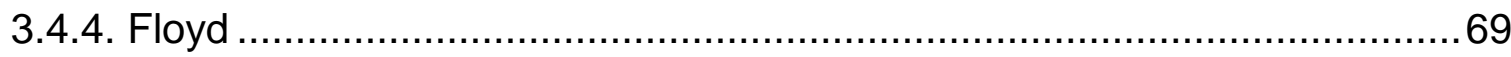

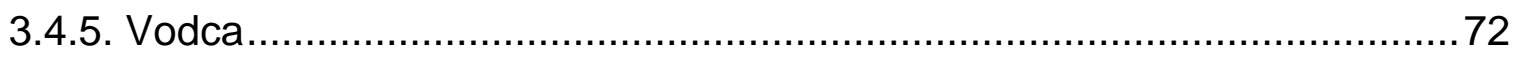

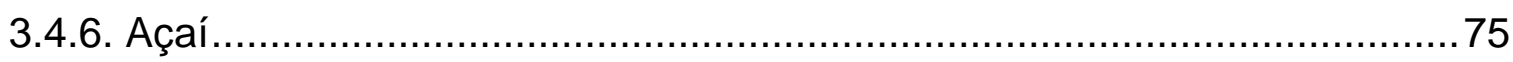

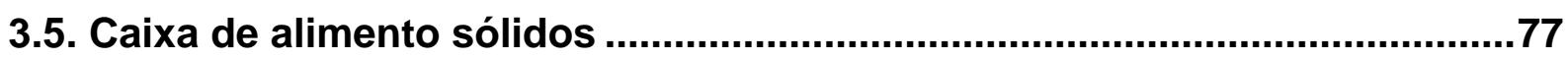

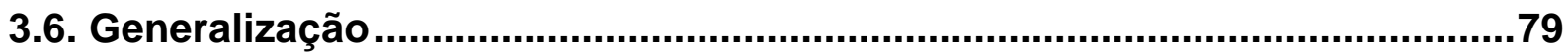

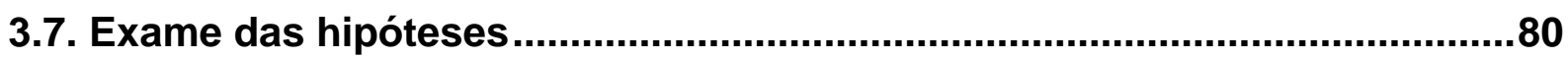

4. DISCUSSÃO ............................................................................. 82

4.1. Diferença no desempenho de machos e fêmeas ............................................83

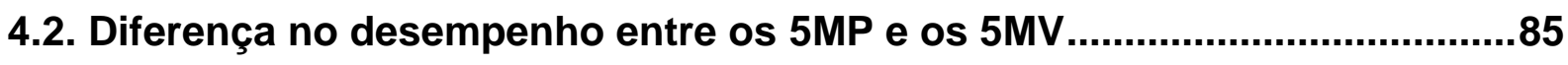

4.3. Avaliação da trajetória individual dos sujeitos proficientes ........................86

4.3.1. O primeiro sucesso se seguiu após Inserções Observadas? ...................86

4.3.2. O primeiro sucesso se seguiu a um aumento de Manipulação de

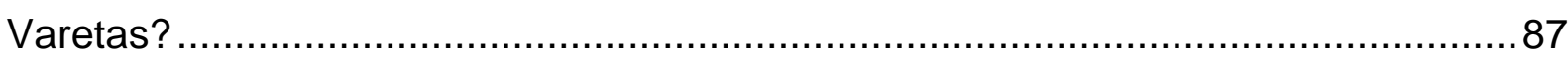

4.3.3. O primeiro sucesso se seguiu após Inserções Involuntárias? ..................87

4.3.4. Inserções Observadas levaram a um aumento subsequente na Manipulação de Varetas?

4.3.5. Períodos de Facilitação levaram a um aumento na Manipulação de Varetas? 88

4.3.6. Eventos de scrounging levaram a um aumento subsequente na Manipulação de Varetas?

4.3.7. O que pode ter contribuído para um aumento na manipulação de varetas?

4.4. $O$ uso de ferramentas pós-sucesso 90

4.4.1. Manipulações nocivas e não-funcionais, são interrompidas após o primeiro sucesso?

4.4.2. Manipulações não-funcionais de varetas que persistiram após o sucesso, aconteceram em associação com as primeiras inserções? ..................................... 91

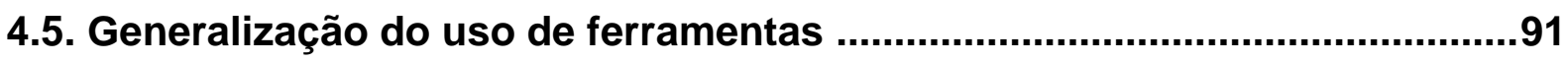

5. CONCLUSÃO............................................................................. 93

6. REFERÊNCIAS BIBLIOGRÁFICAS............................................ 95

7. APÊNDICES..........................................................................107

APÊNDICE A - DATAS DE COLETA DE DADOS ......................................108 
APÊNDICE B - TABELA DE DADOS DAS VARIÁVEIS PARA CADA INDIVÍDUO..110 APÊNDICE C - TESTE de CORRELAÇÃo de PEARson (DAdOS BRUTOS) ...112 APÊNDICE D - TESTE dE CORRELAÇÃo de PEARSON (DADOS CORRIGIDOS) 136

APÊNDICE E - TESTES ESTATÍSTICOS NÃO PARAMÉTRICOS (DADOS BRUTOS) 164

APÊNDICE F - TESTES ESTATÍSTICOS NÃO PARAMÉTRICOS (DADOS CORRIGIDOS) 174 


\section{LISTA DE FIGURAS}

Figura 1 - Mapa do Parque Ecológico do Tietê. Os locais de experimento estão indicados por: F1 - para a primeira fase (presencial) e F2 - para a

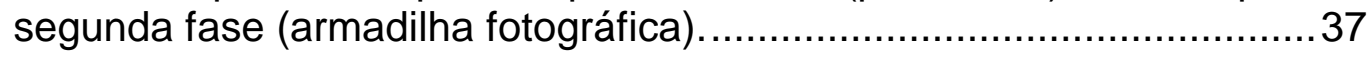

Figura 2 - Caixas-problema. a: caixa de melado; b: caixa de sólidos.

Figura 3 - (a) Varetas disponibilizadas aos macacos para uso como ferramentas; (b) Facilitação com varetas pré-inseridas; (c) caixa de melado com duas varetas fixas.

Figura 4 - Linha do tempo indicando a disponibilidade das caixas e varetas durante todo o experimento. Traços pretos indicam períodos de intervalo na coleta de dados.

Figura 5 - Indicação dos momentos de sucesso do Acácio na Caixa de Melado (seta amarela) e na Caixa de Sólidos (seta vermelha) durante a primeira fase do experimento.

Figura 6 - Tempo total que cada indivíduo esteve em contato com a caixa de melado. Para os sujeitos bem-sucedidos (em azul) o tempo equivale até o momento do primeiro sucesso. Tempo indicado em horas:minutos:segundos (hh:mm:ss). .53

Figura 7 - Tempo total de contato com a caixa de melado para cada indivíduo dos grupos de 5MP (azul), 5MV (laranja) e 5FV (rosa). Tempo apresentado no formato horas:minutos:segundos (hh:mm:ss).

Figura 8 - Comparação do tempo na caixa entre os 5MP (laranja) e os 5MV (azul). 55

Figura 9 - Valor total da variável Manipular Varetas para os 5MP (azul) e os 5MV (laranja).

Figura 10 - Valores totais do ato de Manipular Varetas efetuadas pelo Acácio nos dias de experimento anteriores ao dia de seu sucesso.

Figura 11 - Inserção Involuntária segundos antes do sucesso (Acácio).

Figura 12 - Os atos de Retirar Varetas pré-inseridas efetuados pelo Acácio antes do dia do sucesso não tiveram um reflexo na quantidade de manipulações das varetas. 
Figura 13 - Comparação dos registros de comportamentos relacionados a manipulação de varetas executados pelo Acácio até o dia de seu

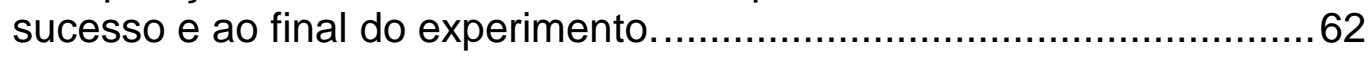

Figura 14 - Linha do tempo que abrange os eventos próximos da primeira Inserção Deliberada bem-sucedida do Acerola. A faixa mais clara indica o momento em que o Acerola está junto com o Acácio na caixa de melado. Os traços pretos são as inserções efetuadas pelo Acácio nesse espaço de tempo. A seta azul indica o momento do sucesso do Acerola. A seta vermelha indica uma Inserção Deliberada Inepta que ocorreu na caixa de sólidos por volta de 10 minutos antes do sucesso. 63

Figura 15 - Quantidade de Inserções Observadas, Manipular Vareta e Tolerated Scrounging realizadas durante um intervalo de tempo dentro da primeira fase. As sessões experimentais estão representadas pelas datas 64

Figura 16 - Total de ocorrências dos comportamentos de Manipular Varetas efetuados pelo Acerola até o momento de seu sucesso comparado ao valor total ao final do experimento. 65

Figura 17 - Linha do tempo mostrando os registros de Esfregar Varetas no dia do sucesso. As faixas claras indicam os eventos que ocorreram na caixa de melado. Cada traço representa uma ação, enquanto que os traços mais largos representam duas ações daquele comportamento naquele tempo. 66

Figura 18 - O comportamento de Manipular Varetas teve uma frequência constante até o dia que o Caju chegou ao sucesso. O gráfico abrange do início do experimento até o dia do sucesso do Caju.

Figura 19 - Total de ocorrências para manipulações de varetas realizadas pelo Caju até o dia de seu sucesso e no experimento como um todo. Valores referentes aos comportamentos efetuados na caixa de melado. 68

Figura 20 - Comportamento de Girar Vareta executado pelo Caju. 69

Figura 21 - Ocorrências do comportamento de Manipular Varetas do início da Segunda Fase até o dia do sucesso. No dia do sucesso Floyd efetuou 43 manipulações, sendo apenas 2 anteriores ao momento do sucesso.70

Figura 22 - Ocorrências do comportamento de Manipular Varetas efetuados pelo Floyd durante e após os cinco Períodos de Facilitação. 71

Figura 23 - Registros de ocorrências de manipulação de varetas executados pelo Floyd até o momento de seu sucesso em comparação com o valor total no experimento. 
Figura 24 - Tempo em que Vodca passou na caixa junto com um sujeito proficiente até o dia do seu sucesso.

Figura 25 - Quantidade de manipulações de varetas efetuadas pelo Vodca do início da segunda fase até o dia do sucesso. 74

Figura 26 - Total de ocorrências dos comportamentos de Manipular Varetas efetuados pelo Vodca até o momento de seu sucesso comparado ao valor total ao final do experimento. ..................................................74

Figura 27 - Tempo em que o Açaí passou em conjunto com algum sujeito proficiente na caixa de melado. O gráfico abrange toda a Segunda Fase do experimento por ter sido em seu início o primeiro contato do Açaí com um proficiente. .75

Figura 28 - Registros do comportamento de Manipular Varetas durante a segunda fase do experimento.

Figura 29 - Registros totais de Manipular Varetas efetuados pelo Açaí até o momento do sucesso e no experimento como um todo. 77

Figura 30 - Tempo total que cada indivíduo passou em contato com a caixa de sólidos. Para os sujeitos proficientes (barras azuis) o tempo conta até o momento do sucesso. 78 


\section{LISTA DE TABELAS}

Tabela 1 - Composição dos indivíduos do grupo ao final do experimento. ND = sexo não identificado. 39

Tabela 2 - Etograma com as categorias comportamentais registradas durante o experimento.50

Tabela 3 - Indivíduos bem-sucedidos na caixa de melado por ordem de sucesso. 53

Tabela 4 - Valores totais do comportamento de Manipular Varetas efetuados pelo Acerola durante os períodos de facilitação com varetas pré-inseridas 64

Tabela 5 - Data do sucesso de cada indivíduo em ambas as caixas. 77

Tabela 6 - Dados dos indivíduos proficientes referentes a algumas ações na caixa de sólidos. Tempo medido em horas:minutos:segundos (hh:mm:ss). 78

Tabela 7 - O tempo apresentado na tabela representa o intervalo entre a solução na caixa de melado e a solução na caixa de sólidos para cada sujeito.

Tabela 8 - Manipulações de varetas realizadas no intervalo de tempo entre os primeiros sucessos em cada caixa.

Tabela 9 - Quantidade de dias em que a ação correspondente a hipótese foi realizada. Eventos ocorridos no mesmo dia do sucesso estão indicados pelo valor 0. São considerados apenas os dias em que os indivíduos estiveram em contato com o experimento.

Tabela 10 - Avaliação das hipóteses para cada um dos sujeitos. Os resultados com o sinal (+) indicada um resposta positiva aquela hipótese, o sinal (-) indica uma resposta negativa e o valor $(\mathrm{P})$ aponta para um resultado parcial. 80

Tabela 11 - Datas das coletas de dados do experimento indicando a duração da coleta para cada dia seguido de informações sobre qual caixa-problema estava disponível no dia e a disponibilidade das varetas.

Tabela 12 - Valores das variáveis para cada indivíduo do grupo. Legenda: IO (Inserções Observadas); TS (Tolerated Scrounging); C/ Pro (Tempo na caixa com proficiente); $2 \mathrm{~m}$ Pro (a 2 metros de um proficiente na caixa); $5 \mathrm{~m}$ Pro (a 5 metros de um proficiente na caixa); $\mathrm{Na}$ caixa (tempo em contato com a caixa); $2 \mathrm{~m}$ (tempo a 2 metros da caixa); 5m (tempo a 5 metros da caixa); RF (retirada de varetas facilitadas); PF (puxar vareta fixa); EC (exploração da caixa); DS (Delayed Scrounging); MV (Manipular Varetas). 110 



\section{RESUMO}

RUFO, H. P. Difusão experimentalmente induzida do uso de ferramentas de sonda em um grupo semi-livre de macacos-prego (Sapajus sp.). São Paulo. 2019. Dissertação (Mestrado) - Instituto de Psicologia, Universidade de São Paulo.

Os macacos-prego selvagens são usuários habilidosos de ferramentas líticas. O uso habitual de sondas, porém, só foi observado em machos de uma única população. Nós disponibilizamos a um grupo de macacos-prego (Sapajus sp.) semilivre caixas-problema das quais eles poderiam extrair melado ou alimentos sólidos através de ferramentas de sonda. A disponibilidade das ferramentas variou em todas as condições. Após $17 \mathrm{hs}$ de interação do grupo com a caixa de melado, 1 macho adulto resolveu a tarefa. Demorou muito mais tempo para que outros cinco machos fossem bem-sucedidos. As fêmeas, no entanto, apresentaram uma frequência de visitação baixa ao experimento. Nós comparamos os comportamentos destes cinco machos proficientes (primeiro macho inovador excluído), com os próximos 5 machos mais ativos (malsucedidos): a frequência de "Manipulação de Varetas" foi a única diferença significativa. Oportunidades de "Inserções Observadas" ou "Scrounging" não tiveram nenhum efeito imediato no sucesso - nem "Retirar varetas facilitadas" (exceto para o primeiro sujeito bem-sucedido). O contato social e a facilitação da extração de sondas levaram a um aumento da manipulação das varetas e do contato com as caixas, aumentando as oportunidades de aprendizagem social: a primeira inserção bem-sucedida pareceu ocorrer inadvertidamente após a frequente manipulação de varetas na caixa de melado. A generalização para o sucesso na Caixa de alimentos sólidos foi extremamente rápida para os macacos bem-sucedidos na caixa de melado.

Palavras-Chaves: macacos-prego, aprendizagem social, uso de ferramentas, sondas, difusão. 


\begin{abstract}
RUFO, H. P. Experimentally induced diffusion of probe tool use in a group of tufted capuchin monkeys (Sapajus sp.). São Paulo. 2019. Dissertation (Master) - Instituto de Psicologia, Universidade de São Paulo.

Wild tufted capuchins are dexterous stone tool users. The customary use of probes, though, has only been observed in males of a single population. We exposed a semi-free group to boxes from which molasses or solid food could be extracted. Probe availability varied across conditions. After 17 hs of group interaction with the molasses box, 1 adult male solved the task. It took much longer for 5 other males to succeed (females visited much less the apparatus). We compared the behaviors of these five proficient males (first excluded) with the next 5 more active (unsuccessful) males: frequency of "General Manipulation" of sticks was the only significant difference. "Probing observation" or "Scrounging" did not have any immediate effect on success - nor did "Pre-inserted Probe Extraction" (except for the first successful subject). Social information and facilitated probe extraction led to an increase of sticks and boxes manipulation, enhancing opportunities for associal learning: the first successful probing seemed to occur inadvertently after clumsy manipulation of sticks on the molasses box. Generalization to probing of solid food was extremely fast for the molasses-proficient monkeys.
\end{abstract}

Keywords: capuchin monkey, social learning, stick tool-use. 


\section{INTRODUÇÃO}

A busca por características exclusivas de nossa espécie, que possam nos distinguir dos outros animais, tem sido uma tarefa antiga, provavelmente remontando aos primórdios da humanidade. Uma clássica definição formulada por Platão apresentava o ser humano como um animal, bípede e sem penas. Essa concepção durou até o momento em que Diógenes soltou no salão uma galinha depenada e exclamou: "Eis o homem de Platão!" (BALLIF; MORAN, 2005, p. 134).

Até o final da década de 50 uma característica tida como exclusivamente humana era o uso e a fabricação de ferramentas. O antropólogo Kenneth Oakley batizou seu livro em 1949 com o título audacioso de "Man the Tool-Maker". Segundo Oakley, grandes primatas até poderiam fazer um limitado uso de ferramentas e em cativeiro, mas fabricar ferramentas a partir de galhos e pedras para um uso especifico era uma característica única e fundamental da espécie humana (OAKLEY, 1944).

Esse pensamento predominava mesmo com estudos realizados em cativeiros, com primatas utilizando ferramentas com muita destreza. Wolfgang Köhler, que foi um pioneiro nos estudos com chimpanzés em cativeiro, desde 1913, demonstrou através de seus experimentos a capacidade desses primatas em manipular objetos/ferramentas para solucionarem tarefas (MCGREW, 1992; DE WAAL, 2005). Oakley tinha conhecimento dos trabalhos de Köhler e os mencionava como exemplos de animais usando ferramentas em cativeiro, mas, para sua definição do que era o ser humano, a capacidade de fabricar ferramentas seria a característica fundamental (OAKLEY, 1956).

O uso de ferramentas por animais não era algo totalmente desconhecido. McGrew (1992), aponta para um dos primeiros relatos de observação naturalística, publicado em 1844, por Savage \& Wyman, em que é descrito o uso de ferramentas de pedra por chimpanzés para a quebra de frutos encapsulados. Em 1794, Erasmus Darwin descrevera uma observação que fez de um primata usando uma pedra como ferramenta para abrir um coco (VISALBERGHI, 
1990) e Charles Darwin, em seu livro de 1871, The Descent of Man and Selection in19 Relation to Sex, escreveu sobre o uso de ferramentas por um chimpanzé:

\footnotetext{
It has often been said that no animal uses any tool; but the chimpanzee in a state of nature cracks a native fruit, somewhat like a walnut, with a stone. Rengger easily taught an American monkey thus to break open hard palm-nuts, and afterwards of its own accord it used stones to open other kinds of nuts, as well as boxes. (DARWIN, 1871, p. 51)
}

O "american monkey" citado se refere a um macaco-prego do gênero Cebus. E Darwin prossegue com um relato sobre uso de vareta como alavanca:

\begin{abstract}
Another monkey was taught to open the lid of a large box with a stick, and afterwards it used the stick as a lever to move heavy bodies; and I have myself seen a young orang put a stick into a crevice, slip his hand to the other end, and use it in the proper manner as a lever. (DARWIN, 1871, p. 51)
\end{abstract}

No início da década de 1960 houve um aumento no número de trabalhos de campo, que seriam os percursores da desconstrução da concepção de Oakley. Principalmente as pesquisas de longo prazo realizadas por Jane Goodall e Toshisada Nishida, na África (DE WAAL, 2005). Os primeiros relatos de Jane Goodall (GOODALL, 1964) descreviam chimpanzés capazes de usar e produzir ferramentas de sonda, modificando galhos para se adequarem à tarefa de capturar cupins em seus ninhos. Posteriormente, outros usos de ferramentas foram observados, como o uso de sondas para capturar formigas (NISHIDA, 1973; MCGREW, 1974; SUGIYAMA, 1995), o uso de folhas para beber água (SOUSA; BIRO; MATSUZAWA, 2009) e o uso de ferramentas líticas para a quebra de cocos (BOESCH; BOESCH, 1983; MATSUZAWA, 1994; INOUE-NAKAMURA; MATSUZAWA, 1997).

Com as primeiras observações naturalísticas de uso de ferramentas por animais nãohumanos se fez necessário uma definição objetiva do que poderia ser classificado como um "uso de ferramenta". Hall (1963) propôs que o uso, por um animal, de um objeto ou de outro organismo vivo como forma de obter uma vantagem ao permitir o animal de ampliar o alcance de seus movimentos e melhorar sua eficiência, seria uma classificação adequada. Um objeto, nesse caso, seria qualquer item externo ao corpo do animal, ou seja, um primata utilizar a cauda, por exemplo, não poderia ser caracterizado como uso de ferramenta.

No entanto, a visão antropocêntrica de Oakley permanece em alguns pesquisadores. Gruber (1969) resiste em abandonar a definição dada por Oakley ao afirmar que somente humanos seriam habilidosos para transformar objetos em ferramentas e que as ferramentas utilizadas por outros animais não consistem em "ferramentas verdadeiras". 
John Alcock (1972) apresenta uma definição semelhante à de Hall (op. cit.) em que "o20 uso de ferramentas envolve a manipulação de um objeto inanimado, não produzido internamente, aumentando a eficiência do animal em alterar a forma ou posição de um segundo objeto qualquer".

Benjamin Beck, em 1980, formulou uma definição que se tornou referência na área nas décadas seguintes, tratando o uso de ferramentas como "o emprego externo de um objeto solto do ambiente para alterar, com mais eficiência, a forma, posição ou a condição de outro objeto, de outro organismo ou do próprio usuário, quando este segura ou carrega a ferramenta durante ou logo antes de seu uso e é responsável pela orientação adequada e efetiva da ferramenta".

A partir dessa definição versões alternativas com pequenas modificações foram sendo propostas, entre elas a de St Amant e Horton (2008) que criticou a atenção excessiva dada sobre os aspectos físicos relacionados ao uso de ferramentas. Através de uma revisão da literatura científica envolvendo o uso de ferramentas por animais não-humanos, Shumaker, Walkup e Beck (2011) apresentaram uma definição atualizada, a qual seguimos nesse trabalho, considerando "o emprego externo de um objeto do ambiente, não fixado ou fixado e manipulável, para alterar de modo mais eficiente a forma, posição ou condição de outro objeto, outro organismo ou o próprio usuário, quando ele segura ou manipula diretamente a ferramenta durante ou antes do uso e é responsável pela orientação correta e efetiva da ferramenta”.

Atualmente é conhecido o uso de ferramentas em animais invertebrados, como polvos (Octupus vulgaris) (MATHER, 1994) e aranhas (HENSCHEL, 1995). Em aves, como os corvos da Nova Caledônia (Corvus moneduloides), que são capazes de fabricar gravetos com pontas em formato de gancho (HUNT, 1996). E em espécies de mamíferos como elefantes (HART et al., 2001; BYRNE; BATES; MOSS, 2009), golfinhos (PARRA, 2007; MANN; SARGEANT, 2009), lontras (HALL; SCHALLER, 2006), entre outras.

Entre os grandes primatas, além dos chimpanzés já mencionados, há registros para orangotangos (Pongo pygmaeus) que usam ferramentas de sondas no forrageio, modificando galhos através da remoção de ramos e folhas, para captura de insetos ou mel de colmeias e até para outras atividades como se coçar (GALDIKAS, 1982; VAN SCHAIK; FOX; SITOMPUL, 1996; FOX et al., 2004). Gorilas (Gorilla gorilla) foram observados usando troncos como uma espécie de cajado ao atravessar ambientes pantanosos (BREUER et al., 2005). Já os 
bonobos (Pan paniscus) raramente são vistos usando ferramentas na natureza e quando são,21 não estão ligadas ao forrageamento, como a utilização de galhos folhosos para se proteger da chuva, ou a um contexto social como o comportamento de esfregar ramos de folhas pelo chão (KOOPS; FURUICHI; HASHIMOTO, 2015).

Primatas da espécie Macaca fascicularis fazem uso de ferramentas de pedra para abrir ostras, gastrópodes, crustáceos e frutos encapsulados na Tailândia (GUMERT et al., 2011). E recentemente, uma população de Cebus capucinus foi observada utilizando ferramentas líticas para a quebra de cocos e carapaças de gastrópodes e crustáceos, no Panamá. Esse é o primeiro registro de uso de ferramentas por macacos-prego-de-cara-branca em vida livre (BARRETT et al., 2018).

Entre os macacos do Novo Mundo, os macacos-prego (Sapajus) e espécies do gênero Cebus se destacam pela destreza e habilidade em manusear objetos (FRAGASZY; VISALBERGHI; FEDIGAN, 2004). Capacidade bem explorada em experimentos de laboratório/cativeiro, antes mesmo do uso de ferramentas ser estudado em populações selvagens (VISALBERGHI, 1987; ANDERSON, 1990; WESTERGAARD; SUOMI, 1993, 1994). Um estudo comparando macacos-prego, chimpanzés, bonobos e orangotangos (VISALBERGHI; FRAGASZY; SAVAGE-RUMBAUGH, 1995), mostrou uma capacidade semelhante na solução das tarefas entre esses primatas, contudo os autores apontam para uma ausência na "compreensão das causas" pelos macacos-prego.

\subsection{Uso de ferramentas percussivas por macacos-prego}

A quebra de cocos realizada pelos macacos-prego requer a combinação de 3 elementos: dois deles móveis, o recurso (geralmente um fruto encapsulado) e o martelo (uma rocha solta na maior parte dos casos) e um substrato fixo, a bigorna, que se trata de uma superfície dura e levemente plana, onde os macacos posicionam o recurso (FRAGASZY et al., 2004; MANNU; OTTONI, 2009). Apesar da tendência dos sítios de quebra (locais onde ocorrem as quebras dos frutos encapsulados) serem relativamente estáveis, o transporte dos elementos móveis se faz necessário em alguns casos. Os macacos-prego podem carregar pedras com pesos equivalentes a 33-77\% de seu peso corporal (LIU et al., 2009) e tendem a priorizar a coleta do recurso e em seguida do martelo. Também otimizam o transporte optando, na maior parte das vezes, por um martelo mais próximo da bigorna (CORAT; SIQUEIRA; OTTONI, 2016). 
Os macacos-prego estão distribuídos por praticamente todo território brasileiro22 (LYNCH ALFARO et al., 2012), no entanto, o uso espontâneo e habitual de ferramentas em ambiente selvagem não é observado nas espécies que vivem em regiões de floresta e Mata Atlântica (exceção feita a poucos casos anedóticos, v. adiante), apenas nas populações do gênero Sapajus encontradas em biomas de cerrado e caatinga (OTTONI; IZAR, 2008; CANALE et al., 2009). Evidências arqueológicas obtidas recentemente demostram que a prática de uso de ferramentas líticas pelos macacos-prego no Nordeste do Brasil ocorre há pelo menos 3 mil anos (FALÓTICO et al., 2019).

As primeiras observações naturalísticas envolvendo o uso de ferramentas para a quebra de cocos foram realizadas em um grupo de macacos-prego (Sapajus sp.) que vive em semiliberdade no Parque Ecológico do Tietê (PET), em São Paulo (MANNU; OTTONI, 1996; OTTONI; MANNU, 2001), mesmo local onde foi realizado o presente trabalho, e no Parque Municipal Arthur Thomas, no Paraná (ROCHA; REIS; SEKIAMA, 1998). A partir desse momento até o presente, outras populações que fazem uso de ferramentas vêm sendo descobertas em ambientes de cerrado e/ou caatinga como em Goiás e Tocantins (MENDES et al., 2015), Rio Grande do Norte (FERREIRA; EMIDIO; JERUSALINSKY, 2010) e na Serra Talhada, em Pernambuco (DE MORAES; DA SILVA SOUTO; SCHIEL, 2014).

Contudo, as duas populações mais estudadas, submetidas a estudos de longo prazo, pertencem a espécie Sapajus libidinosus e estão localizadas no Piaúí, na região da Fazenda Boa Vista (FBV) em Gilbués e na área do Parque Nacional Serra da Capivara (PNSC) em São Raimundo Nonato, com aproximadamente $320 \mathrm{~km}$ de distância entre elas (OTTONI; IZAR, 2008). Recentemente uma nova população usuária de ferramentas (também Sapajus libidinosus) passou a ser estudada sistematicamente numa região localizada entre a FBV e o PNSC, na área do Parque Nacional Serra das Confusões (FALÓTICO et al., 2018).

$\mathrm{Na}$ FBV os macacos-prego fazem uso de ferramentas percussivas para processar frutos encapsulados, alguns muito resistentes (Orbignya sp.), que exigem o uso de pedras com pesos na média de $1 \mathrm{~kg}$, o que torna a atividade mais comum entre os machos adultos, por conta da força necessária no uso da ferramenta (VISALBERGHI et al., 2007; SPAGNOLETTI et al., 2011). As ferramentas percussivas também são usadas para processar castanhas de caju (Anacardium spp.). Enquanto fresca a castanha possuí um composto líquido e cáustico, que pode queimar a pele e irritar a mucosa dos macacos. Para evitar esse líquido, os macacos costumam esfregar e/ou bater as castanhas em substratos duros e algumas vezes usam 
ferramentas percussivas nesse processo, mas o uso dos martelos é mais frequente contra os23 frutos secos (VERDERANE, 2010; SIRIANNI; VISALBERGHI, 2013).

Os grupos de macacos-prego do PNSC apresentam um kit de ferramentas (tool-kit) mais variado, utilizando ferramentas percussivas na quebra de diversos tipos de recursos (DE A. MOURA, 2004) e no caso das castanhas de caju, diferente da população da FBV, o fruto é processado ainda verde com ferramentas líticas (FALOTICO; OTTONI, 2016; FALÓTICO et al., 2017). Ferramentas líticas também são usadas para cavar o solo em busca de aranhas, raízes ou tubérculos (FALOTICO; OTTONI, 2016), para a quebra de troncos mortos em busca de artrópodes, para destacar seixos presos nos paredões de conglomerados e para produzir pequenas partículas de quartzo ao bater pedra com pedra, que podem ser lambidas, inaladas ou esfregadas no corpo, por motivos ainda não compreendidos (MANNU; OTTONI, 2009; FALOTICO; OTTONI, 2016).

Mannu e Ottoni (2009) também observaram a reutilização de uma mesma ferramenta para diversas funções, com o relato de um caso de uma fêmea que transportou e usou o mesmo martelo para 5 atividades diferentes em um período de aprox. 4 minutos. O uso sequencial de diferentes ferramentas também foi visto, podendo envolver ferramentas do mesmo tipo ou de tipos diferentes para alcançar um mesmo objetivo. Em um dos relatos um indivíduo fazia uso de um martelo de pedra para soltar outro seixo do paredão e usar esse novo seixo como martelo para a quebra de cocos, de troncos ou para a produção do pó de quartzo. $\mathrm{O}$ uso de ferramentas diferentes ocorreu em situações de forrageio em que os indivíduos usaram pedras e varetas como sondas, alternando entre elas, para desentocar uma presa (artrópodes ou pequenos vertebrados) de frestas de rochas ou de dentro de troncos. Eventos semelhantes foram observados recentemente por Falótico e Ottoni (2016).

O comportamento de bater pedra com pedra para soltar seixos da matriz de arenito ou "esfarelar" o quartzo com frequência acaba por fragmentar essas rochas. Em alguns casos os macacos reposicionam os seixos partidos e voltam a bater neles com um martelo gerando fragmentos ainda menores. Esses fragmentos foram analisados por Proffitt e colaboradores (2016), que identificaram semelhanças com as lascas produzidas por hominíneos. As lascas acidentalmente produzidas pelos macacos-prego inclusive são cortantes, no entanto, não há nenhum registro que indique algum uso dessas lascas pelos macacos.

O uso de ferramentas líticas também é observado em contexto social nos macacos-prego do PNSC. Mais especificamente, em um contexto sexual: Falótico e Ottoni (2013) descrevem 
fêmeas que durante o período de estro, que pode durar até 7 dias, adicionaram ao display24 sexual característico da espécie o comportamento de arremessar pedras na direção dos machos. Ferramentas líticas também são usadas em conjunto com comportamentos agonísticos. Os macacos, geralmente machos adultos, batem pedras contra um substrato fazendo barulho, esse tipo de comportamento foi observado na presença de possíveis predadores, podendo servir para dissuadir o predador de atacar ao revelar sua presença (MOURA, 2007).

\subsection{Uso de ferramentas de sondas por macacos-prego}

Em um clássico experimento de laboratório realizado por Westergaard e Fragaszy (1987), os macacos-prego precisavam fazer uso de varetas como sonda para obter uma recompensa de dentro de um aparato. Os macacos foram bem-sucedidos e demonstraram a capacidade de modificar a ferramenta para adequá-la à tarefa, removendo ramos ou alterando o comprimento das varetas. Em outro experimento, os macacos foram desafiados a retirar uma recompensa de dentro de um tubo cilíndrico transparente usando varetas. Porém, havia uma armadilha no meio do tubo, um compartimento por onde a recompensa poderia cair e ficar presa. Após algumas tentativas eles foram bem-sucedidos em evitar a armadilha e empurrar a recompensa pelo lado correto do tubo, mas não mostraram compreender a causalidade da tarefa. Mesmo quando o tubo era rotacionado e a armadilha ficava para cima (inoperante), os macacos agiam de forma a evitá-la (VISALBERGHI; LIMONGELLI, 1994). Um experimento semelhante foi oferecido a um grupo da espécie Sapajus nigritus (da qual não há registro de uso espontâneo de ferramentas), e nenhum indivíduo teve sucesso na tarefa (GARBER; GOMES; BICCA-MARQUES, 2012).

Até o presente momento, a única população conhecida que faz uso habitual de ferramentas de sondas no forrageio são os macacos-prego (Sapajus libidinosus) do PNSC, que utilizam varetas para desentocar presas (artrópodes ou pequenos vertebrados, como lagartos) e obter mel de colmeias (FOREST; MOURA; LEE, 2004; OTTONI; IZAR, 2008; MANNU; OTTONI, 2009). Observa-se um viés sexual no uso de ferramentas de sonda (predominantemente por machos) ainda pouco compreendido (FALÓTICO; OTTONI, 2014). Em um episódio peculiar, que não envolvia uma ação de forrageamento, uma fêmea fez uso 
de um graveto para cutucar o nariz, desencadeando espirros, e também para cutucar os25 dentes (HASLAM; FALÓTICO, 2015).

Um trabalho experimental comparando o grupo da Pedra Furada no PNSC e o grupo Chicão na FBV, ambos da espécie Sapajus libidinosus, quanto ao uso de ferramentas de sonda, encontrou uma diferença no desempenho entre esses dois grupos e uma diferença intragrupo no caso do PNSC (CARDOSO; OTTONI, 2016). A tarefa consistia em usar varetas como sondas para obter melado de uma caixa-problema. O grupo Pedra Furada resolveu a tarefa no primeiro dia de experimento, enquanto o grupo da FBV, mesmo quando exposto à caixa com varetas pré-inseridas, não foi bem-sucedido. Isso pode ter se dado pelo fato do grupo Chicão não ser um usuário habitual de ferramentas de sonda. Cardoso e Ottoni (op. cit.) observaram que no grupo da FBV os indivíduos interagiam pouco com a caixa, mostrando pouco interesse e não transportaram nenhum objeto até o aparato Mesmo o grupo sendo usuário de pedras muito pesadas não houve tentativas de usá-las contra a caixa.

No grupo do PNSC a interação foi maior e os indivíduos transportaram varetas e pedras até a caixa, mas assim como observado anteriormente (FALÓTICO; OTTONI, 2014), o uso de ferramentas de sondas e, por conseguinte a solução da tarefa, foi exclusiva dos machos adultos. Mesmo quando as fêmeas encontravam alguma vareta pré-inserida (deixada assim por algum macho), retiravam a vareta para lamber o melado e descartavam sem reutilizar.

O mesmo aparato utilizado por Cardoso e Ottoni (2016) foi oferecido à uma população (Sapajus sp.) na qual não havia registro de uso de ferramentas e após algumas sessões de facilitações (com varetas disponíveis pré-inseridas e varetas fixas - que não podiam ser retiradas totalmente, apenas parcialmente) alguns indivíduos solucionaram a tarefa, com uma fêmea adulta demonstrando o melhor desempenho (CARDOSO, 2013), indicando, como esperado, que não há qualquer impedimento físico, motor ou cognitivo para o uso de ferramentas de sondas pelas fêmeas de macacos-prego.

Em um experimento com macacos-prego cativos, os autores ofereceram uma tarefa envolvendo o uso de sondas como parte de uma atividade de enriquecimento ambiental, que consistia em retirar mel de uma caixa de acrílico (CAMARGO; MENDES, 2016). O foco do trabalho não estava na capacidade dos macacos em usar as sondas de forma eficiente ou não, porém, nesse grupo de 6 indivíduos (3 machos e 3 fêmeas), dois deles, um macho e uma fêmea, apresentaram uma alta performance em uma categoria denominada "sucesso", que representava a inserção de varetas para obtenção do mel. 
O uso de sondas para obtenção de água foi observado em duas localidades, dois26 parques urbanos. No Parque Areião Municipal, Goiânia, foi observado um macho juvenil utilizando um galho ainda com as folhas para mergulhar em uma fenda em um tronco de árvore, retirar e sugar as folhas molhadas. Outro episódio corresponde ao uso de um pedaço de tronco como martelo para a quebra de um fruto encapsulado por um macho juvenil. $\mathrm{Na}$ segunda localidade, no Bosque Jardim Ipê em Foz do Iguaçu, Paraná, um indivíduo que não teve o sexo identificado, utilizou um galho com folhas para obter água nas frestas de um tronco (AGUIAR et al., 2014).

Outro relato anedótico descreve o uso de ferramentas de sondas, pela primeira vez, na espécie Sapajus flavius. Esses macacos que vivem em região de Mata Atlântica nunca foram descritos fazendo uso de ferramentas. Souto e colaboradores (2011) descrevem alguns indivíduos de S. flavius, na Paraíba, que utilizaram galhos como sondas na captura de cupins, modificando essas varetas conforme a necessidade. No entanto, esse relato abrange menos de 10 observações.

\subsection{Aprendizagem Socialmente Mediada}

A aprendizagem socialmente mediada (ASM) pode ser definida como "o aprendizado que é influenciado pela observação de (ou da interação com) um coespecífico ou seus produtos" (HEYES, 1994). Para determinar quais os processos envolvidos na transmissão de informação através da aprendizagem socialmente mediada, diversos mecanismos têm sido propostos (WHITEN; HAM, 1992; HEYES; GALEF JR., 1996; HOPPITT; LALAND, 2013), entre eles:

Realce de estímulo (Stimulus enhancement): ocorre quando a ação de observar um demonstrador (ou seus produtos) expõe o observador a um novo estímulo e esse estímulo causa uma mudança no comportamento do observador (HOPPITT; LALAND, 2013). Uma definição semelhante foi proposta por Heyes (1994). O realce de estímulo funciona como um reforço de aprendizagem, em que a resposta a um estimulo aumenta após a observação do comportamento de outros indivíduos (HOPPITT; LALAND, 2013).

Realce de local (Local enhancement): ocorre quando, após ou durante a presença de um demonstrador, ou a interação com objetos em um determinado local, um observador se torna 
mais propicio a visitar ou interagir com os objetos naquela localidade (HOPPITT;27 LALAND, 2013).

Ao formular essa definição os autores modificaram um conceito mais antigo (THORPE, 1956) cujo produto final focava em uma "aparente imitação" ao estímulo. Galef (1988) sugere que todo o processo que leva da atração a um local determinando ao aprendizado subsequente seja classificado como realce de local. Apesar do realce de local e de estímulo, se sobreporem em alguns momentos, o realce de estímulo requer que o indivíduo exiba o aprendizado do estímulo enquanto o realce de local pode ocorrer sem o aprendizado. Contudo, esse mecanismo parece ocorrer raramente sem um componente de transmissão social em conjunto (HOPPITT; LALAND, 2013).

Imitação: Para Michael Tomasello (1999), uma Teoria da Mente "básica" (envolvendo uma capacidade de entender a intencionalidade alheia) é fundamental para a imitação e para a "atenção conjunta", e, consequentemente, para uma cultura cumulativa. Em que medida ocorre imitação em não-humanos, entretanto, é uma questão em aberto. Para nosso proposito nesse trabalho iremos considerar a definição apresentada por Heyes (1993) em que " $a$ imitação ocorre quando um indivíduo replica os movimentos de outro, de forma exata, após tê-lo observado".

Emulação: ocorre quando, após observar um demonstrador interagir com “objetos” em seu ambiente, um observador se torna propenso a executar qualquer ação que resulte em um efeito semelhante sobre esses objetos (HOPPITT; LALAND, 2013). Dessa forma, através da observação de outros, o observador pode associar determinado objeto a uma recompensa, chegando ao mesmo resultado a sua maneira (TOMASELLO; CALL, 1997).

Ensino: o conceito de ensino proposto por pesquisadores como Galef e Tomasello (cf. LALAND; HOPPITT, 2003) tornam esse mecanismo restrito aos seres humanos por conta da necessidade de uma Teoria da Mente. Um conceito mais abrangente é o de "ensino funcional" que pode ser definido como o comportamento que ocorre na presença de um aprendiz ingênuo, podendo ter algum custo ou nenhum benefício ao tutor, mas que facilitaria a aprendizagem desse outro indivíduo (MUSGRAVE et al., 2016).

Contudo, observações naturalísticas envolvendo o ensino em animais não-humanos é rara. Em uma população de chimpanzés no Triangulo de Goualougo, no Congo, foi observado um processo de "ensino funcional" através da transferência de ferramentas em um episódio de pesca de cupins onde os indivíduos adultos passaram suas ferramentas de sonda, prontas para 
o uso, para indivíduos mais jovens ainda incapazes de produzirem as próprias ferramentas de28 forma correta (MUSGRAVE et al., 2016).

Quando um indivíduo adquire um novo comportamento através da inovação ele passa a servir de fonte de informação para outros indivíduos. Essa informação poderá ser agregada ao reportório comportamental dos demais indivíduos através da aprendizagem socialmente mediada (FRAGASZY; VISALBERGHI, 2001). Reader e Laland (2003, p. 14 apud RAMSEY; BASTIAN; van SCHAIK, 2007) definem inovação como "um processo que resulta em um novo ou uma modificação de um comportamento aprendido e que introduz. novas variantes comportamentais dentro do repertório populacional" (para uma discussão sobre definições de inovação cf. RAMSEY et al., 2007). Para espécies primatas que são generalistas e oportunistas (como os macacos-prego), a inovação se torna um componente importante da plasticidade comportamental, sendo vital para a sobrevivência desses indivíduos (READER; LALAND, 2001).

Para a compreensão dos mecanismos envolvidos na aprendizagem e sua transmissão, estudos ontogenéticos se fazem necessários. Resende et al. (2008) estudando a ontogenia do comportamento da quebra de cocos por macacos-prego (Sapajus sp.) encontrou uma forte evidência da influência da ASM no processo de aquisição do uso de ferramentas líticas. Os infantes já demonstram padrões gerais de manipulação e exploração dos objetos através de ações percussivas, quando mais velhos, por volta de 1 ano de idade, passam a fazer tentativas de associar martelos e cocos realizando tentativas ineptas de quebra, até conseguirem associar os 3 elementos necessários para um episódio de quebra eficiente (RESENDE op. cit.), um processo que leva em torno de 3 anos (MANNU, 2002). Mesmo adultos que não saibam usar as ferramentas podem aprender ao se associarem com outros indivíduos proficientes, como foi observado por Ottoni et al. (2009).

O fato dos indivíduos adultos serem bem tolerantes nos grupos de macacos-prego, principalmente com infantes e juvenis, permite uma observação próxima dos eventos de quebra e interações com os objetos e restos alimentares, o que favorece a difusão desse comportamento através da aprendizagem socialmente mediada (COELHO, 2009). Ottoni et al. (2005) observaram que os macacos-prego conseguem distinguir entre seus coespecíficos quem são os melhores quebradores de cocos e preferem se associar com estes durante os eventos de quebra. Uma óbvia vantagem de se associar a bons quebradores é a maior possibilidade de se alimentar de sobras (scrounging) e esse ambiente favorece a ASM já que também proporciona 
mais oportunidades de observação da técnica. Coelho et al. (2015) observou uma preferência29 dos macacos-prego por observar indivíduos mais velhos e de alta posição na hierarquia, podendo se tratar de uma predisposição dos indivíduos em observar/copiar os sujeitos mais velhos/dominantes (LALAND, 2011).

Essa seletividade possibilita que a informação social recebida tenha um melhor aproveitamento, facilitando a transmissão de tradições comportamentais e de novos comportamentos benéficos para o indivíduo. Copiar outros indivíduos indiscriminadamente não seria uma estratégia adaptativa e nem traria benefício ao fitness desse indivíduo. Assim, através das chamadas Estratégias de Aprendizagem Social (em inglês, Social Learning Strategies - SLS) é esperado que os indivíduos copiem comportamentos específicos (estratégia “o que"), executados por sujeitos específicos (estratégia "quem") e em circunstâncias adequadas (estratégia "quando") (OTTONI; DE RESENDE; IZAR, 2005; COELHO et al., 2015; KENDAL et al., 2018).

O estudo de processos de Aprendizagem Socialmente Mediada em grupos (cativos, semi-livres ou selvagens) de animais, entretanto, passa por uma fase de refinamentos metodológicos significativos. Métodos experimentais e estatísticos para verificar em que medida as interações sociais determinam as vias de difusão social de novos comportamentos (experimentalmente introduzidos) podem produzir evidências mais rigorosas de difusão social de inovações. Recentemente, pesquisas em nosso laboratório tem incorporado estas metodologias (Option Bias Analysis (KENDAL et al., 2009) e Network-Based Diffusion Analysis (FRANZ; NUNN, 2009)) aos seus estudos sobre o uso de ferramentas e outras aparentes tradições dos macacos-prego (COELHO, 2015; COELHO et al., 2015).

\subsection{Tradições Comportamentais e Cultura em animais não-humanos}

Do ponto de vista de algumas linhas de pensamento mais clássicas dentro da antropologia, "cultura" seria um fenômeno exclusivo da espécie humana, por conta de seu conceito abarcar elementos complexos que não esperamos encontrar nos animais nãohumanos, sendo o único processo possivelmente cultural compartilhado entre humanos e nãohumanos a transmissão contínua de informações, ao longo das gerações, através da aprendizagem social (FRAGASZY; PERRY, 2009). Uma definição clássica de cultura (TYLOR, 1873) se mostra vaga, restritiva e antropocêntrica: “cultura é aquele todo complexo 
que inclui conhecimento, crença, arte, lei, moral, costumes e quaisquer outras capacidades30 e hábitos adquiridos pelo homem como membro da sociedade”.

Pelo fato do termo cultura vir carregado com esses preceitos, envolvendo mais do que apenas variação geográfica entre características comportamentais, as autoras optaram, ao desconsiderar a criação de um novo termo, por utilizar "tradição" quando se referir aos animais não-humanos e evitar essas conotações que acompanham o termo "cultura" (FRAGASZY; PERRY, 2009; PERRY, 2009, 2011).

Dessa forma ao adotar uma visão menos antropocêntrica e "mais biológica", Fragaszy e Perry (2009) definem tradição como sendo "padrões comportamentais duradouros que são compartilhados por membros de um mesmo grupo e dependem, em certo grau, de contribuições sociais para o aprendizado individual". Essa manutenção da tradição através de “contribuições sociais" é feita pela aprendizagem socialmente mediada (ASM). No entanto, cultura pode ser definida como "comportamentos típicos de grupo compartilhados por membros de uma comunidade que dependem de informações aprendidas e transmitidas socialmente" (LEGARE, 2017), uma definição que contempla os animais não-humanos.

Os estudos clássicos sobre culturas em chimpanzés e outros primatas não-humanos, baseados na abordagem comparativa ou etnográfica, se apoiavam num método baseado na exclusão, onde casos com variação interpopulacional que não pudessem ser explicados por fatores genéticos ou ecológicos eram tratados como tradição (WHITEN et al., 1999). Embora constitua um importante ponto de partida na detecção de tradições, o método comparativo é sujeito a "falsos positivos" (existência de diferença comportamental, mas que não dependa de fatores sociais) e "falsos negativos" (ausência de diferença comportamental, mas que dependem da ASM) - especialmente por não examinar os processos definidores de tradições comportamentais: a influência social em sua aprendizagem (FRAGASZY; PERRY, 2009).

No entanto, essa divisão entre "cultura para humanos" e "tradições para não-humanos" é criticada por alguns pesquisadores (LALAND; JANIK, 2006), como McGrew (2009), que afirma que esse tipo de separação serve apenas para fortalecer antigas barreiras especistas. Outra crítica se refere a uma equiparação entre tradição e cultura, como se fossem sinônimos. Tradições seriam informações propagadas por transmissão vertical (transmitida pelos pais). Enquanto que nem toda transmissão cultural é vertical, algumas são horizontais, entre indivíduos de uma mesma geração, como "modas" de curto prazo e outras são obliquas, entre 
gerações, porém sem vínculo parental (professores, padres, xamãs etc.). E a transmissão31 horizontal pode se propagar sem processos intergeracionais (MCGREW, 2009).

Em contrapartida, alguns pesquisadores do comportamento adotam uma posição contrária à existência de tradições e/ou culturas entre animais não-humanos. Para Galef (1992) a aprendizagem por imitação e pelo ensino são as características que tornam a cultura em seres humanos possível. Por não considerar que os animais possam aprender por imitação, o autor classifica uma possível "tradição" animal, através da aprendizagem social, como algo análogo e não homólogo a cultura humana. Não haveria razão para considerar a cultura como um fenômeno que pode ser traçado filogeneticamente e que tenha evoluído em espécies ancestrais ao Homo sapiens. No entanto, os defensores da primatologia cultural contestam essa visão e entendem a cultura animal como um avanço na compreensão das origens evolutivas da cultura humana (DE WAAL, 2005; MCGREW, 2015).

Tomasello (2010) salienta que a imitação e o ensino garantem um alto grau de fidelidade na transmissão da informação, sendo características presentes apenas na espécie humana e que viabilizam uma capacidade de acúmulo de informações ao longo do tempo, permitindo um aumento de complexidade. Os animais não-humanos, segundo Tomasello (2010), podem apresentar alguma forma de transmissão cultural, através da aprendizagem social, mas por essa não ocorrer através da imitação, não produziriam uma transmissão fiel, impedindo a existência de uma cultura cumulativa. $\mathrm{O}$ conceito de cultura cumulativa pode ser definido como "um processo pelo qual as inovações são progressivamente incorporadas ao estoque de habilidades e conhecimentos de uma população, gerando repertórios mais complexos" (LEGARE, 2017).

No entanto, o processo de aprendizagem por imitação, segundo Heyes (1993) está sujeito a influências do ambiente como qualquer outro processo de aprendizagem social. Quando uma informação é copiada do sujeito A pelo sujeito B e, posteriormente, é copiada do sujeito B pelo sujeito C, ela está sujeita a ser perdida ou modificada pelo imitador, por conta de suas experiências individuais. Portanto, a aprendizagem por imitação não se difere de outros mecanismos de aprendizagem social no que tange a manutenção de um processo cultural.

E a capacidade de imitação pelos seres humanos não é motivo suficiente para acreditar que essa é a principal forma que temos de transferir informações, pode ser que boa parte daquilo que aprendemos ocorra através da emulação, como em outros primatas (LALAND; 
HOPPITT, 2003). Além disso, a cumulatividade das culturas não tem, necessariamente, que32 constituir um fenômeno "tudo-ou-nada". Assim como a transição, no clássico caso dos macacos japoneses, da lavagem de batatas da água doce para a salgada (HUFFMAN, 1996) poderia ser entendida como um pequeno avanço cumulativo, é possível supor que, mesmo na ausência dos mecanismos mais sofisticados que caracterizam a ASM em humanos, algum grau de cumulatividade simples poderia ser observado na difusão de novos comportamentos em um grupo de animais não-humanos (LALAND; HOPPITT, 2003).

E considerando períodos da pré-história humana, como durante a cultura Olduvaiense e a Acheuliana, temos um tempo de pelo menos 1 milhão de anos para cada uma em que não houve mudanças significativas (LALAND; HOPPITT, 2003). Laland e Hoppitt (op. cit.) também contestam a alegação de ausência de cumulatividade cultural em outros animais, já que primatas não-humanos poderiam apresentar uma taxa de cumulatividade semelhante a essas dos antepassados humanos. Os trabalhos etnográficos com comportamentos de primatas não-humanos contêm alguns exemplos de cultura cumulativa (MCGREW, 2015).

Em experimento de laboratório, pombos foram bem-sucedidos em tarefas envolvendo cumulatividade (SASAKI; BIRO, 2017), porém em uma comparação sobre cumulatividade numa tarefa entre crianças humanas, chimpanzés e macacos-prego (DEAN et al., 2012), apenas as crianças foram bem-sucedidas. Embora haja evidências de tradições culturais tanto entre chimpanzés (MCGREW, 1992; WHITEN et al., 1999) quanto em grupos de macacosprego selvagens (OTTONI, 2015), nenhuma destas espécies mostrou durante o experimento qualquer evidência de aprendizagem cultural cumulativa. Nossa tentativa de demonstrar esse fenômeno experimentalmente em uma população de macacos-prego de vida livre também encontrou dificuldades (CORAT, 2017).

Para compreender como um comportamento se mantém como tradição, Fragaszy e Visalberghi (2001) sugerem que é preciso olhar para os indivíduos como agentes dinâmicos que estão constantemente manipulando e modificando o seu ambiente através do comportamento. Esse processo é denominado Construção de Nicho (ODLING-SMEE, 1988; LALAND; ODLING-SMEE; FELDMAN, 2000). Essas modificações ocasionadas no ambiente através da construção de nicho resultarão em uma alteração nas pressões seletivas que esse ambiente exerce sobre as espécies que nele se encontram. Um exemplo clássico pode ser encontrado nas obras de Charles Darwin em que ele descreve um experimento realizado com minhocas, observando como elas alteram o solo, adequando-o conforme suas 
necessidades (DARWIN, 1881). Essa alteração radical do ambiente faz com que as novas33 gerações nasçam em ambientes completamente modificados sendo expostas a diferentes pressões seletivas (LALAND; ODLING-SMEE; FELDMAN, 1999). Os autores dão a esse processo o nome de Herança Ecológica (LALAND et al., 2000; ODLING-SMEE, 1988).

Ambos processos mudam a perspectiva dos organismos dentro da evolução biológica, que deixam de ser meros agentes passivos (os organismos se adaptam ao ambiente) e passam a ter um papel mais ativo influenciando diretamente na seleção natural (LALAND; MATTHEWS; FELDMAN, 2016). Esse conceito, proposto por Lewontin (1983) é melhor compreendido através de suas próprias palavras:

\section{A cada momento, a seleção natural está operando com vistas a modificar a composição genética das populações em resposta ao ambiente momentâneo; no entanto, à medida que essa composição se modifica, ela gera uma mudança concomitante no próprio ambiente. Assim, tanto o organismo como o ambiente são causa e efeito em um processo coevolutivo (LEWONTIN, 2002, p. 128)}

Aplicando o pensamento da construção de nicho aos macacos-prego é intuitivo pensar no uso de ferramentas líticas como parte desse processo. Os sítios de quebra (locais onde os macacos vão para quebrar os cocos) são pontos geralmente fixos e duráveis. As ferramentas utilizadas na quebra, também duráveis, são, geralmente, deixadas no local de uso. Indivíduos jovens que observaram o comportamento de macacos mais velhos quebrando cocos, tem a oportunidade de manipular as ferramentas e restos dos cocos sobre as bigornas após a saída dos indivíduos adultos do local (FRAGASZY et al., 2013).

Esse cenário, no entanto, é diferente quando se trata das ferramentas de sondas. Esse tipo de ferramenta não é durável e mesmo que deixada próxima do local de uso pode não surtir um efeito como no caso das ferramentas líticas. No caso dos chimpanzés, varetas podem ser deixadas inseridas em cupinzeiros e formigueiros de vez em quando (FRAGASZY et al., 2013), mas no caso de macacos-prego que utilizam as varetas para caçar lagartos (FALÓTICO; OTTONI, 2016) não há essa possibilidade. Um pouco mais provável seria no caso da sondagem de colmeias (MANNU; OTTONI, 2009), que porventura pode acabar com alguma vareta inserida deixada para trás, mas de toda forma esse não seria um evento duradouro. Os experimentos envolvendo caixas-problema e ferramentas de sondas (CARDOSO; OTTONI, 2016; presente estudo) podem se assemelhar mais aos sítios de quebras sob a ótica da construção de nicho. 
Atuando em conjunto com a construção de nicho, a aprendizagem socialmente34 mediada pode favorecer a manutenção de comportamentos típicos de um grupo, fazendo com que as tradições comportamentais se tornem parte de um nicho construído (FRAGASZY; VISALBERGHI, 2001).

\subsection{Objetivos}

O presente projeto teve como objetivo a introdução de uma nova técnica de forrageamento e o acompanhamento de sua difusão numa população semi-livre de macacosprego que mantemos sob estudo desde as primeiras observações de uso de ferramentas (OTTONI; MANNU, 2001). No passado, o grupo foi exposto a uma tarefa envolvendo o uso de sondas para a extração de melado de uma caixa-problema. Cinco indivíduos chegaram a utilizar varetas, três dos quais com grande proficiência (AQUINO; OTTONI, 2001). Nenhum destes, entretanto, se encontra atualmente no grupo. Como o grupo atual não teve contato prévio com esse tipo de tarefa, tivemos que aguardar, de início, o surgimento de um inovador.

Nosso objetivo inicial visava desenvolver ao longo do experimento tarefas mais complexas, através de modificações nas caixas-problema, gerando um ambiente propício para a investigação de uma cumulatividade cultural. No entanto, encontramos problemas com a difusão da técnica. O inovador surgiu logo no começo do experimento, no entanto a difusão para outros sujeitos não estava acontecendo, mesmo com tentativas de facilitar a solução da tarefa, o que nos levou a prolongar o cronograma do experimento. E foi somente durante essa extensão do projeto que outros indivíduos aprenderam a técnica.

Esse fato nos forçou a modificar os objetivos iniciais, abandonando o desenvolvimento de tarefas mais complexas e uma investigação sobre cumulatividade cultural. Sendo assim, nos concentramos nos processos de difusão do comportamento e nos mecanismos de aprendizagem socialmente mediada envolvidos, assim como num possível uso generalista da ferramenta pelos indivíduos proficientes. Para uma análise do desempenho dos indivíduos bem-sucedidos desenvolvemos três conjuntos de hipóteses buscando investigar quais eventos durante o experimento podem ter contribuído para o sucesso de cada um.

Cada conjunto foi pensado para abranger momentos específicos. Sendo o primeiro focando em eventos mais próximos ao sucesso que podem ter contribuído para tal como, por exemplo, observar outro sujeito realizando a tarefa. Já o segundo conjunto investiga os fatores 
que, possivelmente, poderiam aumentar o interesse dos macacos pelas ferramentas. E o35 terceiro conjunto trata dos eventos pós-sucesso, verificando se houve mudanças no comportamento relacionado a manipulação das ferramentas após a aprendizagem da técnica. 


\section{MATERIAIS E METÓDOS}

O presente experimento se enquadra em uma classificação proposta por Matsuzawa e colaboradores, durante os primeiros experimentos de campo, com chimpanzés selvagens, que eles chamaram de "laboratório de campo". A lógica e o rigor seguem os mesmos parâmetros de um experimento em laboratório, porém realizado em condições naturalísticas. E se diferencia de um trabalho naturalístico por conta da intervenção no ambiente, através da adição de elementos não encontrados naquela região e a modificação e controle de algumas condições/variáveis ao longo do experimento, além da possibilidade de ser transportado entre diferentes pontos (MATSUZAWA; HUMLE; SUGIYAMA, 2011).

\subsection{Local}

O Parque Ecológico do Tietê (PET) está localizado na região da zona leste da cidade de São Paulo às margens do Rio Tietê e abrange uma área de $14 \mathrm{~km}^{2}$. O parque é um local de lazer e prática de esportes da comunidade, oferecem programas de educação ambiental e visitas guiadas. É também um dos principais locais, na região, de liberação de animais ilegalmente capturados e subsequentemente apreendidos, que são encaminhados ao Centro de Recuperação de Animais Silvestres (CRAS). O CRAS está contido em uma área de preservação e reflorestamento, restrita a visitantes, que contém algumas edificações de pequeno porte, três lagos e um viveiro de mudas de quatro hectares (Figura 1). 
Figura 1 - Mapa do Parque Ecológico do Tietê. Os locais de experimento estão indicados por: F1 - para a37 primeira fase (presencial) e F2 - para a segunda fase (armadilha fotográfica).

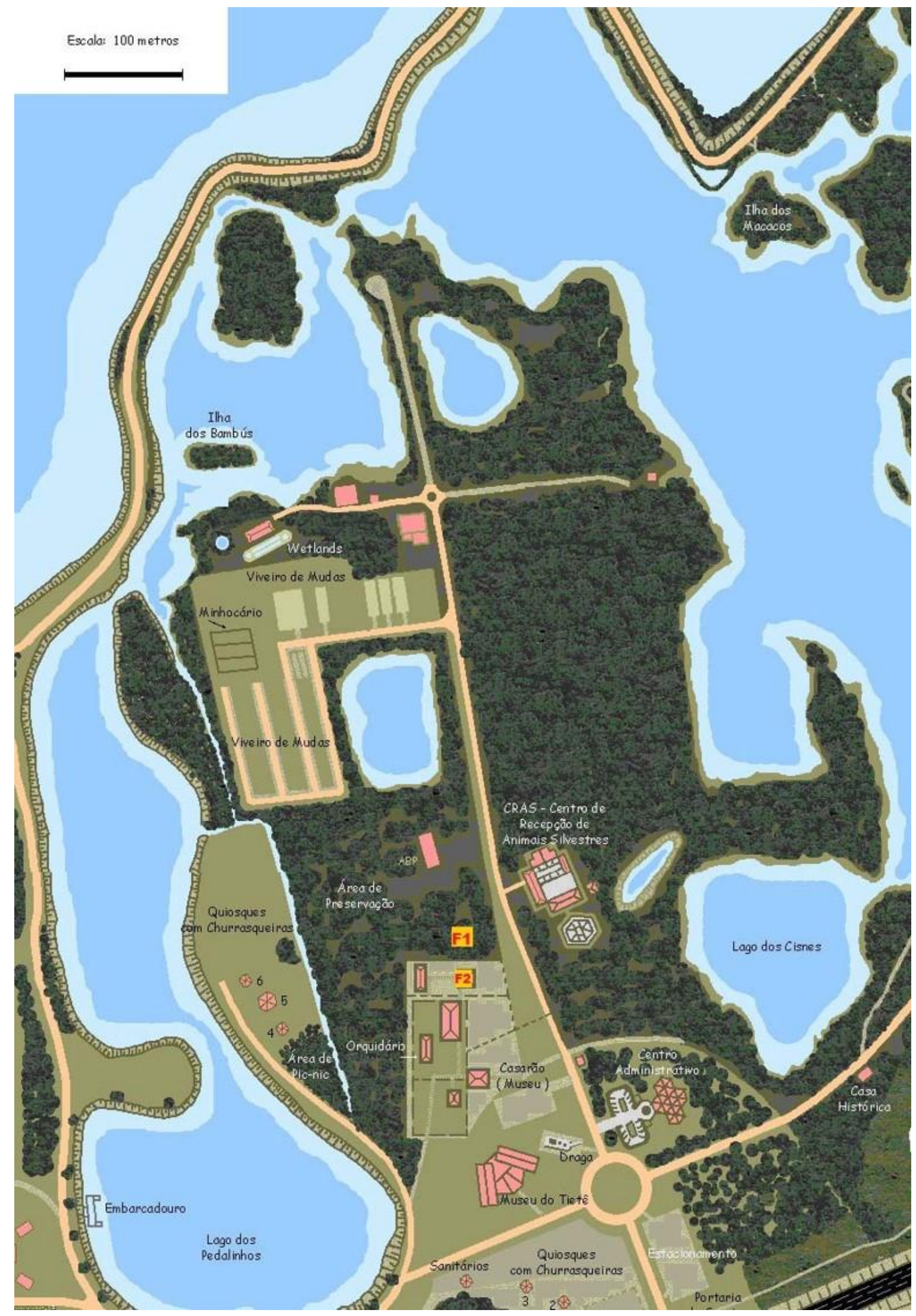




\subsection{Sujeitos}

O grupo experimental de macacos-prego vive em semi-liberdade na área de preservação do PET, mas fazendo incursões constantes à área comum do parque estabelecendo contato com os visitantes. Este grupo vive no local desde 1988. Os adultos "fundadores" foram soltos nas ilhas do parque após sua apreensão pelo IBAMA e formaram um grupo espontaneamente, após escapar a nado das ilhas; a maioria dos outros indivíduos nasceu no local, mas houve introduções posteriores (em função da falta de dados detalhados sobre a origem dos animais e das evidências de hibridação, nos referiremos a esta população como constituída por Sapajus sp.). Este foi o grupo em que, há mais de vinte anos, foi descoberto o uso espontâneo de ferramentas líticas pelos macacos-prego (OTTONI; MANNU, 2001). Os macacos são diariamente provisionados, mas não se limitam à comida fornecida pelos funcionários do parque (principalmente ovo cozido, mamão, melancia, banana, mexerica e melão), ao contrário, forrageiam por toda a área, consumindo itens naturalmente disponíveis.

Em um experimento anterior realizado por Aquino e Ottoni (2001) esse grupo foi exposto a uma tarefa envolvendo a aprendizagem e transmissão do uso de sondas. Na ocasião o grupo contava com 26 indivíduos (6 machos adultos, 5 fêmeas adultas, 4 juvenis machos, 4 juvenis fêmeas e 6 infantes), que foram expostos a 108 sessões experimentais de 1 hora cada, com um macho adulto (Suspeito) e dois machos juvenis (Quinzinho e Pedro) sendo bemsucedidos na tarefa. Suspeito se tornou bem-sucedido na tarefa logo após observar Quinzinho utilizando a ferramenta algumas vezes. Pedro e Suspeito também foram capazes de produzir suas próprias ferramentas a partir de galhos quando varetas padronizadas deixaram de ser oferecidas pela experimentadora. No entanto, nenhum dos três indivíduos bem-sucedidos encontram-se atualmente no grupo.

No início do experimento o grupo contava com 33 indivíduos. Em janeiro de 2018 duas fêmeas de Sapajus nigritus, previamente castradas, foram soltas no parque e acolhidas pelo bando, com observações da fêmea mais nova (Vandinha) sendo carregada por alguns machos adultos. Dois nascimentos também ocorreram em dezembro de 2017, as primeiras observações foram feitas na última semana do mês, com as fêmeas Frida e Amora dando à luz a um filhote cada, França e Amon respectivamente. Ao final do experimento o grupo era 
composto de 37 indivíduos sendo, 2 infantes, 12 juvenis (10 machos e 2 fêmeas), 13 fêmeas39 adultas, e 10 machos adultos (Tabela 1).

Foram considerados como infantes os indivíduos recém-nascidos até o período de independência da mãe, que é atingido entre 12 e 15 meses de idade; como juvenis os indivíduos até 8 anos de idade para os machos e até a primeira gestação para as fêmeas, que costuma ocorrer por volta dos 5 anos de idade. Indivíduos acima de 8 anos foram considerados adultos no caso dos machos e as fêmeas adultas aquelas que já passaram pela primeira gestação. Em casos em que não há o registro de nascimento do indivíduo as faixas etárias foram estimadas através de características corporais como tamanho, peso e altura do topete (FRAGASZY; VISALBERGHI; FEDIGAN, 2004).

Tabela 1 - Composição dos indivíduos do grupo ao final do experimento. ND = sexo não identificado.

\begin{tabular}{l|l|l} 
Indivíduos & Sexo & Faixa etária \\
\hline Abelha & Macho & Adulto \\
\hline Acácio & Macho & Adulto \\
\hline Açaí & Macho & Adulto \\
\hline Acerola & Macho & Adulto \\
\hline Adam & Macho & Juvenil \\
\hline Alice & Fêmea & Adulto \\
\hline Amom & ND & Infante \\
\hline Amora & Fêmea & Adulto \\
\hline Ana & Fêmea & Adulto \\
\hline Angélica & Fêmea & Adulto \\
\hline Cacá & Fêmea & Adulto \\
\hline Caju & Macho & Adulto \\
\hline Capacete & Macho & Juvenil \\
\hline Careca & Macho & Adulto \\
\hline Cisca & Fêmea & Adulto \\
\hline Cláudia & Fêmea & Adulto \\
\hline Davi & Macho & Adulto \\
\hline
\end{tabular}

\begin{tabular}{l|l|l|}
\hline Demolidor & Macho & Juvenil \\
\hline Feioso & Macho & Juvenil \\
\hline Física & Fêmea & Adulto \\
\hline Floyd & Macho & Adulto \\
\hline Folha & Macho & Juvenil \\
\hline França & ND & Infante \\
\hline Frank & Macho & Juvenil \\
\hline Frida & Fêmea & Adulto \\
\hline Frodo & Macho & Juvenil \\
\hline Jabá & Fêmea & Adulto \\
\hline Janete & Fêmea & Adulto \\
\hline Químico & Macho & Adulto \\
\hline Ravena & Fêmea & Juvenil \\
\hline Sam & Macho & Juvenil \\
\hline Tigela & Macho & Juvenil \\
\hline Vader & Macho & Juvenil \\
\hline Val & Fêmea & Adulto \\
\hline Vandinha & Fêmea & Juvenil \\
\hline Vavá & Fêmea & Adulto \\
\hline Vodca & Macho & Adulto \\
\hline
\end{tabular}




\subsection{Experimento}

O procedimento experimental consistiu na disponibilização de dois dispensadores de alimentos (caixas-problema) aos macacos-prego do PET numa situação de "difusão aberta". Para a obtenção da recompensa (alimento) se fez necessário o uso de sondas (varetas) como ferramentas. O tipo de recompensa recebida variou conforme a caixa, sendo uma com recompensa líquida (melado) e outra com recompensas sólidas (amendoim, avelã e ração para macaco-prego).

Inicialmente oferecemos aos macacos a mesma caixa-problema utilizada no experimento de Aquino e Ottoni (2001). Uma caixa retangular de acrílico (Figura 2a) contendo melado (substância composta de sacarose, glucose, frutose e água) que só poderia ser extraído através do uso de sondas. Uma segunda caixa (Figura 2b) foi construída de forma que os macacos precisariam utilizar as varetas para empurrar um alimento sólido, uma variante de tarefas aplicadas em experimentos anteriores (VISALBERGHI; TRINCA, 1989; GARBER; GOMES; BICCA-MARQUES, 2012). Essa segunda caixa permite que a extração de alimento seja feita de duas formas, inserindo a vareta pela parte superior (como na caixa de melado) ou na parte frontal.

Figura 2 - Caixas-problema. a: caixa de melado; b: caixa de sólidos.

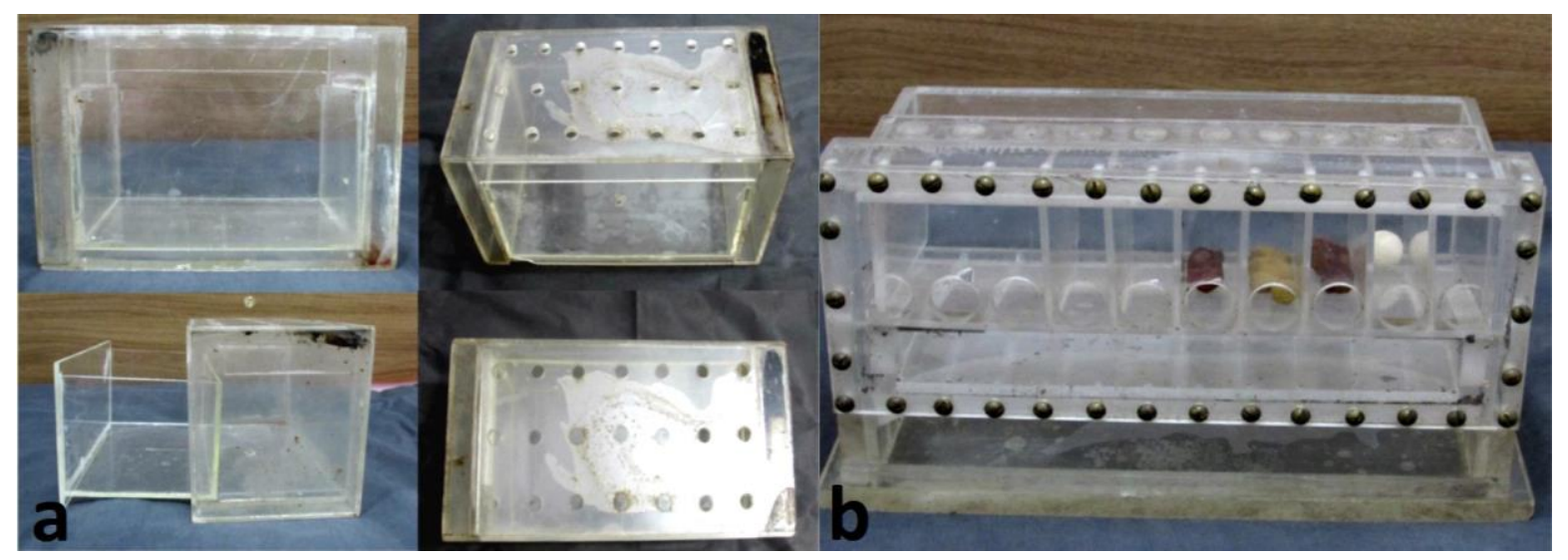

O experimento foi dividido em duas fases de coleta de dados com um intervalo de 4 meses entre o fim da primeira e o início da segunda fase. Durante a primeira fase a coleta foi feita com o uso de duas filmadoras manuseadas pelo experimentador e durante a segunda fase a coleta foi realizada através de uma armadilha fotográfica. Ao contrário da fase presencial em que a disponibilidade das caixas para os macacos dependia da presença do experimentador, o uso da 
armadilha fotográfica permitiu que as caixas-problema ficassem disponíveis 24 horas por dia. Ampliando a oportunidade de contato dos indivíduos com o experimento.

\subsubsection{Caixa de Melado}

O aparato consiste em uma estrutura retangular de acrílico medindo $27 \mathrm{~cm}$ de largura, $15,2 \mathrm{~cm}$ de altura e $13,3 \mathrm{~cm}$ de profundidade. Uma gaveta removível, inacessível aos macacos, retém o conteúdo. A parte superior conta com 21 orifícios de $1 \mathrm{~cm}$ cada distribuídos em 3 fileiras horizontais com uma distância de $2 \mathrm{~cm}$ entre os orifícios e 3,3cm entre as fileiras, por onde podia ser feita a extração do melado através do uso de uma vareta. A caixa de melado era encaixada a um suporte de madeira, que impedia os macacos de abrirem a gaveta que continha o melado, que por sua vez, era fixado em uma árvore através de dois parafusos e uma haste de metal, mantendo a caixa a aproximadamente $1 \mathrm{~m}$ de distância do solo.

\subsubsection{Caixa de Alimentos Sólidos}

A segunda caixa-problema também feita de acrílico em formato retangular, mede $30 \mathrm{~cm}$ de largura, $16 \mathrm{~cm}$ de altura e $13 \mathrm{~cm}$ de profundidade. Nessa caixa a recompensa pode ser extraída de duas formas diferentes. Na parte superior da caixa há uma única fileira com 10 orifícios de $1 \mathrm{~cm}$ e na parte frontal há mais uma fileira com 10 orifícios de $2,5 \mathrm{~cm}$ por onde os macacos podem inserir as sondas e empurrar a recompensa, que após rolar por uma rampa sairá por um dispensador na frente da caixa.

Após um primeiro contato do grupo com a caixa foi necessária sua retirada para aplicarmos alguns ajustes por conta de alguns indivíduos que obtinham as recompensas sem o uso das varetas. Indivíduos menores (juvenis) conseguiam, após algum esforço, empurrar a recompensa inserindo o dedo pelos furos na parte superior da caixa e, por conta disso, reduzimos para $1 \mathrm{~cm} \mathrm{o}$ tamanho desses orifícios (ficando igual a caixa de melado). Pela parte frontal não era possível alcançar a recompensa que ficava mais ao fundo da caixa e distante dos orifícios frontais. Outros macacos (Caju e Vodca) inseriam o braço através do dispensador e alcançavam a recompensa com a ponta dos dedos. Para solucionar tal problema adicionamos uma barreira de acrílico que impedia a passagem do braço do macaco e não interferia na rolagem da recompensa pelo dispensador. 
Assim como o aparato anterior, este foi encaixado a um suporte de madeira e fixado numa árvore. Optamos por deixar essa caixa mais próxima do solo para possibilitar a exploração da parte frontal pelos macacos que estivessem no chão.

\subsubsection{Disponibilização de ferramentas (Facilitações)}

Num primeiro momento, não foram disponibilizadas sondas potenciais e os macacos precisariam produzir suas próprias ferramentas através de galhos disponíveis em abundância no ambiente. Posteriormente, varetas padronizadas de madeira com 19,5cm de comprimento foram disponibilizadas (Figura 3a). A partir da primeira disponibilização, essas varetas tornaram-se um item comum na área do experimento com a possibilidade de serem encontradas e transportadas até os aparatos em qualquer momento do experimento.

Com o intuito de desencadear e acelerar um processo de difusão a partir do sujeito inovador, desenvolvemos duas estratégias que facilitavam aos indivíduos chegar à conclusão da tarefa e obter o alimento. Foram elas:

Facilitação com varetas pré-inseridas: em alguns momentos as varetas foram disponibilizadas pré-inseridas na caixa. Ao entrar em contato com a caixa os macacos teriam a vantagem de obter melado apenas retirando as varetas já inseridas. Essa facilitação aplicou-se apenas na caixa de melado (Figura 3b).

Esses eventos facilitadores são situações que podem ocorrer espontaneamente durante o uso e a manipulação de varetas pelos indivíduos, como observado no experimento no PNSC (CARDOSO; OTTONI, 2016). As varetas eram repostas no momento em que não havia nenhum sujeito em contato com a caixa. Em alguns momentos, o retorno dos macacos poderia ocorrer antes da reposição; nesses casos deu-se prioridade para o contato do indivíduo com a caixa e a gravação era iniciada mesmo sem a reposição ter sido feita. Afastar os animais da caixa para realizar a reposição poderia afugentar e interromper o interesse dos indivíduos jovens e/ou fêmeas pelo experimento. 
Essa facilitação foi aplicada em 5 períodos ${ }^{1}$ durante a primeira fase:

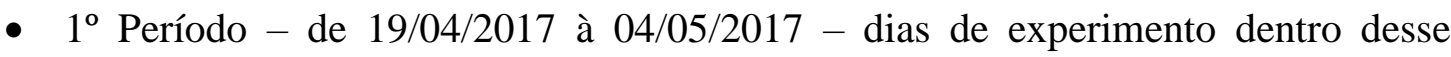
período: 19/04, 25/04 e 04/05.

- $2^{\circ}$ Período - de 12/07/2017 à 31/07/2017 - dias de experimento dentro desse período: 12/07, 13/07, 17/07, 20/07, 21/07, 28/07 e 31/07.

- $3^{\circ}$ Período - de 10/08/2017 à 05/09/2017 - dias de experimento dentro desse período: 10/08 e 05/09.

- $4^{\text {o }}$ Período - de 11/09/2017 à 27/09/2017 - dias de experimento dentro desse período: 11/09, 13/09, 14/09, 20/09, 21/09, 26/09 e 27/09.

- $5^{\circ}$ Período - de 31/10/2017 à 09/01/2018 - dias de experimento dentro desse período: 31/10, 01/11, 06/11, 08/11, 09/11, 10/11, 29/11, 30/11, 11/12, 14/12, 26/12, 27/12, 04/01, 05/01 e 09/01.

O fato dessa facilitação com varetas pré-inseridas ser disponibilizada em períodos intercalados e não contínuos, objetivou verificar se a exposição a esse tipo de facilitação traria um resultado direto na compreensão da solução da tarefa pelos indivíduos.

Facilitação com vareta fixa: esse tipo de facilitação consiste em uma alteração da facilitação com varetas pré-inseridas. Uma modificação temporária na caixa de melado acrescenta duas varetas de metal que não podiam ser totalmente retiradas (Figura 3c). Essa facilitação permitia aos macacos puxarem a vareta fixa de dentro do melado e, simplesmente ao soltar, inseri-la novamente, permitindo a "retirada infinita de varetas" pelos macacos. Também dispensava a necessidade de reposição de varetas pelo experimentador. Esse tipo de facilitação foi inspirado em uma tarefa semelhante desenvolvida por Cardoso (2013). A vareta fixa ficou disponível em conjunto com o $5^{\circ}$ período de varetas pré-inseridas.

\footnotetext{
${ }^{1}$ Para mais detalhes conferir a Tabela 11 no Apêndice A.
} 
Figura 3 - (a) Varetas disponibilizadas aos macacos para uso como ferramentas; (b) Facilitação com varetas préinseridas; (c) caixa de melado com duas varetas fixas.

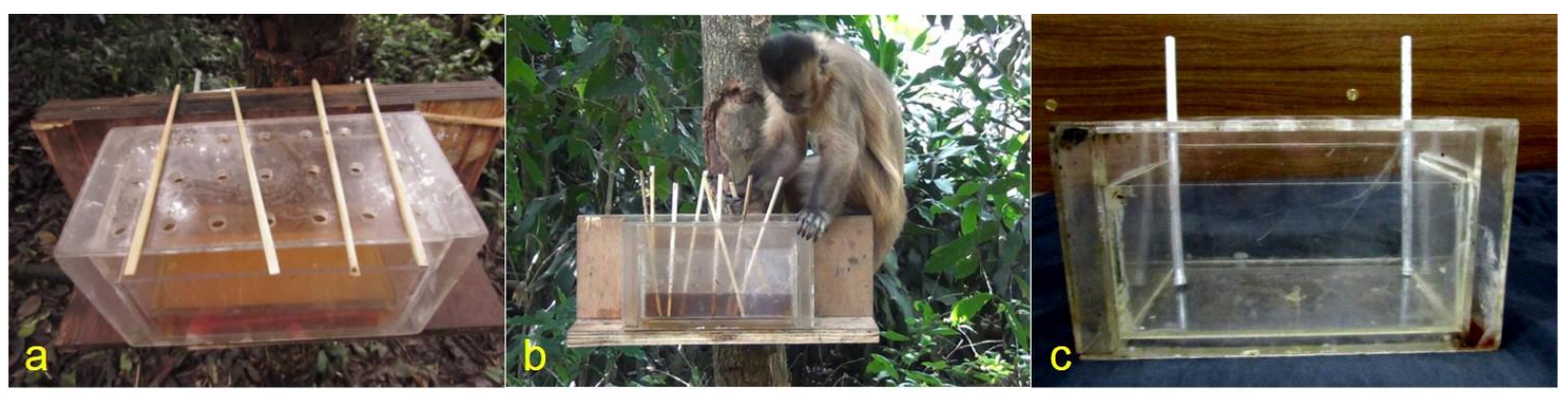

\subsection{Coleta de dados}

O experimento teve início em fevereiro de 2016 com a coleta de dados sendo finalizada em agosto de 2018. O cronograma inicial previa o término das coletas em fevereiro de 2018, onde ela chegou a ser interrompida. No entanto, decidimos por prolongar o experimento e, dessa forma, após 4 meses de interrupção, retomamos a coleta em junho de 2018. A decisão em prolongar o tempo de coleta se deu, principalmente, pelo fato da difusão não ter ocorrido até o término previsto inicialmente. A possibilidade em usar uma armadilha fotográfica na coleta também foi um fator importante na retomada da coleta dos dados. Portanto, dividimos o período total do experimento em duas fases. A primeira fase sendo o período do início do experimento até a primeira interrupção e a segunda fase da retomada até a finalização da coleta.

O período total do experimento, somando as duas fases, resultou em 300 horas estimadas de esforço de campo, que gerou um total de 130 horas e 55 minutos de filmagens dos macacos interagindo com as caixas-problema. A primeira fase resultou em, aproximadamente, 93 horas de vídeo com interação dos macacos em 75 sessões (dias de experimento). Na segunda fase a armadilha fotográfica ficou ativa por 46 dias (24 horas por dia) e gerou aproximadamente 38 horas de vídeo com interações dos macacos.

A diferença entre essas duas fases se deu, principalmente, na disponibilidade das caixas, sendo a primeira fase dependente da presença do experimentador, para montar, filmar e desmontar o sítio experimental ao final. Na primeira fase foram utilizadas duas filmadoras (Sony Full HD) acopladas a tripés e posicionadas a uma distância de um pouco mais de 1m das caixas. Uma das câmeras era direcionada todo o tempo para a caixa (ou as caixas) e a segunda servindo de auxílio para identificar os indivíduos presentes na área do experimento. A dinâmica nessa fase 
consistiu em montar o sítio experimental, posicionando as câmeras e encaixando a caixa (ou as caixas) ao respectivo suporte fixado na árvore. As filmagens eram iniciadas quando algum indivíduo se aproximava do experimento e era interrompida quando os macacos se distanciavam para mais de 2 metros das caixas, não havendo nenhum sujeito em contato direto com as caixas.

Já na segunda fase as caixas-problema ficaram 24 horas disponíveis. A área escolhida era em parte coberta, possuía pilastras onde a câmera e as caixas poderiam ser fixadas e era cercada por grades e um portão, o que impedia que outros animais entrassem no local - com exceção dos quatis (Nasua nasua), que escalavam as grades. Na Figura 1 os pontos de cada fase estão indicados pela marcação "F1" (primeira fase) e "F2" (segunda fase).

As caixas foram posicionadas lado a lado, com menos de 1 metro de distância entre elas e a uma distância de aproximadamente 1 metro da câmera. A câmera utilizada foi uma Trophy Cam HD 20MP da marca Bushnell e estava configurada para, ao ser ativada pelo sensor de movimento, fotografar e iniciar uma filmagem de 1 minuto (tempo máximo da câmera). As posições registradas nessa fase foram o contato com a caixa e a presença dos indivíduos num raio de 2 metros, a estrutura do local e a limitação do raio de visão da câmera não permitiram o registro dos sujeitos a 5 metros de distância. Varetas eram disponibilizadas sobre as caixas e na área do experimento em grande quantidade. $\mathrm{O}$ sítio experimental era visitado a cada 3 dias para troca de pilhas da câmera e o reabastecimento dos recursos das caixas-problema e das ferramentas disponíveis no local.

A presença do experimentador é outra das diferenças entre as duas fases experimentais, porém esse grupo é habituado a presença de humanos (OTTONI; MANNU, 2001) e não deixaram de visitar a caixa enquanto o experimentador estava presente.

\subsection{Etapas Experimentais}

O experimento foi dividido em algumas etapas podendo as caixas serem disponibilizadas separadamente ou em conjunto e com ou sem facilitações. A Figura 4 apresenta uma linha do tempo detalhando a configuração do experimento a cada momento. As datas de todas as sessões de coleta e a configuração detalhada de cada uma podem ser conferidas na Tabela 11 no Apêndice A. 
Figura 4 - Linha do tempo indicando a disponibilidade das caixas e varetas durante todo o experimento. Traços pretos indicam períodos de intervalo na coleta de dados.

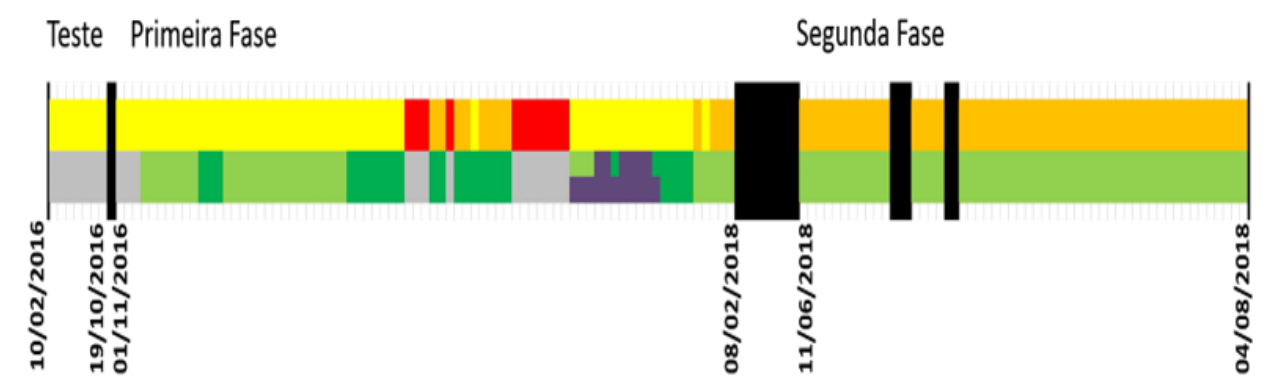

Disp. Caixas-problema

Caixa de melado

Caixa de sólidos

Ambas as caixas

Disp. de varetas

Sem varetas

Nível 1 de Facilitação

Nivel 2 de Facilitação

Nível 3 de Facilitação

No início do experimento se estabeleceu um período de teste com o intuito de escolher o melhor local para o posicionamento da caixa e em verificar a prontidão dos indivíduos do grupo em produzir e utilizar varetas como sondas, assim como foi feito no PNSC por Cardoso e Ottoni (2016). Durante esse período foram realizadas 7 sessões experimentais entre fevereiro e outubro de 2016 (sendo 2 dias em fevereiro, 4 em setembro e 1 em outubro). Nesse período a parte superior da caixa foi coberta com melado para que os macacos tivessem acesso e conhecimento do alimento oferecido e assim aumentar o interesse pelo objeto experimental.

A caixa foi fixada em vários locais do PET e chegou a ser movida para acompanhar o deslocamento do grupo, porém seu transporte mostrou-se inviável e pouco produtivo para a coleta. Após esse período ficou estabelecido que a caixa ficaria fixa na área de preservação próxima ao lugar onde os macacos são diariamente alimentados. Nesse local era possível prever o horário de visitação do grupo, já que a comida era oferecida por volta das 10:00 horas da manhã (com algumas poucas alterações).

A partir do primeiro momento em que as varetas padronizadas foram inseridas no experimento (novembro/2016), passou a ser necessária uma maior intervenção do experimentador com o experimento para a reposição dessas varetas. Optou-se por fazer a reposição quando os indivíduos cessavam o contato com as caixas e a filmagem era interrompida. Em alguns momentos, o retorno dos macacos poderia ocorrer antes da reposição; nesses casos deu-se prioridade para o contato do indivíduo com a caixa e a gravação era iniciada mesmo sem a reposição ter sido feita. Afastar os animais da caixa para realizar a reposição poderia afugentar e interromper o interesse dos indivíduos jovens e/ou fêmeas pelo experimento. Caso não houvesse 
varetas para a reposição, devido à ação dos macacos de danificar ou levar as varetas consigo, a sessão experimental era encerrada.

Vale ressaltar que, após essa primeira introdução de varetas padronizadas, elas se tornaram um item comum no ambiente do experimento. O que fazia com que, vez ou outra, os macacos encontrassem alguma vareta ou fragmentos de varetas no ambiente. Essa dispersão de varetas pelo ambiente era feita pelos próprios macacos, que costumavam carregar algumas consigo e descartá-las nos arredores.

Um indivíduo (Acácio) foi bem-sucedido na tarefa ainda na primeira fase do experimento (maio/2017). A partir desse ponto, até o final do experimento, o indivíduo proficiente tornou-se um potencial modelo da técnica para solução da tarefa. $\mathrm{O}$ mesmo sujeito também foi o primeiro (e único) a realizar a tarefa na caixa de alimentos sólidos durante a primeira fase (Figura 5).

Figura 5 - Indicação dos momentos de sucesso do Acácio na Caixa de Melado (seta amarela) e na Caixa de Sólidos (seta vermelha) durante a primeira fase do experimento.

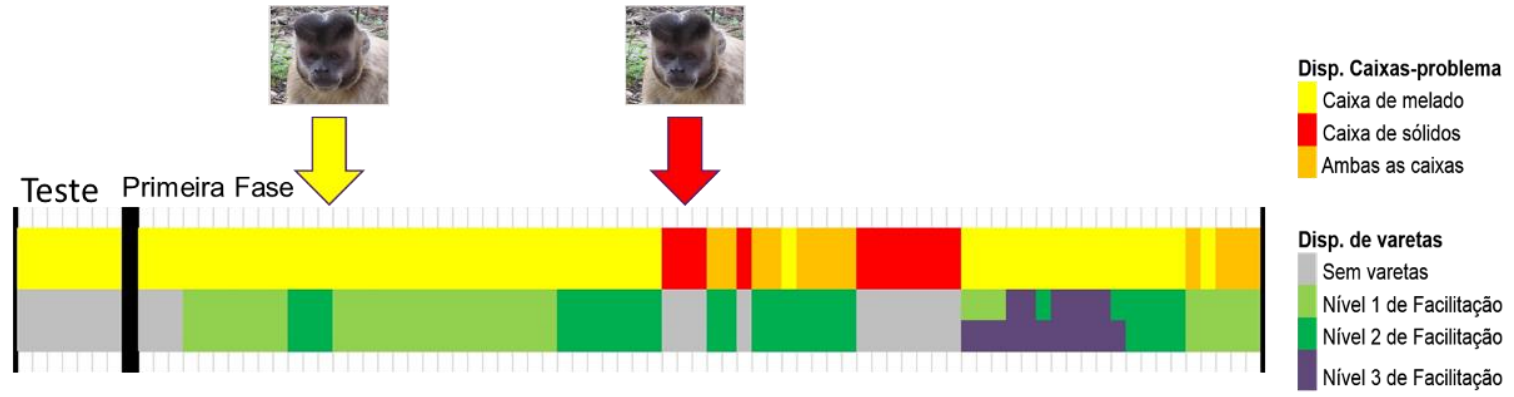

\subsection{Etograma}

Os potenciais processos de difusão foram monitorados diretamente e registrados em vídeo para análises subsequentes. Os indivíduos presentes são registrados através de procedimentos de "varredura", categorizando-se as distâncias que os indivíduos se encontravam da caixa. Ações ocorridas dentro da área do experimento eram registradas "ad libitum" e para os indivíduos presentes na caixa registramos "todas as ocorrências" (ALTMANN, 1974).

Os vídeos gerados nas coletas de dados foram transcritos e analisados através do programa The Observer XT 14, desenvolvido pela Noldus Information Technology. As transcrições seguiram o etograma apresentado na Tabela 2. Com os comportamentos divididos em 4 categorias (Proximidade, Manipulação da caixa, Manipulação de varetas e Sociais) e passiveis de 
possuírem modificadores, que são subcategorias de um mesmo comportamento, servindo para detalhar melhor a ação daquele ato comportamental.

\subsection{Análise dos dados}

Para averiguar quais das variáveis (representadas pelas colunas da Tabela 12 no Apêndice A) podem ter contribuído (ou não) para o sucesso na tarefa aplicamos os testes estatísticos não paramétricos de Kruskal-Wallis e o teste U de Mann-Whitney (sendo considerado significativo o valor de $\mathrm{p}=0,05)$, assim como o teste de correlação de Pearson, com base nos dados individuais dos sujeitos apresentados na Tabela 12 no Apêndice A.

Para uma primeira análise dividimos a amostra em 3 grupos: (1) foram agrupados os indivíduos proficientes, excluindo o Acácio por ter sido o primeiro bem-sucedido, o que totalizou 5 sujeitos machos; (2) levando em consideração o total de 5 indivíduos do primeiro grupo, agrupamos no segundo os próximos 5 indivíduos, que não foram bem-sucedidos, mas que passaram mais tempo em contato com a caixa. Porventura, esses 5 também foram machos; (3) para possibilitar uma comparação entre gêneros selecionamos para o terceiro grupo as 5 fêmeas que mais estiveram em contato com a caixa.

Consideramos para essa análise estatísticas os dados em relação a caixa de melado, já que estávamos olhando para o momento do sucesso e essa foi a primeira caixa a ser solucionada por todos os proficientes e também foi a caixa exposta por um tempo maior. 
Tabela 2 - Etograma com as categorias comportamentais registradas durante o experimento.

\begin{tabular}{|c|c|}
\hline CATEGORIAS DE PROXIMIDADE & DESCRIÇÃO \\
\hline Em contato com a caixa & $\begin{array}{l}\text { Iniciar e permanecer em contato físico direto com } \\
\text { uma das caixas-problema. }\end{array}$ \\
\hline Até $2 \mathrm{~m}$ & $\begin{array}{l}\text { Estar posicionado dentro de um raio de } 2 \mathrm{~m} \text { de } \\
\text { distância da(s) caixa(s). }\end{array}$ \\
\hline Até $5 \mathrm{~m}$ & $\begin{array}{l}\text { Estar posicionado entre um raio de } 2 \mathrm{~m} \text { e } 5 \mathrm{~m} \text { de } \\
\text { distância da(s) caixa(s). }\end{array}$ \\
\hline \multicolumn{2}{|c|}{ CATEGORIAS DE MANIPULAÇÃO DE CAIXA } \\
\hline Inserir dedo & Inserir o dedo em um dos furos da caixa. \\
\hline Inserir língua & Inserir a língua em um dos furos da caixa. \\
\hline Lamber & Lamber uma das superfícies da caixa. \\
\hline Batucar & $\begin{array}{l}\text { O indivíduo bate rapidamente com as pontas dos } \\
\text { dedos na caixa. }\end{array}$ \\
\hline Bater pedra & Usar uma pedra contra a caixa. \\
\hline \multicolumn{2}{|c|}{ CATEGORIAS DE MANIPULAÇÃO DE VARETAS } \\
\hline Pegar vareta & Ato de agarrar/segurar uma ou mais varetas. \\
\hline Levar vareta & $\begin{array}{l}\text { Pegar uma ou mais varetas e transportá-las para a } \\
\text { área de } 2 \mathrm{~m}, 5 \mathrm{~m} \text { ou além; }\end{array}$ \\
\hline Trazer vareta & Transportar uma ou mais varetas até a caixa. \\
\hline Morder vareta & Levar a vareta a boca e morder. \\
\hline Quebrar vareta & $\begin{array}{l}\text { Danificar a vareta, partindo-a em um ou mais } \\
\text { pedaços com as mãos e/ou boca. }\end{array}$ \\
\hline Bater vareta & Bater a vareta contra uma superfície. \\
\hline Esfregar vareta & $\begin{array}{l}\text { Esfregar a vareta em uma superfície ou em outra } \\
\text { vareta. }\end{array}$ \\
\hline Manipular Varetas & $\begin{array}{l}\text { Categoria que acopla os comportamentos de Bater, } \\
\text { Morder, Esfregar vareta e Outras Manipulações. }\end{array}$ \\
\hline Inserção Deliberada bem-sucedida & Inserir a vareta de forma precisa e direcionada. \\
\hline Inserção Deliberada Inepta & $\begin{array}{l}\text { Inserir a vareta realizando movimentos imprecisos } \\
\text { direcionados a caixa. }\end{array}$ \\
\hline Inserção Involuntária & Inserção a vareta de forma não intencional. \\
\hline Retirar vareta & Retirar uma vareta previamente inserida na caixa. \\
\hline Lamber vareta & Lamber uma vareta que esteja em sua pose. \\
\hline Descartar vareta & Soltar/largar a vareta. \\
\hline Puxar vareta fixa & Puxar uma vareta fixa. \\
\hline Outra Manipulação & $\begin{array}{l}\text { Qualquer ação que não se enquadre nas categorias } \\
\text { propostas. }\end{array}$ \\
\hline \multicolumn{2}{|l|}{ CATEGORIAS SOCIAIS } \\
\hline Catação & $\begin{array}{l}\text { Vasculhar o pelo de outro animal em busca de } \\
\text { ectoparasitas. }\end{array}$ \\
\hline Vocalização & Quando um indivíduo emite sons. \\
\hline Ameaça & $\begin{array}{l}\text { Assumir postura agonística e/ou perseguir/afugentar } \\
\text { outro animal. }\end{array}$ \\
\hline
\end{tabular}


Brincadeira

Amamentação

Tolerated Scrounging

Delayed Scrounging
Dois ou mais indivíduos interagem em brincadeiras de Luta e/ou Perseguição não envolvendo ameaças e agressividade.

O filhote leva a boca até o mamilo.

Alimentar-se das sobras deixadas por outros indivíduos durante uma ação de forrageio e na presença do forrageador.

Alimentar-se das sobras deixadas por outros indivíduos em uma ação de forrageio prévia. 


\section{RESULTADOS}

\subsection{Caixa de melado}

Foram realizadas 696 sessões (dias de experimento) de exposição da caixa de melado durante todo o período do experimento, gerando um total aproximado de 83 horas de filmagens com interações dos macacos com essa caixa. O tempo de contato com a caixa é a variável base, essencial para medir o desempenho dos sujeitos, já que, obviamente, não é possível solucionar o experimento sem estar em contato com ele. A maioria dos comportamentos registrados no Etograma também são dependentes do contato com a caixa.

Para verificarmos a influência do tempo na caixa no sucesso medimos o tempo total que cada indivíduo esteve em contato com a caixa de melado ao longo do experimento (Figura 6), considerando para os indivíduos bem-sucedidos o tempo até o momento do primeiro sucesso. $\mathrm{O}$ indivíduo Abelha, por ser periférico, teve a oportunidade de interagir com a caixa em um único dia, durante a fase de teste quando a caixa era movida de lugar e, sendo assim, ficou de fora da análise dos dados. Assim como os dois infantes, Amom e França, que não interagiram com o experimento. 
Figura 6 - Tempo total que cada indivíduo esteve em contato com a caixa de melado. Para os sujeitos bem-sucedidos (em azul) o tempo equivale até o momento do primeiro sucesso. Tempo indicado em horas:minutos:segundos (hh:mm:ss).

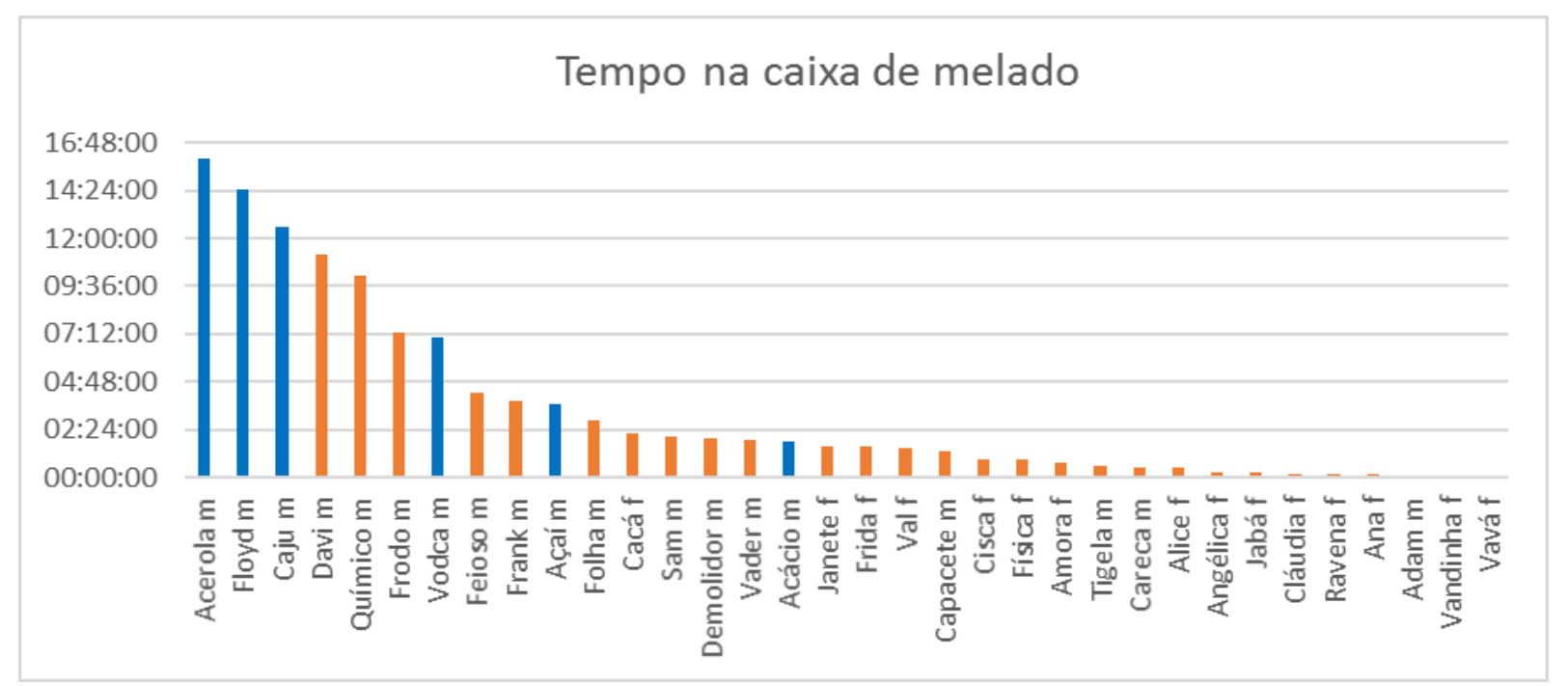

O surgimento de um indivíduo inovador aconteceu no $16^{\circ}$ dia de experimento. Desde o sucesso inicial do primeiro indivíduo houve um intervalo de tempo de 64 dias de experimento até que um outro indivíduo fosse bem-sucedido na tarefa. Já entre o segundo indivíduo e o sexto e último proficiente, esse intervalo de tempo foi de 40 dias de experimento (Tabela 3).

Tabela 3 - Indivíduos bem-sucedidos na caixa de melado por ordem de sucesso.

\begin{tabular}{lllll}
\hline Ordem & Indivíduo & Sexo & Faixa etária & Data \\
\hline Inovador & Acácio & Macho & Adulto & $04 / 05 / 2017$ \\
$2^{\text {o }}$ & Acerola & Macho & Adulto & $12 / 06 / 2018$ \\
$3^{\text {o }}$ & Caju & Macho & Adulto & $21 / 06 / 2018$ \\
$4^{\text {o }}$ & Floyd & Macho & Adulto & $26 / 06 / 2018$ \\
$5^{\circ}$ & Vodca & Macho & Adulto & $04 / 07 / 2018$ \\
$6^{\circ}$ & Açaí & Macho & Adulto & $27 / 07 / 2018$ \\
\hline
\end{tabular}




\subsection{Análise dos dados}

Aplicamos para os 3 grupos amostrais selecionados (ver 2.7), que correspondem aos 5 machos proficientes (5MP), aos 5 machos não proficientes que mais tempo visitaram a caixa $(5 \mathrm{MV})$ e as 5 fêmeas que mais visitaram a caixa (5FV), o teste de Kruskal-Wallis. O resultado mostrou uma diferença significativa para Tempo na Caixa $(H=9,500 ; \mathrm{df}=2 ; \mathrm{p}=0,009)$, apontando para uma diferença maior entre as 5FV (Média = 3) do que entre os 5MP (Média = 11) e os 5MV (Média =10). Quando olhamos para o total de Tempo na Caixa para cada indivíduo desses grupos fica evidente a discrepância entre machos e fêmeas (Figura 7). A Manipulação de Varetas também apresentou uma diferença significativa entre esses 3 grupos $(\mathrm{H}=11,601$; $\mathrm{df}=2$; $\mathrm{p}=0,003)$.

Figura 7 - Tempo total de contato com a caixa de melado para cada indivíduo dos grupos de 5MP (azul), 5MV (laranja) e 5FV (rosa). Tempo apresentado no formato horas:minutos:segundos (hh:mm:ss).

\section{Tempo na caixa}

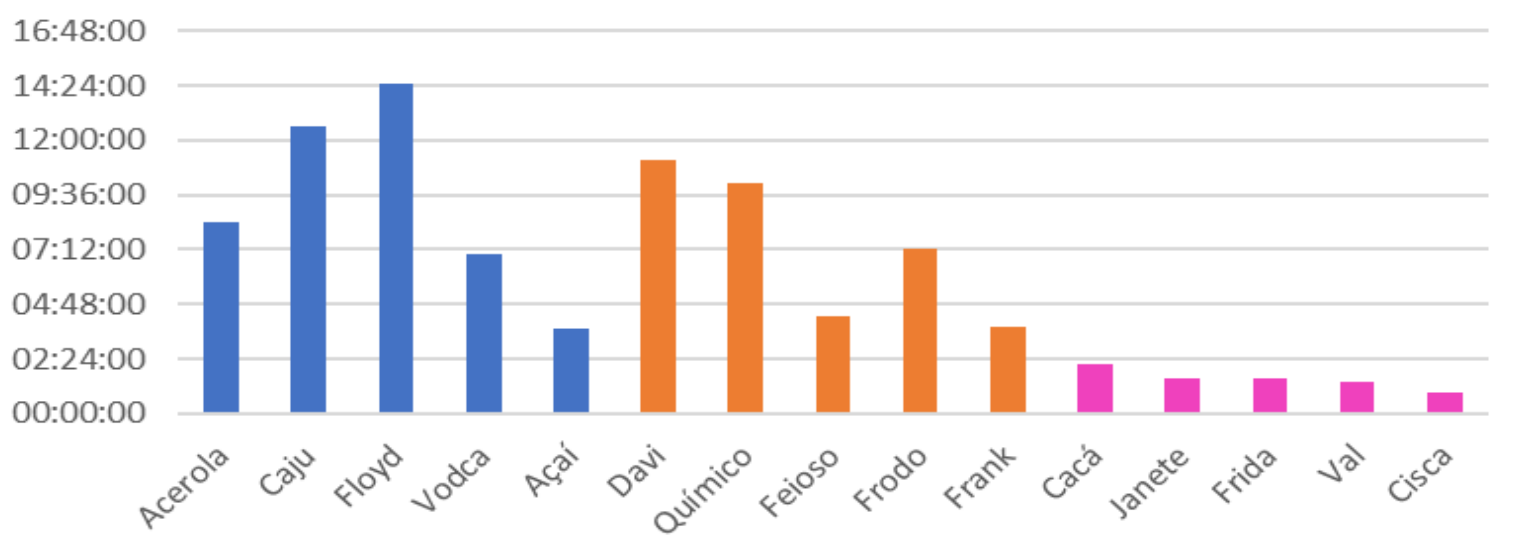

Então comparamos os grupos amostrais entre si, em testes de 1 pra 1, através do teste $\mathrm{U}$ de Mann-Whitney. Comparando os 5MP com as 5FV observamos uma diferença na variável Tempo na Caixa que foi considerada significativa $(U=0 ; p=0,009)$. A baixa frequência das fêmeas na área do experimento também é evidenciada por diferenças significativas no Tempo a $2 \mathrm{~m}(\mathrm{U}=0$; $\mathrm{p}=0,009)$ e no Tempo a $5 \mathrm{~m}(\mathrm{U}=2,000 ; \mathrm{p}=0,028)$. Ademais, variáveis como Manipulação de Varetas, Inserções Observadas, Tempo com Proficiente e eventos de scrounging se mostraram não significativos, um reflexo do pouco tempo que as fêmeas tiveram de contato com o experimento. Comparando o Tempo na Caixa das fêmeas com os $5 \mathrm{MV}$ também temos uma diferença significativa $(U=0 ; p=0,009)$. 
Em contrapartida, quando analisamos o Tempo na Caixa para os 5MP e os 5MV não há diferença significativa $(U=10,000 ; p=0,690)$, indicando que somente o tempo de contato com caixa não é suficiente para se chegar ao sucesso (Figura 8).

Figura 8 - Comparação do tempo na caixa entre os 5MP (laranja) e os 5MV (azul).

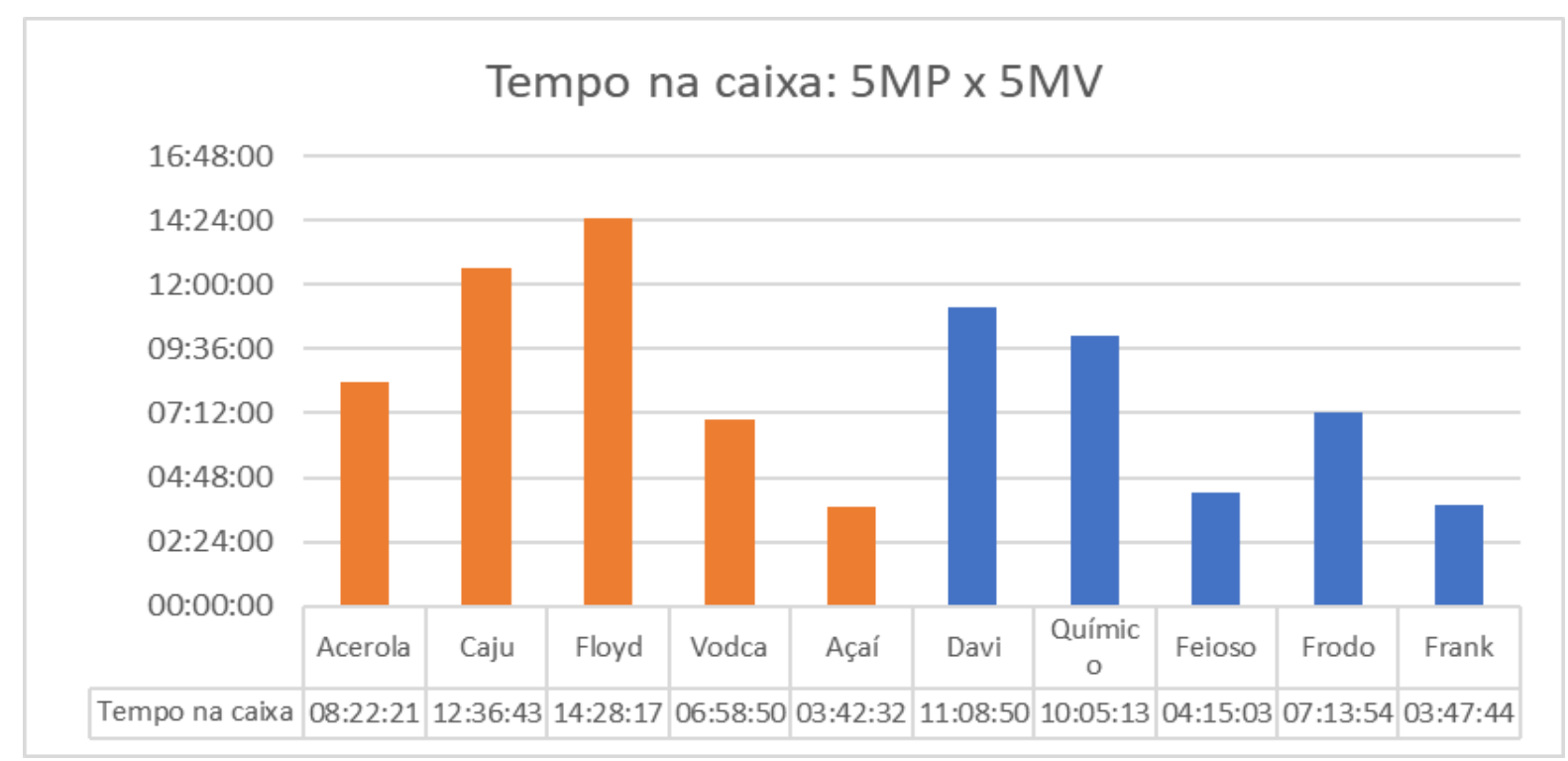

Levando em conta que o contato com a caixa foi semelhante estatisticamente, caberia olhar para os períodos de facilitação e comportamentos que podem desencadear uma aprendizagem associal. Para ambas variáveis relacionadas as facilitações como, Retirar Vareta Facilitada $(\mathrm{U}=$ 10,000; $\mathrm{p}=0,600)$ e Puxar Vareta Fixa $(\mathrm{U}=10,000 ; \mathrm{p}=0,602)$ nenhuma apresentou diferença significativa e o mesmo se deu para a ação de Explorar a Caixa $(U=11,000 ; p=0,754)$. O Delayed Scrounging (DS) apresentou uma diferença significativa ( $\mathrm{U}=3,000 ; \mathrm{p}=0,044)$, mas com a média maior entre os 5MV $(\mathrm{M}=7,40)$.

A variável Manipulação de Varetas se mostrou significativa entre esses dois grupos $(\mathrm{U}=$ 2,000; $\mathrm{p}=0,028)$, indicando que o ato de manipular as varetas, de estar em contato com as ferramentas, pode ser o fator chave para ter sucesso na tarefa. Os dados dos valores totais de manipulações de varetas de cada um desses indivíduos mostram que, de fato, há uma diferença grande entre esses dois grupos (Figura 9). 
Figura 9 - Valor total da variável Manipular Varetas para os 5MP (azul) e os 5MV (laranja).

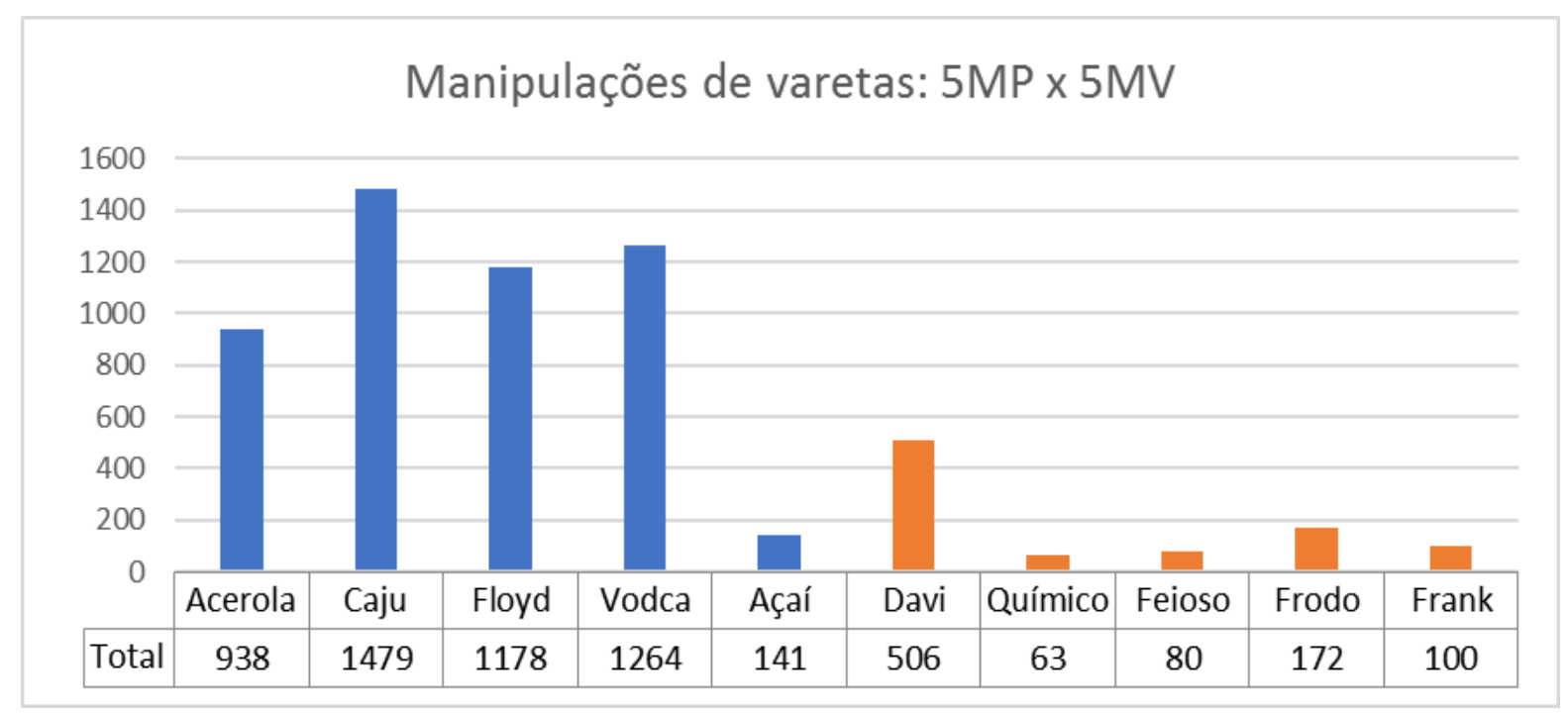

Já para variáveis que podem contribuir para uma aprendizagem socialmente mediada, como o Tempo com proficiente na caixa, Inserções Observadas, Tolerated Scrounging (TS) e a presença a 2 metros ou 5 metros de um proficiente, todas se mostraram não significativas.

Para verificar a relação entre as variáveis aplicamos a análise de correlação de Pearson nos dados para os 3 grupos (5MP, 5MV e 5FV). Em um primeiro momento fizemos a análise com os dados da Tabela 12, porém, a maioria das variáveis se correlacionaram por conta da dependência do Tempo na Caixa. Para diminuir o peso dessa variável na análise reformulamos os valores dividindo os dados de cada uma pelo valor do Tempo na Caixa (cf. Apêndices C-F). Aplicamos aos dados corrigidos o teste de correlação de Pearson.

Os resultados mostraram uma correlação entre o Tempo na Caixa com Proficiente (TCP) e as Inserções Observadas $(\mathrm{r}=0,979 ; \mathrm{p}=0,001)$. O TCP também se correlacionou com o Tolerated Scrounging ( $\mathrm{r}=0,947 ; \mathrm{p}=0,001)$, mostrando, como esperado, que estar junto com um indivíduo proficiente na caixa é uma condição necessária para o TS e para a observação da técnica. O TS também teve uma correlação significativa com as Inserções Observadas $(r=0,940 ; p=0,001)$. No entanto, nenhuma das variáveis apresentou uma correlação com Manipular Varetas. Então, para podermos checar em detalhes a influência que Manipular Varetas teve para o sucesso da tarefa precisamos olhar separadamente para o desempenho de cada um dos indivíduos proficientes ao longo do experimento. 


\subsection{Investigação das variáveis entre os bem-sucedidos}

Com base nos dados apresentados até aqui é possível observar que a única variável que se mostrou estatisticamente significante foi Manipular Varetas. As análises estatísticas indicaram que as diferenças entre os 5MP e os 5MV não estariam relacionadas ao tempo que cada macaco esteve no experimento, nem o contato com proficientes ou as Inserções Observadas, mas na quantidade de manipulações de varetas executadas por eles. No entanto, as análises estatísticas não demonstram como uma alta taxa de manipulações de varetas pode ter levado o sujeito ao sucesso e nem quando grandes quantidades de manipulação de varetas ocorreram. Para isso é necessário olhar para a trajetória de cada um dos 6 indivíduos bem-sucedidos e verificar a influência dessas manipulações na aquisição da técnica de uso de varetas como ferramentas de sondas. Dessa forma, desenvolvemos 3 conjuntos de hipóteses para investigar quais seriam os fatores que possibilitaram o sucesso na tarefa, considerando a trajetória individual de cada sujeito.

O primeiro conjunto se baseia em eventos, como as Inserções Observadas, Manipulação de Varetas e Inserções Involuntárias, ocorridos em momentos próximos ao sucesso. Em um primeiro momento é possível supor que através da ocorrência desses eventos algum indivíduo possa chegar à solução da técnica, seja por vias sociais ou associais. Desenvolvemos então 3 hipóteses (H1, H2 e H3), uma para cada um desses eventos, acompanhadas de questões correspondentes que busquem analisar como tais casos podem ter contribuído para a solução da tarefa.

- H1 - Observar um indivíduo proficiente realizando inserções pode levar ao sucesso. ○ O primeiro sucesso se seguiu após Inserções Observadas?

- H2 - Manipular Varetas em alta quantidade pode ocasionar o sucesso.

○ O primeiro sucesso se seguiu a um aumento de Manipulação de Varetas?

- H3 - Inserções Involuntárias podem ocasionar o sucesso.

○ O primeiro sucesso se seguiu após Inserções Involuntárias?

No segundo conjunto de hipóteses buscamos averiguar o que poderia ter influenciado o aumento na frequência de Manipular Varetas que diferenciou os sujeitos proficientes dos nãoproficientes. Criamos mais 3 hipóteses (H4, H5 e H6) para analisar se, em algum momento do 
experimento, interagir com as facilitações ou com indivíduos proficientes (observando e fazendo scrounging) possa ter impulsionado um interesse pelas ferramentas.

- H4 - Observar um indivíduo proficiente realizando inserções pode levar a um aumento na frequência de Manipular Varetas.

○ Inserções Observadas levaram a um aumento subsequente na Manipulação de Varetas?

- H5 - O contato com os períodos de Facilitação Completa pode levar a um aumento na frequência de Manipular Varetas.

- Períodos de Facilitação Completa levaram a um aumento na Manipulação de Varetas?

- H6 - O scrounging pode levar a um aumento na frequência de Manipular Varetas.

- Eventos de scrounging levaram a um aumento subsequente na Manipulação de Varetas?

Já o nosso terceiro conjunto de hipóteses considerou os eventos ocorridos após o sucesso, no intuito de verificar se os indivíduos "refinam" o uso das ferramentas, tornando-o mais eficiente. Supõe-se que os comportamentos que inviabilizem a ferramenta ou que não estejam diretamente ligados ao ato de inserir a vareta na caixa sejam interrompidos. Caso algumas dessas ações permaneçam no repertório comportamental do sujeito proficiente supomos que estes podem ter sido mantidos através de um reforço positivo. Dessa forma, outras 3 hipóteses (H7, H8 e H9) foram levantadas para analisar o comportamento dos sujeitos proficientes após a solução da tarefa. 
- H7 - Alguns tipos de manipulações de varetas podem ter um valor negativo para o sucesso.

○ Manipulações nocivas, como Quebrar e Levar vareta, são interrompidas após o primeiro sucesso?

- H8 - Manipulações que não estão envolvidas diretamente com a inserção tendem a ser interrompidas após o sucesso.

○ Manipulações não-funcionais de varetas são interrompidas após o primeiro sucesso?

- H9 - Manipulações não-funcionais que se mantém no repertório comportamental, provavelmente, foram reforçadas com o sucesso.

○ Manipulações não-funcionais de varetas que persistiram após o sucesso, aconteceram em associação com as primeiras inserções?

Para verificarmos essas hipóteses e responder as perguntas levantadas é necessário que, primeiramente, analisemos os dados da trajetória individual para cada um dos indivíduos que foram bem-sucedidos.

\subsection{Os indivíduos bem-sucedidos}

O estudo de caso de cada indivíduo proficiente está descrito nas próximas sessões, onde os dados foram apresentados de forma cumulativa, o que significa que após o primeiro valor de uma tabela cada valor subsequente é somado ao valor anterior. Dessa forma, quando esses dados são apresentados em formato de gráfico de linha a curva é sempre ascendente. Quando não há alteração no valor de uma variável (mantendo-se o mesmo) a linha se mantém horizontal, significando que o indivíduo não realizou aquele comportamento durante esse período.

\subsubsection{Acácio}

Acácio, macho adulto e nascido no parque em 2008, tem uma posição hierárquica alta no grupo, já que é bem tolerado pelo macho dominante e por outros machos adultos, sendo também 
bem tolerante. Foi o primeiro indivíduo bem-sucedido, um inovador, portanto sabemos que sua aprendizagem durante esse experimento foi associal.

$\mathrm{O}$ ato de Manipular Varetas foi executado de maneira regular nas sessões anteriores ao sucesso. Em três dias de experimento, anteriores ao dia do sucesso, a quantidade de vezes que ele manipulou as ferramentas subiu de duas para 17 vezes, sendo 15 dessas manipulações efetuadas em um único dia (Figura 10).

Figura 10 - Valores totais do ato de Manipular Varetas efetuadas pelo Acácio nos dias de experimento anteriores ao dia de seu sucesso.

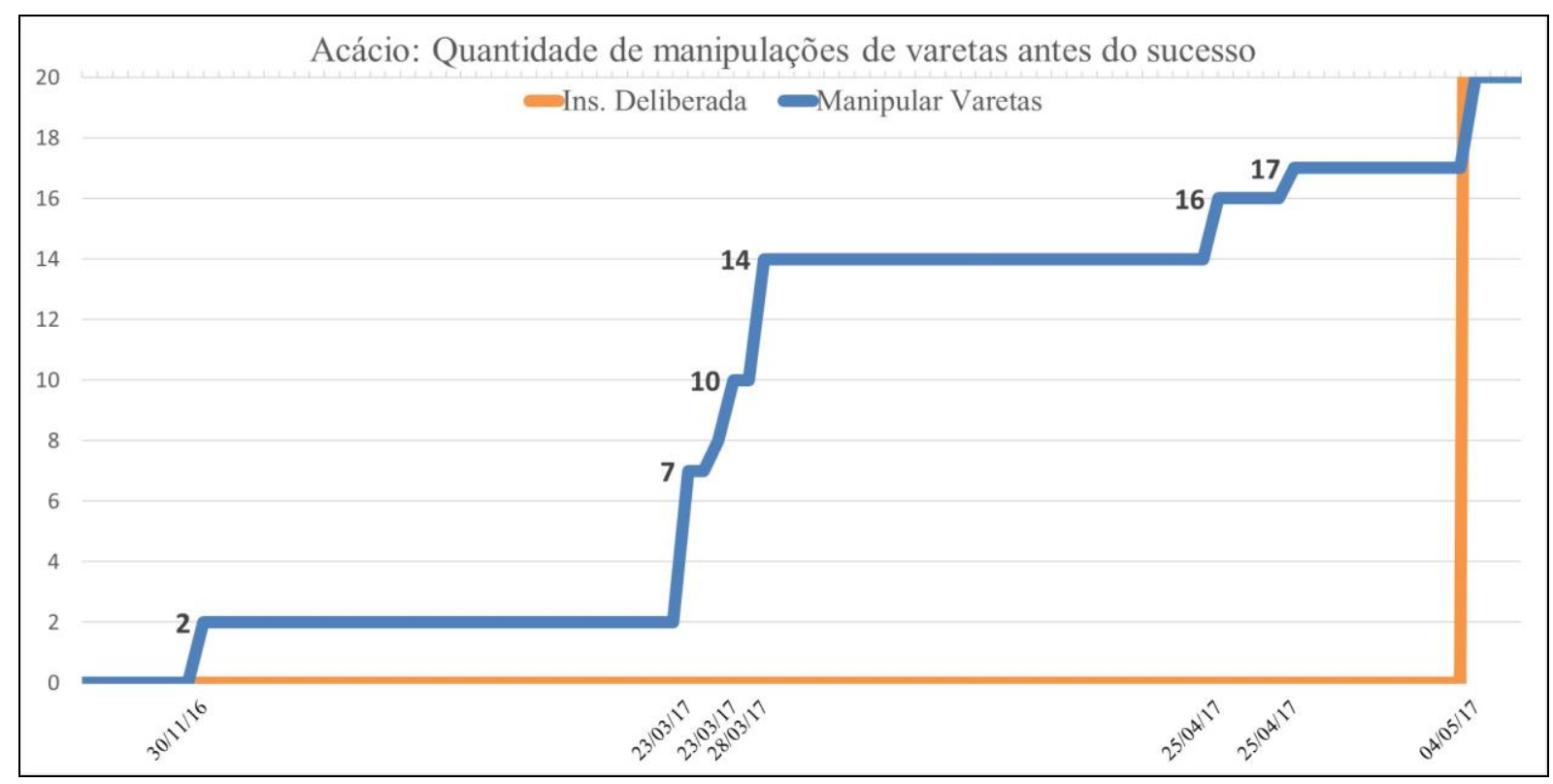

No dia 23/03/2017 (3 sessões antes do dia do sucesso), Acácio realiza duas tentativas de inserção que foram classificadas como Inserção Deliberada Inepta, por conta de as duas tentativas terem sido realizadas com pedaços de varetas quebradas e, caindo dentro da caixa, não possibilitaram a conclusão da tarefa. Já no dia do sucesso, após o transporte de uma vareta do chão para a caixa, ocorre uma Inserção Involuntária, com a ponta da vareta encaixando em um dos furos, mas que não chegou a atingir o melado (Figura 11). Instantes depois, exatamente 15 segundos, Acácio realiza sua primeira Inserção Deliberada bem-sucedida. 
Figura 11 - Inserção Involuntária segundos antes do sucesso (Acácio).

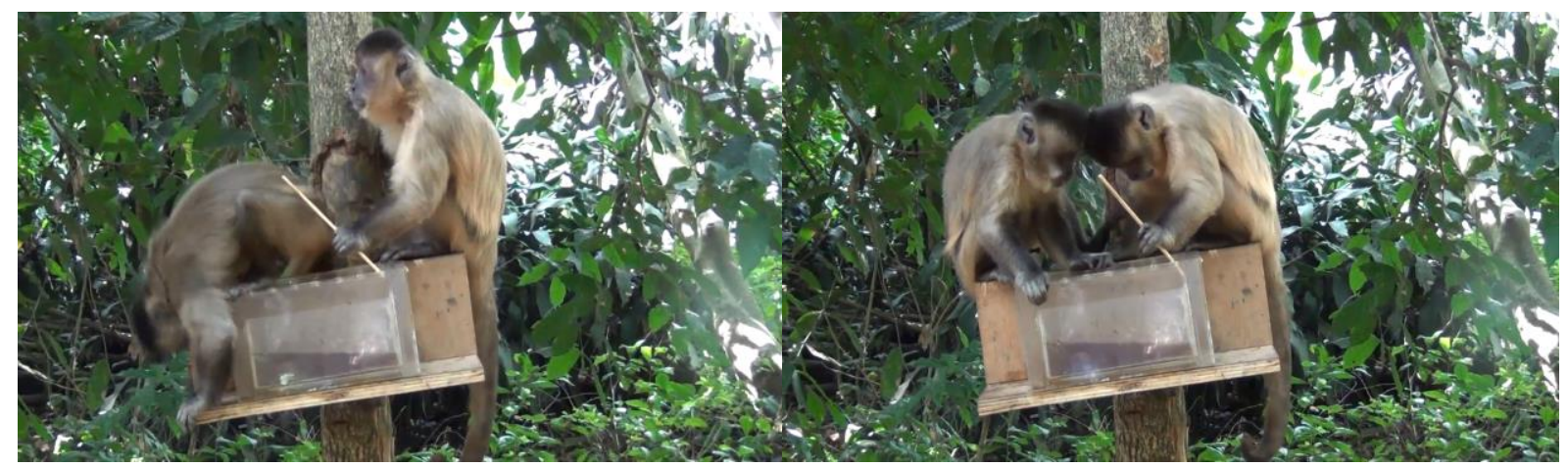

O contato que Acácio teve com o período de Facilitação com varetas pré-inseridas durante uma sessão anterior e no dia do sucesso não tiveram um reflexo direto no ato de Manipular Vareta, que não apresentou um aumento nesse período (Figura 12). Eventos de scrounging não ocorreram nesse intervalo de tempo antes do sucesso.

Figura 12 - Os atos de Retirar Varetas pré-inseridas efetuados pelo Acácio antes do dia do sucesso não tiveram um reflexo na quantidade de manipulações das varetas.

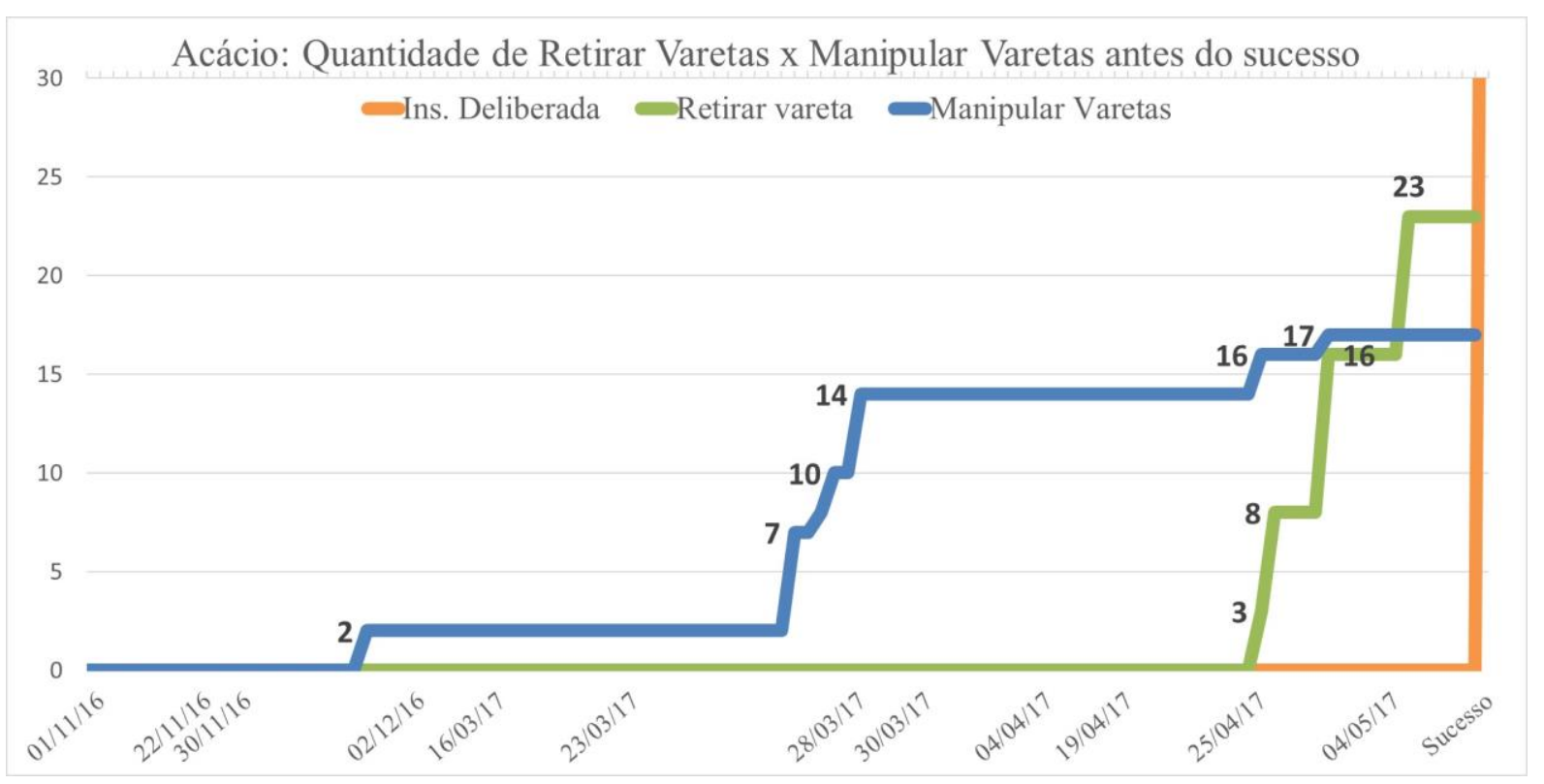

Os comportamentos envolvidos com a manipulação de varetas apresentaram um pequeno aumento entre antes e depois do sucesso (Figura 13). Antes do sucesso o ato de Morder Vareta apresentou o maior número de registros (6 vezes) e Quebrar Vareta não foi executado nenhuma vez. Após o sucesso os comportamentos de Esfregar e Bater varetas foram interrompidos. Enquanto que, ao final do experimento, Morder Vareta apresentava um único registro, Quebrar Vareta dois e outros 2 comportamentos foram classificados como Outra Manipulação. 
Já o comportamento de Levar Vareta aumentou de 2 para 16 ocorrências no período póssucesso. Esses comportamentos foram realizados durante a segunda fase do experimento e podem ter ocorrido por conta de uma quantidade maior de varetas disponíveis na área do experimento.

Figura 13 - Comparação dos registros de comportamentos relacionados a manipulação de varetas executados pelo Acácio até o dia de seu sucesso e ao final do experimento.

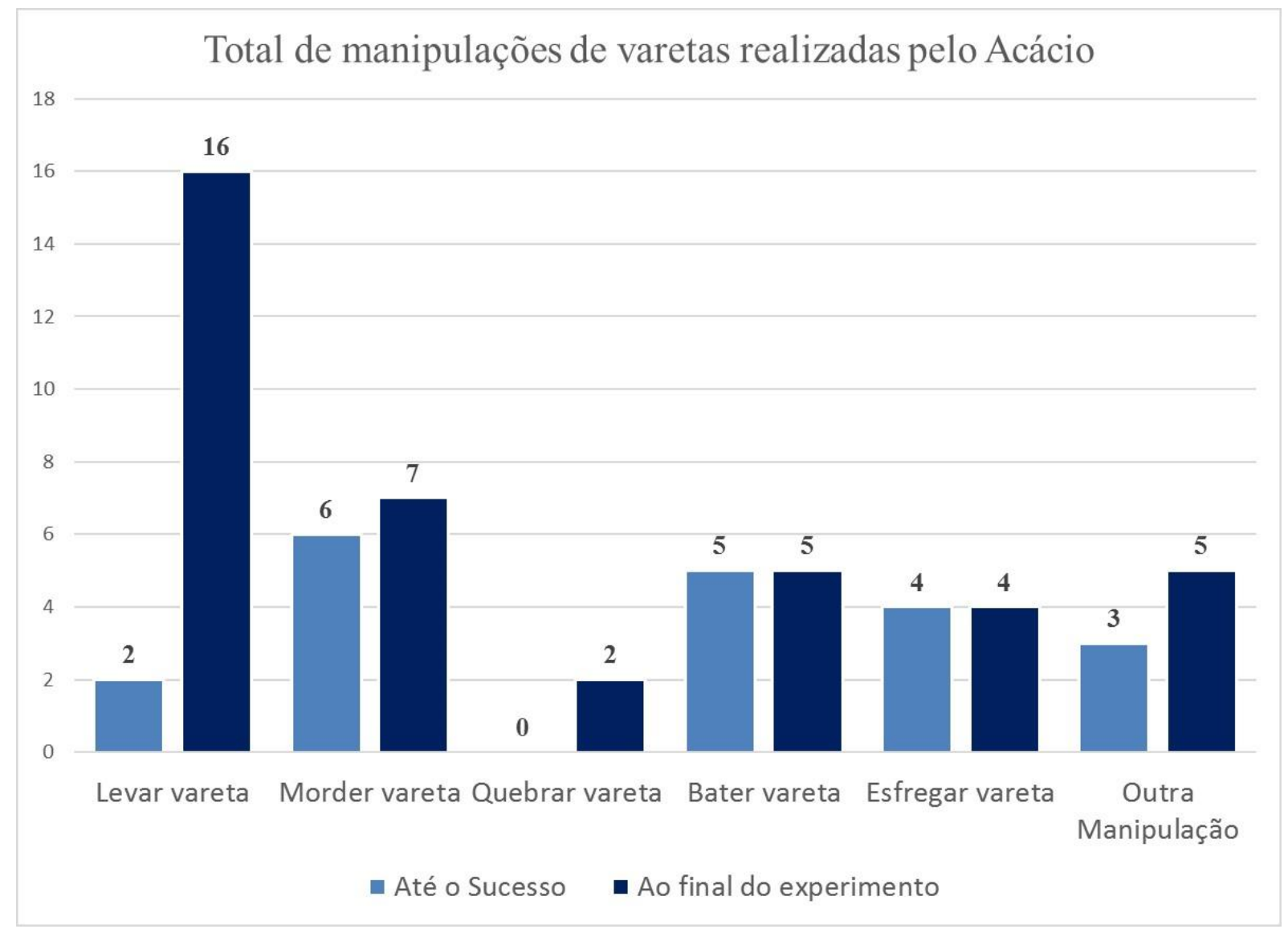

\subsubsection{Acerola}

Macho adulto, sem registro de nascimento - provavelmente nascido no PET. Mantém uma posição mediana na hierarquia, nunca fica ao lado do macho dominante e é por vezes ameaçado por ele e por outros machos adultos. Foi o segundo a solucionar a tarefa. O sucesso do Acerola se deu no início da segunda fase em junho de 2018, após um intervalo de 4 meses de interrupção no experimento.

Sua primeira Inserção Deliberada bem-sucedida se deu após observar o Acácio realizando 6 inserções na caixa de melado e, aproximadamente 4 minutos depois, Acerola realiza sua primeira Inserção Deliberada bem-sucedida na mesma caixa (Figura 14). Do início do experimento até o 
dia de seu sucesso, Acerola teve a oportunidade de observar outras 150 inserções na caixa de melado.

Figura 14 - Linha do tempo que abrange os eventos próximos da primeira Inserção Deliberada bem-sucedida do Acerola. A faixa mais clara indica o momento em que o Acerola está junto com o Acácio na caixa de melado. Os traços pretos são as inserções efetuadas pelo Acácio nesse espaço de tempo. A seta azul indica o momento do sucesso do Acerola. A seta vermelha indica uma Inserção Deliberada Inepta que ocorreu na caixa de sólidos por volta de 10 minutos antes do sucesso.

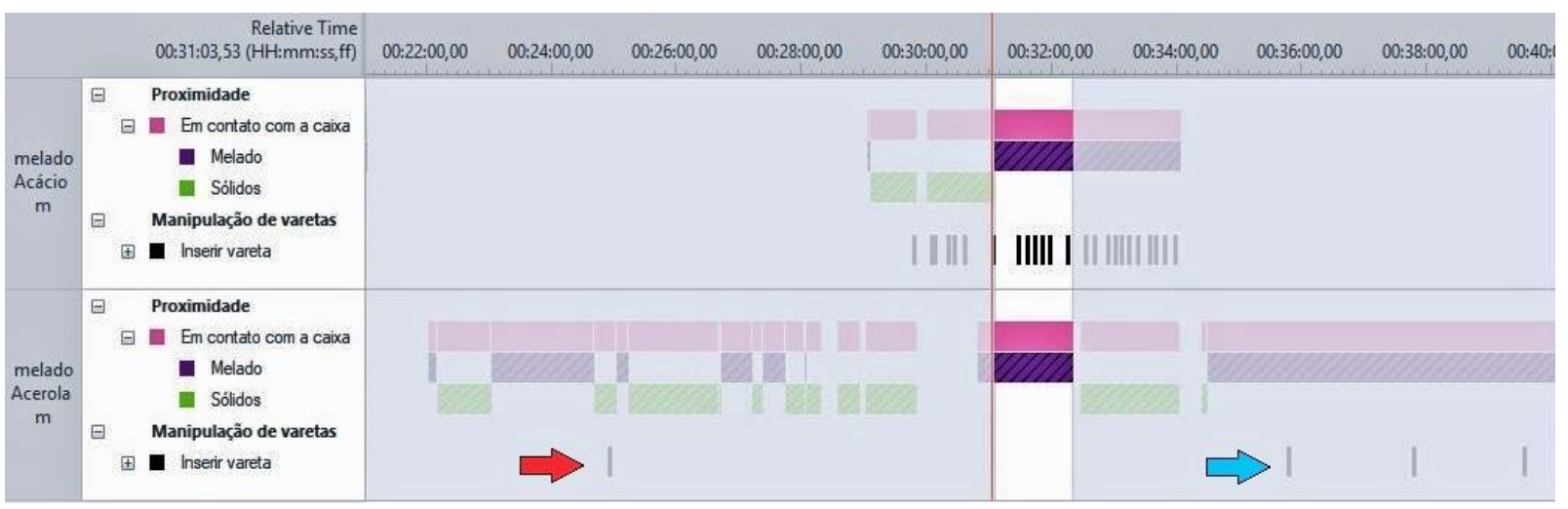

No dia de seu sucesso foram registrados, antes da Inserção Deliberada bem-sucedida, 19 comportamentos de manipulações de varetas $($ Morder Vareta $=9$; Esfregar Vareta $=9$; Bater Vareta $=1$ ), dentro de um período de 12 minutos de interação com a caixa de melado. Nesse período de contato com o experimento antes do sucesso não foi registrado nenhuma Inserção Involuntária na caixa de melado, apenas uma Inserção Deliberada Inepta que ocorreu na caixa de sólidos (Figura 14).

Em três momentos durante a primeira fase foi possível para o Acerola observar uma alta quantidade de inserções realizadas pelo Acácio. Durante um desses momentos (dia 10/11) foi possível para o Acerola realizar algumas ações de Tolerated Scrounging. O ato de Manipular Varetas se intensificou após as Inserções Observadas (Figura 15). Até o dia das primeiras Inserções Observadas (10/05), Acerola tinha realizado apenas 15 comportamentos de Manipular Varetas, sendo que as varetas padronizadas já estavam sendo disponibilizadas há 12 sessões experimentais. 
Figura 15 - Quantidade de Inserções Observadas, Manipular Vareta e Tolerated Scrounging realizadas durante um intervalo de tempo dentro da primeira fase. As sessões experimentais estão representadas pelas datas.

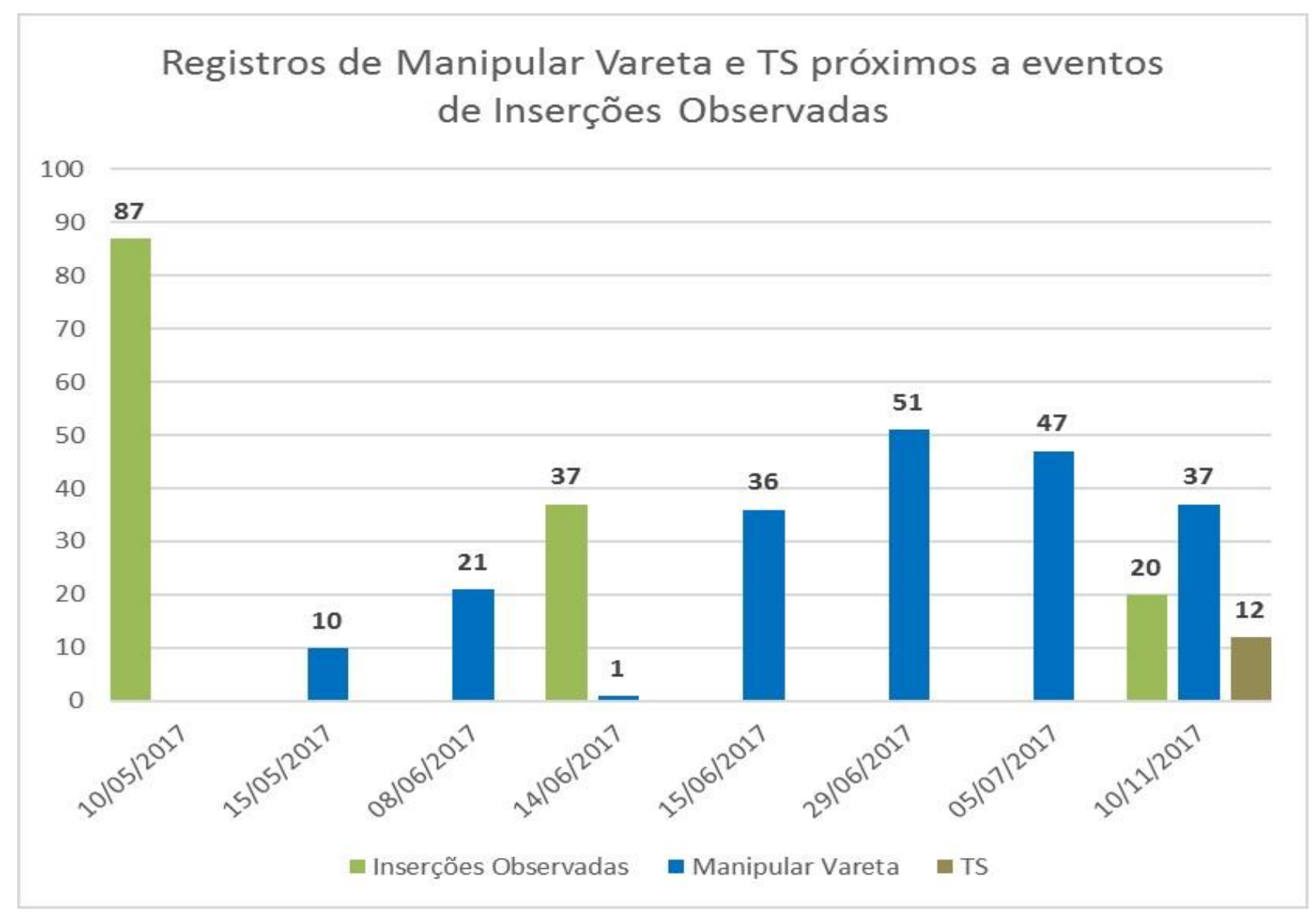

Dos 5 períodos em que a facilitação com varetas pré-inseridas foi aplicada (v. 3.2.3), Acerola só não esteve presente durante o $3^{\circ}$ período e teve a possibilidade de retirar 211 varetas pré-inseridas. O comportamento de Manipular Varetas teve uma expressão maior após o $5^{\circ}$ período de facilitação. Desse ponto até o final da primeira fase Acerola realizou 661 manipulações. Esse intervalo de tempo abrange 5 sessões experimentais nos dias 17/01, 23/01, 25/01, 07/02 e 08/02 de 2018. O total de Manipular Varetas realizados durante os períodos de facilitação estão indicados na Tabela 4. O contato do Acerola com a vareta fixa resultou em 882 registros de Puxar Vareta.

Tabela 4 - Valores totais do comportamento de Manipular Varetas efetuados pelo Acerola durante os períodos de facilitação com varetas pré-inseridas

\begin{tabular}{|l|l|}
\hline Período & Total \\
\hline $1^{\circ}$ Período & 3 \\
\hline $2^{\circ}$ Período & 67 \\
\hline $3^{\circ}$ Período & 0 \\
\hline
\end{tabular}




\begin{tabular}{|l|l|}
\hline $4^{\circ}$ Período & 39 \\
\hline $5^{\circ}$ Período & 176 \\
\hline
\end{tabular}

Alguns comportamentos podem dificultar o sucesso na tarefa, como o ato de Quebrar Varetas (inviabilizando a ferramenta) e Levar Vareta (transportando a ferramenta para longe da caixa). Acerola executou 18 vezes o comportamento de Quebrar Varetas antes do sucesso, mas não quebrou nenhuma vareta após o sucesso. $\mathrm{O}$ ato de Levar Vareta foi efetuado 8 vezes antes do sucesso e se manteve por mais 8 sessões experimentais após o sucesso, sendo executado mais 6 vezes (14 no total). Após o sucesso, alguns dos comportamentos de Manipulação de Varetas classificados como não-funcionais são executados por um tempo até serem interrompidos (Figura 16).

Figura 16 - Total de ocorrências dos comportamentos de Manipular Varetas efetuados pelo Acerola até o momento de seu sucesso comparado ao valor total ao final do experimento.

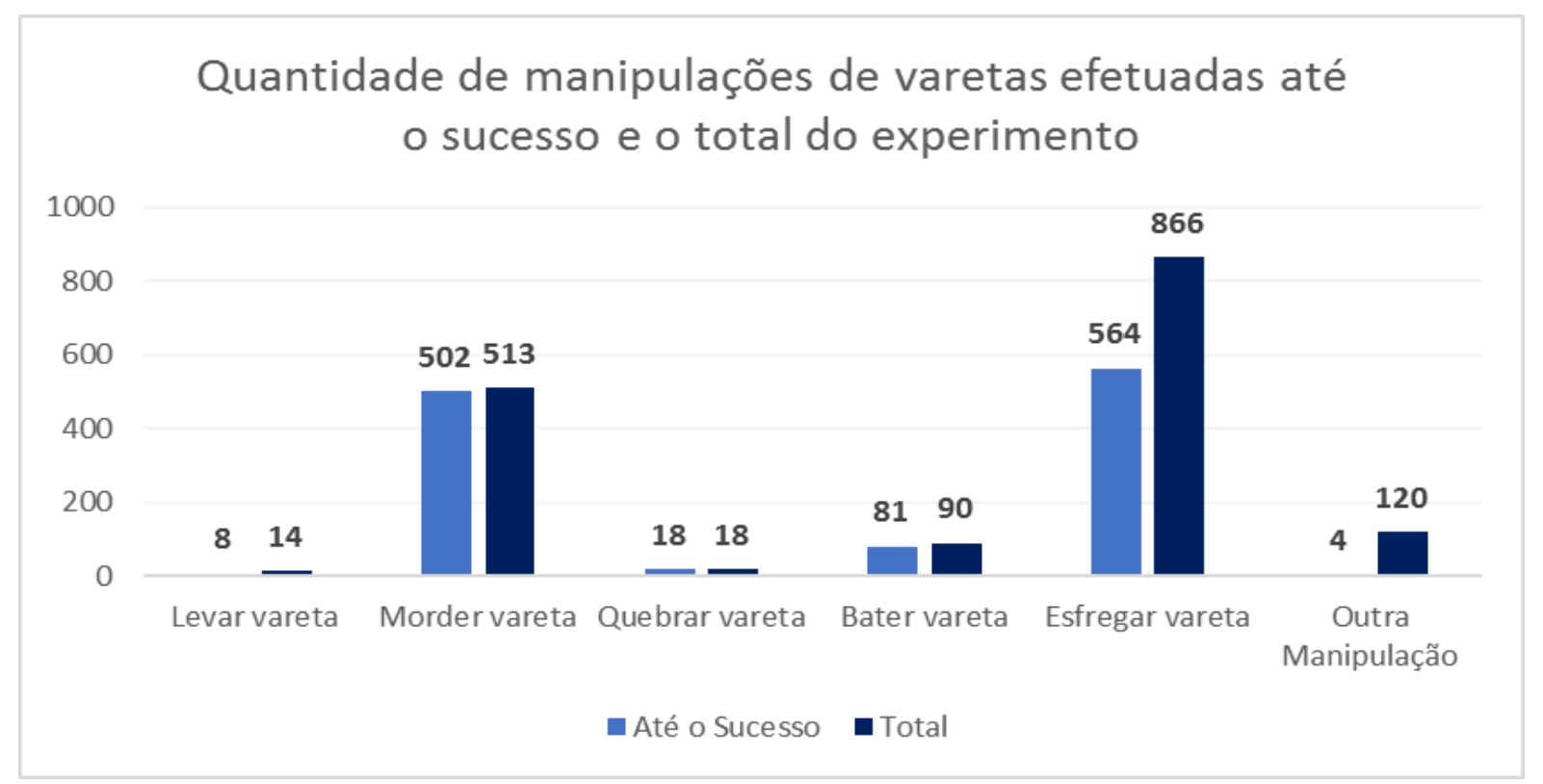

O comportamento de Esfregar Varetas é a manipulação que se mantém frequente após o sucesso até o final do experimento. No dia do sucesso foram registrados 21 atos de Esfregar Vareta, onde 9 dessas ações ocorreram antes da primeira Inserção Deliberada bem-sucedida e as demais em conjunto com outras duas inserções na caixa de melado (Figura 17), o que pode ter reforçado o comportamento por associação a solução da tarefa. Assim como o ato de Girar Vareta (classificado como Outra Manipulação) que aparece em conjunto das primeiras inserções bemsucedidas e se mantém no repertório por um tempo após o sucesso. 
Figura 17 - Linha do tempo mostrando os registros de Esfregar Varetas no dia do sucesso. As faixas claras indicam os eventos que ocorreram na caixa de melado. Cada traço representa uma ação, enquanto que os traços mais largos representam duas ações daquele comportamento naquele tempo.

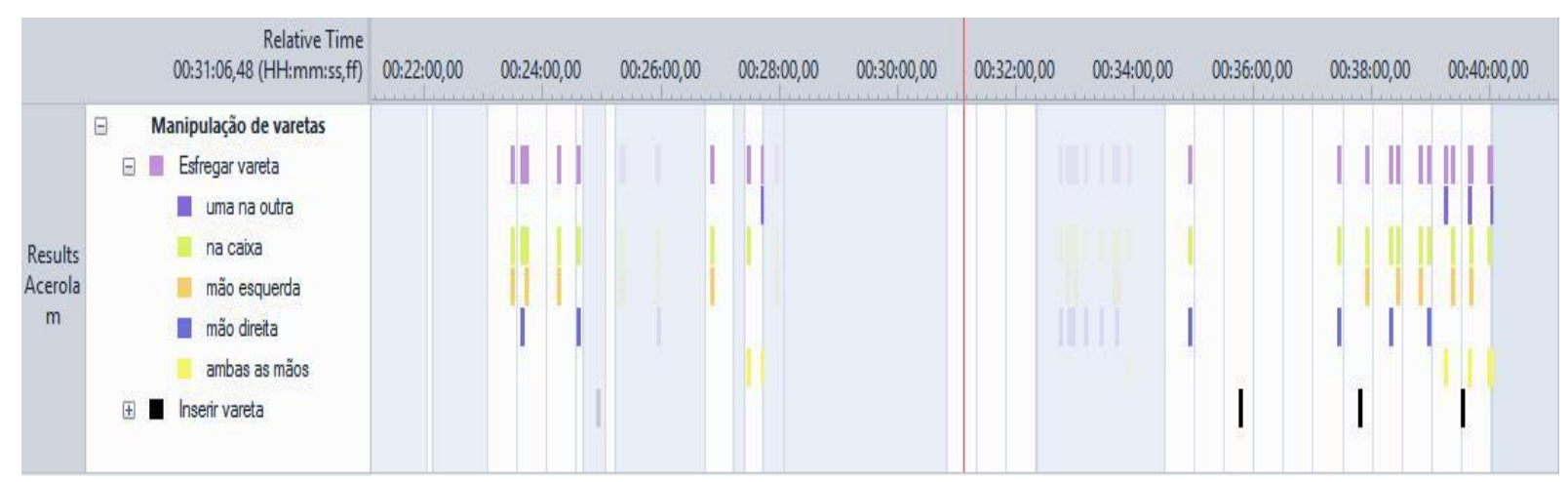

\subsubsection{Caju}

Macho adulto, nascido no PET em 2008 e com uma alta posição hierárquica. É bem tolerado pelo macho dominante e por outros machos adultos. Também é bem tolerante e foi visto carregando o filhote da Amora e a fêmea de Sapajus nigritus, Vandinha. Foi o terceiro a solucionar a tarefa, 9 dias após o Acerola (21/06/2018).

Caju, até o dia do seu sucesso, teve a oportunidade de observar 135 inserções na caixa de melado, sendo que 62 dessas Inserções Observadas ocorreram 2 dias antes (19/06/2018) do seu sucesso. Nesse dia, Caju também pôde realizar 51 eventos de Tolerated Scrounging (até esse dia o registro era de apenas 1) e houve o registro de uma Inserção Involuntária. Outra Inserção Involuntária ocorreu aproximadamente 1 minuto antes de sua primeira Inserção Deliberada bemsucedida. No total foram 7 Inserções Involuntárias ao longo do experimento e antes de seu sucesso.

Dentre os sujeitos proficientes, Caju foi o que mais manipulou varetas, com um aumento crescente desse comportamento ao longo do experimento, somando 1479 manipulações até o dia do sucesso (Figura 18). No entanto, os registros de Manipular Varetas próximos do sucesso foram de apenas 18 ocorrências no dia do sucesso, 11 ocorrências um dia antes e 5 ocorrências dois dias antes. 
Figura 18 - O comportamento de Manipular Varetas teve uma frequência constante até o dia que o Caju chegou ao sucesso. O gráfico abrange do início do experimento até o dia do sucesso do Caju.

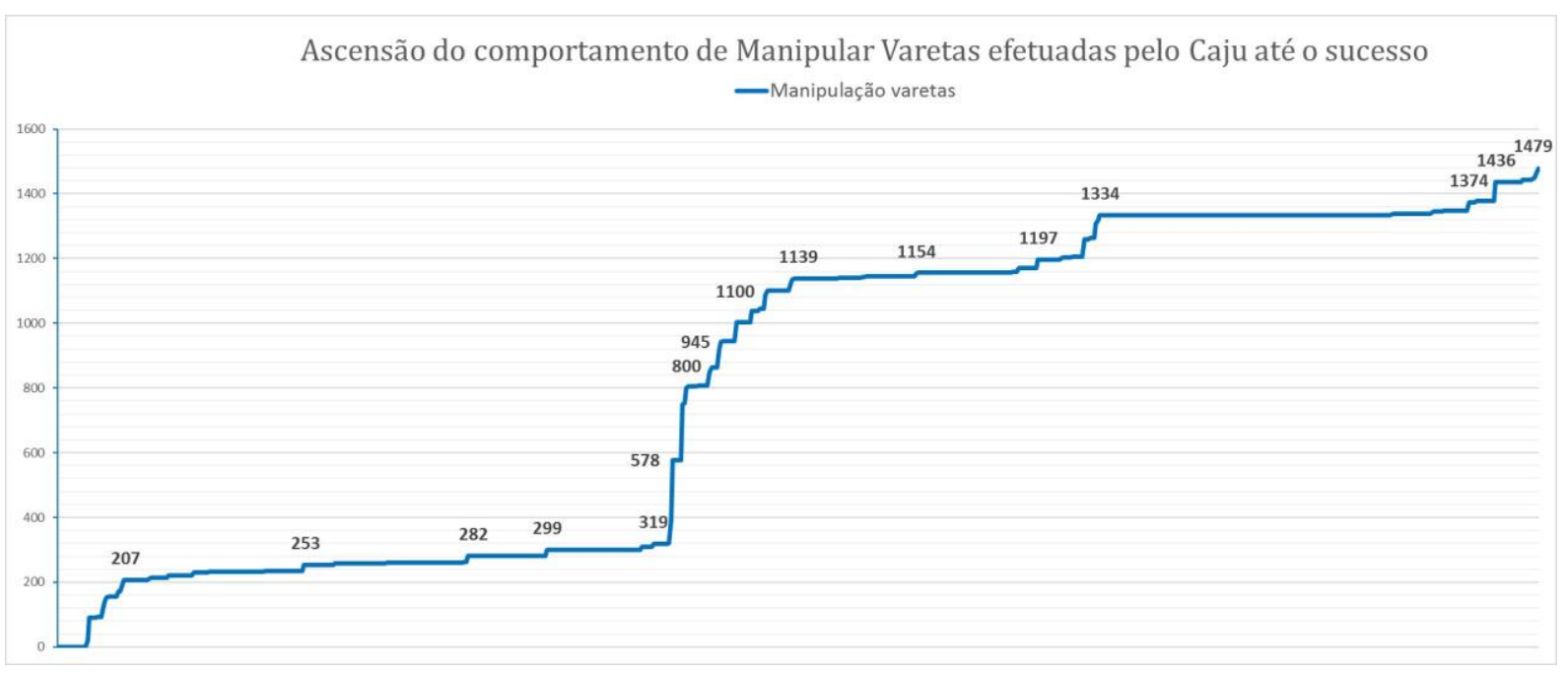

O momento em que se observa um aumento expressivo das manipulações no gráfico da Figura 18 (de 319 para 1139 ocorrências) corresponde a um período de 10 sessões experimentais $^{2}$. Esse aumento ocorreu próximo ou em conjunto com outros eventos. O primeiro deles, no dia 04/07/2017, foi uma Inserção Involuntária que foi seguida por 259 registros de Manipular Varetas efetuados no dia seguinte (05/07/2017). Na próxima sessão (06/05/2017), 2 Inserções Observadas foram acompanhadas de 175 ações de Manipular Varetas. Na sessão seguinte (12/07/2017) deu-se início ao $2^{\circ}$ Período de facilitação com varetas pré-inseridas. Durante esse espaço de tempo Caju executou 392 vezes o ato de Manipular Varetas. Nas duas primeiras sessões desse período foram registradas 40 Inserções observadas e 1 Inserção Involuntária acompanhadas de 72 manipulações de varetas e 32 eventos de Tolerated Scrounging.

Do seu contato com os períodos de facilitação, Caju retirou 271 vezes varetas pré-inseridas e manipulou varetas 2 vezes no $1^{\circ}$ Período, 392 vezes no $2^{\circ}, 12$ vezes no $3^{\circ}, 177$ vezes no $4^{\circ}$ e 40 vezes no $5^{\circ}$ Período de facilitação. No seu contato com a facilitação com vareta fixa efetuou o

${ }^{2}$ São elas: 04/07/2017, 05/07/2017, 06/07/2017 12/07/2017, 13/07/2017, 17/07/2017, 20/07/2017, 21/07/2017 e 28/07/2017. Para detalhes conferir a Tabela 11 no Apêndice A. 
comportamento de Puxar Vareta 289 vezes. A quantidade de cada um dos comportamentos relacionados a manipulação das varetas está apresentada na Figura 19.

Figura 19 - Total de ocorrências para manipulações de varetas realizadas pelo Caju até o dia de seu sucesso e no experimento como um todo. Valores referentes aos comportamentos efetuados na caixa de melado.

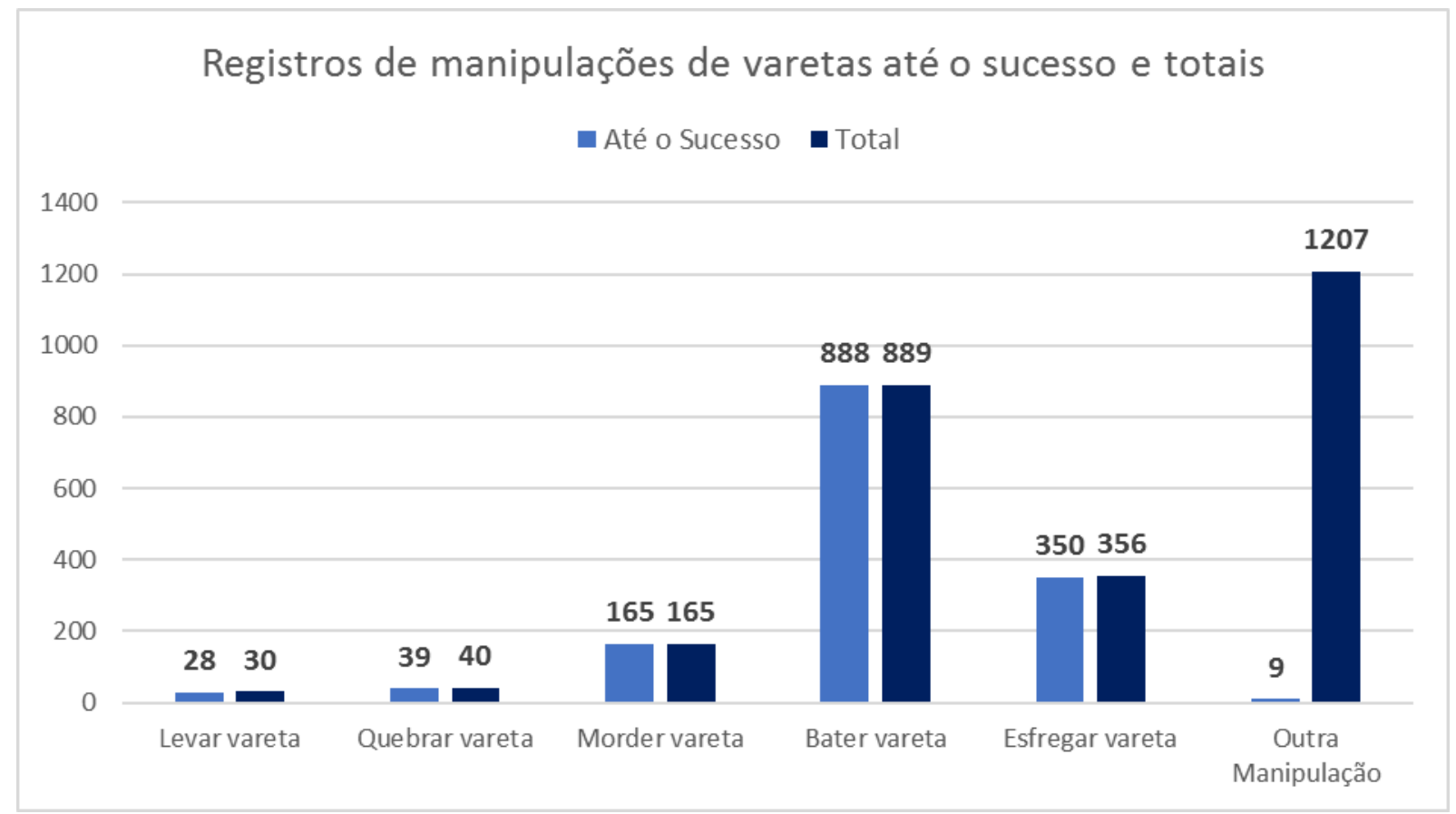

É possível observar que a partir do momento em que o Caju é bem-sucedido na tarefa as manipulações nocivas e não-funcionais são interrompidas, algumas após mais algumas poucas ocorrências. O comportamento classificado como Outra Manipulação é o único que aumenta de frequência após o sucesso e corresponde ao comportamento de girar a vareta com ambas as mãos (Figura 20). Da mesma forma que o Acerola, o Caju passa a girar a vareta antes de realizar as inserções, porém com uma frequência maior que o Acerola. Esse comportamento se desenvolveu em conjunto com as primeiras inserções bem-sucedidas e pode ter sido mantido ao ser reforçado com a solução da tarefa. 
Figura 20 - Comportamento de Girar Vareta executado pelo Caju.

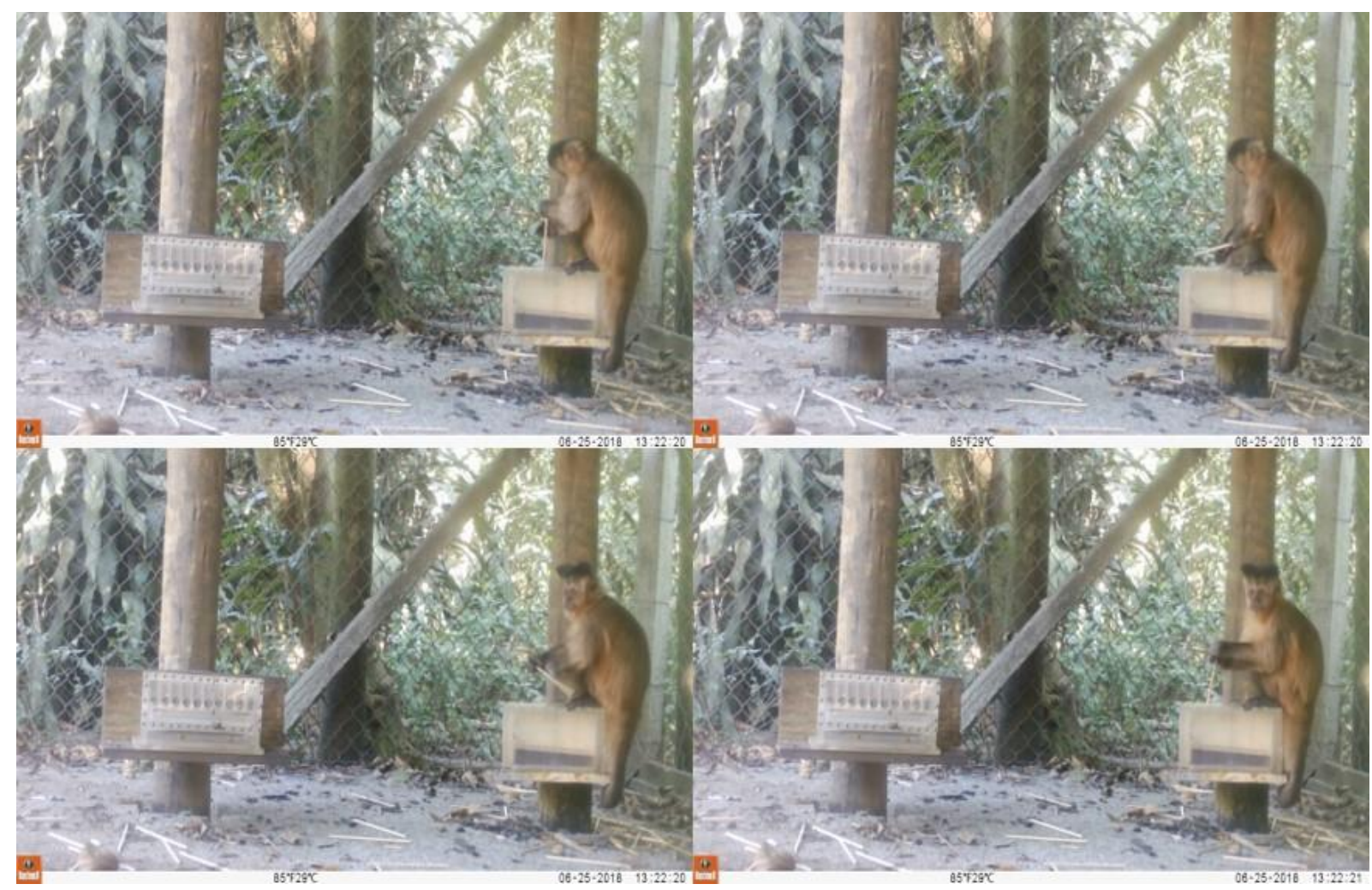

\subsubsection{Floyd}

Macho adulto, nasceu no PET em 2009 e foi o $4^{\circ}$ indivíduo a conseguir solucionar a tarefa. Mantém uma posição alta na hierarquia, não é ameaçado pelo macho dominante e nem por outros machos adultos.

Dos eventos ocorridos próximos ao sucesso, foram registradas 33 Inserções Observadas 8 dias experimentais ${ }^{3}$ antes do sucesso. Nesse dia (17/06/2018) Floyd observou o Acerola realizando as inserções na caixa de melado. No mesmo dia também ocorre uma Inserção Involuntária. Em relação ao comportamento de Manipular Varetas não foi registrado uma alta

\footnotetext{
${ }^{3}$ São eles: 17/06/2018, 18/06/2018, 19/06/2018, 20/06/2018, 21/06/2018, 25/06/2018, 26/06/2018 e 27/06/2018 (dia do sucesso).
} 
frequência de manipulações antes do sucesso (Figura 21). No dia do sucesso Floyd esfregou a vareta em posição vertical na caixa duas vezes e, na sequência, realizou sua primeira Inserção Deliberada bem-sucedida.

Figura 21 - Ocorrências do comportamento de Manipular Varetas do início da Segunda Fase até o dia do sucesso. No dia do sucesso Floyd efetuou 43 manipulações, sendo apenas 2 anteriores ao momento do sucesso.

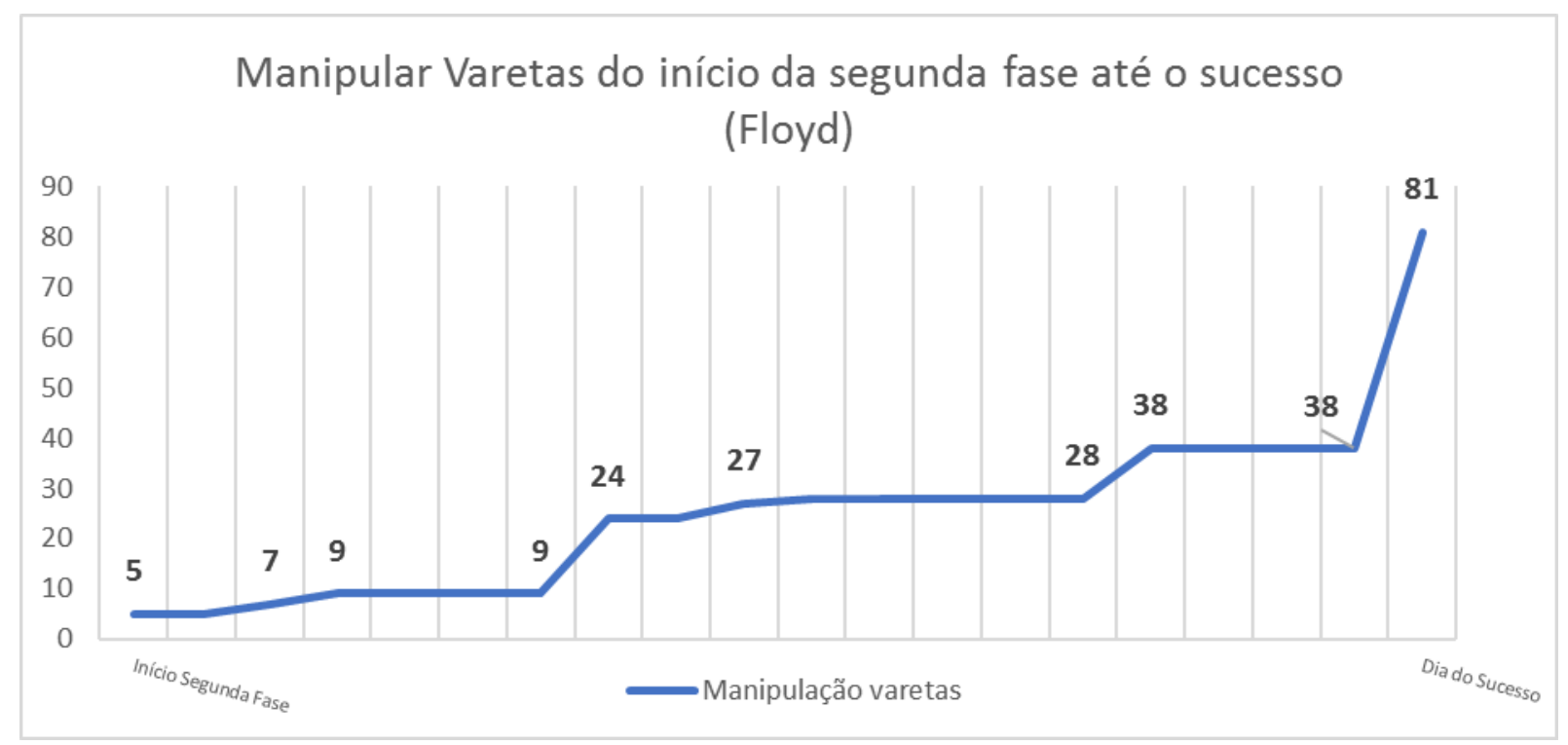

Durante o experimento, aumentos na frequência de Manipular Varetas puderam ser observados próximos a registros de Inserções Observadas. No dia 04/05/2017 (o primeiro sucesso do Acácio), Floyd observa 71 inserções e no dia 09/05/2017, ocorrem mais 89 Inserções Observadas. Já no dia 15/05/2017, duas sessões experimentais depois, foram registradas 30 ações de Manipular Varetas.

No dia 29/06/2017 ocorrem, concomitantemente, 52 Inserções Observadas, 1 Inserção Involuntária, 57 eventos de Tolerated Scrounging e 172 manipulações de varetas. No dia 27/12/2017 foram registradas 10 Inserções Observadas seguidas por 104 ocorrências de Manipular Varetas.

Aumentos na frequência do comportamento de Manipular Varetas também ocorreram em conjunto com algumas Inserções Involuntárias. A primeira Inserção Involuntária ocorre no dia 29/06/2017 quando há um aumento na quantidade de manipulações (172 ocorrências). A segunda Inserção Involuntária também ocorre em um dia de intensa manipulação de varetas (20/07/2017), que registrou 126 ocorrências. No dia 04/01/2018 ocorre a terceira Inserção Involuntária acompanhada de 223 registros de manipulações de varetas. 
Durante seu contato com os períodos de facilitação com varetas pré-inseridas, Floyd apresentou um aumento na frequência de manipulações de varetas, mais expressivamente, durante o segundo e quinto período (Figura 22).

Figura 22 - Ocorrências do comportamento de Manipular Varetas efetuados pelo Floyd durante e após os cinco Períodos de Facilitação.

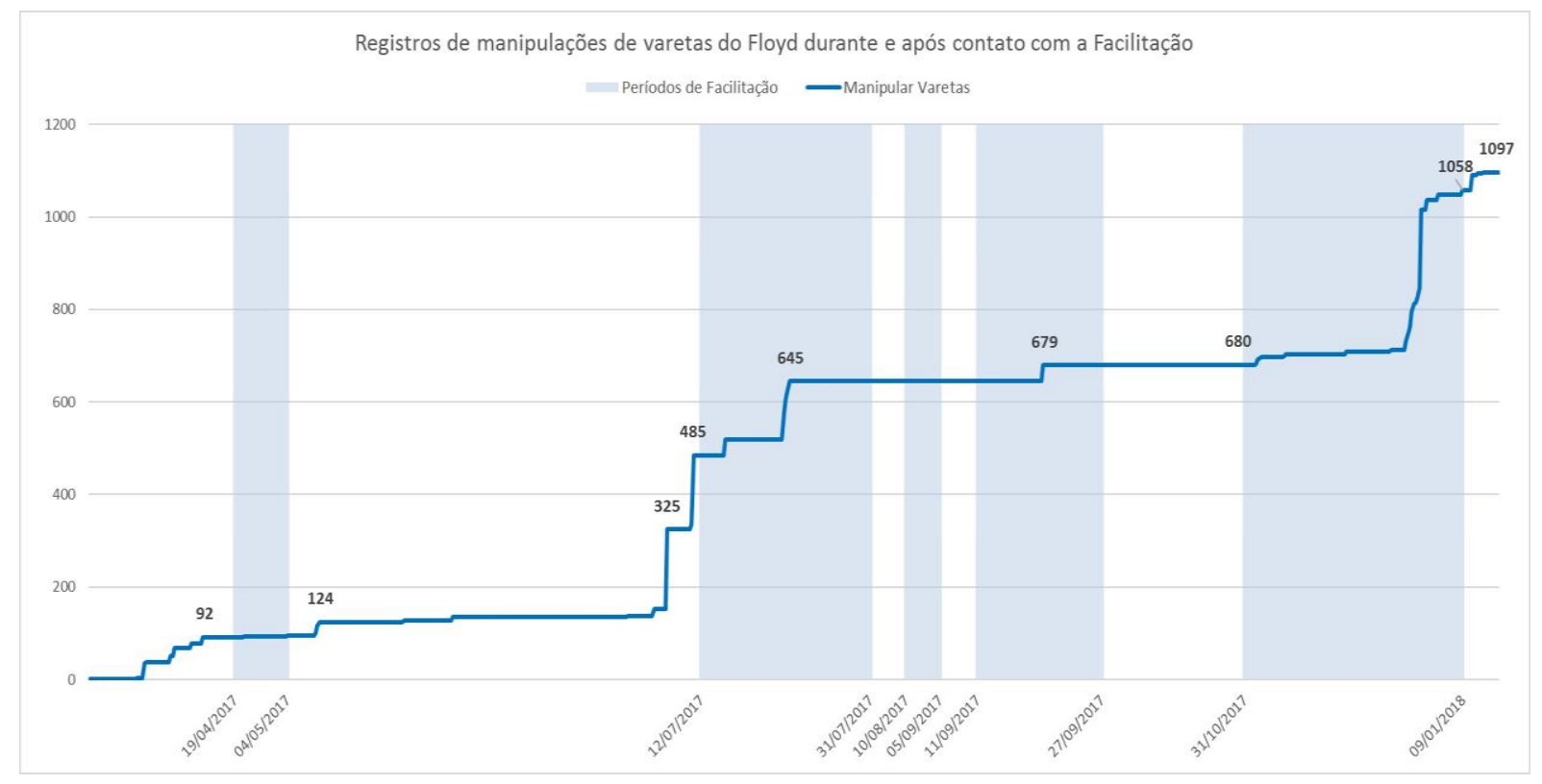

Após o sucesso, comportamentos como Bater, Morder e Quebrar Varetas são interrompidos (Morder Vareta registra apenas uma ocorrência). Levar Varetas é interrompido somente 12 dias após o sucesso. Enquanto que os comportamentos de Esfregar Varetas e Outra Manipulação (Girar Vareta) permanecem no repertório do Floyd até o final do experimento (Figura 23). 
Figura 23 - Registros de ocorrências de manipulação de varetas executados pelo Floyd até o momento de seu sucesso em comparação com o valor total no experimento.

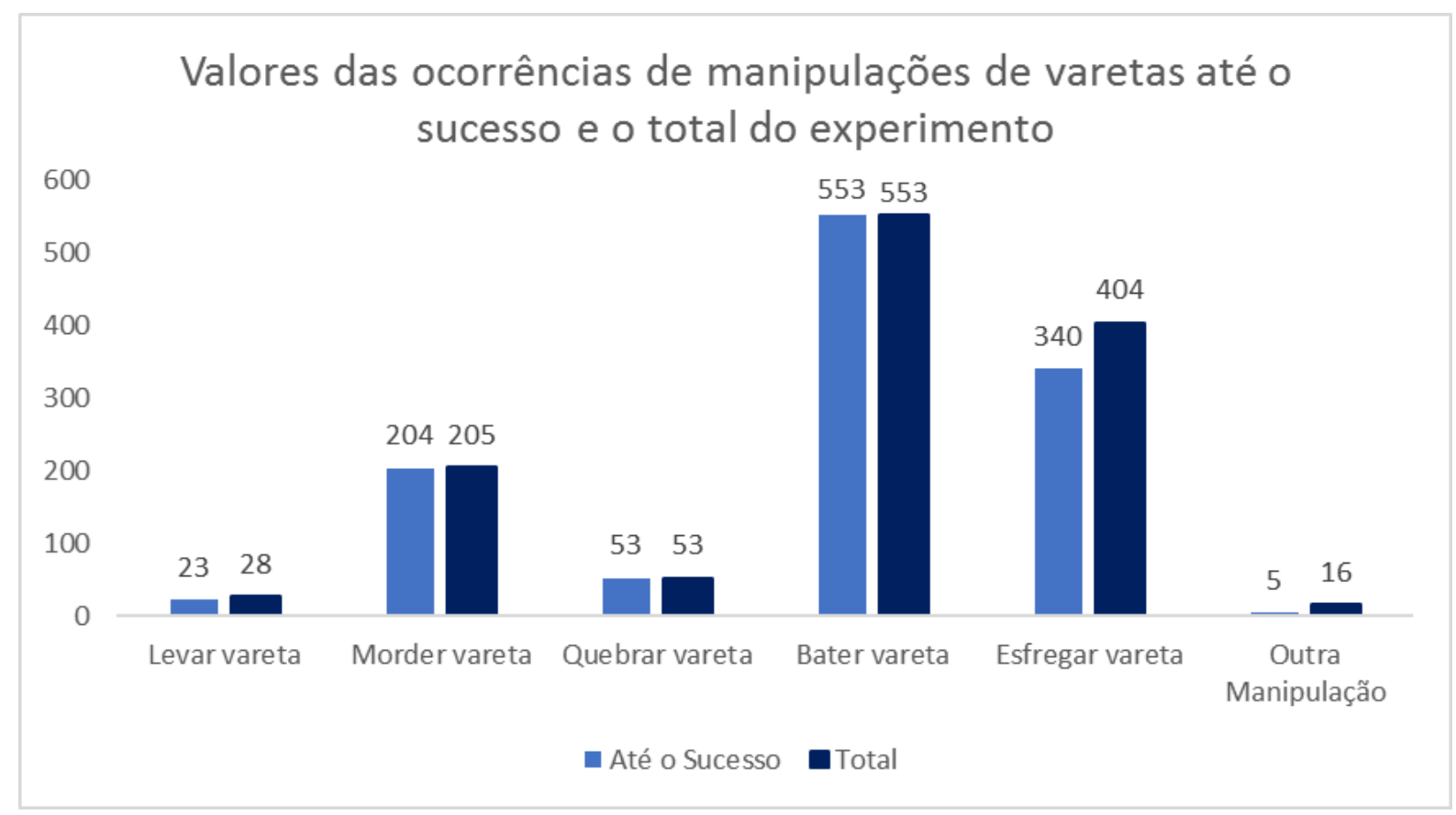

\subsubsection{Vodca}

Macho adulto que nasceu no PET em 2009. Vodca é um sujeito periférico, costuma ser ameaçado e afastado pelo macho dominante e por outros machos adultos. Foi o quinto indivíduo a solucionar a tarefa. O contato do Vodca com um indivíduo proficiente aconteceu de forma tardia no experimento, próximo ao fim da primeira fase, seu primeiro contato na caixa em conjunto com um proficiente se deu no dia 11/12/2017. Durante a segunda fase um aumento gradual desse contato começou a ocorrer 16 dias antes do seu primeiro sucesso (Figura 24). 
Figura 24 - Tempo em que Vodca passou na caixa junto com um sujeito proficiente até o dia do seu sucesso.

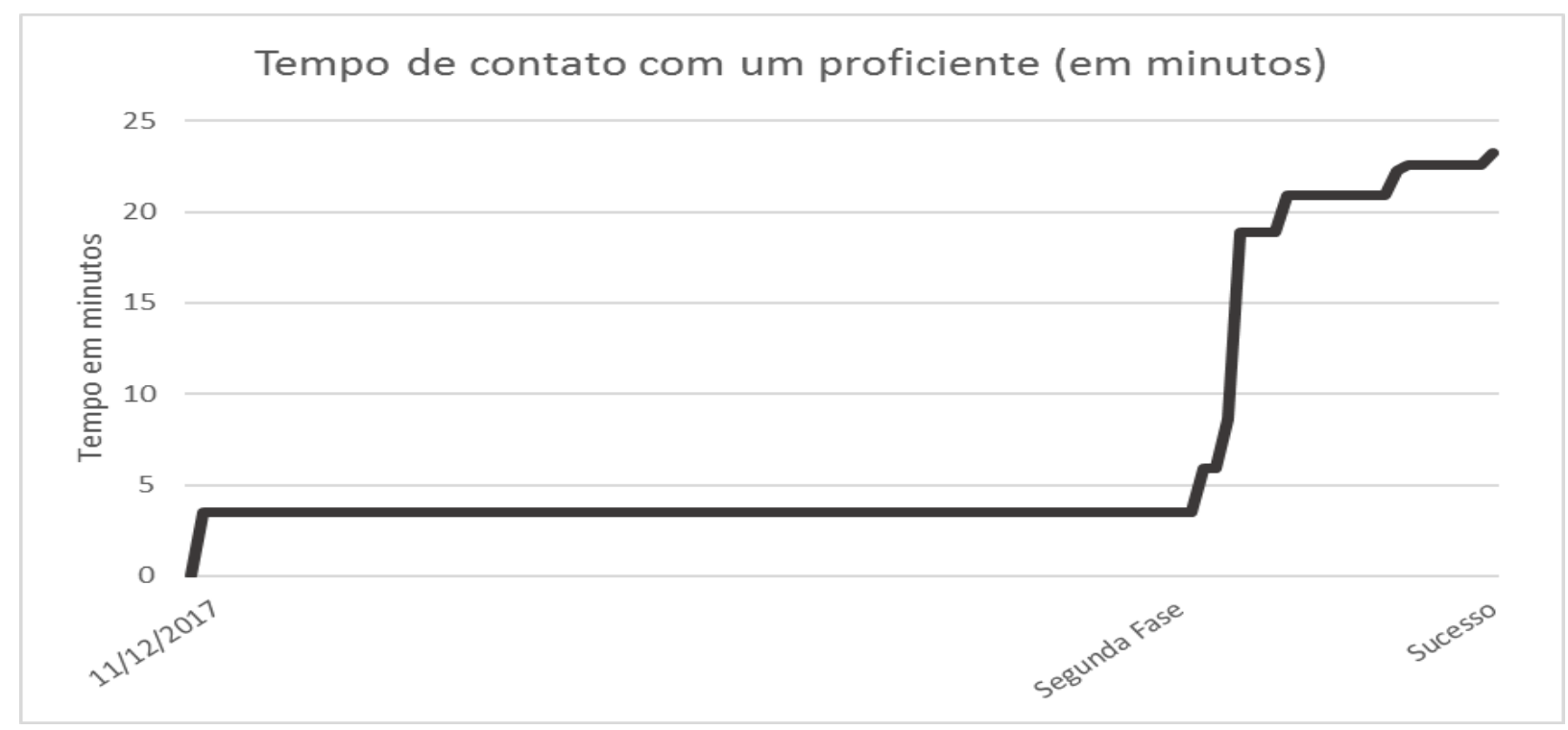

O maior tempo de contato com indivíduos proficientes possibilitou um aumento na frequência das Inserções Observadas. Foram 8 Inserções Observadas no dia 12/06/2018 e 17 registros no dia 14/06/2018, que foram acompanhadas de um aumento de manipulações varetas que somaram 171 ocorrências do dia 12/06 até o dia 16/06/2018. Nos dias 26/06 e 27/06/2018 ocorreram 9 Inserções Observadas e 39 ocorrências de Manipular Varetas.

Após esse último registro de Inserções Observadas e manipulações de varetas, passaram-se 5 dias de experimento sem a presença do Vodca. No dia 04/07/2018, o dia do primeiro sucesso, ocorreu apenas uma única manipulação (Esfregar Vareta) antes da Inserção Deliberada bemsucedida. Vodca apresentou um aumento na frequência de Manipular Varetas durante a segunda fase, mas não houve um aumento expressivo próximo ao sucesso (Figura 25). 
Figura 25 - Quantidade de manipulações de varetas efetuadas pelo Vodca do início da segunda fase até o dia do sucesso.

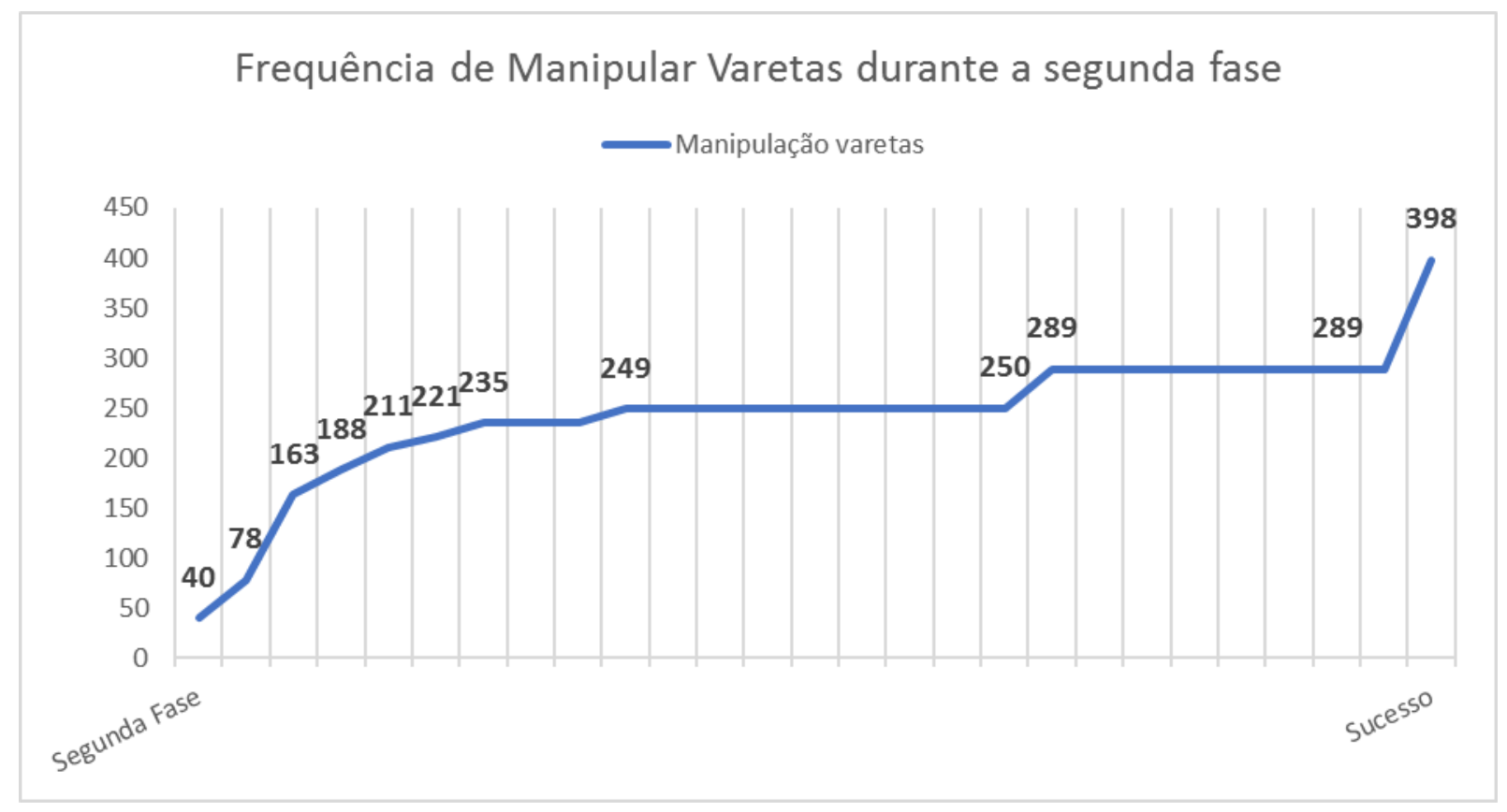

No período do experimento após o sucesso as manipulações consideradas nocivas (Quebrar e Levar Varetas) não foram executadas nenhuma vez. Comportamentos como Bater e Morder Vareta também foram interrompidos, mantendo-se no repertório do Vodca apenas o ato de Esfregar Vareta e Outra Manipulação - referente ao ato de Girar Vareta (Figura 26). O comportamento de Girar a Vareta se desenvolveu no dia do sucesso em conjunto com algumas das primeiras Inserções Deliberadas bem-sucedidas.

Figura 26 - Total de ocorrências dos comportamentos de Manipular Varetas efetuados pelo Vodca até o momento de seu sucesso comparado ao valor total ao final do experimento.

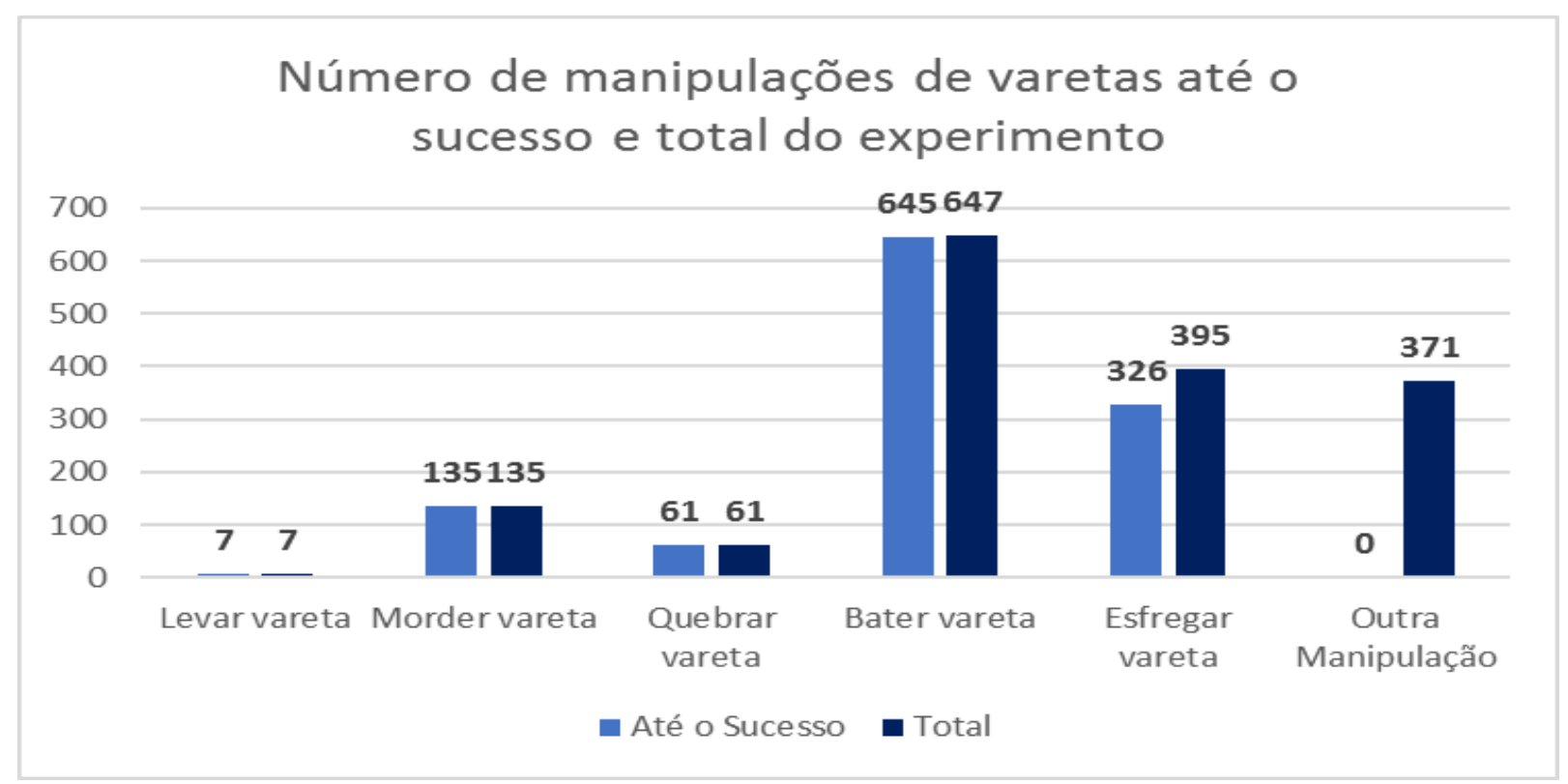




\subsubsection{Açaí}

Macho adulto, sem registro de nascimento, provavelmente nasceu no PET. Foi o sexto e último sujeito a completar a tarefa, já no final do experimento. É um indivíduo periférico, costuma ser ameaçado pelo macho dominante e outros machos adultos. Era mais comum ser visto próximo ao Acerola, Vodca ou Caju. Açaí entrou em contato com o experimento desde o seu início, ainda na fase de teste, e manteve uma certa frequência de visitação ao local do experimento. No entanto, o contato na caixa em conjunto com um indivíduo proficiente só foi possível durante a Segunda Fase (Figura 27).

Figura 27 - Tempo em que o Açaí passou em conjunto com algum sujeito proficiente na caixa de melado. O gráfico abrange toda a Segunda Fase do experimento por ter sido em seu início o primeiro contato do Açaí com um proficiente.

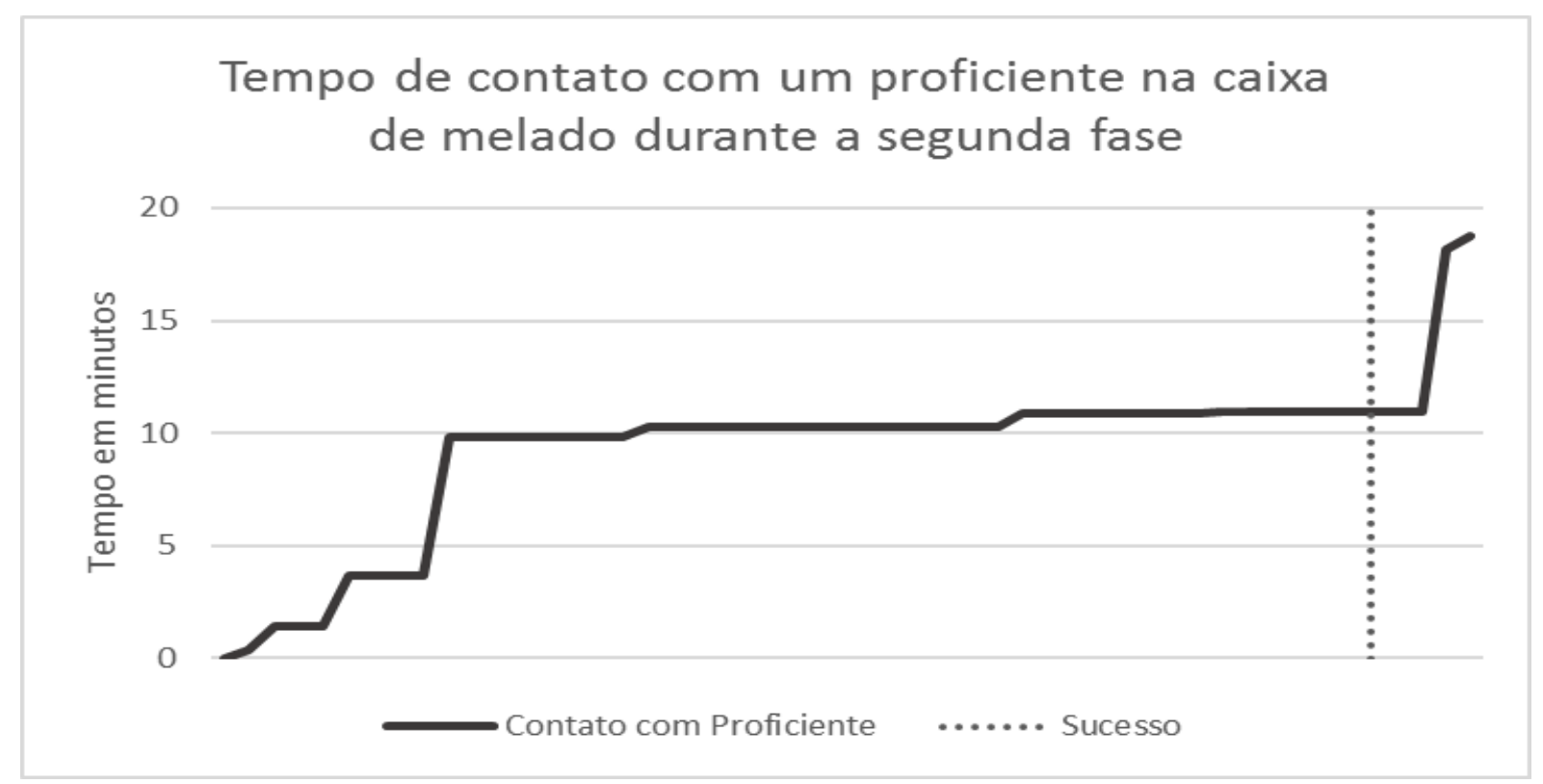

Durante os períodos de contato com sujeitos proficientes, Açaí teve a oportunidade de observar 9 inserções (7 vezes o Acerola e 2 vezes o Caju). Sendo 4 Inserções Observadas no dia 14/06/2018, 2 no dia 25/06/2018 e 3 no dia 10/07/2018. Esse contato com os proficientes também possibilitou eventos de Tolerated Scrounging, que registraram 7 ocorrências até o dia do sucesso e 16 ao final do experimento. Já o comportamento de Manipular Vareta aumentou de frequência gradualmente, durante a segunda fase, até o momento do sucesso (Figura 28). 
Figura 28 - Registros do comportamento de Manipular Varetas durante a segunda fase do experimento.

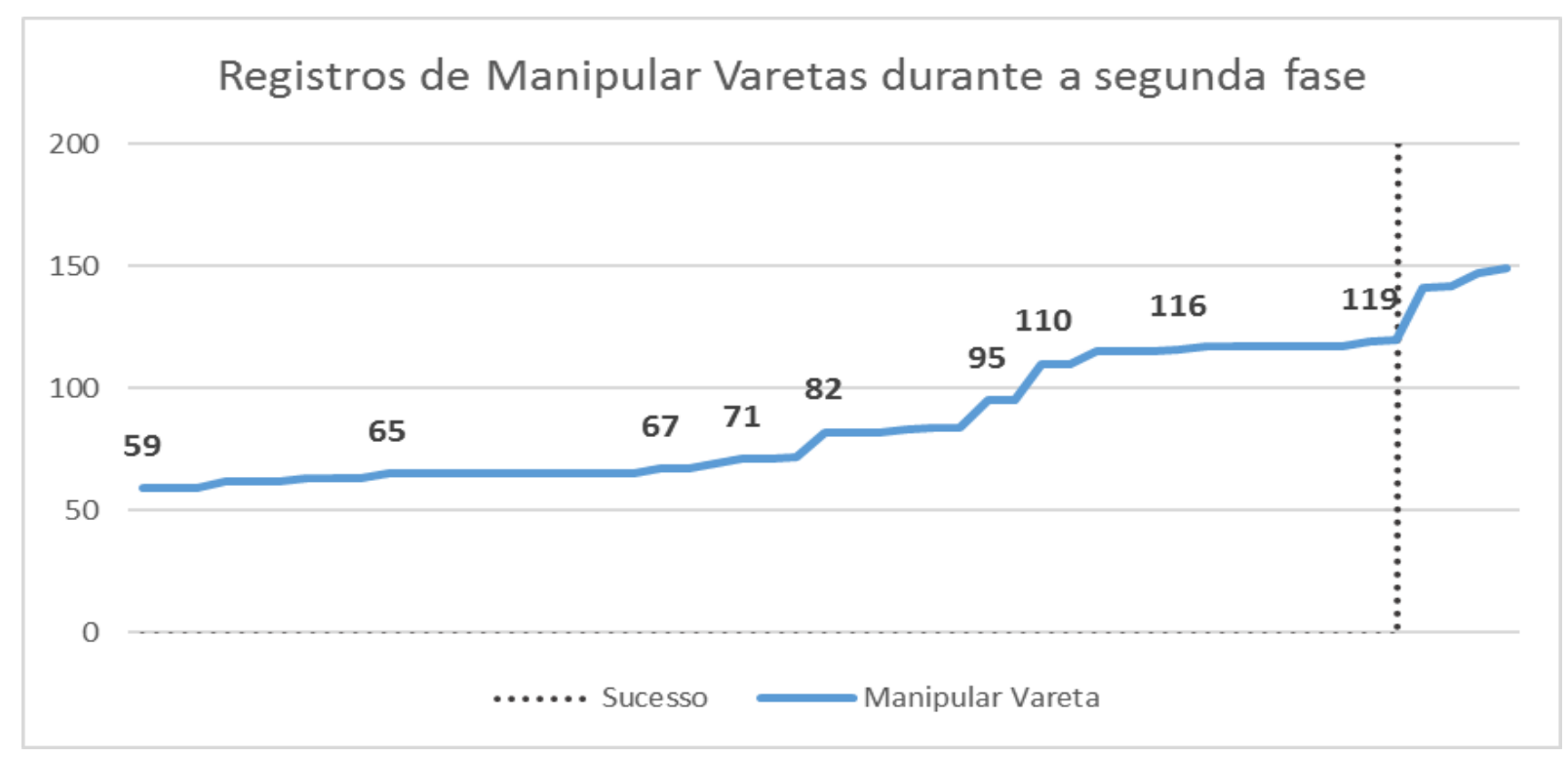

Uma única Inserção Involuntária ocorreu no dia 09/07/2018 - 18 dias antes do primeiro sucesso. Nesse mesmo dia ocorreram 11 manipulações de varetas, sendo 10 delas o ato de Esfregar Vareta e 1 ocorrência de Levar Vareta. Comportamentos que podem dificultar o sucesso, como Quebrar e Levar Varetas, ocorreram poucas vezes durante o experimento e não apresentam nenhum registro após o sucesso. O ato de Levar Varetas teve um pequeno aumento de frequência em conjunto com o aumento da frequência de Manipular Varetas, podendo ser reflexo de uma maior oportunidade de acesso as ferramentas ou um aumento no interesse por elas. As Manipulações não-funcionais também não apresentam ocorrências após o sucesso, com exceção do ato de Esfregar Vareta que permanece no repertório comportamental do Açaí até o final do experimento (Figura 29).

Por ter solucionado a tarefa próximo ao final do experimento, Açaí teve um curto período de "pós-sucesso", o que limita a análise para os comportamentos ocorridos nesse intervalo de tempo. Os 2 registros para Outra Manipulação que ocorrem após o sucesso são referentes ao comportamento de Girar Vareta, também desenvolvido pelos outros sujeitos com exceção do Acácio. 
Figura 29 - Registros totais de Manipular Varetas efetuados pelo Açaí até o momento do sucesso e no experimento como um todo.

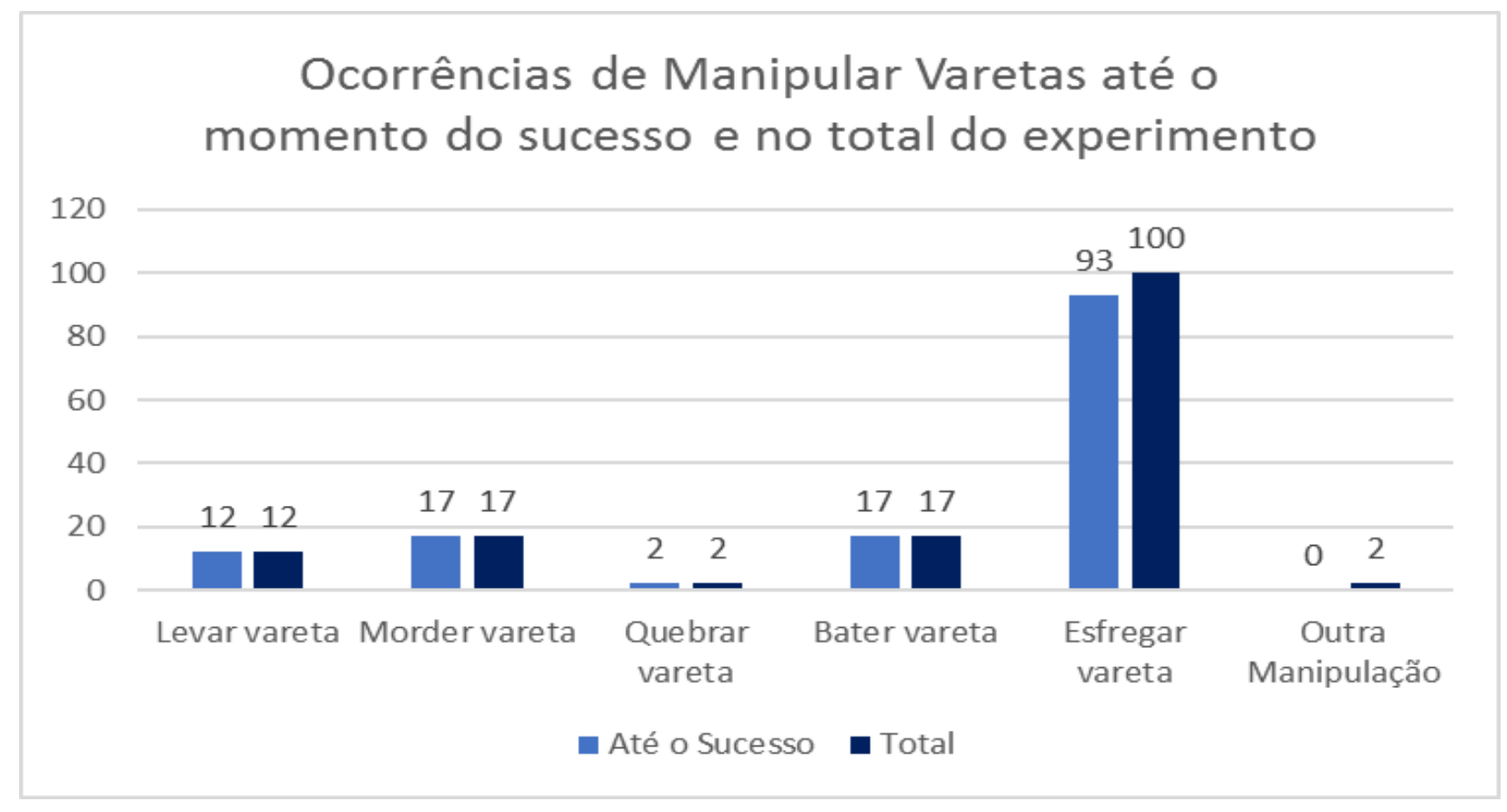

\subsection{Caixa de alimento sólidos}

A caixa de alimentos sólidos ficou disponível em 251 sessões, resultando em aproximadamente 27 horas e 25 minutos de filmagens com interações dos macacos. Foi disponibilizada pela primeira vez no dia 02/08/2017. A ordem de sucesso nessa caixa manteve-se a mesma da caixa de melado. Todos os indivíduos que foram bem-sucedidos resolveram primeiro a caixa de melado e em seguida a caixa de sólidos (Tabela 5).

Tabela 5 - Data do sucesso de cada indivíduo em ambas as caixas.

\begin{tabular}{lllllll}
\hline Ordem & Indivíduo & Sexo & $\begin{array}{l}\text { Faixa } \\
\text { etária }\end{array}$ & $\begin{array}{l}\text { Caixa de } \\
\text { Melado }\end{array}$ & $\begin{array}{l}\text { Caixa de } \\
\text { Sólidos }\end{array}$ & $\begin{array}{l}\text { Intervalo entre } \\
\text { os sucessos }\end{array}$ \\
\hline $1^{\text {o }}$ & Acácio & Macho & Adulto & $04 / 05 / 2017$ & $03 / 08 / 2017$ & 3 meses \\
$2^{\text {o }}$ & Acerola & Macho & Adulto & $12 / 06 / 2018$ & $14 / 06 / 2018$ & 2 dias \\
$3^{\text {o }}$ & Caju & Macho & Adulto & $21 / 06 / 2018$ & $25 / 06 / 2018$ & 4 dias \\
$4^{\text {o }}$ & Floyd & Macho & Adulto & $26 / 06 / 2018$ & $28 / 06 / 2018$ & 2 dias \\
$5^{\circ}$ & Vodca & Macho & Adulto & $04 / 07 / 2018$ & $05 / 07 / 2018$ & 1 dia \\
$6^{\circ}$ & Açaí & Macho & Adulto & $27 / 07 / 2018$ & $02 / 08 / 2018$ & 6 dias \\
\hline
\end{tabular}


Quando a caixa de sólidos passou a ser disponibilizada o Acácio já era um indivíduo proficiente na caixa de melado e solucionou a tarefa após 12 minutos em seu primeiro contato com o novo aparato. O tempo de contato para cada sujeito na caixa de sólidos está apresentado na Figura 30. É possível observar que se fossemos elencar, como fizemos para a caixa de melado, os 5 machos e as 5 fêmeas não-proficientes que mais estiveram em contato com a caixa, teríamos alguns sujeitos diferentes. Entre os machos temos Feioso, Frodo e Frank, que estavam entre os 5MV na caixa de melado, e Vader e Sam. Entre as fêmeas a Cacá, Cisca, Janete e Val permanecem e a Angélica, que não estava na lista para a caixa de melado, aparece entre a primeira das 5FV na caixa de sólidos.

Figura 30 - Tempo total que cada indivíduo passou em contato com a caixa de sólidos. Para os sujeitos proficientes (barras azuis) o tempo conta até o momento do sucesso.

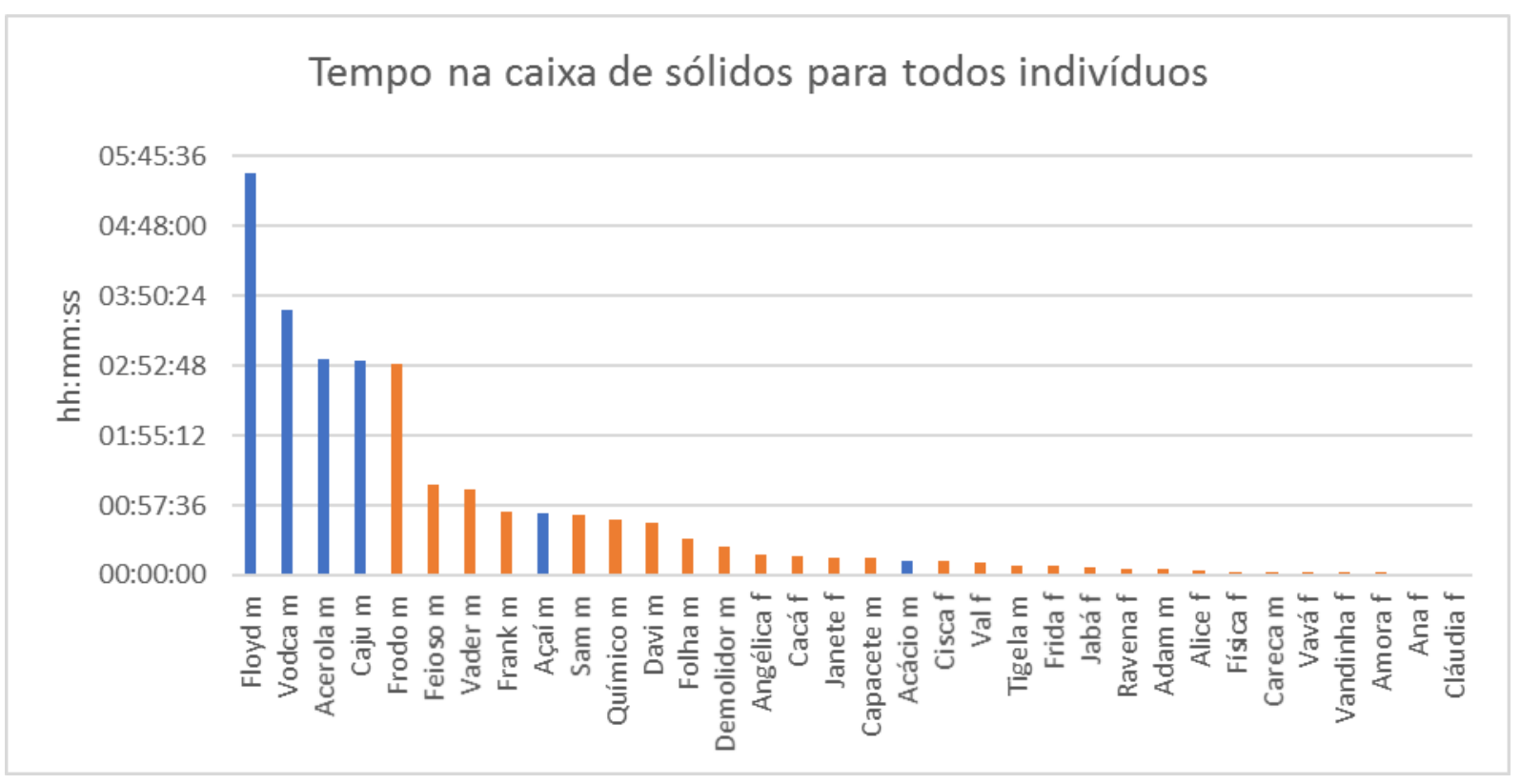

Dos indivíduos proficientes (excluindo o Acácio), todos passaram algum tempo em conjunto ou próximo de um proficiente, possibilitando as Inserções Observadas e eventos de Tolerated Scrounging (Tabela 6).

Tabela 6 - Dados dos indivíduos proficientes referentes a algumas ações na caixa de sólidos. Tempo medido em horas:minutos:segundos (hh:mm:ss).

\begin{tabular}{|l|l|l|l|l|l|}
\hline Indivíduo & $\begin{array}{l}\text { Tempo com } \\
\text { proficiente }\end{array}$ & $\begin{array}{l}2 \mathrm{~m} \text { do } \\
\text { Proficiente }\end{array}$ & $\begin{array}{l}5 \mathrm{~m} \text { do } \\
\text { Proficiente }\end{array}$ & $\begin{array}{l}\text { Inserções } \\
\text { Observadas }\end{array}$ & $\begin{array}{l}\text { Tolerated } \\
\text { Scrounging }\end{array}$ \\
\hline Acerola & $00: 06: 48$ & $00: 27: 29$ & $01: 34: 52$ & 17 & 1 \\
\hline Caju & $00: 31: 18$ & $00: 38: 37$ & $00: 27: 48$ & 52 & 3 \\
\hline Floyd & $00: 51: 41$ & $00: 11: 17$ & $00: 57: 48$ & 100 & 9 \\
\hline Vodca & $00: 05: 17$ & $00: 08: 14$ & $00: 06: 45$ & 15 & 17 \\
\hline Açaí & $00: 00: 59$ & $00: 06: 38$ & $00: 09: 37$ & 4 & 2 \\
\hline
\end{tabular}




\subsection{Generalização}

Após os indivíduos serem bem-sucedidos na caixa de melado, pouco tempo foi necessário para que também resolvessem a caixa de alimento sólidos. Para mensurar o desempenho de cada indivíduo na solução da segunda caixa após o sucesso na primeira, olhamos para o intervalo de tempo a partir do minuto em que o sujeito tem sua primeira Inserção Deliberada bem-sucedida na caixa de melado até o minuto em que ele tem sua primeira Inserção Deliberada bem-sucedida na caixa de sólidos. A Tabela 7 traz o tempo que cada indivíduo esteve em contato com a caixa de sólidos, dentro desse intervalo entre os sucessos.

Tabela 7 - O tempo apresentado na tabela representa o intervalo entre a solução na caixa de melado e a solução na caixa de sólidos para cada sujeito.

\begin{tabular}{c|c}
\hline Indivíduo & Tempo Total (min) \\
\hline Acerola & $00: 01: 39$ \\
\hline Caju & $00: 03: 32$ \\
\hline Floyd & $00: 02: 21$ \\
\hline Vodca & $00: 04: 45$ \\
\hline Açaí & $00: 02: 39$ \\
\hline
\end{tabular}

Em relação aos comportamentos de Manipular Varetas dentro desse intervalo, as manipulações não-funcionais e nocivas quase não são executadas. O comportamento com mais registros foi o de Esfregar Vareta, ação que permanece a todos os sujeitos após o sucesso, sendo executado mais vezes pelo Vodca. Já o ato de Girar Vareta dentro desse intervalo de tempo só foi executado pelo Caju (Tabela 8).

Tabela 8 - Manipulações de varetas realizadas no intervalo de tempo entre os primeiros sucessos em cada caixa.

\begin{tabular}{l|l|l|l|l|l|l}
\hline Indivíduo & Bater & Morder & Esfregar & Levar & Quebrar & Outra Manipulação \\
\hline Acerola & 0 & 1 & 1 & 1 & 0 & 0 \\
\hline Caju & 0 & 0 & 2 & 0 & 0 & 21 (girar) \\
\hline Floyd & 0 & 0 & 4 & 0 & 0 & 0 \\
\hline Vodca & 1 & 0 & 13 & 0 & 0 & 0 \\
\hline Açaí & 0 & 0 & 1 & 0 & 0 & 0 \\
\hline
\end{tabular}




\subsection{Exame das hipóteses}

Com base nos dados apresentados para cada sujeito é possível revisitarmos nossas hipóteses e verificar quais foram corroboradas ou não. Em relação ao primeiro conjunto, relacionado aos eventos próximos ao sucesso, podemos observar que nem todos os indivíduos seguiram pelo caminho previsto. Para os eventos próximos do sucesso como Inserções Observadas, alta frequência de Manipular Varetas e Inserções Involuntárias, a Tabela 9 indica o período em que cada sujeito realizou essas ações antes do sucesso.

Tabela 9 - Quantidade de dias em que a ação correspondente a hipótese foi realizada. Eventos ocorridos no mesmo dia do sucesso estão indicados pelo valor 0. São considerados apenas os dias em que os indivíduos estiveram em contato com o experimento.

\begin{tabular}{l|l|l|l}
\hline Indivíduo & $\mathrm{H} 1$ & $\mathrm{H} 2$ & $\mathrm{H} 3$ \\
\hline Acácio & - & - & 0 \\
\hline Acerola & 0 & 2 & 2 \\
\hline Caju & 3 & - & $1 ; 0$ \\
\hline Floyd & 5 & 3 & 4 \\
\hline Vodca & 2 & 2 & - \\
\hline Açaí & 9 & 8 & 10 \\
\hline
\end{tabular}

Em um panorama geral acerca de todas as hipóteses, a Tabela 10 indica qual delas pode ser considerada como um resultado positivo ou negativo para cada sujeito. No caso das 3 hipóteses que examinam as manipulações pós-sucesso o resultado também pode ser considerado como parcial (P), já que algumas manipulações podem se manter enquanto outras são interrompidas.

Tabela 10 - Avaliação das hipóteses para cada um dos sujeitos. Os resultados com o sinal (+) indicada um resposta positiva aquela hipótese, o sinal (-) indica uma resposta negativa e o valor (P) aponta para um resultado parcial.

\begin{tabular}{l|l|l|l|l|l|l|l|l|l}
\hline Indivíduo & H1 & H2 & H3 & H4 & H5 & H6 & H7 & H8 & H9 \\
\hline Acácio & - & - & + & - & - & - & + & + & - \\
\hline Acerola & + & + & + & + & + & + & P & - & + \\
\hline Caju & - & - & + & + & + & + & + & P & + \\
\hline Floyd & - & - & - & + & + & + & + & P & + \\
\hline Vodca & + & + & - & + & - & + & + & P & + \\
\hline Açaí & - & - & - & + & + & + & + & P & + \\
\hline
\end{tabular}

Considerar a corroboração ou não de nossas hipóteses envolve um grau de subjetividade. Em apenas 3 delas, excluindo o Acácio, temos um resultado positivo para todos os indivíduos (H4, H6 e H9). No entanto, se considerarmos como um resultado positivo a hipótese que 
contempla até 4 dos 5 proficientes esse número aumenta para 5 hipóteses confirmadas. Para as três primeiras, que investigam ações próximas ao sucesso, tivemos que estabelecer o que seria "próximo ao sucesso", uma definição também subjetiva. Nesse caso consideramos um limite de até 2 dias antes do sucesso para configurar como um resultado positivo, porém, se alteramos esse limite tanto para mais quanto para menos, o status de positivo ou negativo das hipóteses também se alteram. Os resultados de $\mathrm{H} 8$ foram em sua maioria parciais por conta de comportamentos como Girar Vareta e/ou Esfregar Vareta na caixa que persistem para a maioria dos sujeitos. Com exceção do Acerola que mantem quase todos os comportamentos ativos em seu repertório. 


\section{DISCUSSÃO}

O presente trabalho teve como proposta inicial a verificação da difusão de um novo comportamento de forrageamento através do uso de ferramentas de sonda e a aplicação estágios complicadores nas tarefas para se verificar a possibilidade de cultura cumulativa nessa população. Com a ocorrência de uma difusão lenta da técnica entre os sujeitos tornou-se inviável a aplicação de testes voltados a cumulatividade cultural nesse trabalho. Um experimento anterior realizado por nosso laboratório demonstrou que o estudo da cumulatividade não é uma tarefa simples (CORAT, 2013). Sendo assim, direcionamos nosso foco ao processo de difusão da técnica e na destreza individual de cada um dos proficientes em manipular as varetas.

Em um experimento anterior já mencionado (AQUINO; OTTONI, 2001) essa população foi exposta a uma tarefa de forrageamento envolvendo o uso de sondas. Apesar desse experimento não ter sido finalizado, alguns indivíduos do grupo tornaram-se proficientes no uso das sondas. Em um relato posterior de 2011 (dez anos depois), um desses sujeitos proficientes (Suspeito) quando em contato com outro experimento envolvendo uma caixa-problema que não necessitava do uso de ferramentas, apareceu com uma vareta e uma pedra para tentar solucionar o problema (COELHO, comunicação pessoal).

Todos os indivíduos proficientes surgiram na segunda fase do experimento e foram machos adultos, já que as fêmeas tiveram uma participação pouco expressiva no experimento (v. adiante).

Essa população faz uso habitual de ferramentas líticas (OTTONI; MANNU, 2001) e com bastante destreza, inclusive fêmeas, como trabalhos anteriores tem demonstrado (FALÓTICO, 2006, 2011; CORAT; SIQUEIRA; OTTONI, 2016). O comportamento de uso de percutores é difundido pela população através de processos de aprendizagem socialmente mediada (RESENDE, 2014; COELHO et al., 2015) e os indivíduos do grupo também costumam ser bem tolerantes, principalmente com os sujeitos jovens (OTTONI; DE RESENDE; IZAR, 2005), facilitando o processo de aprendizagem.

No entanto, o uso de ferramentas de sonda se mostra mais raro nas populações conhecidas em relação ao uso das ferramentas líticas - algo que parece ser a regra (OTTONI; IZAR, 2008), já 
que, até o presente momento, o uso habitual de ferramentas de sonda foi encontrado em apenas uma população (MANNU; OTTONI, 2009).

Nosso experimento se assemelha mais com um sitio de quebra, do ponto de vista da durabilidade no ambiente, do que de uma situação naturalística de uso de sondas, como a caça de lagartos (FALÓTICO; OTTONI, 2014). Principalmente durante a segunda fase de coleta, com as caixas disponíveis permanentemente em um mesmo local, aumentando as oportunidades de contato com o aparato e as ferramentas, como ocorre em um sítio de quebra. Sendo nessa fase em que ocorreu a difusão da técnica, porém, restrita a poucos sujeitos.

Para chegar ao sucesso os indivíduos poderiam seguir pela via puramente associal ou socialmente mediada. Apesar de ser complexo dizer quando um processo é exclusivamente associal (HEYES, 1993), poderíamos considerar a aprendizagem por tentativa-e-erro e casos de inovação (READER; LALAND, 2001). Em relação ao primeiro sujeito bem-sucedido (Acácio) podemos supor que sua aprendizagem foi associal. Não há registros de que esse indivíduo tenha entrado em contato com alguma situação envolvendo sondas anteriormente. Acácio coexistiu com alguns dos indivíduos que foram proficientes no uso de sondas no experimento de Aquino e Ottoni (2001), contudo nenhum registro de uso espontâneo de varetas como sondas foi registrado nessa população, o que torna difícil supor que ele possa ter aprendido socialmente com algum desses sujeitos.

\subsection{Diferença no desempenho de machos e fêmeas}

Segundo Reader e Laland (2001), há uma tendência, entre os primatas, dos machos serem mais inovadores do que as fêmeas e mais propensos a se engajar em situações que envolvam o uso de ferramentas. Isso por conta do gasto energético associado com eventuais falhas no processo de uso de ferramentas para obter comida. Os machos poderiam lidar com esse gasto de energia extra, enquanto que as fêmeas, principalmente em períodos de gestação e cuidado maternal, não poderiam (MCGREW, 1992). Entretanto, esse consumo extra de energia necessário pelas fêmeas pode impeli-las ao uso de ferramentas para aumentar a eficiência no forrageamento e na obtenção de recursos, como ocorre com as fêmeas de chimpanzés (MCGREW, 1992).

Em um grupo de chimpanzés no Tai National Park, na Costa do Marfim, o uso de ferramentas líticas para quebra de frutos encapsulados, alguns muito duros, é uma atividade quase que de exclusividade das fêmeas que se mostram mais eficientes que os machos (BOESCH; BOESCH, 1981, 1984). Em Gombe, Tanzania, o uso de varetas como ferramentas para a "pesca" 
de cupins é executado por ambos os sexos. Contudo, foi observado por Lonsdorf et al. (2004) que as fêmeas aprendem a técnica mais cedo (em questão de idade) do que os machos e, talvez por conta desse fator, demonstram maior destreza no uso dessas ferramentas. Fêmeas jovens também costumam copiar a técnica da mãe, enquanto os machos não. Nessa população em que foi observado eventos de "ensino funcional” (MUSGRAVE et al., 2016) essa pode ser uma diferença crucial.

Entre os macacos-prego as diferenças encontradas no uso de ferramentas por machos e fêmeas parecem estar de acordo com a premissa de Reader e Laland (op. cit.). Na população da FBV, onde ambos os sexos utilizam ferramentas de pedra para quebra de frutos encapsulados, Spagnoletti et al. (2011) observam que os machos usam esse tipo de ferramenta mais frequentemente que as fêmeas e quebram frutos mais resistentes, também com maior frequência. Na FBV a presença de cocos com invólucro duro exige o uso de pedras muito pesadas e como relatado nesse mesmo estudo os indivíduos mais "encorpados" são os que quebram os frutos duros com maior frequência e eficiência. Dessa forma, a diferença entre gêneros nessa população pode ser relacionada ao dimorfismo sexual (FRAGASZY et al., 2010).

No PNSC onde os indivíduos quebram frutos bem menos resistentes (MANNU; OTTONI, 2009), Moura e Lee (2010) observaram uma diferença bem menos acentuada na frequência do uso das ferramentas líticas por machos e fêmeas. Nesse caso o dimorfismo sexual não caberia como uma explicação plausível. Em relação ao uso de ferramentas de sonda essa discrepância é bem maior. Fêmeas quase nunca são vistas usando varetas para forragear (poucos relatos se referem a fêmeas juvenis), o que torna essa atividade majoritariamente um comportamento dos machos (FALÓTICO; OTTONI, 2014).

No presente estudo, nenhuma das fêmeas do grupo chegou a solucionar a tarefa. Analisando a variável Manipulação de Varetas de todas as fêmeas do grupo durante todo o experimento, elas somam 89 manipulações, o que corresponde a $1 \%$ de todas as manipulações de varetas registradas. Essa baixa taxa de Manipulação de Varetas pode se dar por conta da pouca frequência que as fêmeas tiveram no contato com as caixas-problema durante todo o experimento em comparação com os outros sujeitos do grupo.

Do ponto de vista cognitivo ou motor não há qualquer impedimento, aparentemente, no uso de ferramentas de sondas pelas fêmeas, como demonstram alguns experimentos com cativos (VISALBERGHI; TRINCA， 1989；VISALBERGHI； LIMONGELLI，1994；CAMARGO; MENDES, 2016). E também em um grupo semi-livre em que uma fêmea se mostrou bem proficiente no uso de varetas (CARDOSO, 2013). 
Moura e Lee (2010) sugerem que esse viés poderia ocorrer por conta de diferenças no investimento parental, com as fêmeas preferindo economizar a energia gasta com o uso de ferramentas e se dedicarem ao scrounging dos machos. Contudo, o uso de varetas não é custoso em termos energéticos, como é no caso do uso de ferramentas líticas. E como observado por Falótico e Ottoni (2014) o viés de gênero também não estaria relacionado a preferências na dieta, já que as fêmeas tem predileções pelos mesmos itens alimentares que os machos, no PNSC. A hipótese da preferência alimentar também não se aplica ao nosso experimento para explicar o aparente viés de gênero, já que as fêmeas se alimentavam do melado quando esse estava disponível na superfície da caixa e após retirar as varetas facilitadas, como também faziam scrounging sempre que possível, assim como os machos. O mesmo vale para os alimentos sólidos oferecidos como recompensa na segunda caixa. Falótico e Ottoni (em preparação) constataram que as jovens fêmeas na população do PNSC, ao longo do desenvolvimento, tendiam a observar menos atividades de manipulação de ferramentas do que os machos (independente da proximidade aos eventos).

\subsection{Diferença no desempenho entre os 5MP e os 5MV}

A diferença entre machos e fêmeas em relação ao Tempo na Caixa se mostrou significativa nos testes estatísticos. E sabemos que o tempo na caixa é a variável base, que possibilita a ocorrência de quase todas as outras. A baixa frequência da presença das fêmeas no aparato se reflete na baixa ocorrência das demais variáveis. Para uma comparação, selecionamos os 5 machos que foram malsucedidos, mas que passaram mais tempo em contato com a caixa (5MV). A diferença entre as fêmeas e os 5MV com relação ao Tempo na Caixa também foi significativa. No entanto, não se observou estatisticamente uma diferença entre os 5MP e os 5MV em relação

ao Tempo na Caixa. Portanto, o tempo em contato com a caixa, apesar de crucial, não é o único requisito para se chegar ao sucesso. A única variável que apresentou uma diferença significativa foi Manipular Varetas

Os macacos-prego são animais manipuladores e se interessam por manipular objetos desde cedo, como observado em laboratório (FRAGASZY; ADAMS-CURTIS, 1991) e na natureza, onde os comportamentos manipulativos durante o desenvolvimento contribuem para a aquisição do uso de ferramentas líticas (DE RESENDE; OTTONI; FRAGASZY, 2008). 


\subsection{Avaliação da trajetória individual dos sujeitos proficientes}

Percebemos que o que diferenciou os indivíduos bem-sucedidos dos demais foi a frequência em que a variável Manipular Varetas foi executada. Para tentar compreender o que levou esses indivíduos a se tornarem manipuladores mais frequentes, examinamos a trajetória individual de cada um deles, tendo como base o desenvolvimento de 9 hipóteses que trataram de levantar algumas questões.

\subsubsection{O primeiro sucesso se seguiu após Inserções Observadas?}

A observação de um indivíduo proficiente realizando a tarefa seria o melhor cenário para uma aprendizagem social. E apenas dois indivíduos, Acerola e Vodca, tiveram a oportunidade de observar inserções serem realizadas próximas de seu sucesso. No caso do Acerola ele observou 6 inserções efetuadas pelo Acácio minutos antes do seu primeiro sucesso. O Vodca também observou algumas inserções serem realizadas pelo Acácio, porém, em um intervalo de tempo mais longo que do Acerola, 2 dias. Enquanto que o Caju observou 62 inserções em um intervalo de 3 dias antes do sucesso.

Acácio é o único sujeito que ao realizar as inserções faz de uma forma um tanto peculiar, utilizando a boca para manipular e encaixar a vareta na caixa enquanto direciona/limita o posicionamento da vareta com ambas as mãos sobre a superfície da caixa. Todos os demais sujeitos utilizam as mãos para efetuarem as inserções e nunca foram observados tentando utilizar a mesma técnica do Acácio. Se seguirmos a definição de Heyes (1993) para imitação (quando um indivíduo replica os movimentos de outro de forma exata), essa opção estaria descartada nesse caso. No entanto, ambos os casos poderiam ser vistos como casos de emulação, onde o observador obtém o mesmo resultado do demonstrador, porém, executando a tarefa a sua maneira (TOMASELLO; CALL, 1997; HOPPITT; LALAND, 2013).

No entanto, vale ressaltar que o Acerola observou inserções serem realizadas ao longo de todo experimento, resultando em um total de 150 Inserções Observadas. Vodca teve um contato tardio com um indivíduo proficiente, mas ainda assim observou 40 inserções no período até o seu sucesso. Sujeitos que não foram bem-sucedidos no experimento também tiveram a chance de observar inserções. Alguns em grande quantidade como Frodo (juvenil), que observou 822 inserções e Frank (juvenil) que observou 287 inserções ao longo do experimento. Davi, o macho 
dominante, observou 185 inserções. O que nos leva a supor que o peso dessa variável na solução da tarefa é mínimo, tornando a resposta para essa hipótese negativa.

\subsubsection{O primeiro sucesso se seguiu a um aumento de Manipulação de Varetas?}

Apesar do comportamento de Manipular Varetas ser a variável que se destacou para os sujeitos proficientes, uma frequência elevada de manipulações não aparenta estar relacionada a uma forma imediata de sucesso. Acerola e Vodca, dias antes do sucesso, apresentaram um aumento na frequência de manipulações de varetas. Floyd apresentou um aumento nas manipulações 3 dias antes de seu sucesso, porém a frequência foi decaindo até ocorrer a primeira Inserção Deliberada bem-sucedida.

\subsubsection{O primeiro sucesso se seguiu após Inserções Involuntárias?}

Em algumas situações a inserção de uma vareta pode ocorrer de forma involuntária. Eventos desse tipo poderiam levar os indivíduos à solução da tarefa subsequentemente por conta de um reforço acidental. O sucesso de alguns indivíduos se seguiu após eventos de Inserções Involuntárias. Dentre eles, Acácio, Acerola e Caju. Uma Inserção Involuntária tem maiores chances de acontecer durante momentos com alta taxa de manipulação de varetas, como ocorreu no caso do Acerola, que 2 dias antes do sucesso um aumento na frequência de manipulações de varetas culminou em duas Inserções Involuntárias.

\subsubsection{Inserções Observadas levaram a um aumento subsequente na Manipulação de Varetas?}

Observar um modelo proficiente no ato de Inserir Vareta antecedeu um aumento em eventos de manipulação de varetas para todos os sujeitos. Esse aumento nas manipulações poderia ser devido a um processo de realce de estímulo, onde os indivíduos que observam o comportamento teriam sua atenção atraída às ferramentas, acarretando um aumento na manipulação de varetas. 


\subsubsection{Períodos de Facilitação levaram a um aumento na Manipulação de Varetas?}

Durante a primeira fase, na tentativa de impulsionar o processo de difusão, aplicamos uma facilitação que consiste em disponibilizar varetas pré-inseridas, situação que pode acontecer de forma espontânea quando usuários proficientes de sondas deixam varetas inseridas na caixaproblema ao final das sessões (CARDOSO; OTTONI, 2016). Nossa intervenção buscou promover o aumento desses episódios. Contudo, ao se depararem com a Facilitação Completa os indivíduos retiravam a vareta para lamber o melado, mas não tornavam a inseri-la, da mesma forma que ocorreu com o grupo da FBV no experimento de Cardoso e Ottoni (2016), quando este foi exposto a varetas pré-inseridas. O mesmo ocorreu em um experimento com chimpanzés (GRUBER et al., 2011) em uma população não-usuária de varetas. Outro tipo de facilitação foi a Vareta Fixa, inspirada no experimento realizado com um grupo semi-livre por Cardoso (2013).

Em nosso experimento os períodos de facilitação não apresentaram associação com um sucesso subsequente da tarefa. Apesar do sujeito inovador ter surgido durante um período de facilitação, ele se mostrou bem destro em sua primeira inserção e já havia realizado uma tentativa de inserção anterior na qual não foi bem-sucedido (v. Resultados). Contudo, após os períodos de facilitação um aumento na frequência de Manipular Varetas pôde ser observado para 4 dos 5 proficientes. A exceção nesse caso foi o Vodca, que teve pouco contato com os períodos de facilitação.

\subsubsection{Eventos de scrounging levaram a um aumento subsequente na Manipulação de Varetas?}

Em um estudo clássico com pombos (GIRALDEAU; LEFEBVRE, 1987) foi observado que alguns indivíduos se especializavam em fazer scrounging em detrimento de solucionar o problema através da técnica realizada por um demonstrador. Contudo, quando esses indivíduos eram colocados sozinhos, mostravam-se aptos a resolver a tarefa. Esse resultado levou Giraldeau e Lefebvre (op. cit.) a supor que comportamentos de scrounging atrapalhariam a ASM e a transmissão cultural nos pombos. Uma conclusão contrária a essa foi apresentada por Caldwell e Whiten (2003) em um trabalho com saguis. Onde o scrounging foi tido como um facilitador da aprendizagem social (ver também (WHITEN; VAN DE WAAL, 2018).

Nos macacos-prego foi observado uma preferência dos indivíduos jovens em se associar aos melhores quebrados de cocos durante os eventos de quebra. Essa associação, no entanto, pode 
ocorrer por um reforço do scrounging (OTTONI; DE RESENDE; IZAR, 2005), já que se associar aos melhores e mais frequentes quebradores pode resultar em um aumento nas oportunidades de comer algumas sobras. De toda forma, esse é um cenário propicio para a ocorrência da aprendizagem social. Sendo assim, nos perguntamos se eventos de scrounging poderiam, de alguma forma, estarem acompanhados de um subsequente aumento na frequência em Manipular Varetas. E o resultado foi positivo para todos os sujeitos.

\subsubsection{O que pode ter contribuído para um aumento na manipulação de varetas?}

Essas perguntas exploradas até aqui sintetizam o processo de aprendizagem até o momento do sucesso para cada indivíduo. Como sabemos, Manipular Varetas é o que diferencia os

proficientes dos demais. No entanto, o interesse por varetas e sua manipulação não é necessariamente um comportamento que dependa de mediação social para se iniciar. Uma Inserção Involuntária ou o contato com períodos de facilitação podem reforçar a manipulação de varetas até que o indivíduo compreenda a tarefa ou tenha sucesso por tentativa-e-erro. Contudo, os indivíduos estão, normalmente, em constante contato com outros sujeitos, mesmo que a uma certa distância. Dessa forma há diversos fatores sociais que podem contribuir para um maior interesse pelas ferramentas. E fatores sociais e associais podem se entrecruzar, o que torna difícil em alguns casos distinguir a fronteira entre um e outro.

Dos processos associais, as interações com os períodos de facilitação foram seguidas por um aumento na frequência de Manipular Varetas para 4 dos 5 sujeitos (excluindo o Acácio). Aparentemente, retirar varetas pré-inseridas pode ajudar a reforçar o interesse pelas ferramentas. Vodca por ser um sujeito periférico e comumente sofrer ameaças de outros machos teve poucas oportunidades de interagir com a Facilitação Completa. Dos processos sociais, as Inserções Observadas foram seguidas por um aumento em Manipular Varetas por todos os sujeitos. Durante algum momento do experimento observar um modelo proficiente resolvendo a tarefa antecedeu uma maior frequência nas manipulações de varetas. O scrounging foi outro evento seguido de um aumento nas manipulações de varetas para todos os proficientes. Portanto, se associar a um sujeito proficiente gera uma possibilidade para o scrounging e aumenta as chances de observar inserções que, provavelmente, podem estar associadas a um aumento na frequência de Manipular Varetas. 


\subsection{O uso de ferramentas pós-sucesso}

Os eventos ocorridos após a primeira Inserção Deliberada bem-sucedida podem indicar se há um progresso na eficiência do uso das varetas por parte dos proficientes. Com o refino da técnica esperamos que os indivíduos proficientes deixem de executar comportamentos que não estão relacionados ao sucesso na tarefa e passem a manipular as ferramentas de forma mais eficiente.

\subsubsection{Manipulações nocivas e não-funcionais, são interrompidas após o primeiro sucesso?}

Classificamos como "manipulações nocivas" comportamentos como o de Quebrar Vareta, que inviabilizava ou dificulta o uso eficiente da ferramenta e Levar Vareta que afasta a ferramenta da caixa-problema. Em alguns casos, a supressão desses comportamentos contraproducentes foi parcial, com apenas um dos comportamentos sendo suprimido. A interrupção foi completa para Acácio, Caju, Floyd, Vodca e Açaí. E parcial para o Acerola, que interrompeu o comportamento de Quebrar Varetas, mas manteve o ato de Levar Varetas por um tempo. Durante a segunda fase, Acácio voltou a Levar Varetas consigo com grande frequência, o que pode ser entendido como uma "valorização" da ferramenta após o sucesso ou a possibilidade de carregá-la para continuar lambendo.

Como manipulações não-funcionais foram consideradas aquelas que não estejam diretamente ligadas a inserção na caixa, como Bater, Morder, Esfregar e Outras Manipulações, mas que não inviabilizem a utilização subsequente das varetas na solução da tarefa. Ainda que não tão "danosas" para o sucesso na tarefa quanto as manipulações que chamamos de "nocivas", seria de se esperar que o reforçamento diferencial (ou alguma compreensão causal) de inserções bem-sucedidas levasse também a um declínio das manipulações não-funcionais.

No entanto, apenas o Acácio interrompeu completamente esse tipo de comportamento. Acerola não interrompeu nenhum deles enquanto que Caju, Floyd, Vodca e Açaí o fizeram de forma parcial. O Caju manteve apenas um comportamento que consistiu em girar a vareta com ambas as mãos antes das inserções, mesmo comportamento desenvolvido pelo Acerola, Floyd, Vodca e que teve apenas dois registros para o Açaí. Apesar do Caju ser o que mais realizou esse comportamento, o Acerola foi o que efetuou primeiro essa ação em conjunto com as primeiras inserções. 


\subsubsection{Manipulações não-funcionais de varetas que persistiram após o sucesso, aconteceram em associação com as primeiras inserções?}

As manipulações de varetas não-funcionais que se mantiveram após o sucesso poderiam estar temporalmente muito associadas às primeiras inserções deliberadas bem-sucedidas e por isso, continuariam presentes no repertório comportamental, como comportamentos “supersticiosos” (BENVENUTI; SOUSA; MIGUEL, 2009).

Essa hipótese se mostrou verdadeira para todos os indivíduos que mantiveram algumas dessas manipulações no período pós-sucesso. Alguns indivíduos esfregavam as varetas na caixa, normalmente na posição vertical, passando uma extremidade da vareta pela caixa, até a inserção ser realizada. No entanto, o comportamento que mais chama atenção é o de girar as varetas, que foi desenvolvido e mantido pelo Acerola, Caju, Floyd e Vodca e que pode ter sido reforçado ao ser executado em conjunto com as primeiras inserções deliberadas bem-sucedidas.

\subsection{Generalização do uso de ferramentas}

A capacidade de generalizar o uso de uma ferramenta para outras tarefas que não a tarefa habitual, pode ser um fator determinante para a solução de novas tarefas (CARDOSO; OTTONI, 2016). Os macacos-prego são animais onívoros que exploram diversos recursos alimentares disponíveis no ambiente (FRAGASZY; VISALBERGHI; FEDIGAN, 2004) e um uso generalista das ferramentas pode permitir um melhor aproveitamento desses recursos. Contudo, a única população estudada a longo prazo em que foi observado um grau significativo de generalização no uso de ferramentas é a população do PNSC, em que as ferramentas de pedras são usadas, além da quebra de cocos, para cavar, pulverizar o quartzo, destacar seixos de conglomerados de rochas e como display sexual pelas fêmeas; além de ferramentas de sondas para caçar lagartos ou artrópodes de fendas de rochas ou frestas de troncos (MANNU; OTTONI, 2009; FALÓTICO; OTTONI, 2013, 2014, 2016; FALÓTICO; SIQUEIRA; OTTONI, 2017).

Além disso, Cardoso e Ottoni (2016) apresentaram a nova tarefa experimental de forrageamento envolvendo uma caixa-problema - semelhante à nossa caixa de melado - a um grupo de macacos do PNSC. Alguns dos indivíduos, antes de obter sucesso utilizando galhos como sondas, transportaram ferramentas de pedra e sondas (seu tool-kit) até o aparato ao tentar solucionar a tarefa, uma demonstração da generalização do uso dessas ferramentas. A mesma tarefa experimental foi disponibilizada a um grupo da FBV, que fazem uso de ferramentas líticas, 
mas não de sondas, e eles não transportaram pedras até o aparato para tentar solucionar a tarefa, uma possível consequência de seu uso menos diversificado de ferramentas líticas.

Em experimentos com macacos-prego cativos foi possível observar a capacidade desses primatas em generalizar o uso de uma ferramenta, porém, foi observada uma dificuldade desses indivíduos em compreender a causalidade e a relação espacial envolvendo tarefas com 3 elementos (FUJITA; KUROSHIMA; ASAI, 2003), como no experimento envolvendo a retirada de alimento de um tubo contendo uma armadilha (VISALBERGHI; LIMONGELLI, 1994). Em todo caso, um entendimento rudimentar de causalidade no uso de ferramentas é proposto por Fujita et al. (2003). O fato desses macacos não serem bem-sucedidos na tarefa com o tubo pode ocorrer por conta do desenho experimental, afinal, como indicado por Fujita et al. (2011), os macacos-prego podem apresentar uma compreensão rudimentar da causalidade no uso de ferramentas que envolvam até 3 elementos, como os eventos de quebra de cocos em que utilizam a ferramenta, o fruto e o substrato (FRAGASZY et al., 2004).

Em nosso trabalho, todos os indivíduos proficientes fizeram a primeira inserção deliberada bem-sucedida na caixa de melado. Embora a maioria dos sucessos tenham ocorrido na segunda fase a Caixa de Melado foi a que ficou mais tempo disponível, praticamente durante toda a fase presencial. A solução da nossa tarefa com alimentos sólidos pode ter passado pelo mesmo problema de compreensão de causalidade que Fujita et al. (2011) identificaram para o experimento com o tubo de Visalberghi e Limongelli (1994). O fato dos macacos terem de empurrar a recompensa alimentar para longe, ao invés de traze-la para si, pode exigir um certo autocontrole (FUJITA; SATO; KUROSHIMA, 2011) por ser uma ação contra intuitiva.

No entanto, após serem bem-sucedidos na caixa de melado, os sujeitos proficientes precisaram de pouco tempo de contato com a caixa de alimentos sólidos para solucionarem a tarefa. Uma mudança no comportamento de Manipular Varetas foi observada no período entre o sucesso na Caixa de Melado e o sucesso na Caixa de Sólidos. Comportamentos não-funcionais de manipulação de varetas quase não são executados na caixa de sólidos após os macacos já terem sido bem-sucedidos. 


\section{CONCLUSÃO}

O presente estudo encontrou uma diferença significativa para o comportamento de Manipular Varetas, sendo essa a variável que correlacionada ao sucesso dos indivíduos proficientes. Estar em contato com a caixa ao mesmo tempo que um indivíduo proficiente mostrou uma correlação significativa com a possibilidade de observar inserções e realizar scrounging. No entanto, nenhuma dessas variáveis sozinhas, assim como o Tempo na Caixa per $s e$, possibilitou a aquisição do uso de ferramentas de sonda pelos sujeitos experimentais.

Assim como no caso das fêmeas do PNSC em relação ao não-uso de ferramentas de sonda, o não-sucesso pelas fêmeas do grupo em nosso estudo, também permanece em aberto (FALÓTICO; OTTONI, 2014). O fato das fêmeas sequer apresentarem um tempo de contato significativo com o experimento dificulta a possibilidade de especularmos sobre detalhes desse processo. Sendo assim, experimentos prolongados, naturalísticos ou experimentais, que busquem observar especificamente o uso de ferramentas de sondas pelas fêmeas, podem contribuir para essa discussão.

Em princípio o fato desse grupo não estar habituado ao uso de varetas como ferramentas pode ter contribuído para essa difusão lenta. No experimento de Cardoso e Ottoni (2016) o grupo da FBV, que não é usuário habitual de ferramentas de sonda, apresentou dificuldades e não conseguiu ser bem-sucedido na tarefa e assim como na FBV, o grupo do PET ao entrar em contato com as varetas pré-inseridas faziam a retirada para se alimentar e não voltavam a reinserilas. Contudo, o experimento supracitado teve uma duração menor que o nosso. No entanto, a mesma dificuldade foi observada por Gruber et al. (2011) em um experimento que tentou induzir o uso de ferramentas de sonda em uma população de chimpanzés não-habituada ao seu uso.

De toda forma, essa "tecnologia" que se mostra rara na natureza (OTTONI; IZAR, 2008), se difundiu entre 6 membros do grupo, com alguns indícios da aquisição do uso de ferramentas de sonda ter ocorrido por possíveis processos de aprendizagem socialmente mediada, como o realce de local e o realce de estímulo. A manipulação de varetas apresentou aumentos de frequência subsequentes ao contato com períodos de facilitação, as Inserções Observadas de um modelo 
proficiente e eventos de scrounging. O que pode indicar uma provável relação com o mecanismo de realce de estímulo, que promoveria um interesse maior dos macacos pelas ferramentas e que, consequentemente, facilitaria a trajetória desses sujeitos ao sucesso. Em alguns casos em que o sucesso na tarefa ocorreu logo após a observação de sua solução por um indivíduo proficiente poderíamos supor um processo de emulação. No entanto, esse não parece ser o caso. A questão sobre a imitação de um comportamento peculiar, girar vareta, que foi observado em 4 sujeitos após os respectivos sucessos, permanece em aberto e uma investigação subsequente mais detalhada sobre as interações entre esses sujeitos pode apontar a ocorrência ou não de um processo de imitação.

No tocante à generalização do uso das ferramentas de sonda, foi possível observar que após a proficiência na Caixa de Melado ter sido adquirida, a solução da tarefa na Caixa de Sólidos ocorreu com pouco tempo de interação, para todos os indivíduos. Essa generalização do uso de ferramentas é um fator importante para a solução de novos problemas ou exploração de um novo recurso, através de uma flexibilização do uso da ferramenta e na promoção de comportamentos inovativos.

O processo de difusão de uma nova tarefa de forrageamento através do uso de ferramentas de sonda na população do PET, apresentou alguns indicativos de possíveis influências da aprendizagem socialmente mediada, através de mecanismos como o realce de local e de estímulo. E uma vez que a difusão foi desencadeada e o uso das ferramentas de sonda estabelecido no grupo, se tornou mais simples acompanhá-la e oferecer ao grupo tarefas que possam investigar processos de cumulatividade cultural. Assim como aplicar novas tarefas que envolvam o uso de ferramentas de sonda para averiguar a extensão da capacidade de generalização desse grupo. 


\section{REFERÊNCIAS BIBLIOGRÁFICAS}

ALCOCK, J. The evolution of the use of tools by feeding animals. Evolution, p. 464473, 1972.

AGUIAR, L. M. et al. Tool use in urban populations of capuchin monkeys Sapajus spp. (Primates: Cebidae). Zoologia (Curitiba), v. 31, n. 5, p. 516-519, 2014.

ALTMANN, J. Observational Study of Behavior: Sampling Methods. Behaviour, v. 49, n. 3-4, p. 227-266, 1974.

AQUINO, C. M. C.; OTTONI, E. B. Uso induzido de ferramentas por macacos-prego (Cebus apella) em condições de semi-liberdade. Anais do XIX Congresso Brasileiro de Etologia: Juiz de Fora, 2001. p. 74.

ANDERSON, J. R. Use of objects as hammers to open nuts by capuchin monkeys (Cebus apella). Folia Primatologica, 1990.

BALLIF, M.; MORAN, M. G. Classical rhetorics and rhetoricians: critical studies and sources. Westport, Conn.: Praeger, 2005.

BARRETT, B. J. et al. Habitual stone-tool-aided extractive foraging in white-faced capuchins, Cebus capucinus. Royal Society Open Science, v. 5, n. 8, 2018.

BECK, B. Animal tool behaviour. New York: Garland STPM Press. 1980.

BENVENUTI, M. F. L.; SOUSA, J. De; MIGUEL, C. F. Avaliando a interação de instruções e comportamento supersticioso em esquemas concorrentes. Interação em Psicologia, v. 13, n. 1, 29 out. 2009.

BOESCH, C.; BOESCH, H. Sex differences in the use of natural hammers by wild chimpanzees: A preliminary report. Journal of Human Evolution, v. 10, n. 7, p. 585-593, 1 nov. 1981.

BOESCH, C.; BOESCH, H. Optimisation of Nut-Cracking With Natural Hammers by Wild Chimpanzees. Behaviour, 1983.

BOESCH, C.; BOESCH, H. Possible causes of sex differences in the use of natural hammers by wild chimpanzees. Journal of Human Evolution, v. 13, n. 5, p. 415-440, jul. 1984.

BREUER, T.; NDOUNDOU-HOCKEMBA, M.; FISHLOCK, V. First Observation of Tool Use in Wild Gorillas. PLoS Biology, v. 3, n. 11, p. e380, 1 out. 2005. 
BYRNE, R. W.; BATES, L. A.; MOSS, C. J. Elephant cognition in primate perspective. Comparative Cognition \& Behavior Reviews, 2009.

CALDWELL, C. A.; WHITEN, A. Scrounging facilitates social learning in common marmosets, Callithrix jacchus. Animal Behaviour, 2003.

CAMARGO, M. R.; MENDES, F. D. C. Indução do Uso de Ferramentas como Enriquecimento Ambiental para Macacos-prego (Sapajus libidinosus) Cativos. Psicologia: Teoria e Pesquisa, v. 32, p. 1-8, 2016.

CANALE, G. R. et al. First record of tool use by wild populations of the yellow-breasted capuchin monkey (Cebus xanthosternos) and new records for the bearded capuchin (Cebus libidinosus). American Journal of Primatology, v. 71, n. 5, p. 366-372, 2009.

CARDOSO, R. M. Resolução de problema por macacos-prego selvagens (Sapajus libidinosus) de duas populações com diferentes repertórios de uso de ferramentas. 2013. Tese (Doutorado - Programa de Pós-Graduação em Psicologia. Área de Concentração: Psicologia Experimental) - Instituto de Psicologia da Universidade de São Paulo.

CARDOSO, R. M.; OTTONI, E. B. The effects of tradition on problem solving by two wild populations of bearded capuchin monkeys in a probing task. Biology Letters, v. 12, n. 11, p. 604, 2016.

COELHO, C. G. Observação por co-específicos e influências sociais na apresendizagem do uso de ferramentas para quebrar cocos por macacosprego (Cebus sp.) em semi-liberdade. 2009. Dissertação (Mestrado em Psicologia Experimental) - Instituto de Psicologia, Universidade de São Paulo, São Paulo,

COELHO, C. G. et al. Social learning strategies for nut-cracking by tufted capuchin monkeys (Sapajus spp.). Animal Cognition, v. 18, n. 4, p. 911-919, 2015.

COELHO, C. G. Dinâmica social e difusão de novos padrões comportamentais em macacos-prego (Sapajus libidinosus) que habitam o Parque Nacional da Serra da Capivara. 2015. Tese (Doutorado - Programa de Pós-Graduação em Psicologia. Area de Concentração: Psicologia Experimental) - Instituto de Psicologia da Universidade de São Paulo.

CORAT, C. Organização sequencial e otimização do comportamento na quebra de frutos encapsulados por macacos-prego (Sapajus sp.) em semi-liberdade. 2013. Dissertação (Mestrado em Psicologia Experimental) - Instituto de Psicologia, Universidade de São Paulo, São Paulo.

CORAT, C.; SIQUEIRA, J.; OTTONI, E. B. Sequential organization and optimization of the nut-cracking behavior of semi-free tufted capuchin monkeys (Sapajus sp.). Primates, v. 57, n. 1, p. 113-121, 2016. 
CORAT, C. Fatores sociais e cognitivos na difusão de novos padrões comportamentais em macacos-prego (Sapajus libidinosus) do Parque Nacional da Serra da Capivara - PI. 2017. Tese (Doutorado em Psicologia Experimental) - Instituto de Psicologia, Universidade de São Paulo, São Paulo.

DARWIN, C. The descent of man, and Selection in relation to sex, Vol 1. London: John Murray, 1871.

DARWIN, C. The formation of vegetable mould through the action of worms: with observations on their habits. London: John Murray, 1881.

DE A. MOURA, A. C. Capuchin Stone Tool Use in Caatinga Dry Forest. Science, v. 306, n. 5703, p. 1909-1909, 10 dez. 2004.

DE A. MOURA, A. C.; LEE, P. C. Wild Capuchins Show Male-Biased Feeding Tool Use. International Journal of Primatology, v. 31, n. 3, p. 457-470, 8 jun. 2010.

DE MORAES, B. L. C.; DA SILVA SOUTO, A.; SCHIEL, N. Adaptability in stone tool use by wild capuchin monkeys (Sapajus libidinosus). American Journal of Primatology, v. 76, n. 10, p. 967-977, 2014.

DE RESENDE, B. D.; OTTONI, E. B.; FRAGASZY, D. M. Ontogeny of manipulative behavior and nut-cracking in young tufted capuchin monkeys (Cebus apella): A Perception-action perspective. Developmental Science, v. 11, n. 6, p. 828-840, 2008.

DE WAAL, F. B. M. A century of getting to know the chimpanzee. Nature, v. 437, n. 7055, p. 56-59, 2005.

DEAN, L. G. et al. Identification of the social and cognitive processes underlying human cumulative culture. Science, v. 23, n. 1974, p. 1114-1118, 2012.

FALÓTICO, T. Estudo experimental do uso de ferramentas para quebra de frutos encapsulados por macacos-prego (Cebus apella) em semi-liberdade. 2006. Dissertação (Mestrado em Psicologia Experimental) - Instituto de Psicologia, Universidade de São Paulo, São Paulo.

FALÓTICO, T. Uso de ferramentas por macacos-prego (Sapajus libidinosus) do parque nacional Serra da capivara - Pl. 2011. Tese (Doutorado em Psicologia Experimental) - Instituto de Psicologia, Universidade de São Paulo, São Paulo.

FALÓTICO, T.; OTTONI, E. B. Stone throwing as a sexual display in wild female bearded capuchin monkeys, Sapajus libidinosus. PLoS ONE, v. 8, n. 11, p. 1-6, 2013.

FALÓTICO, T.; OTTONI, E. B. Sexual bias in probe tool manufacture and use by wild bearded capuchin monkeys. Behavioural Processes, v. 108, n. October, p. 117-122, 2014. 
FALÓTICO, T.; OTTONI, E. B. The manifold use of pounding stone tools by wild capuchin monkeys of Serra da Capivara National Park, Brazil. Behaviour, v. 153, p. 421-442, 2016.

FALÓTICO, T.; SIQUEIRA, J. O.; OTTONI, E. B. Digging up food: Excavation stone tool use by wild capuchin monkeys. Scientific Reports, v. 7, n. 1, 2017.

FALÓTICO, T. et al. Cashew Nut Positioning during Stone Tool Use by Wild Bearded Capuchin Monkeys (Sapajus libidinosus). Folia Primatologica, v. 87, n. 6, p. 392-397, 2017.

FALÓTICO, T. et al. Stone tool use by wild capuchin monkeys (Sapajus libidinosus) at Serra das Confusões National Park, Brazil. Primates, v. 59, n. 4, p. 385-394, 17 jul. 2018.

FALÓTICO, T. et al. Three thousand years of wild capuchin stone tool use. Nature Ecology \& Evolution, p. 1, 2019.

FERREIRA, R. G.; EMIDIO, R. A.; JERUSALINSKY, L. Three stones for three seeds: Natural occurrence of selective tool use by capuchins (Cebus libidinosus) based on an analysis of the weight of stones found at nutting sites. American Journal of Primatology, v. 72, n. 3, p. 270-275, 2010.

FOREST, C. D.; MOURA, A. C. D. A.; LEE, P. C. Capuchin Stone Tool Use in. Science, n. December, p. 2004, 2004.

FOX, E. A. et al. Intra-and interpopulational differences in orangutan (Pongo pygmaeus) activity and diet: Implications for the invention of tool use. American Journal of Physical Anthropology, v. 125, n. 2, p. 162-174, 1 out. 2004.

FRAGASZY, D. M.; PERRY, S. The Biology of Traditions. Cambridge University Press, 2009.

FRAGASZY, D. M.; VISALBERGHI, E. Recognizing a swan: Socially-biased learning. Psychologia, 2001.

FRAGASZY, D. et al. Wild capuchin monkeys (Cebus libidinosus) use anvils and stone pounding tools. American Journal of Primatology, v. 64, n. 4, p. 359-366, 2004.

FRAGASZY, D. et al. Bearded capuchin monkeys' and a human's efficiency at cracking palm nuts with stone tools: field experiments. Animal Behaviour, v. 79, n. 2, p. 321-332, 2010.

FRAGASZY, D. M. et al. The fourth dimension of tool use: temporally enduring artefacts aid primates learning to use tools. Philosophical transactions of the Royal Society of London. Series B, Biological sciences, v. 368, n. 1630, p. 410, 2013.

FRAGASZY, D. M.; VISALBERGHI, E.; FEDIGAN, L. M. The complete capuchin: the biology of the genus Cebus. Cambridge University Press, 2004. 
FRAGASZY, D. M.; ADAMS-CURTIS, L. E. Generative aspects of manipulation in tufted capuchin monkeys (Cebus apella). Journal of Comparative Psychology, v. 105, n. 4, p. 387-397, 1991.

FRANZ, M.; NUNN, C. L. Network-based diffusion analysis: A new method for detecting social learning. Proceedings of the Royal Society B: Biological Sciences, v. 276, n. 1663, p. 1829-1836, 2009.

FUJITA, K.; KUROSHIMA, H.; ASAI, S. How do tufted capuchin monkeys (Cebus apella) understand causality involved in tool use? Journal of Experimental Psychology: Animal Behavior Processes, v. 29, n. 3, p. 233-242, 2003.

FUJITA, K.; SATO, Y.; KUROSHIMA, H. Learning and generalization of tool use by tufted capuchin monkeys (Cebus apella) in tasks involving three factors: Reward, tool, and hindrance. Journal of Experimental Psychology: Animal Behavior Processes, v. 37, n. 1, p. 10-19, 2011.

GALDIKAS, B. M. F. Orang-utan tool-use at Tanjung Puting Reserve, Central Indonesian Borneo (Kalimantan Tengah). Journal of Human Evolution, v. 11, $\mathrm{n}$. 1, p. 19-33, 1982.

GALEF, B. G. Imitation in animals: history, definition, and interpretation of data from the psychological laboratory. In: ZENTALL, T. R.; GALEF, B. G. (Ed.), Social Learning: Psychological and Biological Perspectives. New York: Psychology Press, 2013. P3-28.

GALEF, B. G. The question of animal culture. Human Nature, v. 3, n. 2, p. 157-178, jun. 1992.

GARBER, P. A.; GOMES, D. F.; BICCA-MARQUES, J. C. Experimental field study of problem-solving using tools in free-ranging capuchins (Sapajus nigritus, formerly Cebus nigritus). American Journal of Primatology, v. 74, n. 4, p. 344-358, 2012.

GIRALDEAU, L.-A.; LEFEBVRE, L. Scrounging prevents cultural transmission of foodfinding behaviour in pigeons. Animal Behaviour, v. 35, n. 2, p. 387-394, 1 abr. 1987.

GOODALL, J. Tool-using and aimed throwing in a community of free-living chimpanzees. Nature, 1964.

GRUBER, T. et al. Community-specific evaluation of tool affordances in wild chimpanzees. Scientific Reports, v. 1, n. 1, p. 128, 3 dez. 2011.

GUMERT, M. D.; HOONG, L. K.; MALAIVIJITNOND, S. Sex differences in the stone tool-use behavior of a wild population of burmese long-tailed macaques (Macaca fascicularis aurea). American Journal of Primatology, v. 73, n. 12, p. 12391249, 1 dez. 2011.

HALL, K. R. L. Tool-using performances as indicators of behavioral adaptability. Current Anthropology, 4(5), 479-494.1963. 
HALL, K. R. L.; SCHALLER, G. B. Tool-Using Behavior of the California Sea Otter. Journal of Mammalogy, 2006.

HART, B. L. et al. Congnitive behavior in Asia elephant: Use and modification of branches for fly switching. Animal Behaviour, 2001.

HASLAM, M.; FALÓTICO, T. Nasal probe and toothpick tool use by a wild female bearded capuchin (Sapajus libidinosus). Primates, v. 56, n. 3, p. 211-214, 2015.

HENSCHEL, J. R. Tool Use by Spiders: Stone Selection and Placement by Corolla Spiders Ariadna (Segestriidae) of the Namib Desert. Ethology, 1995.

HEYES, C. M. Imitation, culture and cognition. Animal Behaviour, 1993.

HEYES, C. M. Social learning in animals: categories and mechanisms. Biological reviews of the Cambridge Philosophical Society, 1994.

HEYES, C. M.; GALEF JR., B. G. Social Learning in Animals: The Roots of Culture. San Diego, CA: Academic Press, 1996.

HOPPITT, W.; LALAND, K. N. Social learning: an introduction to mechanisms, methods, and models. Princeton University Press, 2013.

Huffman, M. A. Acquisition of innovative cultural behaviors in nonhuman primates: A case study of stone handling, a socially transmitted behavior in Japanese macaques. In C. M. Heyes \& B. G. Galef, Jr. (Eds.), Social learning in animals: The roots of culture. San Diego, CA, US: Academic Press. 1996. p. 267-289.

HUNT, G. R. Manufacture and use of hook-tools by New Caledonian crows. Nature, 1996.

INOUE-NAKAMURA, N.; MATSUZAWA, T. Development of Stone Tool Use by Wild Chimpanzees (Pan troglodytes). Journal of Comparative Psychology, 1997.

KENDAL, R. L. et al. Identifying social learning in animal populations: A new "optionbias" method. PLoS ONE, v. 4, n. 8, 2009.

KENDAL, R. L. et al. Social Learning Strategies: Bridge-Building between Fields. Trends in Cognitive Sciences, v. 22, n. 7, p. 651-665, 1 jul. 2018.

KOOPS, K.; FURUICHI, T.; HASHIMOTO, C. Chimpanzees and bonobos differ in intrinsic motivation for tool use. Scientific Reports, v. 5, p. 11356, 2015.

LALAND, K.; MATTHEWS, B.; FELDMAN, M. W. An introduction to niche construction theory. Evolutionary Ecology, v. 30, n. 2, p. 191-202, 2016.

LALAND, K. N. Social learning strategies. Animal Learning \& Behavior, 2011.

LALAND, K. N.; HOPPITT, W. Do Animals Have Culture? Evolutionary Anthropology, v. 12, n. 3, p. 150-159, 2003. 
LALAND, K. N.; JANIK, V. M. The animal cultures debate. Trends in Ecology \& Evolution, v. 21, n. 10, p. 542-547, 1 out. 2006.

LALAND, K. N.; ODLING-SMEE, F. J.; FELDMAN, M. W. Evolutionary consequences of niche construction and their implications for ecology. Proceedings of the National Academy of Sciences of the United States of America, v. 96, n. 18, p. 10242-7, 31 ago. 1999.

LALAND, K. N.; ODLING-SMEE, J.; FELDMAN, M. W. Niche construction, biological evolution, and cultural change. Behavioral and Brain Sciences, v. 23, n. 1, fev. 2000.

LEWONTIN, R. C. The Organism as the Subject and Object of Evolution. Scientia 77 (18):65., 1983.

LEWONTIN, R. C. A tripla hélice: Gene, organismo ambiente. Brasil: Edições 70, 2002.

LIU, Q. et al. Kinematics and energetics of nut-cracking in wild capuchin monkeys (Cebus libidinosus) in Piauí, Brazil. American Journal of Physical Anthropology, v. 138, n. 2, p. 210-220, 2009.

LONSDORF, E. V.; EBERLY, L. E.; PUSEY, A. E. Sex differences in learning in chimpanzees. Nature, v. 428, n. 6984, p. 715-716, abr. 2004.

LONSDORF, E. V; HOPKINS, W. D. Wild chimpanzees show population-level handedness for tool use. Proceedings of the National Academy of Sciences of the United States of America, v. 102, n. 35, p. 12634-8, 30 ago. 2005.

LYNCH ALFARO, J. W. et al. Explosive Pleistocene range expansion leads to widespread Amazonian sympatry between robust and gracile capuchin monkeys. Journal of Biogeography, v. 39, n. 2, p. 272-288, 2012.

MANN, J.; SARGEANT, B. Tool-Use in Wild Bottlenose Dolphins. In PERRIN, W. F.; WÜRSIG, B. G.; THEWISSEN, J. G. M. (Eds.) Encyclopedia of marine mammals. Amsterdam: Elsevier/Academic Press, 2009.

MANNU, M. Uso espontâneo de ferramentas por macacos-prego (Cebus apella) em condições de semi-liberdade: descrição e demografia. 2002. Universidade de São Paulo, São Paulo.

MANNU, M.; OTTONI, E. B. Observacoes preliminares das tecnicas de forrageamento e uso espontaneo de ferramentas por um grupo de macacos-prego (cebus apella, primates-cebidae) em condicoes de semicativeiro. Anais.. Uberlandia: Sociedade Brasileira de Etologia, 1996.

MANNU, M.; OTTONI, E. B. The enhanced tool-kit of two groups of wild bearded capuchin monkeys in the caatinga: Tool making, associative use, and secondary tools. American Journal of Primatology, v. 71, n. 3, p. 242-251, 2009. 
MATHER, J. A. 'Home' choice and modification by juvenile Octopus vulgaris (Mollusca: Cephalopoda): specialized intelligence and tool use? Journal of Zoology, 1994.

MATSUZAWA, T. Field experiments on use of stone tools by chimpanzees in the wild. In R. W. Wrangham, W. C. McGrew, F. B. M. de Waal, \& P. G. Heltne (Eds.), Chimpanzee cultures (pp. 351-370). Cambridge, MA, US: Harvard University Press. 1994.

MCGREW, W. C. Tool use by wild chimpanzees in feeding upon driver ants. Journal of Human Evolution, 1974.

MCGREW, W. C. Chimpanzee Material Culture. Cambridge: Cambridge University Press, 1992.

MCGREW, W. C. Ten dispatches from the chimpanzee culture wars, plus, postscript (revisiting the battlefronts). In: LALAND, K. N.; GALEF, B. G. (Ed.). The question of animal culture. Harvard Univ. Press, 2009. p. 41-69.

MCGREW, W. C. The cultured chimpanzee: nonsense or breakthrough? Human Ethology Bulletin - Proc. of the XXII. ISHE Conference, p. 41-52, 2015.

MCGREW, W. C. Chimpanzee Material Culture: Implications for Human Evolution. Cambridge University Press, 1992.

MENDES, F. D. C. et al. Diversity of nutcracking tool sites used by Sapajus libidinosus in Brazilian Cerrado. American Journal of Primatology, v. 77, n. 5, p. 535-546, 2015.

MOURA, A. C. de A. Stone Banging by Wild Capuchin Monkeys: An Unusual Auditory Display. Folia Primatologica, v. 78, n. 1, p. 36-45, 2007.

MUSGRAVE, S. et al. Tool transfers are a form of teaching among chimpanzees. Scientific Reports, v. 6, n. 1, p. 34783, 11 dez. 2016.

NISHIDA, T. The ant-gathering behaviour by the use of tools among wild chimpanzees of the Mahali Mountains. Journal of Human Evolution, 1973.

OAKLEY, K. The Earliest Tool-makers. Antiquity, v. 30, n. 117, p. 4-8, 2 mar. 1956.

OAKLEY, K. P. Man the Tool-Maker. Proceedings of the Geologists' Association, v. 55, n. 2, p. 115-118, 1944.

ODLING-SMEE, F. J. Niche-constructing phenotypes. In: PLOTKIN, H. C. (Ed.), The role of behavior in evolution (pp. 73-132). Cambridge, MA, US: The MIT Press.

OTTONI, E. B. Tool Use Traditions in Nonhuman Primates: The Case of Tufted Capuchin Monkeys. Human Ethology Bulletin, v. 30, n. 1, p. 22-40, 2015. 
OTTONI, E. B.; DE RESENDE, B. D.; IZAR, P. Watching the best nutcrackers: what capuchin monkeys (Cebus apella) know about others' tool-using skills. Animal Cognition, v. 8, n. 4, p. 215-219, 18 out. 2005.

OTTONI, E. B.; IZAR, P. Capuchin monkey tool use: Overview and implications. Evolutionary Anthropology, v. 17, n. 4, p. 171-178, 2008.

OTTONI, E. B.; MANNU, M. Semi-free ranging tufted capuchin monkeys (Cebus apella) espontaneously use tools to crack open nuts. International Journal of Primatology, v. 22, n. 3, p. 347-358, 2001.

PARRA, G. J. Observations of an Indo-Pacific humpback dolphin carrying a sponge: Object play or tool use? Mammalia, 2007.

PERRY, S. Are nonhuman primates likely to exhibit cultural capacities like those of humans? In K. N. Laland \& B. G. Galef (Eds.), The question of animal culture (pp. 247-268). Cambridge, MA, US: Harvard University Press.

PERRY, S. Social traditions and social learning in capuchin monkeys (Cebus). Philosophical transactions of the Royal Society of London. Series B, Biological sciences, v. 366, n. 1567, p. 988-96, 12 abr. 2011.

PROFFITT, T. et al. Wild monkeys flake stone tools. Nature, p. 1-13, 2016.

READER, S. M.; LALAND, K. N. Primate innovation: Sex, age and social rank differences. International Journal of Primatology, 2001.

RESENDE, B. Ontogenia de comportamentos manipulativos em um grupo de macacos-prego (Cebus Apella) em situação de semiliberdade. 2004. Tese (Doutorado em Psicologia Experimental) - Instituto de Psicologia, Universidade de São Paulo, São Paulo.

ROCHA, V. J.; REIS, N. R. dos; SEKIAMA, M. L. Uso de ferramentas por Cebus Apella (Linnaeus) (Primates, Cebidae) para obtenção de larvas de coleoptera que parasitam sementes de syagrus romanzoffianum (Cham.) Glassm. (Arecaceae). Revista Brasileira de Zoologia, v. 15, n. 4, p. 945-950, dez. 1998.

SASAKI, T.; BIRO, D. Cumulative culture can emerge from collective intelligence in animal groups. Nature Communications, 2017.

SHUMAKER, R. W.; WALKUP, K. R.; BECK, B. B. Animal tool behavior: the use and manufacture of tools by animals. Johns Hopkins University Press, 2011.

SIRIANNI, G.; VISALBERGHI, E. Wild Bearded Capuchins Process Cashew Nuts Without Contacting Caustic Compounds. American Journal of Primatology, v. 75, n. 4, p. 387-393, 1 abr. 2013.

SOUSA, C.; BIRO, D.; MATSUZAWA, T. Leaf-tool use for drinking water by wild chimpanzees (Pan troglodytes): Acquisition patterns and handedness. Animal Cognition, 2009. 
SOUTO, A. et al. Critically endangered blonde capuchins fish for termites and use new techniques to accomplish the task. Biology Letters, v. 7, n. 4, p. 532-535, 2011.

SPAGNOLETTI, N. et al. Stone tool use by adult wild bearded capuchin monkeys (Cebus libidinosus). Frequency, efficiency and tool selectivity. Journal of Human Evolution, v. 61, n. 1, p. 97-107, 2011.

ST AMANT, R.; HORTON, T. E. Revisiting the definition of animal tool use. Animal Behaviour, v. 75, n. 4, p. 1199-1208, 2008.

SUGIYAMA, Y. Tool-use for catching ants by chimpanzees at Bossou and Monts Nimba, West Africa. Primates, 1995.

THORPE, W. H. Learning and instinct in animals. Cambridge, MA, US: Harvard University Press, 1956.

TOMASELLO, M. The cultural origins of human cognition. Harvard university press, 2009.

TOMASELLO, M. Cultural transmission in the tool use and communicatory signaling of chimpanzees? In S. T. Parker \& K. R. Gibson (Eds.), "Language" and intelligence in monkeys and apes: Comparative developmental perspectives (pp. 274-311). New York, NY, US: Cambridge University Press.

TOMASELLO, M.; CALL, J. Primate cognition. Oxford University Press, 1997.

TYLOR, E. B. Primitive culture: researches into the development of mythology, philosophy, religion, language, art and custom. 1873.

VAN SCHAIK, C. P.; FOX, E. A.; SITOMPUL, A. F. Manufacture and use of tools in wild Sumatran orangutans. Naturwissenschaften, v. 83, n. 4, p. 186-188, abr. 1996.

VERDERANE, M. P. Socioecologia de macacos-prego (Cebus libidinosus) em área de ecótono cerrado/caatinga. 2010. Tese (Doutorado em Psicologia Experimental) - Instituto de Psicologia, Universidade de São Paulo, São Paulo.

VISALBERGHI, E. Acquisition of nut-cracking behaviour by 2 capuchin monkeys (Cebus apella). Folia Primatologica, 1987.

VISALBERGHI, E. Tool use in cebus. Folia Primatologica, v. 54, n. 3-4, p. 146-154, 1990.

VISALBERGHI, E. et al. Characteristics of hammer stones and anvils used by wild bearded capuchin monkeys (Cebus libidinosus) to crack open palm nuts. American Journal of Physical Anthropology, v. 132, n. 3, p. 426-444, 2007.

VISALBERGHI, E.; FRAGASZY, D. M.; SAVAGE-RUMBAUGH, S. Performance in a Tool-Using Task by Common Chimpanzees (Pan troglodytes), Bonobos (Pan paniscus), an Orangutan (Pongo pygmaeus), and Capuchin Monkeys (Cebus apella). Journal of Comparative Psychology, 1995. 
VISALBERGHI, E.; LIMONGELLI, L. Lack of comprehension of cause-effect relations in tool-using capuchin monkeys (Cebus apella). Journal of comparative psychology, v. 108, n. 1, p. 15-22, mar. 1994.

VISALBERGHI, E.; TRINCA, L. Tool use in capuchin monkeys: Distinguishing between performing and understanding. Primates, v. 30, n. 4, p. 511-521, 1989.

WESTERGAARD, G. C.; SUOMI, S. J. Use of a tool-set by capuchin monkeys (Cebus apella). Primates, 1993.

WESTERGAARD, G. C.; SUOMI, S. J. A simple stone-tool technology in monkeys. Journal of Human Evolution, 1994.

WHITEN, A. et al. Cultures in chimpanzees. Nature, 1999.

WHITEN, A.; HAM, R. On the nature and evolution of imitation in the animal kingdom. Advances in the study of behavior, p. 239-283. 1992.

WHITEN, A.; VAN DE WAAL, E. The pervasive role of social learning in primate lifetime development. Behavioral Ecology and Sociobiology, 2018. 
7. APÊNDICES 


\section{APÊNDICE A - DATAS DE COLETA DE DADOS}

Tabela 11 - Datas das coletas de dados do experimento indicando a duração da coleta para cada dia seguido de informações sobre qual caixa-problema estava disponível no dia e a disponibilidade das varetas.

\begin{tabular}{|c|c|c|c|c|}
\hline Fase & Data & Duração & Disponibilização de varetas & Tipo de caixa \\
\hline \multirow{7}{*}{ Teste } & $2016-02-10$ & 00:03:02 & Não disponibilizadas & Caixa de melado \\
\hline & 2016-02-16 & $00: 15: 23$ & Não disponibilizadas & Caixa de melado \\
\hline & 2016-09-16 & 00:30:00 & Não disponibilizadas & Caixa de melado \\
\hline & 2016-09-21 & $00: 52: 07$ & Não disponibilizadas & Caixa de melado \\
\hline & 2016-09-28 & 01:03:01 & Não disponibilizadas & Caixa de melado \\
\hline & 2016-09-30 & $00: 55: 16$ & Não disponibilizadas & Caixa de melado \\
\hline & 2016-10-19 & 01:01:16 & Não disponibilizadas & Caixa de melado \\
\hline \multirow{43}{*}{ Primeira Fase } & $01 / 11 / 2016$ & $00: 18: 26$ & Não disponibilizadas & Caixa de melado \\
\hline & $22 / 11 / 2016$ & $00: 36: 37$ & Não disponibilizadas & Caixa de melado \\
\hline & $24 / 11 / 2016$ & $00: 25: 57$ & Não disponibilizadas & Caixa de melado \\
\hline & $30 / 11 / 2016$ & $00: 43: 14$ & Disponibilizadas & Caixa de melado \\
\hline & $02 / 12 / 2016$ & $00: 20: 54$ & Disponibilizadas & Caixa de melado \\
\hline & $16 / 03 / 2017$ & $00: 47: 00$ & Disponibilizadas & Caixa de melado \\
\hline & $23 / 03 / 2017$ & $00: 27: 11$ & Disponibilizadas & Caixa de melado \\
\hline & $28 / 03 / 2017$ & $00: 50: 43$ & Disponibilizadas & Caixa de melado \\
\hline & $30 / 03 / 2017$ & 01:10:00 & Disponibilizadas & Caixa de melado \\
\hline & $04 / 04 / 2017$ & $00: 17: 35$ & Disponibilizadas & Caixa de melado \\
\hline & $19 / 04 / 2017$ & $01: 47: 00$ & Disponíveis pré-inseridas & Caixa de melado \\
\hline & $25 / 04 / 2017$ & $01: 22: 53$ & Disponíveis pré-inseridas & Caixa de melado \\
\hline & $04 / 05 / 2017$ & $02: 47: 27$ & Disponíveis pré-inseridas & Caixa de melado \\
\hline & $09 / 05 / 2017$ & $01: 21: 48$ & Disponibilizadas & Caixa de melado \\
\hline & $10 / 05 / 2017$ & $01: 13: 34$ & Disponibilizadas & Caixa de melado \\
\hline & $15 / 05 / 2017$ & 03:02:40 & Disponibilizadas & Caixa de melado \\
\hline & $23 / 05 / 2017$ & 01:10:07 & Disponibilizadas & Caixa de melado \\
\hline & $24 / 05 / 2017$ & $00: 50: 31$ & Disponibilizadas & Caixa de melado \\
\hline & $29 / 05 / 2017$ & $00: 45: 00$ & Disponibilizadas & Caixa de melado \\
\hline & 08/06/2017 & 01:10:20 & Disponibilizadas & Caixa de melado \\
\hline & $14 / 06 / 2017$ & 01:10:00 & Disponibilizadas & Caixa de melado \\
\hline & $15 / 06 / 2017$ & $01: 27: 00$ & Disponibilizadas & Caixa de melado \\
\hline & $27 / 06 / 2017$ & 01:10:00 & Disponibilizadas & Caixa de melado \\
\hline & $28 / 06 / 2017$ & 01:40:00 & Disponibilizadas & Caixa de melado \\
\hline & $29 / 06 / 2017$ & $02: 11: 30$ & Disponibilizadas & Caixa de melado \\
\hline & $04 / 07 / 2017$ & 00:40:00 & Disponibilizadas & Caixa de melado \\
\hline & $05 / 07 / 2017$ & 01:40:07 & Disponibilizadas & Caixa de melado \\
\hline & 06/07/2017 & $01: 12: 41$ & Disponibilizadas & Caixa de melado \\
\hline & $12 / 07 / 2017$ & $01: 53: 38$ & Disponíveis pré-inseridas & Caixa de melado \\
\hline & $13 / 07 / 2017$ & 01:30:00 & Disponíveis pré-inseridas & Caixa de melado \\
\hline & $17 / 07 / 2017$ & 02:10:47 & Disponíveis pré-inseridas & Caixa de melado \\
\hline & $20 / 07 / 2017$ & 02:51:00 & Disponíveis pré-inseridas & Caixa de melado \\
\hline & $21 / 07 / 2017$ & $01: 20: 41$ & Disponíveis pré-inseridas & Caixa de melado \\
\hline & $28 / 07 / 2017$ & $01: 26: 47$ & Disponíveis pré-inseridas & Caixa de melado \\
\hline & $31 / 07 / 2017$ & $01: 16: 15$ & Disponíveis pré-inseridas & Caixa de melado \\
\hline & 02/08/2017 & $01: 27: 48$ & Não disponibilizadas & Caixa de sólidos \\
\hline & $03 / 08 / 2017$ & 00:31:02 & Não disponibilizadas & Caixa de sólidos \\
\hline & $09 / 08 / 2017$ & 01:18:03 & Não disponibilizadas & Caixa de sólidos \\
\hline & $10 / 08 / 2017$ & 02:07:00 & Disponíveis pré-inseridas & Ambas as caixas \\
\hline & $05 / 09 / 2017$ & 01:04:14 & Disponíveis pré-inseridas & Ambas as caixas \\
\hline & $06 / 09 / 2017$ & $01: 07: 16$ & Não disponibilizadas & Caixa de sólidos \\
\hline & $11 / 09 / 2017$ & 02:06:02 & Disponíveis pré-inseridas & Ambas as caixas \\
\hline & $13 / 09 / 2017$ & $01: 17: 11$ & Disponíveis pré-inseridas & Ambas as caixas \\
\hline
\end{tabular}




\begin{tabular}{|c|c|c|c|c|}
\hline & $14 / 09 / 2017$ & 01:08:09 & Disponíveis pré-inseridas & Caixa de melado \\
\hline & 20/09/2017 & $01: 55: 52$ & Disponíveis pré-inseridas & Ambas as caixas \\
\hline & 21/09/2017 & 01:11:28 & Disponíveis pré-inseridas & Ambas as caixas \\
\hline & 26/09/2017 & $00: 50: 38$ & Disponíveis pré-inseridas & Ambas as caixas \\
\hline & 27/09/2017 & 01:54:04 & Disponíveis pré-inseridas & Ambas as caixas \\
\hline & 05/10/2017 & 01:15:05 & Não disponibilizadas & Caixa de sólidos \\
\hline & $10 / 10 / 2017$ & 00:03:12 & Não disponibilizadas & Caixa de sólidos \\
\hline & $11 / 10 / 2017$ & 01:13:44 & Não disponibilizadas & Caixa de sólidos \\
\hline & 13/10/2017 & 00:50:00 & Não disponibilizadas & Caixa de sólidos \\
\hline & $16 / 10 / 2017$ & $01: 11: 50$ & Não disponibilizadas & Caixa de sólidos \\
\hline & 18/10/2017 & 01:14:09 & Não disponibilizadas & Caixa de sólidos \\
\hline & 24/10/2017 & $00: 13: 34$ & Não disponibilizadas & Caixa de sólidos \\
\hline & $31 / 10 / 2017$ & $01: 22: 35$ & Disponíveis pré-inseridas + Vareta Fixa & Caixa de melado \\
\hline & 01/11/2017 & 01:11:06 & Disponíveis pré-inseridas + Vareta Fixa & Caixa de melado \\
\hline & 06/11/2017 & 00:19:41 & Disponíveis pré-inseridas + Vareta Fixa & Caixa de melado \\
\hline & 08/11/2017 & 00:03:19 & Não disponibilizadas + Vareta Fixa & Caixa de melado \\
\hline & 09/11/2017 & $01: 46: 22$ & Não disponibilizadas + Vareta Fixa & Caixa de melado \\
\hline & $10 / 11 / 2017$ & $01: 24: 20$ & Disponíveis pré-inseridas + Vareta Fixa & Caixa de melado \\
\hline & 29/11/2017 & 00:25:48 & Não disponibilizadas + Vareta Fixa & Caixa de melado \\
\hline & $30 / 11 / 2017$ & $01: 56: 35$ & Não disponibilizadas + Vareta Fixa & Caixa de melado \\
\hline & $11 / 12 / 2017$ & $01: 14: 35$ & Não disponibilizadas + Vareta Fixa & Caixa de melado \\
\hline & $14 / 12 / 2017$ & 02:01:12 & Não disponibilizadas + Vareta Fixa & Caixa de melado \\
\hline & 26/12/2017 & 01:05:40 & Disponíveis pré-inseridas + Vareta Fixa & Caixa de melado \\
\hline & 27/12/2017 & $01: 45: 35$ & Disponíveis pré-inseridas & Caixa de melado \\
\hline & 04/01/2018 & 02:08:29 & Disponíveis pré-inseridas & Caixa de melado \\
\hline & 05/01/2018 & 00:33:07 & Disponíveis pré-inseridas & Caixa de melado \\
\hline & 09/01/2018 & 00:46:16 & Disponíveis pré-inseridas & Caixa de melado \\
\hline & $17 / 01 / 2018$ & 01:21:07 & Disponibilizadas & Ambas as caixas \\
\hline & 23/01/2018 & 01:30:00 & Disponibilizadas & Caixa de melado \\
\hline & $25 / 01 / 2018$ & 01:04:01 & Disponibilizadas & Ambas as caixas \\
\hline & 07/02/2018 & $01: 28: 44$ & Disponibilizadas & Ambas as caixas \\
\hline & $08 / 02 / 2018$ & $00: 39: 25$ & Disponibilizadas & Ambas as caixas \\
\hline & $11 / 06 / 18-21 / 06 / 18$ & 24 horas & Disponibilizadas & Ambas as caixas \\
\hline Enc & $25 / 06 / 18-28 / 06 / 18$ & 24 horas & Disponibilizadas & Ambas as caixas \\
\hline & $01 / 07 / 18-04 / 08 / 18$ & 24 horas & Disponibilizadas & Ambas as caixas \\
\hline
\end{tabular}




\section{APÊNDICE B - TABELA DE DADOS DAS VARIÁVEIS PARA CADA INDIVÍDUO}

Tabela 12 - Valores das variáveis para cada indivíduo do grupo. Legenda: IO (Inserções Observadas); TS (Tolerated Scrounging); C/ Pro (Tempo na caixa com proficiente); $2 \mathrm{~m}$ Pro (a 2 metros de um proficiente na caixa); $5 \mathrm{~m}$ Pro (a 5 metros de um proficiente na caixa); Na caixa (tempo em contato com a caixa); $2 \mathrm{~m}$ (tempo a 2 metros da caixa); $5 \mathrm{~m}$ (tempo a 5 metros da caixa); RF (retirada de varetas facilitadas); PF (puxar vareta fixa); EC (exploração da caixa);

\begin{tabular}{|c|c|c|c|c|c|c|c|c|c|c|c|c|c|c|}
\hline Indiv & $\mathbf{S}$ & 10 & TS & C/ Pro & 2m Pro & $5 \mathrm{~m}$ Pro & Na caixa & $2 m$ & $5 m$ & $\mathbf{R F}$ & PF & EC & DS & MV \\
\hline Acácio & $M$ & 0 & 10 & 00:00:00 & 00:00:00 & 00:00:00 & :48:05 & 00:13:06 & $00: 44: 24$ & 23 & 0 & 269 & 4 & 20 \\
\hline Acerola & $M$ & 150 & 39 & $00: 4$ & 00:20:02 & 15 & 8 & $: 16$ & $06: 54: 57$ & 58 & 882 & 1042 & 4 & 938 \\
\hline Caju & $M$ & 142 & 103 & $00: 40: 49$ & $00: 57: 26$ & 02:16:00 & $12: 36: 43$ & 04:07:20 & 09:07:04 & 269 & 289 & 3594 & 5 & 1479 \\
\hline Floyd & $M$ & 563 & 504 & 03:07:50 & $00: 58: 36$ & 01:19:39 & $14: 2 \varepsilon$ & $03: 34: 46$ & 08:18:47 & 90 & 429 & 2483 & 5 & 1178 \\
\hline Vodca & $M$ & 43 & 32 & $00: 23: 17$ & $00: 30: 51$ & $00: 04: 53$ & $06: 5$ & $01: 31: 31$ & 02:09:50 & 64 & 45 & 1552 & 6 & 1264 \\
\hline Açaí & $M$ & 9 & 8 & $00: 10: 59$ & $00: 20: 21$ & 01:01:30 & $03: 42: 32$ & $02: 1$ & 03:55:05 & 21 & 59 & 1021 & 7 & 141 \\
\hline Davi & $M$ & 185 & 235 & $01: 41: 21$ & $00: 20: 30$ & 01:29:05 & $11: 08: 50$ & $01: 32: 51$ & $05: 34: 37$ & 365 & 1248 & 1688 & 117 & 506 \\
\hline Quím & $M$ & 9 & 17 & $00: 07: 47$ & $00: 0$ & $00: 3$ & 10 & 1:07 & 04:33:57 & 462 & 1380 & 2512 & 44 & 63 \\
\hline Frodo & $M$ & 822 & 1073 & 03:31:29 & $01: 2$ & $00: 37: 18$ & & $4: 29$ & $05:($ & r & 13 & 1516 & 31 & 172 \\
\hline Feioso & $M$ & 58 & 59 & $00: 20: 27$ & $00: 15: 33$ & $00: 42: 00$ & 04:15:03 & $02: 36: 24$ & 04:00:30 & ? & 16 & 1213 & 22 & 80 \\
\hline Frank & $M$ & 287 & 257 & $01: 0$ & $00: 3$ & $01: 3$ & 03: & :31 & $05: 2$ & . & 0 & 515 & 76 & 100 \\
\hline Cisca & $\mathrm{F}$ & 5 & 3 & 00:03:08 & $00: 11: 13$ & $00: 26: 18$ & $00: 5$ & 01:08:15 & $02: 51: 15$ & 6 & 48 & 312 & 16 & 13 \\
\hline & $\mathrm{F}$ & 82 & 48 & $00: 24: 21$ & $00: 0$ & $00:$ & & $: 41$ & $01: 28: 23$ & 39 & 52 & 399 & 4 & 21 \\
\hline Frida & $\mathrm{F}$ & 23 & 10 & 00:03:58 & $00: 00: 42$ & 00:01:10 & 01:31:35 & $00: 38: 28$ & $00: 47: 45$ & 12 & 0 & 394 & 13 & 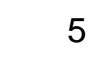 \\
\hline Cacá & $\mathrm{F}$ & 15 & 16 & $00: 04: 14$ & $00: 1$ & 01:02:32 & $02:$ & :56 & 02: & 46 & 64 & 361 & 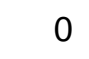 & 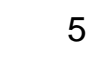 \\
\hline Val & $\mathrm{F}$ & 143 & 101 & $00: 31: 31$ & $00: 15: 07$ & 00:00:00 & $01: 25$ & $00: 30: 32$ & $00:$ & 18 & 0 & 248 & 20 & 4 \\
\hline Sam & $M$ & 49 & 9 & $00: 16: 48$ & $00: 3$ & $00: 5$ & $02:$ & 55 & 02:02:59 & 0 & 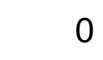 & 271 & 15 & 8 \\
\hline Física & $\mathrm{F}$ & 50 & 29 & $00: 11: 11$ & 00:04:34 & 00:08:04 & 00:54:20 & $00: 21: 28$ & $00: 34: 11$ & 3 & 0 & 212 & 12 & 17 \\
\hline Cláudia & $\mathrm{F}$ & 0 & 0 & 00:00:16 & 00:00:00 & 00:00:00 & 00:09:21 & 00:00:10 & $00: 16: 24$ & 0 & 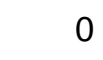 & 1 & 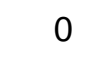 & 0 \\
\hline Demc & $M$ & 85 & 72 & $00: 17: 10$ & $00: 10: 58$ & $00: 2$ & 01 & 2:12 & 01: & 0 & 11 & 721 & 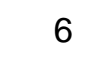 & 58 \\
\hline Capa & $M$ & 55 & 29 & $00: 15: 12$ & 00:23:22 & $00: 4$ & 01:16:42 & $01: 41: 44$ & 02:33:54 & 4 & 4 & 200 & 32 & 4 \\
\hline Amora & $\mathrm{F}$ & 62 & 77 & $00: 20: 38$ & $00: 01: 25$ & 00:05:11 & $00: 42: 36$ & 00:07:59 & $00: 54: 51$ & 0 & 26 & 131 & 6 & 12 \\
\hline Jabá & $\mathrm{F}$ & 38 & 20 & 00:07:59 & 00:01:00 & 00:00:00 & $00: 14: 24$ & $00: 14: 54$ & 00:06:04 & 0 & 0 & 46 & 2 & 1 \\
\hline Adam & $M$ & 0 & 0 & 00:00:00 & 00:02:40 & $00: 0$ & & 16 & 00: & 0 & 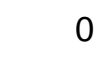 & 27 & 2 & 1 \\
\hline Folha & $M$ & 123 & 86 & $00: 36: 55$ & $00: 31: 23$ & $00: 43: 49$ & $02: 50: 52$ & 03:20:06 & 03:49:45 & 0 & 0 & 681 & 23 & 69 \\
\hline Vader & $M$ & 103 & 33 & $00: 19: 58$ & $00: 10: 17$ & $00: 17: 51$ & 01:53:49 & 01:15:23 & $02: 54: 50$ & 15 & 89 & 442 & 18 & 23 \\
\hline Tigela & $M$ & 24 & 2 & 00:05:57 & $00: 01: 47$ & 00:11:59 & $00: 32: 30$ & $00: 39: 30$ & 01:06:58 & 0 & 0 & 144 & 7 & 50 \\
\hline Alice & $\mathrm{F}$ & 57 & 26 & $00: 15: 44$ & $00: 21: 50$ & 00:00:07 & $00: 30: 48$ & $00: 44: 17$ & $00: 14: 57$ & 0 & 0 & 59 & 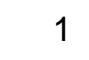 & 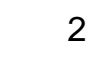 \\
\hline Ana & $\mathrm{F}$ & 8 & 1 & 00:02:29 & $00: 00: 43$ & 00:00:00 & 00:07:52 & $00: 14: 26$ & 00:23:06 & 0 & 0 & 30 & 0 & 0 \\
\hline Angélica & $\mathrm{F}$ & 45 & 35 & 00:08:27 & $00: 14: 59$ & 00:06:38 & $00: 15: 55$ & $00: 25: 23$ & $00: 15: 49$ & 0 & 0 & 31 & $r$ & 1 \\
\hline Careca & $M$ & 0 & 12 & 00:00:00 & 00:00:00 & 00:00:00 & $00: 31: 27$ & 00:09:32 & $00: 01: 13$ & 0 & 38 & 75 & 0 & 0 \\
\hline Vavá & $\mathrm{F}$ & 6 & 0 & 00:01:11 & 00:06:40 & 00:00:17 & 00:05:26 & $00: 16: 51$ & $00: 37: 12$ & 0 & 0 & 12 & 0 & 0 \\
\hline Ravena & $\mathrm{F}$ & 0 & 0 & 00:00:10 & 00:01:39 & 00:04:44 & 00:08:59 & 00:16:05 & $00: 32: 15$ & 0 & 0 & 52 & 9 & 2 \\
\hline Vandinha & $\mathrm{F}$ & 0 & 1 & 00:00:05 & 00:01:00 & 00:06:39 & 00:06:01 & 00:13:05 & 01:20:26 & 1 & 0 & 41 & 0 & 3 \\
\hline
\end{tabular}

DS (Delayed Scrounging); MV (Manipular Varetas). 


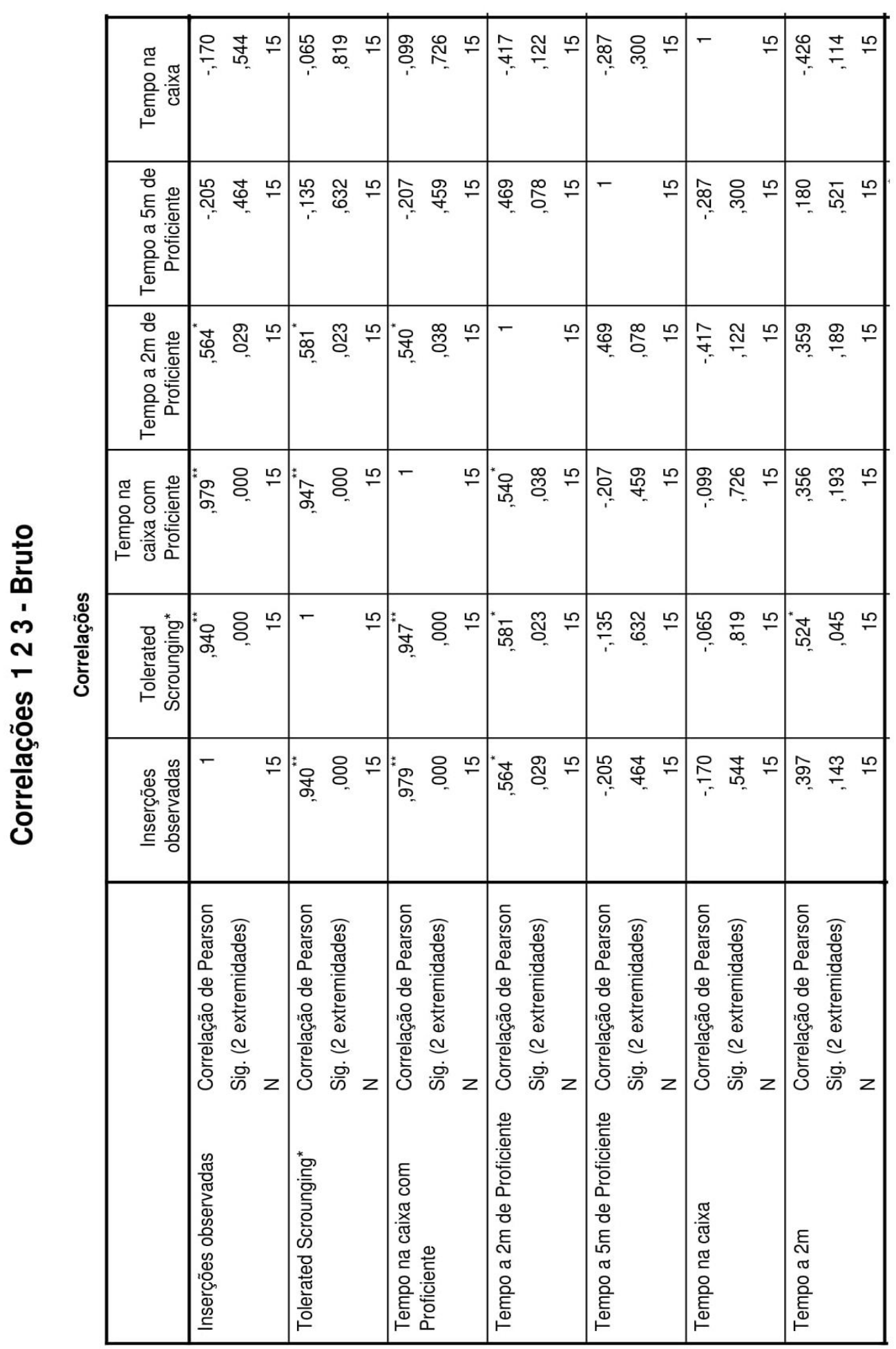




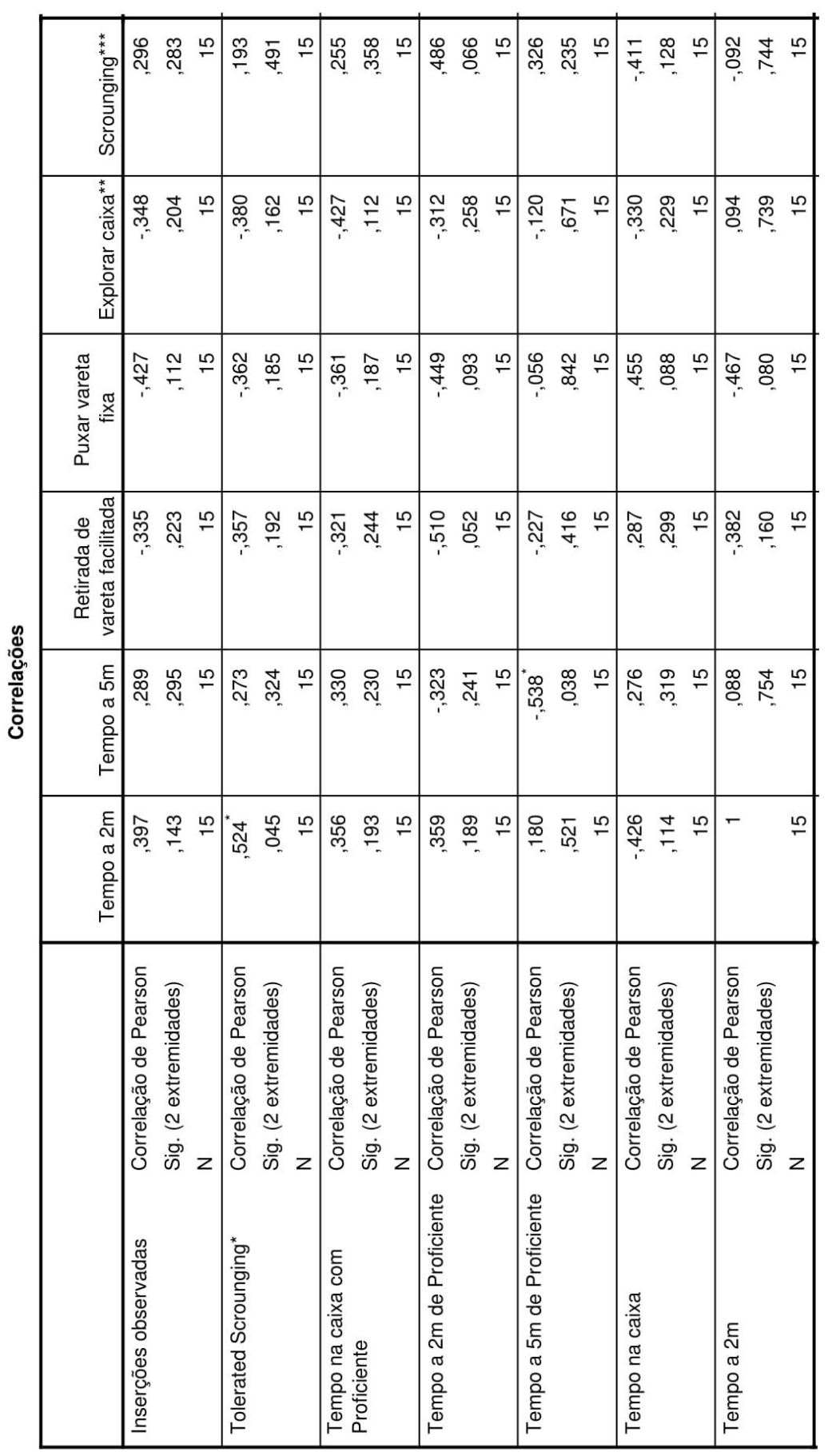

$\frac{0}{8}$ 
๓
্ֻ
0

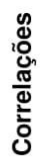

\begin{tabular}{|c|c|c|c|c|c|c|c|}
\hline 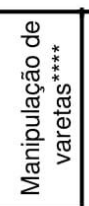 & 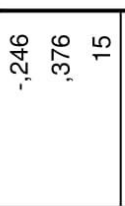 & 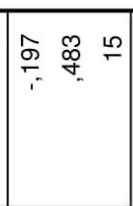 & 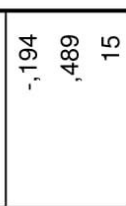 & 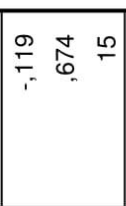 & $\frac{m}{N} \frac{0}{j}$ & 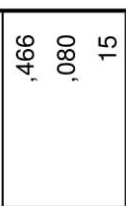 & $\mathbb{\infty}_{0}^{\infty} \stackrel{\circ}{\circ}$ \\
\hline & 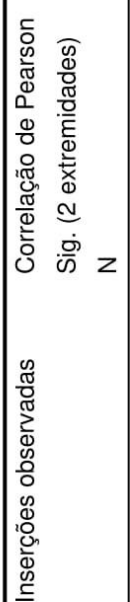 & 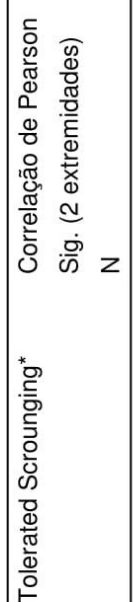 & 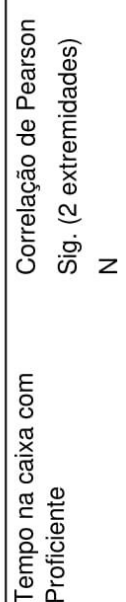 & 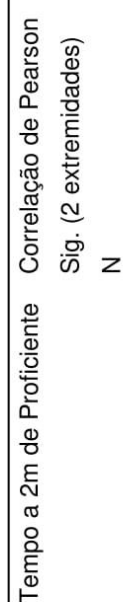 & 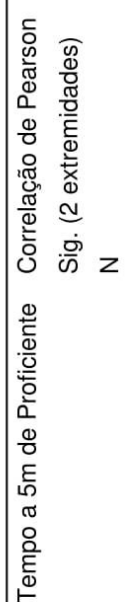 & 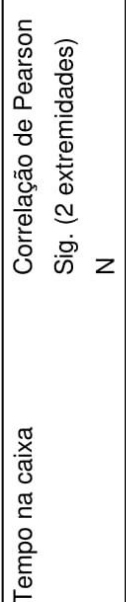 & 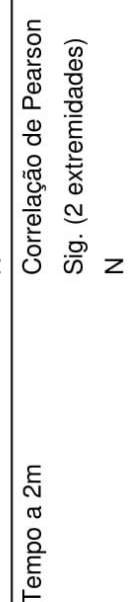 \\
\hline
\end{tabular}




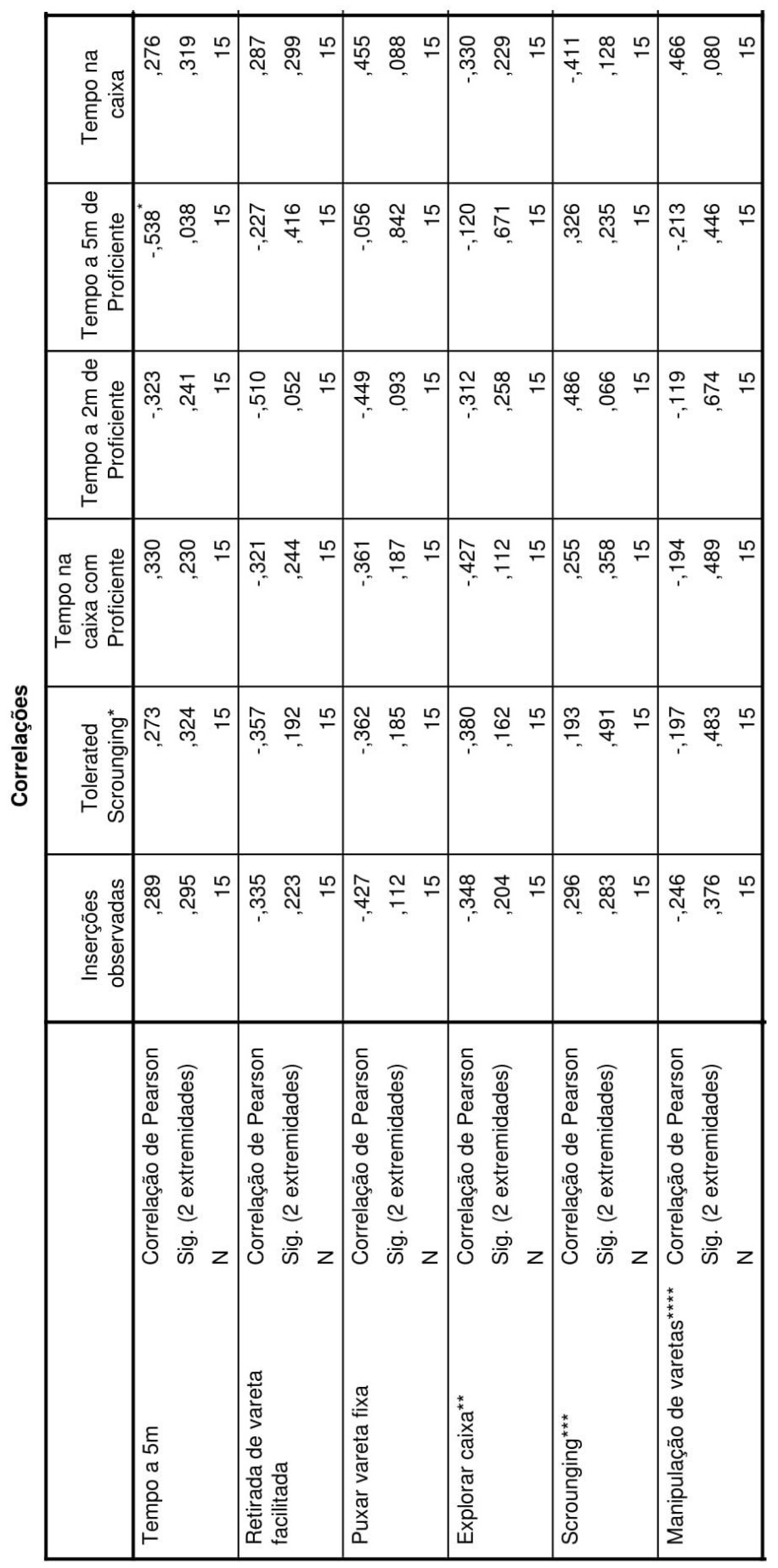




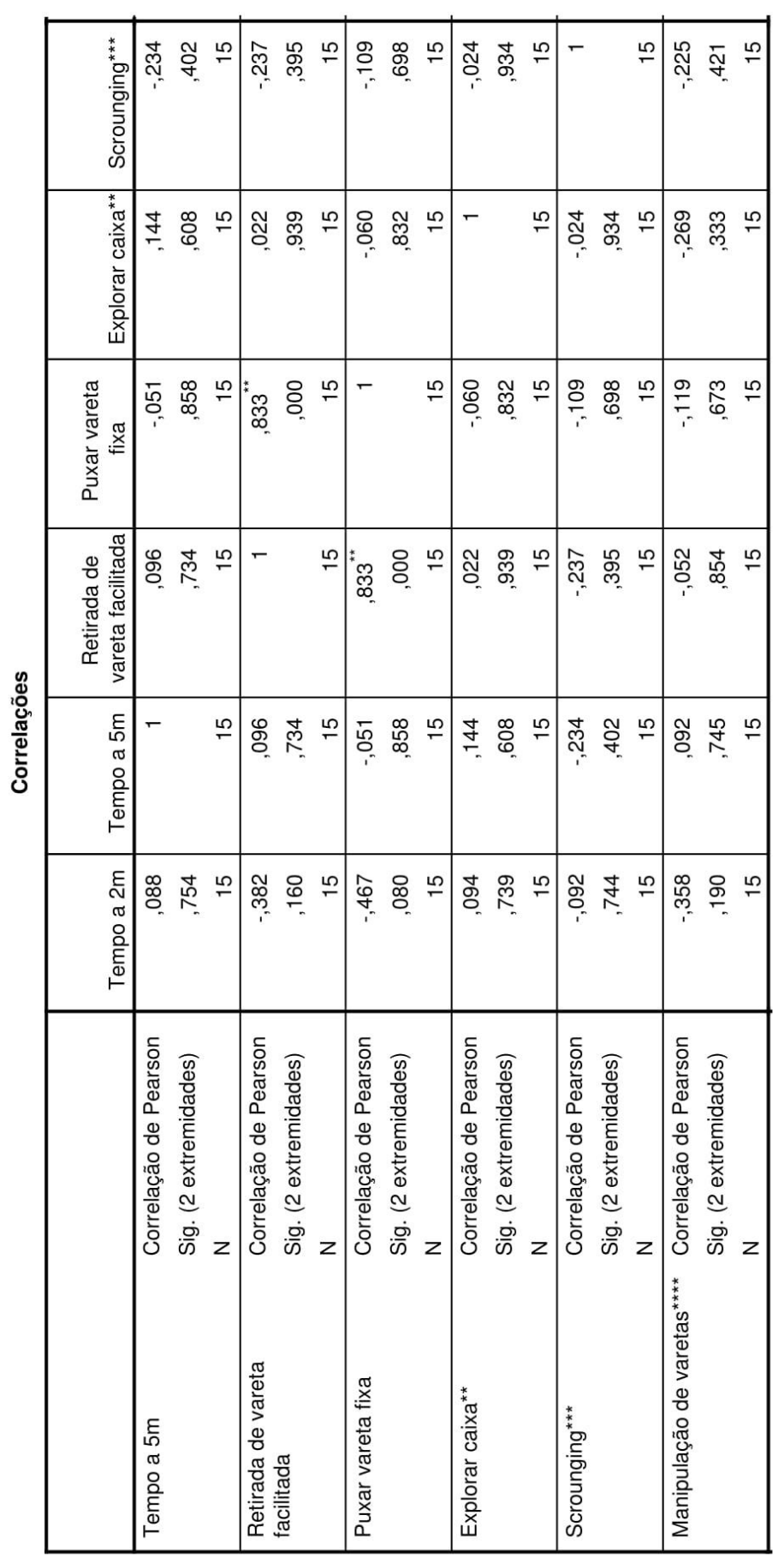

ณ 
0
$\mathbb{8}$
$\mathbb{8}$
0

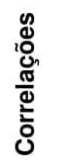

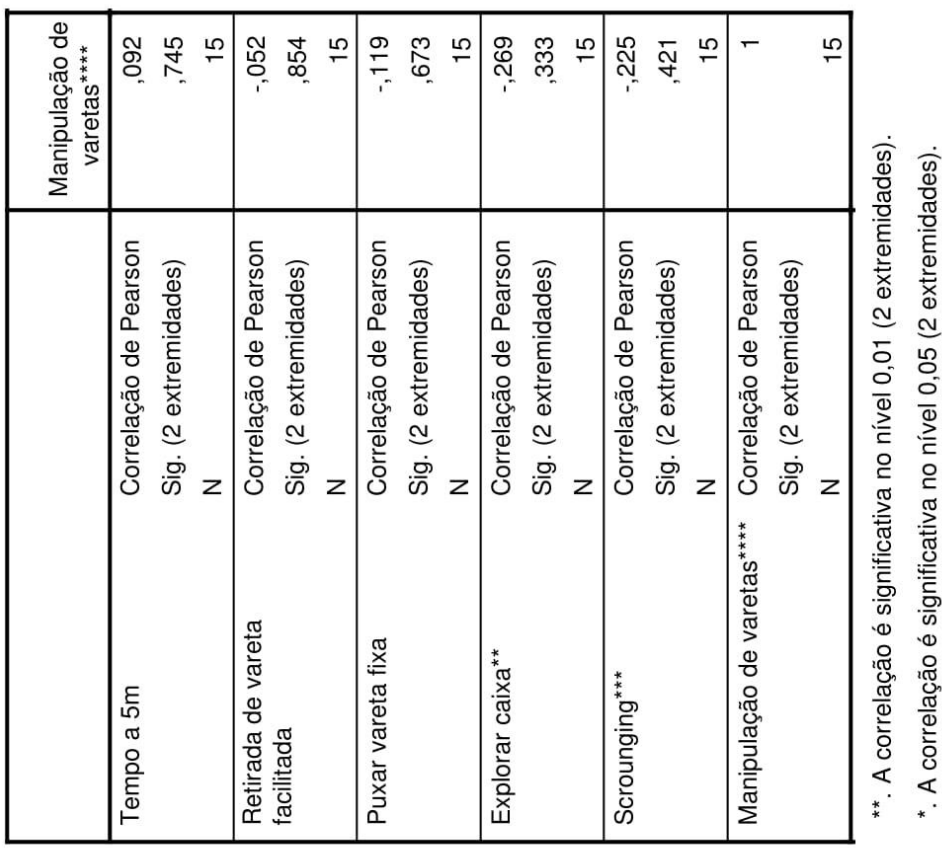

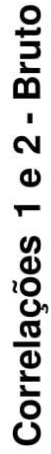




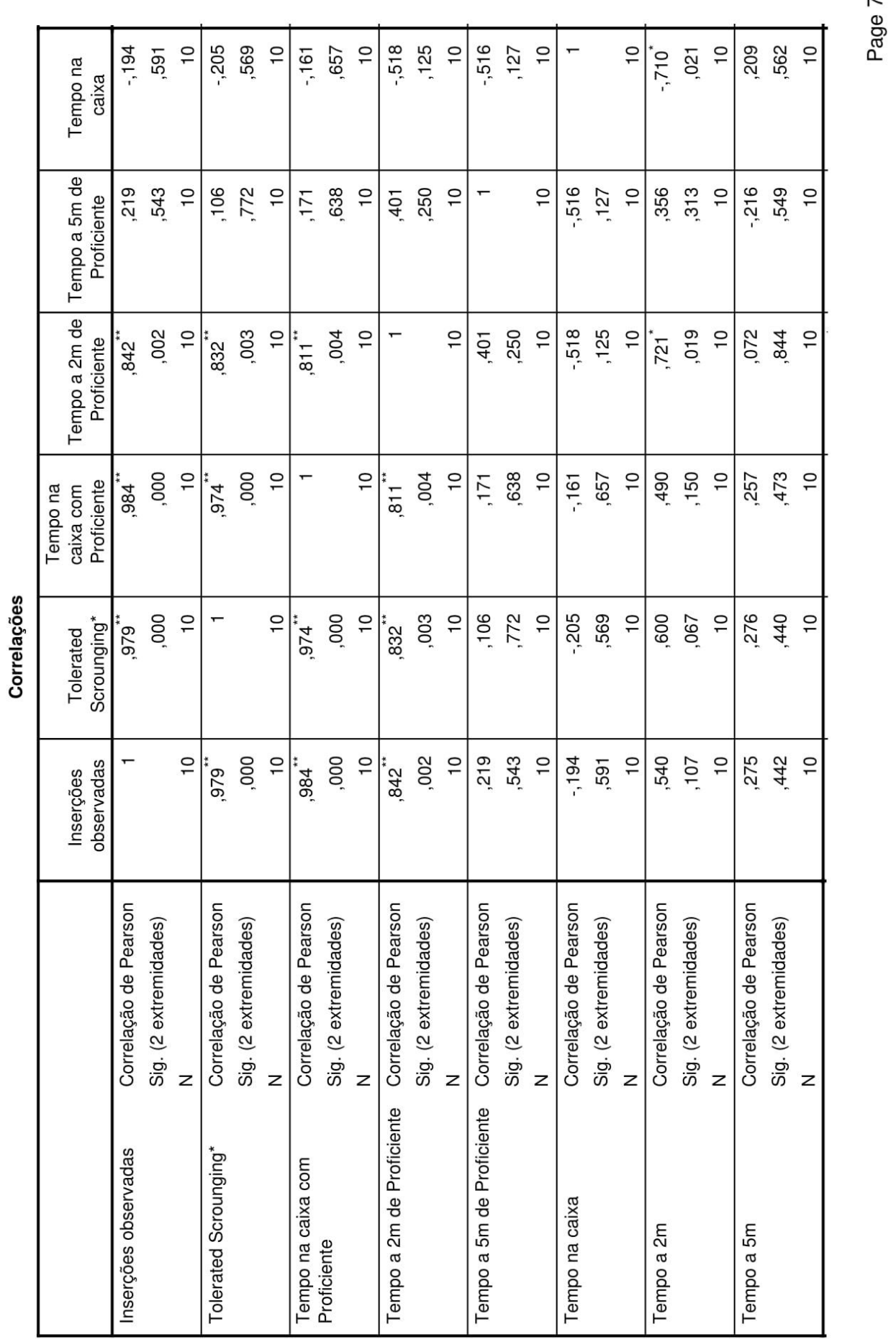




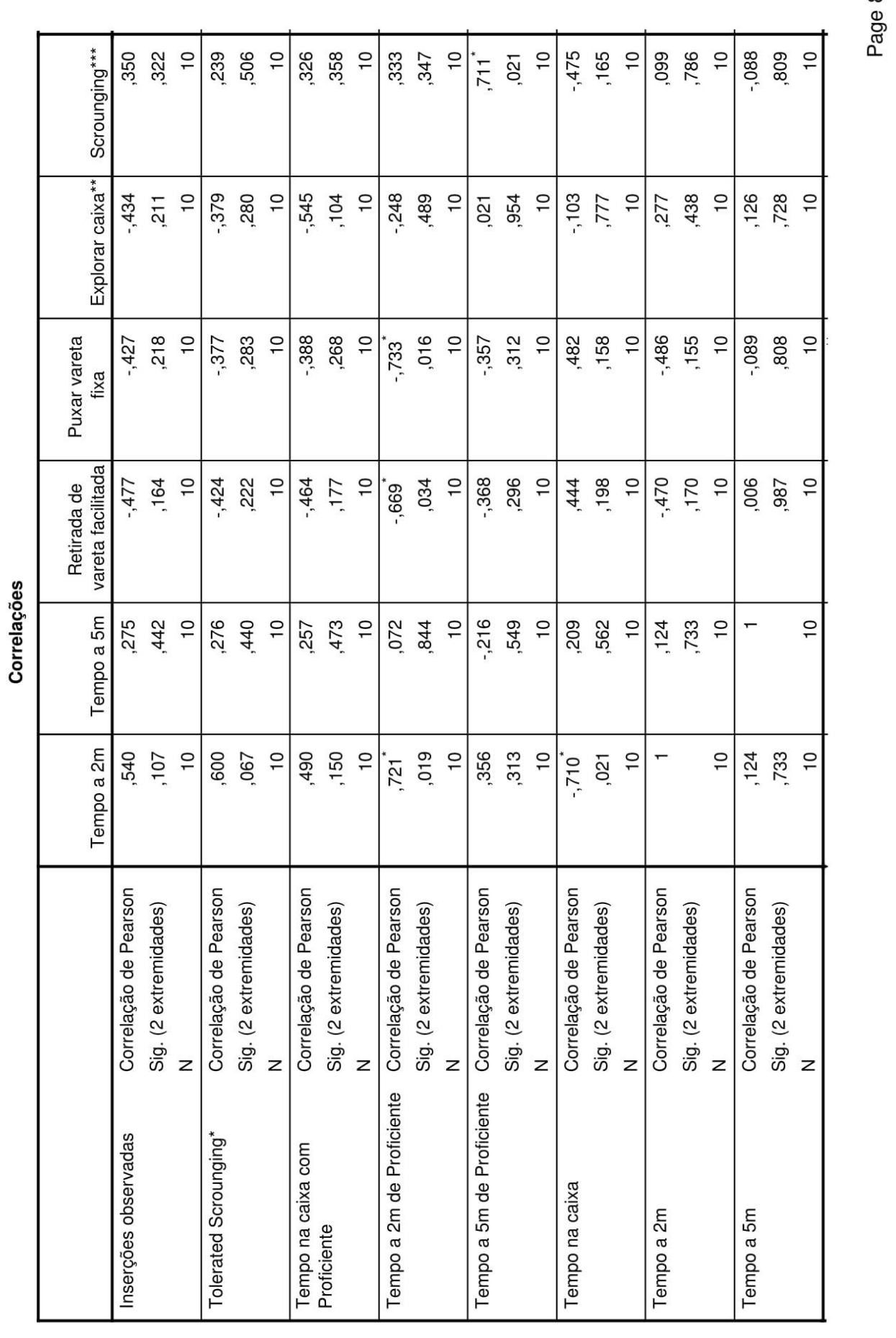




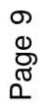

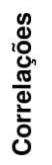

\begin{tabular}{|c|c|c|c|c|c|c|c|c|}
\hline 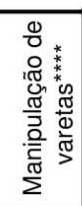 & 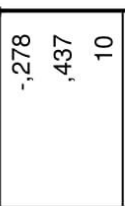 & 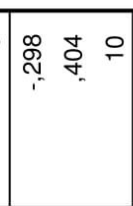 & 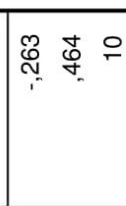 & 岕 & ల్ల్ల & $\infty \frac{\pi}{\sigma}$ & 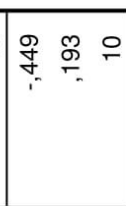 & 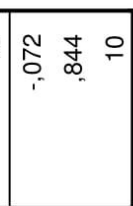 \\
\hline & 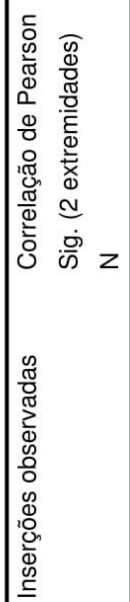 & 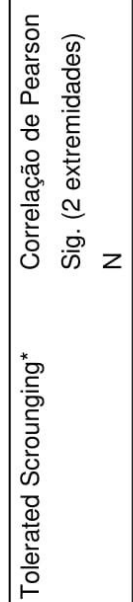 & 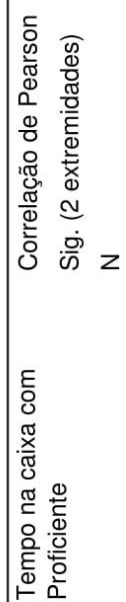 & 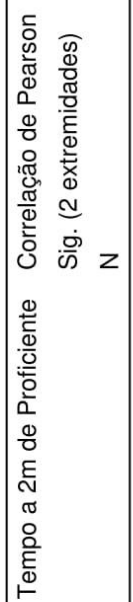 & 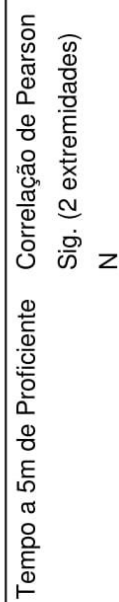 & 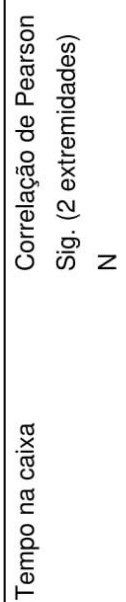 & 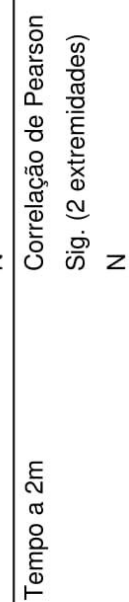 & 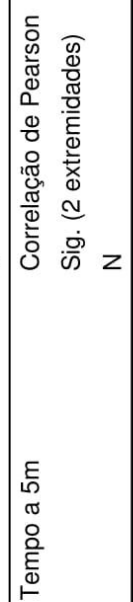 \\
\hline
\end{tabular}




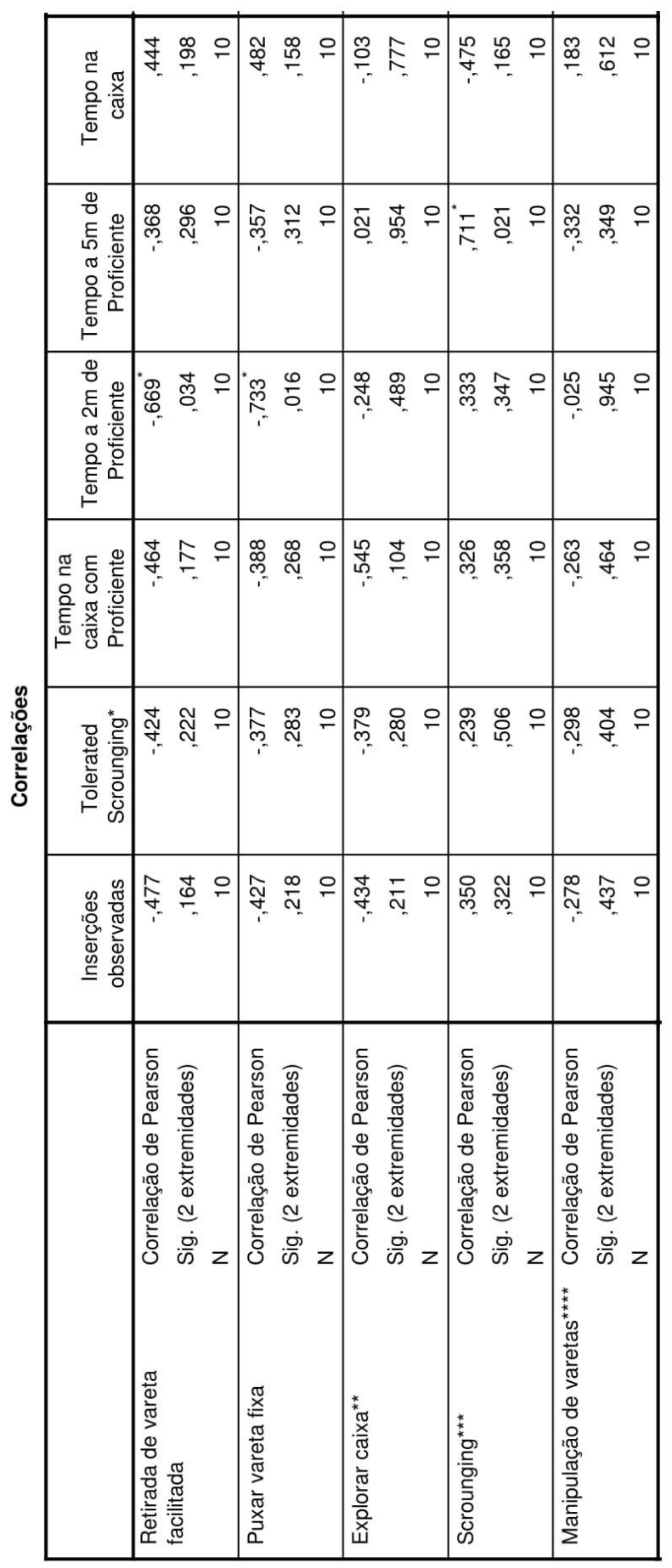

웅 


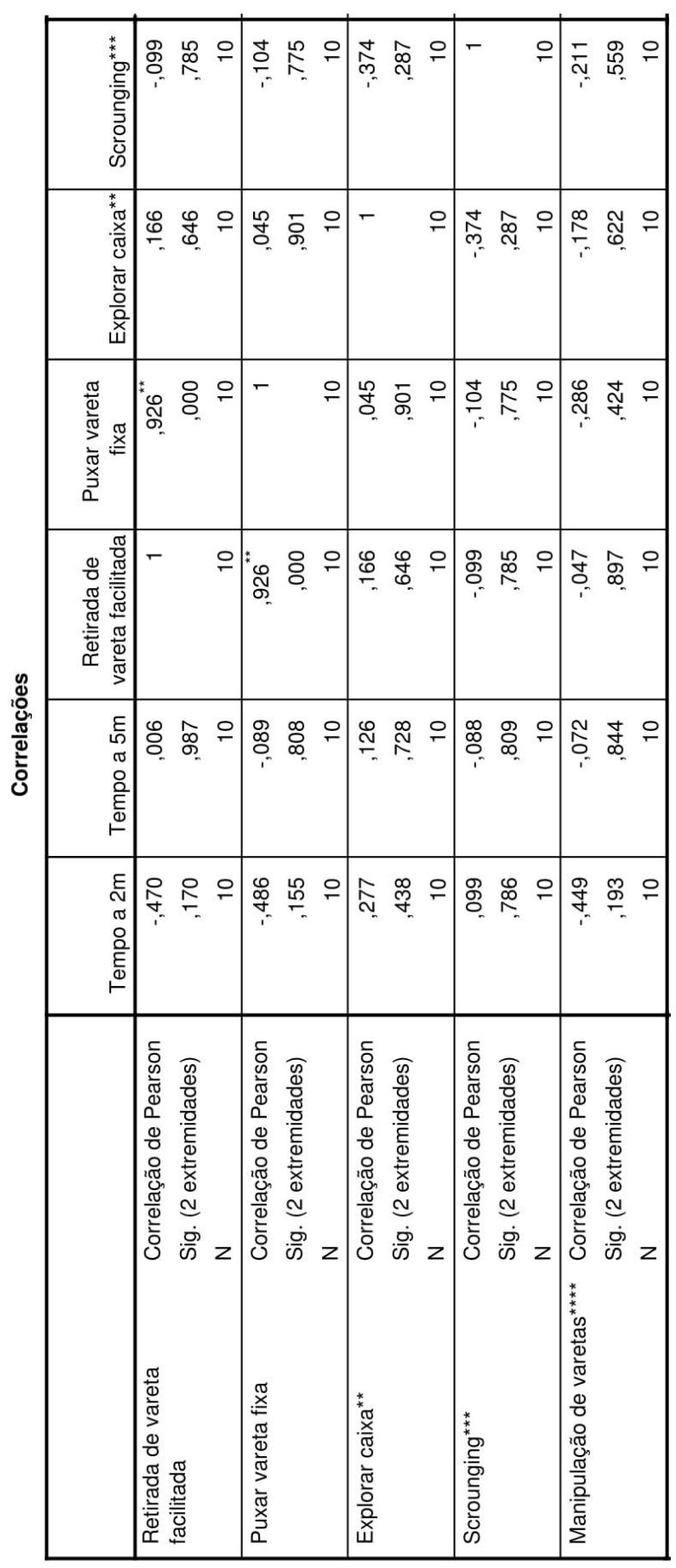

$\overline{7}$
$\mathbb{8}$
$\mathbb{0}$ 


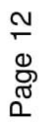

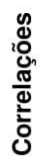

\begin{tabular}{|c|c|c|c|c|c|c|}
\hline 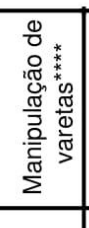 & 安 & 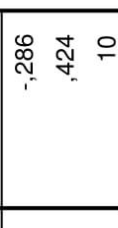 & 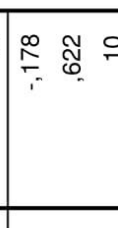 & 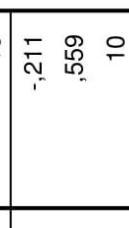 & $\begin{array}{ll}- & ㅇ\end{array}$ & 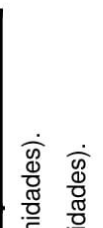 \\
\hline & 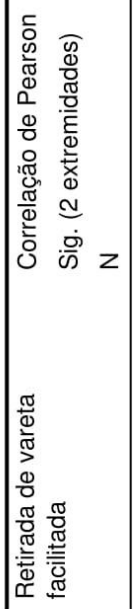 & 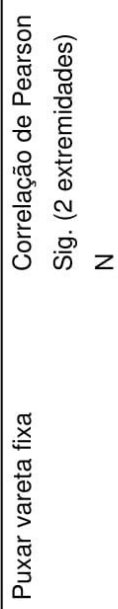 & 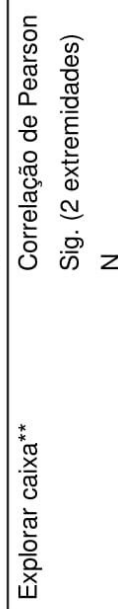 & 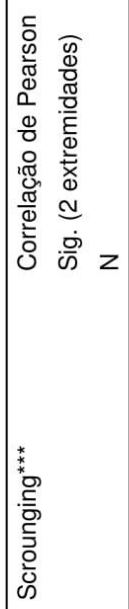 & 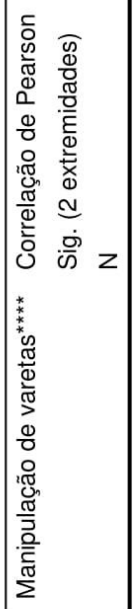 & 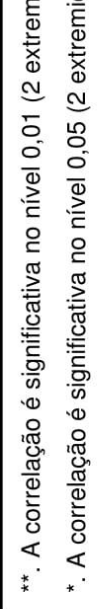 \\
\hline
\end{tabular}




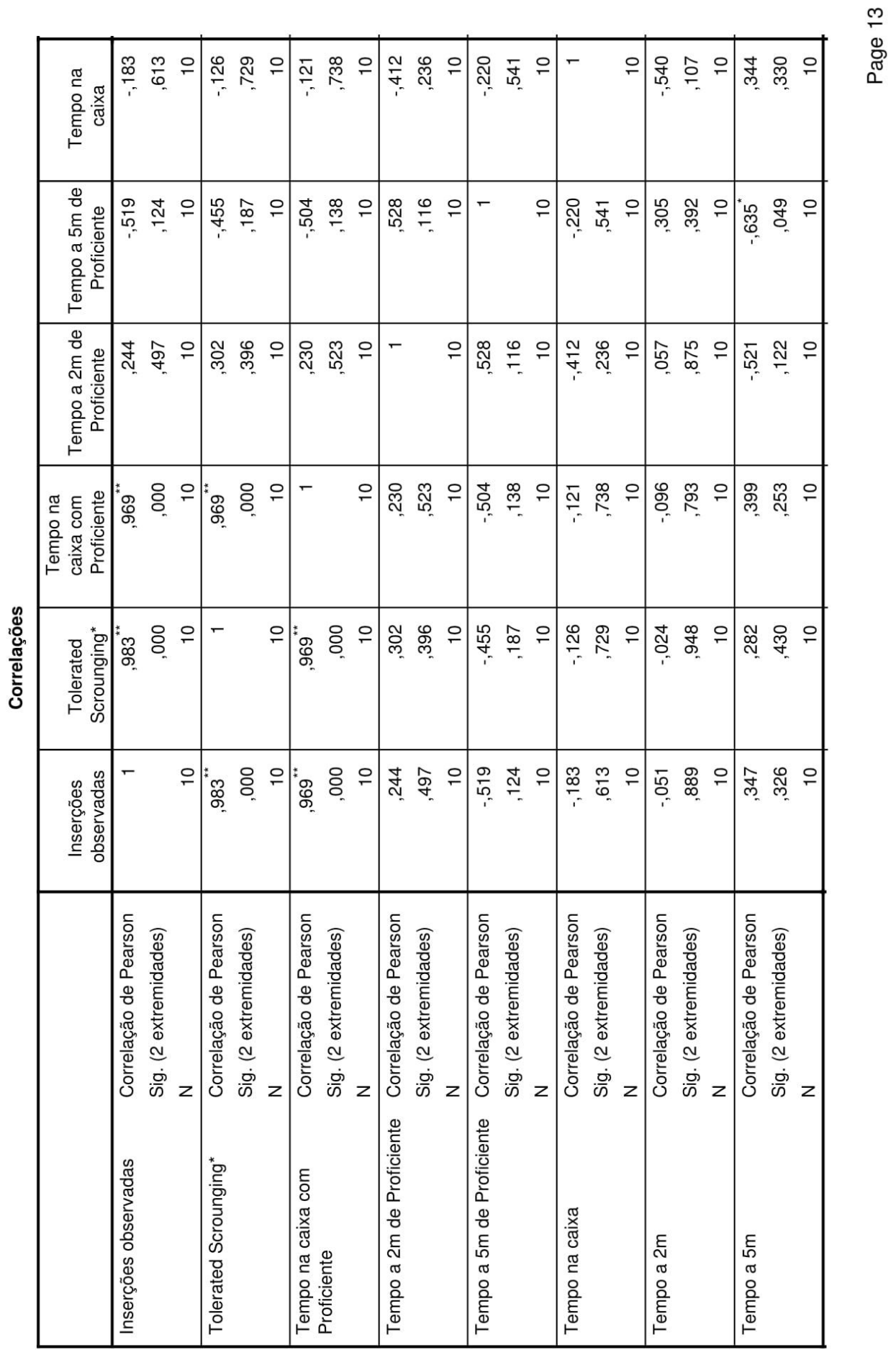




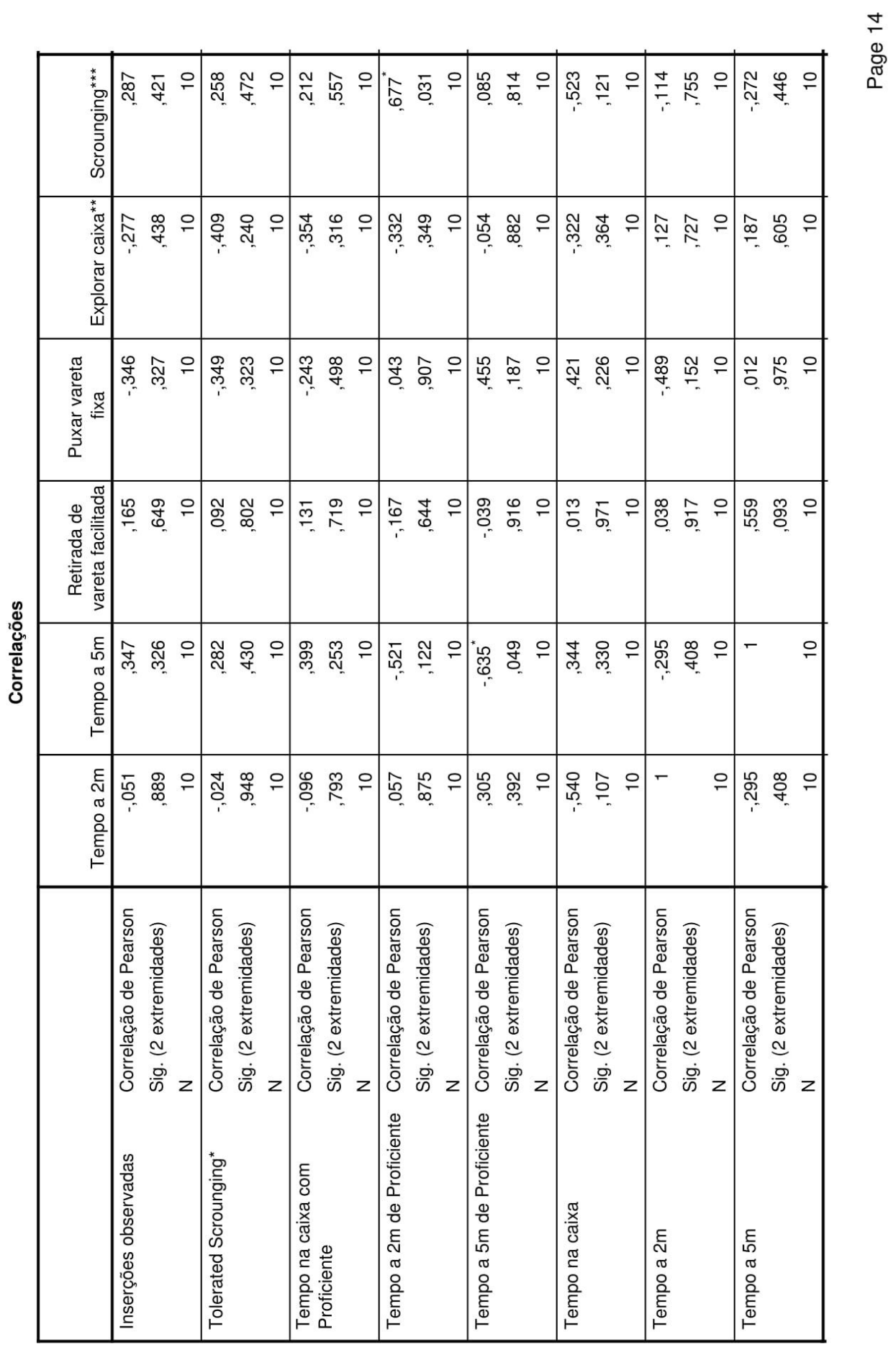


$\frac{10}{8}$
8
0
0

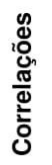

\begin{tabular}{|c|c|c|c|c|c|c|c|c|}
\hline 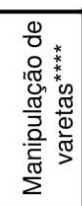 & 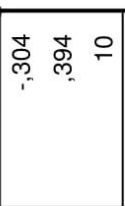 & 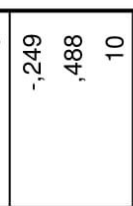 & 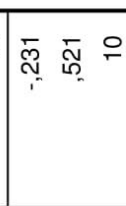 & 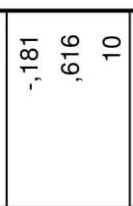 & 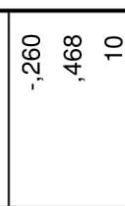 & 員 & 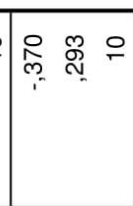 & 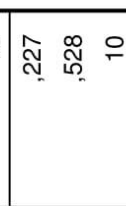 \\
\hline & 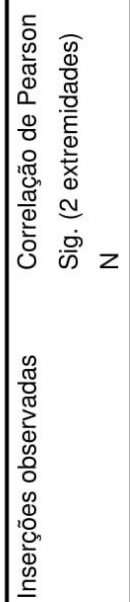 & 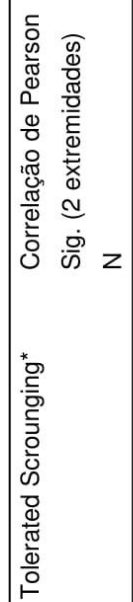 & 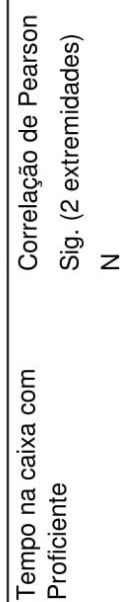 & 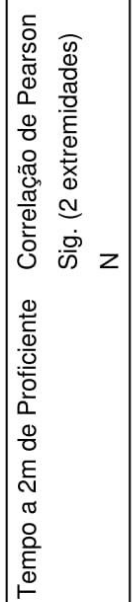 & 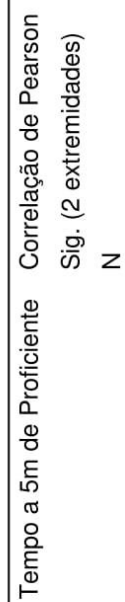 & 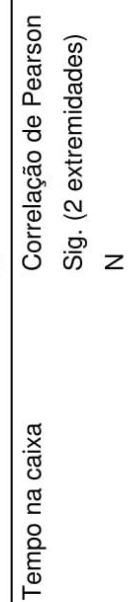 & 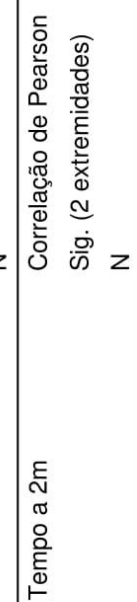 & 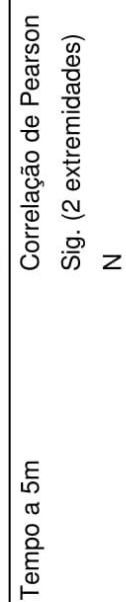 \\
\hline
\end{tabular}




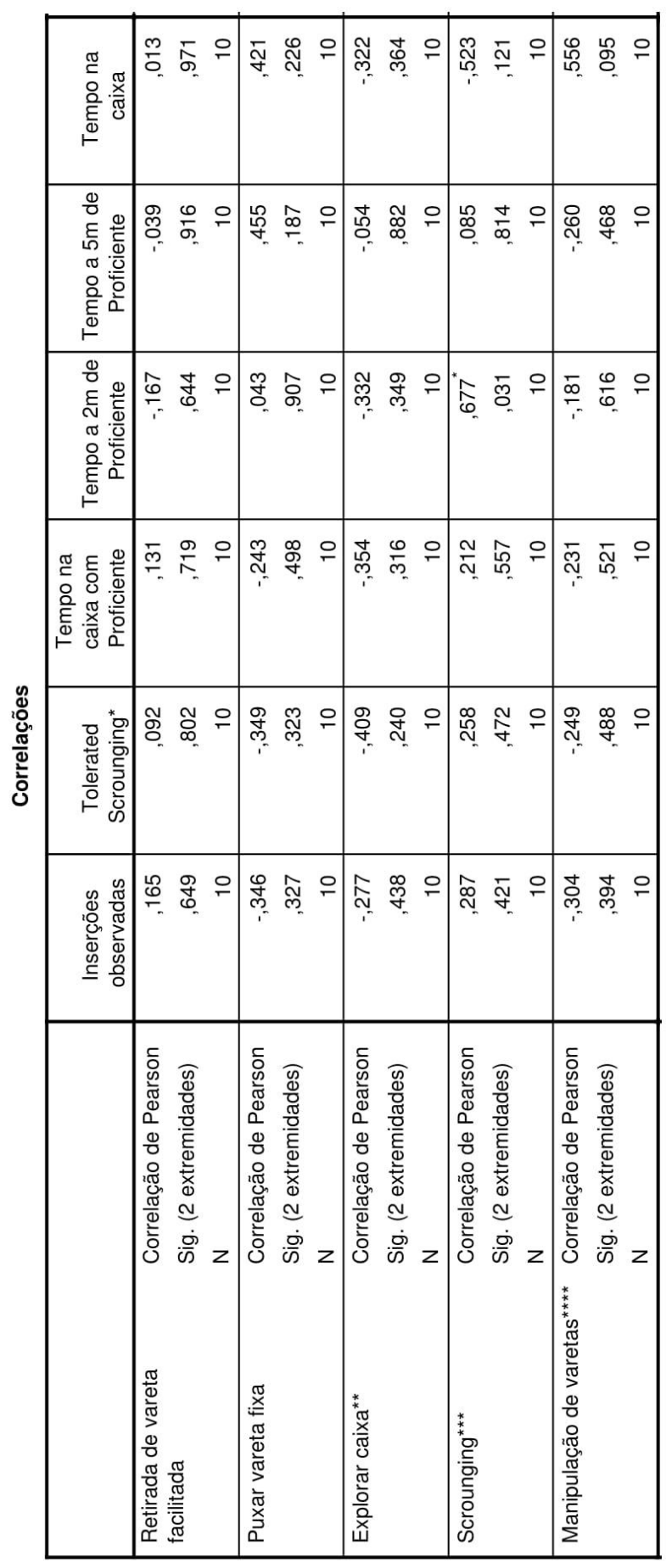

$\frac{0}{8}$ 


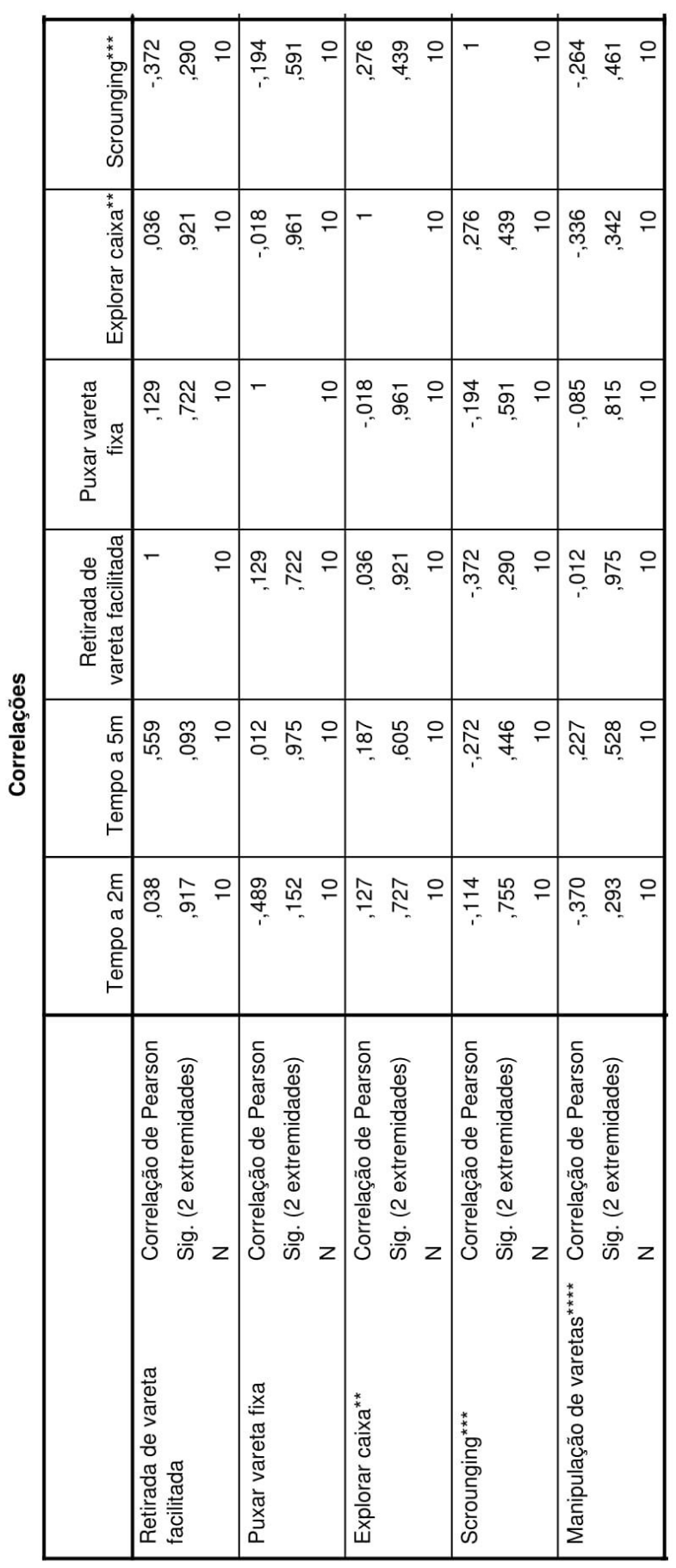

$\frac{1}{8}$ 
$\frac{\infty}{\infty}$

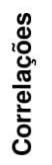

\begin{tabular}{|c|c|c|c|c|c|c|}
\hline 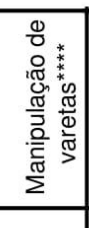 & $\begin{array}{lll}0 & 0 & 0 \\
0 & 0 & 0\end{array}$ & 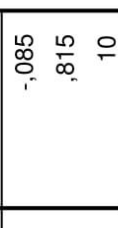 & 总 & 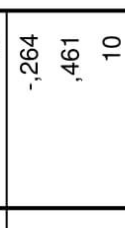 & $\begin{array}{ll}- & ㅇ\end{array}$ & 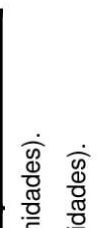 \\
\hline & 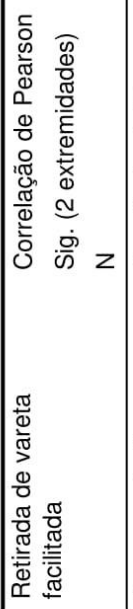 & 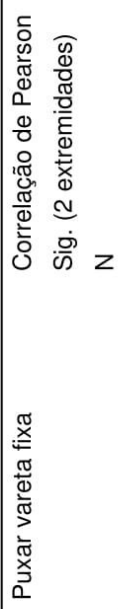 & 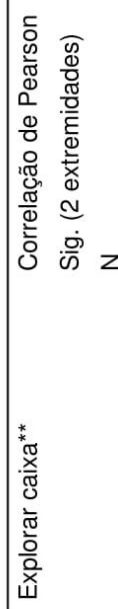 & 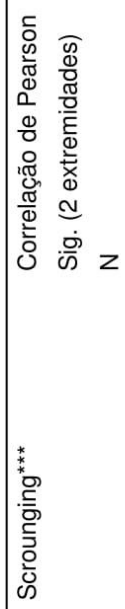 & 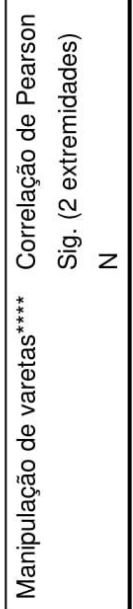 & 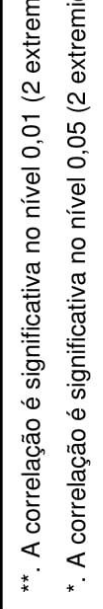 \\
\hline
\end{tabular}




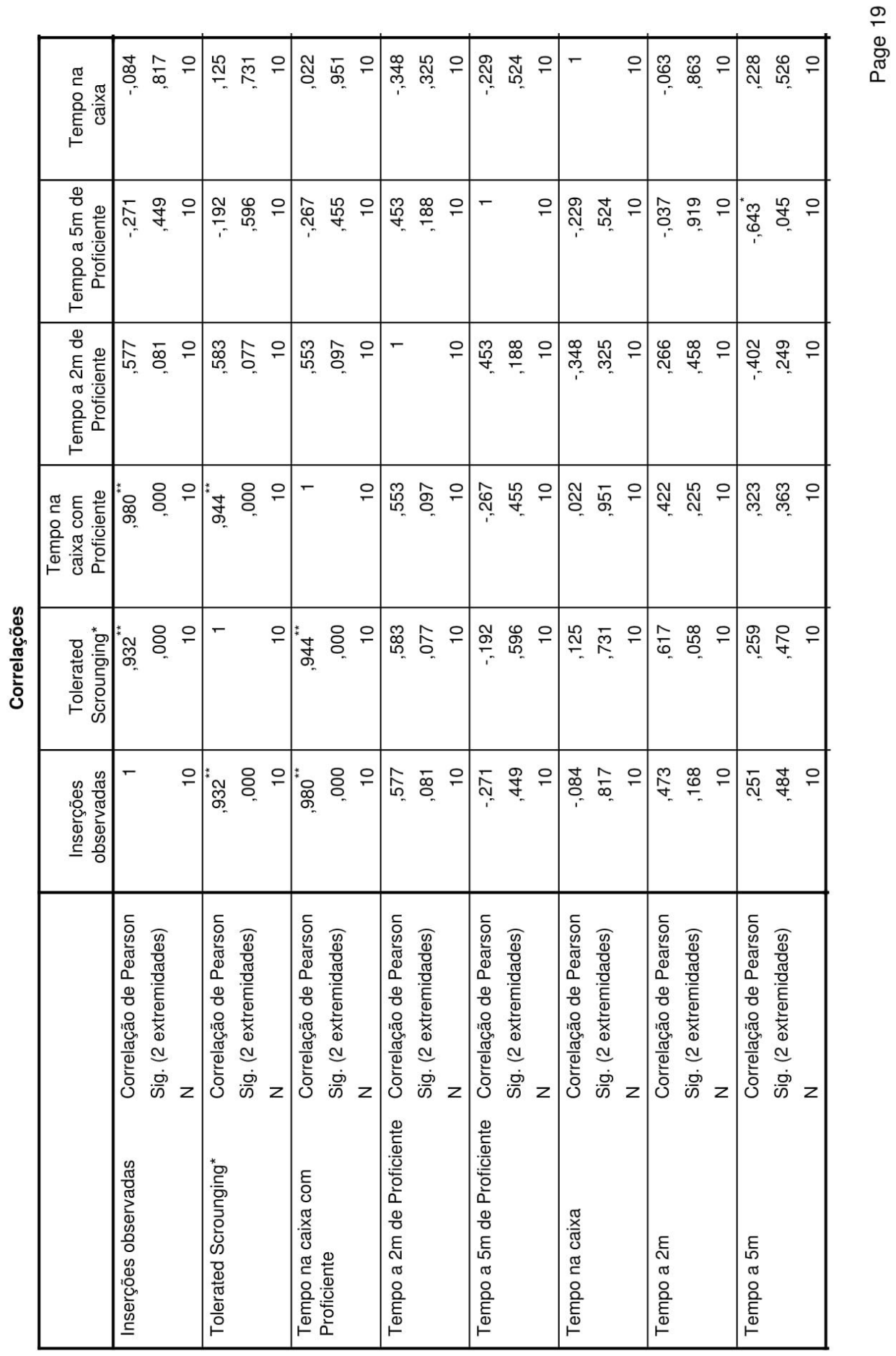




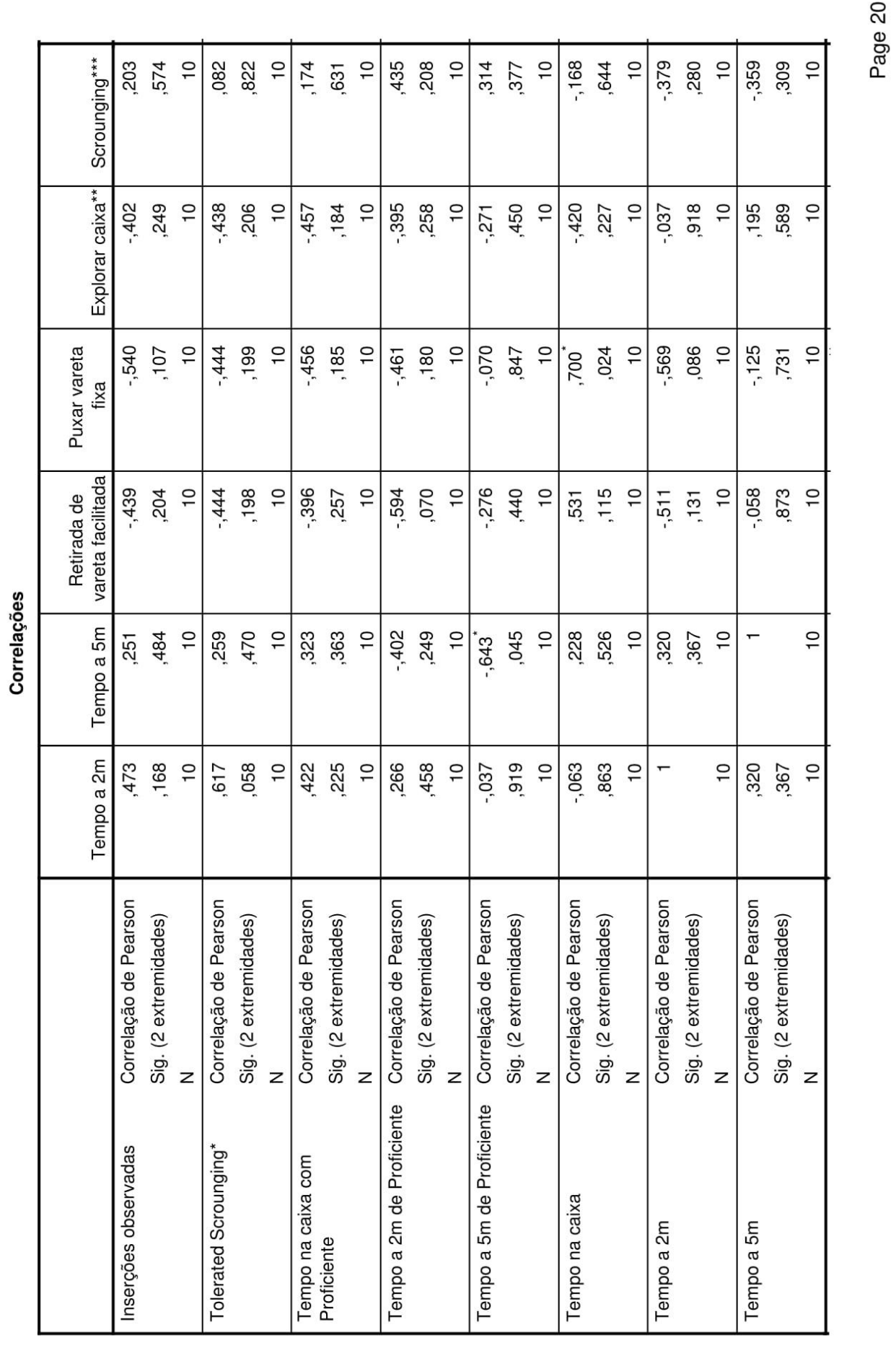


$\bar{N}$
$\stackrel{8}{8}$
0

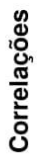

\begin{tabular}{|c|c|c|c|c|c|c|c|c|}
\hline 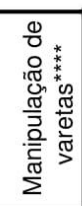 & 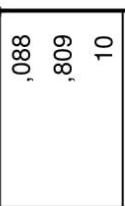 & 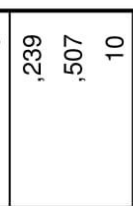 & 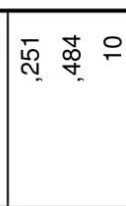 & 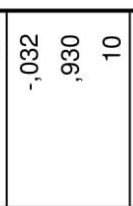 & 只 욤 & $\bar{\delta}$ & 息 & 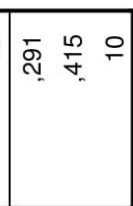 \\
\hline & 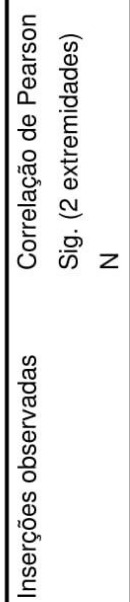 & 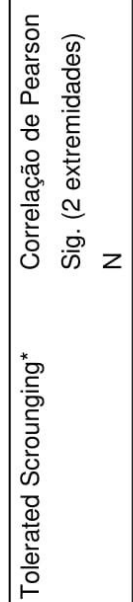 & 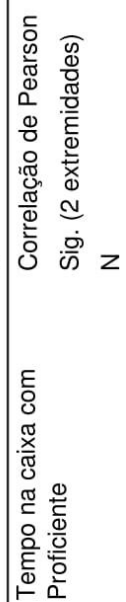 & 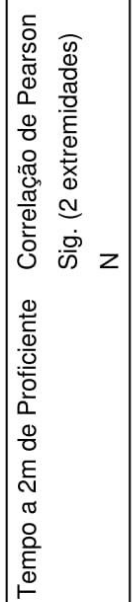 & 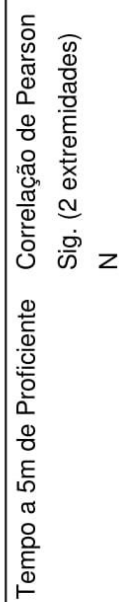 & 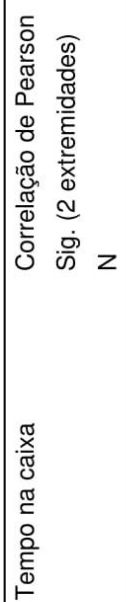 & 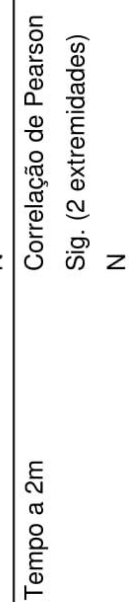 & 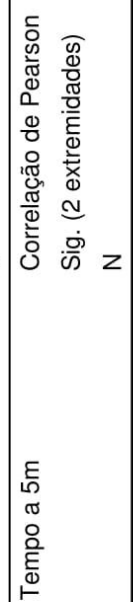 \\
\hline
\end{tabular}




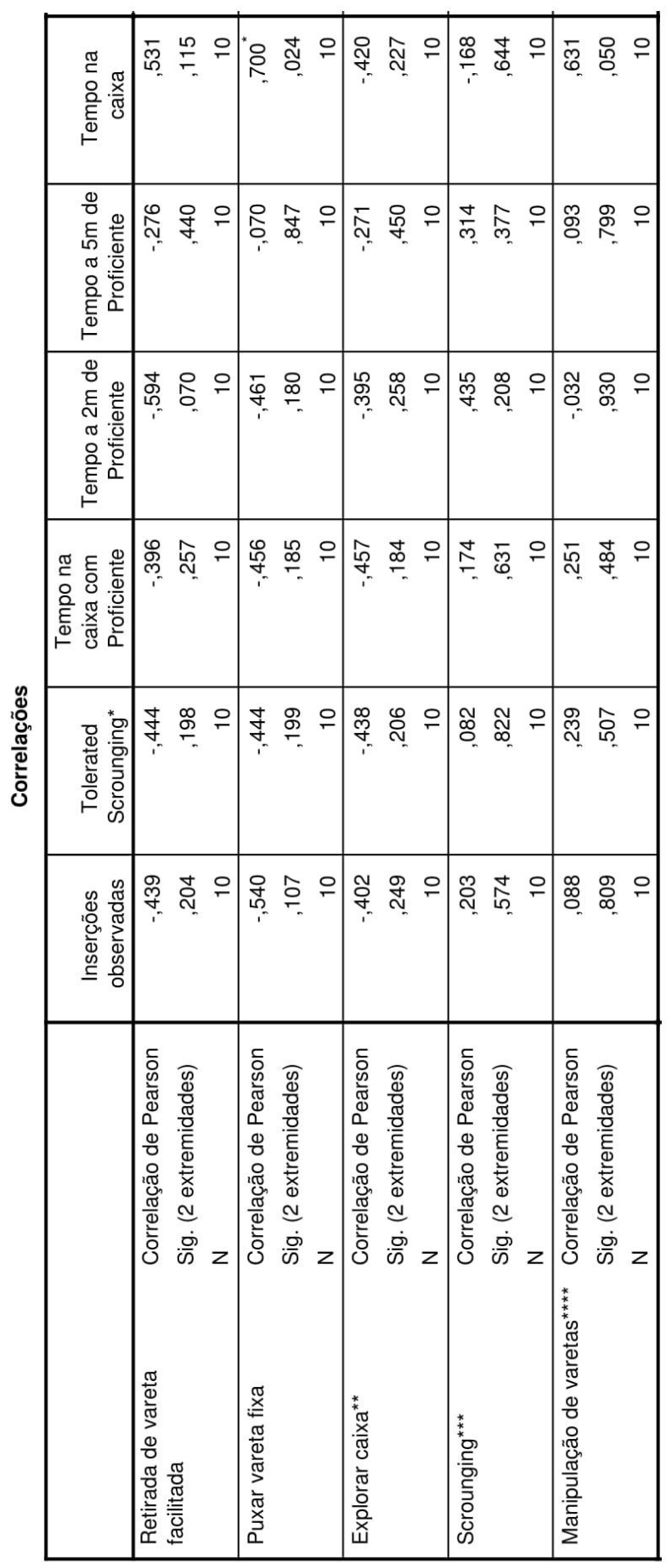

N
$\stackrel{8}{\Xi}$
$\mathbb{0}$ 


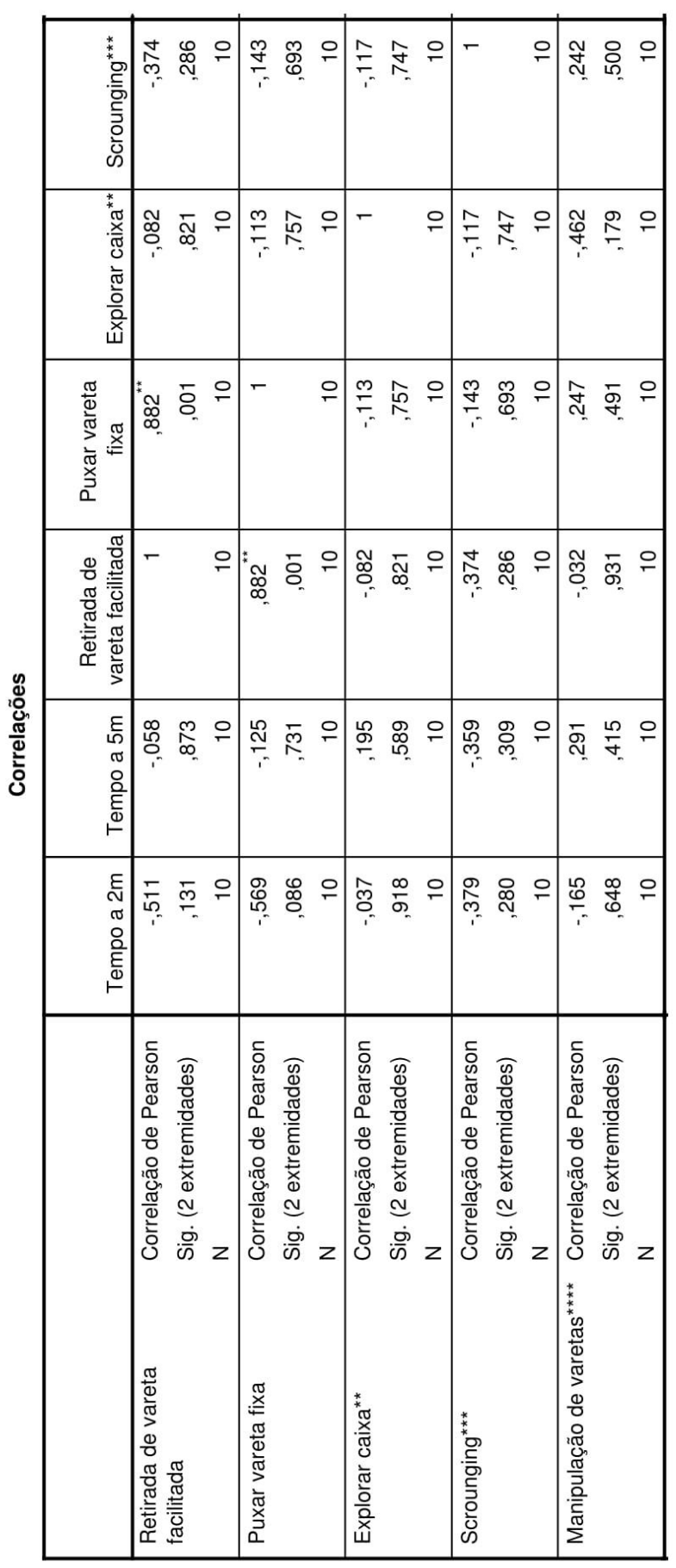

N
$\stackrel{8}{8}$
$\mathbb{0}$ 
$\stackrel{+}{0}$
$\stackrel{\Xi}{\mathbb{O}}$
0

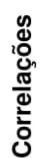

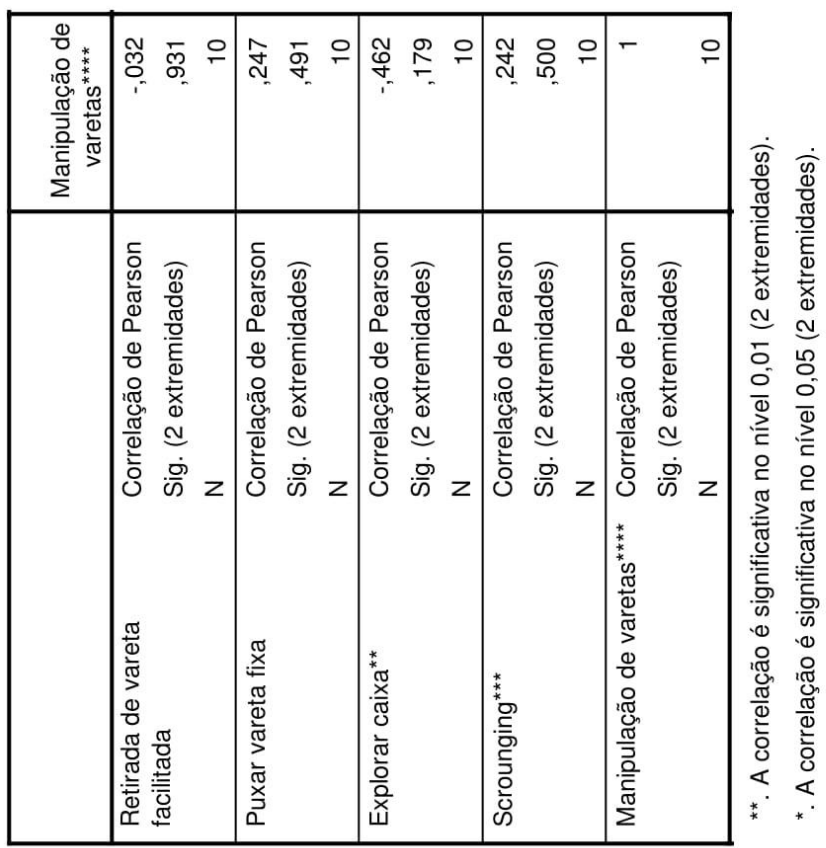




\section{APÊNDICE D - TESTE DE CORRELAÇÃO DE PEARSON (DADOS CORRIGIDOS)}

\section{Correlações - RAZAO 123}

\begin{tabular}{|c|c|c|c|c|}
\hline \multicolumn{5}{|c|}{ Correlações } \\
\hline & & $\begin{array}{l}\text { Inserções } \\
\text { observadas }\end{array}$ & $\begin{array}{l}\text { Tolerated } \\
\text { Scrounging* }\end{array}$ & $\begin{array}{l}\text { Tempo na } \\
\text { caixa com } \\
\text { Proficiente }\end{array}$ \\
\hline \multirow[t]{3}{*}{ Inserções observadas } & Correlação de Pearson & $\overline{1}$ & $916^{*}$ &, $978^{* *}$ \\
\hline & Sig. (2 extremidades) & &, 000 &, 000 \\
\hline & $\mathrm{N}$ & 15 & 15 & 15 \\
\hline \multirow[t]{3}{*}{ Tolerated Scrounging* } & Correlação de Pearson &, 916 ** & 1 &, $926^{\star *}$ \\
\hline & Sig. (2 extremidades) & ,000 & &, 000 \\
\hline & N & 15 & 15 & 15 \\
\hline \multirow{3}{*}{$\begin{array}{l}\text { Tempo na caixa com } \\
\text { Proficiente }\end{array}$} & Correlação de Pearson &, $978 *$ &, $926 *$ & 1 \\
\hline & Sig. (2 extremidades) &, 000 &, 000 & \\
\hline & $\mathrm{N}$ & 15 & 15 & 15 \\
\hline \multirow[t]{3}{*}{ Tempo a $2 m$ de Proficiente } & Correlação de Pearson &, $570^{*}$ &, $579^{*}$ &, $544^{*}$ \\
\hline & Sig. (2 extremidades) & ,026 & ,024 & ,036 \\
\hline & $\mathrm{N}$ & 15 & 15 & 15 \\
\hline \multirow[t]{3}{*}{ Tempo a 5m de Proficiente } & Correlação de Pearson &,- 214 &,- 173 &,- 223 \\
\hline & Sig. (2 extremidades) & ,445 &, 537 & ,425 \\
\hline & $\mathrm{N}$ & 15 & 15 & 15 \\
\hline \multirow[t]{3}{*}{ Tempo na caixa } & Correlação de Pearson &,- 144 &,- 003 &,- 057 \\
\hline & Sig. (2 extremidades) & 608 & ,992 & 840 \\
\hline & N & 15 & 15 & 15 \\
\hline \multirow[t]{3}{*}{ Tempo a $2 \mathrm{~m}$} & Correlação de Pearson & ,381 &, $540^{*}$ & 330 \\
\hline & Sig. (2 extremidades) & ,161 & ,038 & ,230 \\
\hline & N & 15 & 15 & 15 \\
\hline \multirow[t]{3}{*}{ Tempo a $5 \mathrm{~m}$} & Correlação de Pearson & ,267 & ,245 & ,293 \\
\hline & Sig. (2 extremidades) & ,336 & ,379 & ,289 \\
\hline & N & 15 & 15 & 15 \\
\hline \multirow{3}{*}{$\begin{array}{l}\text { Retirada de vareta } \\
\text { facilitada }\end{array}$} & Correlação de Pearson &,- 324 &,- 340 &,- 309 \\
\hline & Sig. (2 extremidades) & ,239 & ,215 & ,263 \\
\hline & N & 15 & 15 & 15 \\
\hline \multirow[t]{3}{*}{ Puxar vareta fixa } & Correlação de Pearson &,- 412 &,- 375 &,- 353 \\
\hline & Sig. (2 extremidades) & 127 & , 168 & , 197 \\
\hline & N & 15 & 15 & 15 \\
\hline \multirow[t]{3}{*}{ Explorar caixa** } & Correlação de Pearson &,- 378 &,- 264 &,- 381 \\
\hline & Sig. (2 extremidades) & , 165 & ,342 & , 162 \\
\hline & $\mathrm{N}$ & 15 & 15 & 15 \\
\hline
\end{tabular}




\begin{tabular}{|c|c|c|c|c|}
\hline \multicolumn{5}{|c|}{ Correlações } \\
\hline & & \begin{tabular}{|c|}
$\begin{array}{c}\text { Tempo a } 2 \mathrm{~m} \text { de } \\
\text { Proficiente }\end{array}$ \\
\end{tabular} & $\begin{array}{c}\text { Tempo a } 5 \mathrm{~m} \text { de } \\
\text { Proficiente }\end{array}$ & $\begin{array}{c}\text { Tempo na } \\
\text { caixa }\end{array}$ \\
\hline \multirow[t]{3}{*}{ Inserções observadas } & Correlação de Pearson &, $570^{*}$ &,- 214 &,- 144 \\
\hline & Sig. (2 extremidades) & 026 & ,445 & ,608 \\
\hline & $\mathrm{N}$ & 15 & 15 & 15 \\
\hline \multirow[t]{3}{*}{ Tolerated Scrounging ${ }^{\star}$} & Correlação de Pearson &, $579^{*}$ &,- 173 &,- 003 \\
\hline & Sig. (2 extremidades) & ,024 &, 537 & ,992 \\
\hline & $\mathrm{N}$ & 15 & 15 & 15 \\
\hline \multirow{3}{*}{$\begin{array}{l}\text { Tempo na caixa com } \\
\text { Proficiente }\end{array}$} & Correlação de Pearson &, $544^{\star}$ &,- 223 &,- 057 \\
\hline & Sig. (2 extremidades) & ,036 & ,425 & ,840 \\
\hline & $\mathrm{N}$ & 15 & 15 & 15 \\
\hline \multirow[t]{3}{*}{ Tempo a $2 \mathrm{~m}$ de Proficiente } & Correlação de Pearson & 1 & ,444 &,- 355 \\
\hline & Sig. (2 extremidades) & & 098 & , 194 \\
\hline & $\mathrm{N}$ & 15 & 15 & 15 \\
\hline \multirow[t]{3}{*}{ Tempo a 5m de Proficiente } & Correlação de Pearson & ,444 & 1 &,- 270 \\
\hline & Sig. (2 extremidades) & ,098 & &, 330 \\
\hline & $\mathrm{N}$ & 15 & 15 & 15 \\
\hline \multirow[t]{3}{*}{ Tempo na caixa } & Correlação de Pearson &,- 355 &,- 270 & 1 \\
\hline & Sig. (2 extremidades) & , 194 & ,330 & \\
\hline & $\mathrm{N}$ & 15 & 15 & 15 \\
\hline \multirow[t]{3}{*}{ Tempo a $2 \mathrm{~m}$} & Correlação de Pearson & ,304 & , 135 &,- 315 \\
\hline & Sig. (2 extremidades) & ,271 & ,631 & ,253 \\
\hline & $\mathrm{N}$ & 15 & 15 & 15 \\
\hline \multirow[t]{3}{*}{ Tempo a $5 \mathrm{~m}$} & Correlação de Pearson &,- 373 &,$- 565^{*}$ & ,297 \\
\hline & Sig. (2 extremidades) & , 170 & ,028 & ,282 \\
\hline & $\mathrm{N}$ & 15 & 15 & 15 \\
\hline \multirow{3}{*}{$\begin{array}{l}\text { Retirada de vareta } \\
\text { facilitada }\end{array}$} & Correlação de Pearson &,- 480 &,- 213 & ,294 \\
\hline & Sig. (2 extremidades) & ,070 & ,446 & ,287 \\
\hline & $\mathrm{N}$ & 15 & 15 & 15 \\
\hline \multirow[t]{3}{*}{ Puxar vareta fixa } & Correlação de Pearson &,- 452 &,- 031 & ,432 \\
\hline & Sig. (2 extremidades) & ,091 & ,912 & , 108 \\
\hline & $\mathrm{N}$ & 15 & 15 & 15 \\
\hline \multirow[t]{3}{*}{ Explorar caixa ${ }^{\star \star}$} & Correlação de Pearson & , 040 & 018 &,- 246 \\
\hline & Sig. (2 extremidades) & ,888 & ,949 & ,376 \\
\hline & $\mathrm{N}$ & 15 & 15 & 15 \\
\hline
\end{tabular}

Page 2 


\begin{tabular}{|c|c|c|c|c|}
\hline \multicolumn{5}{|c|}{ Correlações } \\
\hline & & Tempo a $2 \mathrm{~m}$ & Tempo a $5 \mathrm{~m}$ & $\begin{array}{c}\text { Retirada de } \\
\text { vareta facilitada } \\
\end{array}$ \\
\hline \multirow[t]{3}{*}{ Inserções observadas } & Correlação de Pearson & ,381 & ,267 &,- 324 \\
\hline & Sig. (2 extremidades) & ,161 & ,336 & ,239 \\
\hline & $\mathrm{N}$ & 15 & 15 & 15 \\
\hline \multirow[t]{3}{*}{ Tolerated Scrounging* } & Correlação de Pearson &, $540^{*}$ & ,245 &,- 340 \\
\hline & Sig. (2 extremidades) &, 038 & ,379 & ,215 \\
\hline & $\mathrm{N}$ & 15 & 15 & 15 \\
\hline \multirow{3}{*}{$\begin{array}{l}\text { Tempo na caixa com } \\
\text { Proficiente }\end{array}$} & Correlação de Pearson & ,330 & ,293 &,- 309 \\
\hline & Sig. (2 extremidades) & ,230 & ,289 & ,263 \\
\hline & $\mathrm{N}$ & 15 & 15 & 15 \\
\hline \multirow[t]{3}{*}{ Tempo a $2 \mathrm{~m}$ de Proficiente } & Correlação de Pearson & ,304 &,- 373 &,- 480 \\
\hline & Sig. (2 extremidades) & ,271 & 170 & ,070 \\
\hline & $\mathrm{N}$ & 15 & 15 & 15 \\
\hline \multirow[t]{3}{*}{ Tempo a 5m de Proficiente } & Correlação de Pearson & ,135 &,$- 565^{*}$ &,- 213 \\
\hline & Sig. (2 extremidades) &, 631 &, 028 & ,446 \\
\hline & $\mathrm{N}$ & 15 & 15 & 15 \\
\hline \multirow[t]{3}{*}{ Tempo na caixa } & Correlação de Pearson &,- 315 & ,297 & ,294 \\
\hline & Sig. (2 extremidades) & ,253 & ,282 & ,287 \\
\hline & $\mathrm{N}$ & 15 & 15 & 15 \\
\hline \multirow[t]{3}{*}{ Tempo a $2 \mathrm{~m}$} & Correlação de Pearson & 1 & ,069 &,- 392 \\
\hline & Sig. (2 extremidades) & & ,806 & , 148 \\
\hline & $\mathrm{N}$ & 15 & 15 & 15 \\
\hline \multirow[t]{3}{*}{ Tempo a $5 \mathrm{~m}$} & Correlação de Pearson &, 069 & 1 &,- 018 \\
\hline & Sig. (2 extremidades) & ,806 & & ,948 \\
\hline & $\mathrm{N}$ & 15 & 15 & 15 \\
\hline \multirow{3}{*}{$\begin{array}{l}\text { Retirada de vareta } \\
\text { facilitada }\end{array}$} & Correlação de Pearson &,- 392 &,- 018 & 1 \\
\hline & Sig. (2 extremidades) & ,148 & ,948 & \\
\hline & $\mathrm{N}$ & 15 & 15 & 15 \\
\hline \multirow[t]{3}{*}{ Puxar vareta fixa } & Correlação de Pearson &,- 499 & ,044 &, $704^{* *}$ \\
\hline & Sig. (2 extremidades) & ,059 & ,876 & ,003 \\
\hline & $\mathrm{N}$ & 15 & 15 & 15 \\
\hline \multirow[t]{3}{*}{ Explorar caixa** } & Correlação de Pearson & ,144 &,- 069 & ,002 \\
\hline & Sig. (2 extremidades) & 609 & ,808 & ,994 \\
\hline & $\mathrm{N}$ & 15 & 15 & 15 \\
\hline
\end{tabular}

Page 3 


\begin{tabular}{|c|c|c|c|c|}
\hline \multicolumn{5}{|c|}{ Correlações } \\
\hline & & $\begin{array}{c}\text { Puxar vareta } \\
\text { fixa }\end{array}$ & 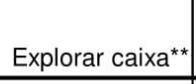 & Scrounging $^{\star \star \star}$ \\
\hline \multirow[t]{3}{*}{ Inserções observadas } & Correlação de Pearson &,- 412 &,- 378 & ,408 \\
\hline & Sig. (2 extremidades) & , 127 & ,165 &, 131 \\
\hline & $\mathrm{N}$ & 15 & 15 & 15 \\
\hline \multirow[t]{3}{*}{ Tolerated Scrounging* } & Correlação de Pearson &,- 375 &,- 264 & ,220 \\
\hline & Sig. (2 extremidades) & , 168 & ,342 & , 430 \\
\hline & $\mathrm{N}$ & 15 & 15 & 15 \\
\hline \multirow{3}{*}{$\begin{array}{l}\text { Tempo na caixa com } \\
\text { Proficiente }\end{array}$} & Correlação de Pearson &,- 353 &,- 381 &, 327 \\
\hline & Sig. (2 extremidades) & , 197 & ,162 & ,234 \\
\hline & $\mathrm{N}$ & 15 & 15 & 15 \\
\hline \multirow[t]{3}{*}{ Tempo a $2 \mathrm{~m}$ de Proficiente } & Correlação de Pearson &,- 452 & 040 &, $616^{*}$ \\
\hline & Sig. (2 extremidades) & 091 & 888 &, 014 \\
\hline & $\mathrm{N}$ & 15 & 15 & 15 \\
\hline \multirow[t]{3}{*}{ Tempo a 5m de Proficiente } & Correlação de Pearson &,- 031 & 018 &, 342 \\
\hline & Sig. (2 extremidades) & ,912 & ,949 & ,213 \\
\hline & $\mathrm{N}$ & 15 & 15 & 15 \\
\hline \multirow[t]{3}{*}{ Tempo na caixa } & Correlação de Pearson & ,432 &,- 246 &,$- 517^{*}$ \\
\hline & Sig. (2 extremidades) & , 108 & ,376 & ,049 \\
\hline & $\mathrm{N}$ & 15 & 15 & 15 \\
\hline \multirow[t]{3}{*}{ Tempo a $2 \mathrm{~m}$} & Correlação de Pearson &,- 499 & ,144 &,- 008 \\
\hline & Sig. (2 extremidades) & ,059 & 609 & ,977 \\
\hline & $\mathrm{N}$ & 15 & 15 & 15 \\
\hline \multirow[t]{3}{*}{ Tempo a $5 \mathrm{~m}$} & Correlação de Pearson & ,044 &,- 069 &,- 342 \\
\hline & Sig. (2 extremidades) & 876 & ,808 & ,213 \\
\hline & $\mathrm{N}$ & 15 & 15 & 15 \\
\hline \multirow{3}{*}{$\begin{array}{l}\text { Retirada de vareta } \\
\text { facilitada }\end{array}$} & Correlação de Pearson &, $704^{\star *}$ & ,002 &,- 339 \\
\hline & Sig. (2 extremidades) & ,003 & ,994 & ,216 \\
\hline & $\mathrm{N}$ & 15 & 15 & 15 \\
\hline \multirow[t]{3}{*}{ Puxar vareta fixa } & Correlação de Pearson & 1 &,- 174 &,- 280 \\
\hline & Sig. (2 extremidades) & &, 535 & ,312 \\
\hline & $\mathrm{N}$ & 15 & 15 & 15 \\
\hline \multirow[t]{3}{*}{ Explorar caixa } & Correlação de Pearson &,- 174 & 1 &, 012 \\
\hline & Sig. (2 extremidades) &, 535 & & ,967 \\
\hline & $\mathrm{N}$ & 15 & 15 & 15 \\
\hline
\end{tabular}




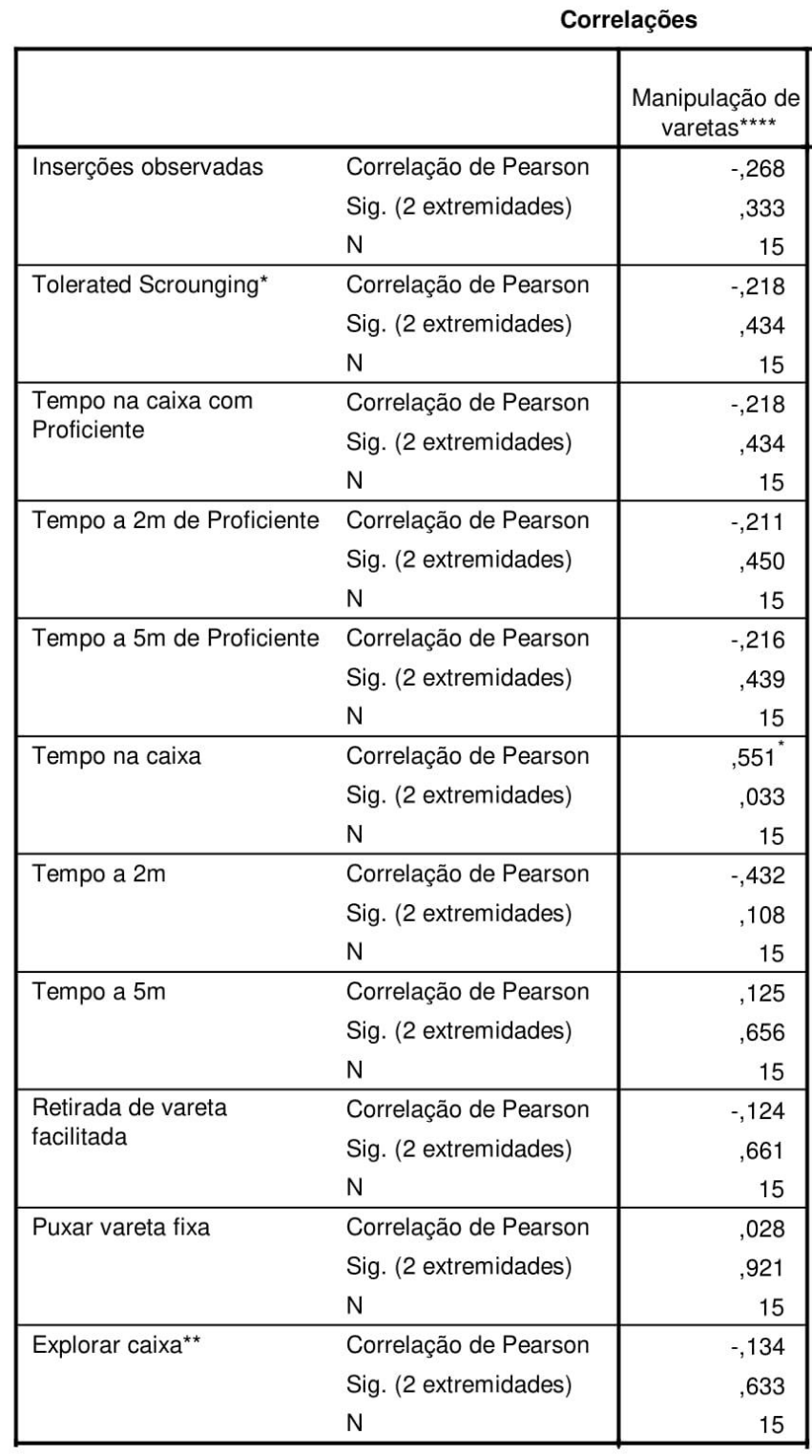




\begin{tabular}{|ll|r|r|r|}
\hline \multicolumn{1}{|c|}{ Correlações } \\
\hline & $\begin{array}{c}\text { Inserções } \\
\text { observadas }\end{array}$ & $\begin{array}{c}\text { Tolerated } \\
\text { Scrounging* }\end{array}$ & $\begin{array}{c}\text { Tempo na } \\
\text { caixa com } \\
\text { Proficiente }\end{array}$ \\
\hline Scrounging ${ }^{* \star *}$ & Correlação de Pearson &, 408 &, 220 &, 327 \\
& Sig. (2 extremidades) &, 131 &, 430 &, 234 \\
& $\mathrm{~N}$ & 15 & 15 & 15 \\
\hline Manipulação de varetas $^{* \star * *}$ & Correlação de Pearson &,- 268 &,- 218 &,- 218 \\
& Sig. (2 extremidades) &, 333 &, 434 &, 434 \\
& $\mathrm{~N}$ & 15 & 15 & 15 \\
\hline
\end{tabular}

Correlações

\begin{tabular}{|ll|r|r|r|}
\hline & Tempo a 2m de & Tempo a 5m de & \multicolumn{2}{c|}{$\begin{array}{c}\text { Tempo na } \\
\text { Proficiente } \\
\text { Proficiente }\end{array}$} \\
\hline Scrounging $^{\star * *}$ & Correlação de Pearson &, $616^{*}$ &, 342 &,$- 517^{*}$ \\
& Sig. (2 extremidades) &, 014 &, 213 &, 049 \\
& $\mathrm{~N}$ & 15 & 15 & 15 \\
\hline Manipulação de varetas $^{* * * *}$ & Correlação de Pearson &,- 211 &,- 216 &, $551^{\star}$ \\
& Sig. (2 extremidades) &, 450 &, 439 &, 033 \\
& $\mathrm{~N}$ & 15 & 15 & 15 \\
\hline
\end{tabular}

Correlações

\begin{tabular}{|ll|r|r|r|}
\hline & & & $\begin{array}{c}\text { Retirada de } \\
\text { vareta facilitada }\end{array}$ \\
\hline Scrounging*** $^{*}$ & Tempo a 2m & Tempo a 5m &,- 339 \\
& Correlação de Pearson &,- 008 &,- 342 &, 216 \\
& Sig. (2 extremidades) &, 977 &, 213 & 15 \\
& $\mathrm{~N}$ & 15 &, 125 &,- 124 \\
\hline Manipulação de varetas $^{* * * *}$ & Correlação de Pearson &,- 432 &, 656 &, 661 \\
& Sig. (2 extremidades) &, 108 & 15 & 15 \\
\hline
\end{tabular}

Correlações

\begin{tabular}{|c|c|c|c|c|}
\hline & & $\begin{array}{c}\text { Puxar vareta } \\
\text { fixa }\end{array}$ & Explorar caixa** & Scrounging ${ }^{\star * *}$ \\
\hline \multirow[t]{3}{*}{ Scrounging $^{\star \star \star}$} & Correlação de Pearson &,- 280 & 012 & 1 \\
\hline & Sig. (2 extremidades) & ,312 & 967 & \\
\hline & $\mathrm{N}$ & 15 & 15 & 15 \\
\hline \multirow[t]{3}{*}{ Manipulação de varetas ${ }^{* * * *}$} & Correlação de Pearson & , 028 &,- 134 &,- 395 \\
\hline & Sig. (2 extremidades) & ,921 & ,633 & , 145 \\
\hline & $\mathrm{N}$ & 15 & 15 & 15 \\
\hline
\end{tabular}

Page 6 


\begin{tabular}{|ll|r|}
\hline \multicolumn{2}{c|}{ Correlações } \\
\hline & & $\begin{array}{c}\text { Manipulação de } \\
\text { varetas }\end{array}$ \\
\hline Scrounging $^{\star \star \star *}$ & Correlação de Pearson &,- 395 \\
& Sig. (2 extremidades) &, 145 \\
& $\mathrm{~N}$ & 15 \\
\hline Manipulação de varetas $^{\star \star \star \star}$ & Correlação de Pearson & 1 \\
& Sig. (2 extremidades) & 15 \\
\hline
\end{tabular}

**. A correlação é significativa no nível 0,01 (2 extremidades).

*. A correlação é significativa no nível 0,05 (2 extremidades).

\section{Correlações 1 e 2}

\begin{tabular}{|c|c|c|c|c|}
\hline \multicolumn{5}{|c|}{ Correlações } \\
\hline & & $\begin{array}{l}\text { Inserções } \\
\text { observadas }\end{array}$ & $\begin{array}{c}\text { Tolerated } \\
\text { Scrounging }\end{array}$ & $\begin{array}{l}\text { Tempo na } \\
\text { caixa com } \\
\text { Proficiente }\end{array}$ \\
\hline \multirow[t]{3}{*}{ Inserções observadas } & Correlação de Pearson & 1 &, $957^{* *}$ &, $983^{* *}$ \\
\hline & Sig. (2 extremidades) & & ,000 &, 000 \\
\hline & $\mathrm{N}$ & 10 & 10 & 10 \\
\hline \multirow[t]{3}{*}{ Tolerated Scrounging ${ }^{\star}$} & Correlação de Pearson &, $957^{* *}$ & 1 & $957^{* *}$ \\
\hline & Sig. (2 extremidades) & ,000 & &, 000 \\
\hline & $\mathrm{N}$ & 10 & 10 & 10 \\
\hline \multirow{3}{*}{$\begin{array}{l}\text { Tempo na caixa com } \\
\text { Proficiente }\end{array}$} & Correlação de Pearson &, $983^{* *}$ & $957^{\star *}$ & 1 \\
\hline & Sig. (2 extremidades) & ,000 & ,000 & \\
\hline & $\mathrm{N}$ & 10 & 10 & 10 \\
\hline \multirow[t]{3}{*}{ Tempo a $2 \mathrm{~m}$ de Proficiente } & Correlação de Pearson & $868^{\star \star}$ & $851^{\star \star}$ & $833^{* *}$ \\
\hline & Sig. (2 extremidades) & ,001 & ,002 & ,003 \\
\hline & $\mathrm{N}$ & 10 & 10 & 10 \\
\hline \multirow[t]{3}{*}{ Tempo a $5 \mathrm{~m}$ de Proficiente } & Correlação de Pearson & ,225 &, 016 & , 157 \\
\hline & Sig. (2 extremidades) &, 531 & ,966 & ,666 \\
\hline & $\mathrm{N}$ & 10 & 10 & 10 \\
\hline \multirow[t]{3}{*}{ Tempo na caixa } & Correlação de Pearson &,- 149 & -102 &,- 085 \\
\hline & Sig. (2 extremidades) & ,681 & ,780 & ,815 \\
\hline & $\mathrm{N}$ & 10 & 10 & 10 \\
\hline \multirow[t]{3}{*}{ Tempo a $2 m$} & Correlação de Pearson &, 534 & ,613 & ,475 \\
\hline & Sig. (2 extremidades) & 112 & ,060 & 166 \\
\hline & $\mathrm{N}$ & 10 & 10 & 10 \\
\hline
\end{tabular}

Page 7 


\begin{tabular}{|c|c|c|c|c|}
\hline \multicolumn{5}{|c|}{ Correlações } \\
\hline & & $\begin{array}{c}\text { Tempo a } 2 \mathrm{~m} \text { de } \\
\text { Proficiente }\end{array}$ & $\begin{array}{c}\text { Tempo a } 5 \mathrm{~m} \text { de } \\
\text { Proficiente }\end{array}$ & $\begin{array}{c}\text { Tempo na } \\
\text { caixa }\end{array}$ \\
\hline \multirow[t]{3}{*}{ Inserções observadas } & Correlação de Pearson &, $868^{\star \star}$ & ,225 &,- 149 \\
\hline & Sig. (2 extremidades) & ,001 &, 531 & ,681 \\
\hline & $\mathrm{N}$ & 10 & 10 & 10 \\
\hline \multirow[t]{3}{*}{ Tolerated Scrounging* } & Correlação de Pearson & $851^{* \star}$ & 016 &,- 102 \\
\hline & Sig. (2 extremidades) & ,002 & ,966 & ,780 \\
\hline & $\mathrm{N}$ & 10 & 10 & 10 \\
\hline \multirow{3}{*}{$\begin{array}{l}\text { Tempo na caixa com } \\
\text { Proficiente }\end{array}$} & Correlação de Pearson &, $833^{* *}$ & ,157 &,- 085 \\
\hline & Sig. (2 extremidades) & ,003 & ,666 & ,815 \\
\hline & $\mathrm{N}$ & 10 & 10 & 10 \\
\hline \multirow[t]{3}{*}{ Tempo a $2 m$ de Proficiente } & Correlação de Pearson & 1 & 354 &,- 372 \\
\hline & Sig. (2 extremidades) & & ,316 & ,289 \\
\hline & $\mathrm{N}$ & 10 & 10 & 10 \\
\hline \multirow[t]{3}{*}{ Tempo a 5m de Proficiente } & Correlação de Pearson &, 354 & 1 &,- 513 \\
\hline & Sig. (2 extremidades) &, 316 & & , 129 \\
\hline & $\mathrm{N}$ & 10 & 10 & 10 \\
\hline \multirow[t]{3}{*}{ Tempo na caixa } & Correlação de Pearson &,- 372 &,- 513 & 1 \\
\hline & Sig. (2 extremidades) & ,289 & ,129 & \\
\hline & $\mathrm{N}$ & 10 & 10 & 10 \\
\hline \multirow[t]{3}{*}{ Tempo a $2 \mathrm{~m}$} & Correlação de Pearson &, $692^{*}$ & ,293 &,- 618 \\
\hline & Sig. (2 extremidades) &, 026 & ,411 & ,057 \\
\hline & $\mathrm{N}$ & 10 & 10 & 10 \\
\hline
\end{tabular}




\begin{tabular}{|c|c|c|c|c|}
\hline \multicolumn{5}{|c|}{ Correlações } \\
\hline & & Tempo a $2 m$ & Tempo a $5 \mathrm{~m}$ & $\begin{array}{c}\text { Retirada de } \\
\text { vareta facilitada }\end{array}$ \\
\hline \multirow[t]{3}{*}{ Inserções observadas } & Correlação de Pearson &, 534 & 188 &,- 480 \\
\hline & Sig. (2 extremidades) & ,112 & 602 & ,161 \\
\hline & $\mathrm{N}$ & 10 & 10 & 10 \\
\hline \multirow[t]{3}{*}{ Tolerated Scrounging ${ }^{*}$} & Correlação de Pearson & 613 & ,203 &,- 406 \\
\hline & Sig. (2 extremidades) & 060 &, 573 & 244 \\
\hline & $\mathrm{N}$ & 10 & 10 & 10 \\
\hline \multirow{3}{*}{$\begin{array}{l}\text { Tempo na caixa com } \\
\text { Proficiente }\end{array}$} & Correlação de Pearson & ,475 & ,159 &,- 465 \\
\hline & Sig. (2 extremidades) & 166 & 661 & 176 \\
\hline & $\mathrm{N}$ & 10 & 10 & 10 \\
\hline \multirow[t]{3}{*}{ Tempo a 2m de Proficiente } & Correlação de Pearson & $692^{*}$ &,- 032 &,$- 658^{*}$ \\
\hline & Sig. (2 extremidades) & ,026 & ,930 & 039 \\
\hline & $\mathrm{N}$ & 10 & 10 & 10 \\
\hline \multirow[t]{3}{*}{ Tempo a 5m de Proficiente } & Correlação de Pearson & 293 &,- 209 &,- 367 \\
\hline & Sig. (2 extremidades) & 411 &, 563 & ,297 \\
\hline & $\mathrm{N}$ & 10 & 10 & 10 \\
\hline \multirow[t]{3}{*}{ Tempo na caixa } & Correlação de Pearson &,- 618 & 232 &, 513 \\
\hline & Sig. (2 extremidades) & ,057 &, 519 & 129 \\
\hline & $\mathrm{N}$ & 10 & 10 & 10 \\
\hline \multirow[t]{3}{*}{ Tempo a $2 \mathrm{~m}$} & Correlação de Pearson & 1 & ,078 &,- 487 \\
\hline & Sig. (2 extremidades) & & ,831 & 153 \\
\hline & $\mathrm{N}$ & 10 & 10 & 10 \\
\hline
\end{tabular}




\begin{tabular}{|c|c|c|c|c|}
\hline \multicolumn{5}{|c|}{ Correlações } \\
\hline & & $\begin{array}{c}\text { Puxar vareta } \\
\text { fixa }\end{array}$ & Explorar caixa** & Scrounging ${ }^{\star \star \star}$ \\
\hline \multirow[t]{3}{*}{ Inserções observadas } & Correlação de Pearson &,- 415 &,- 377 & ,533 \\
\hline & Sig. (2 extremidades) & ,233 & ,283 & ,112 \\
\hline & $\mathrm{N}$ & 10 & 10 & 10 \\
\hline \multirow[t]{3}{*}{ Tolerated Scrounging* } & Correlação de Pearson &,- 398 &,- 194 & 316 \\
\hline & Sig. (2 extremidades) & 255 &, 591 & ,374 \\
\hline & $\mathrm{N}$ & 10 & 10 & 10 \\
\hline \multirow{3}{*}{$\begin{array}{l}\text { Tempo na caixa com } \\
\text { Proficiente }\end{array}$} & Correlação de Pearson &,- 389 &,- 416 & ,461 \\
\hline & Sig. (2 extremidades) & ,267 & 232 & 180 \\
\hline & N & 10 & 10 & 10 \\
\hline \multirow[t]{3}{*}{ Tempo a 2m de Proficiente } & Correlação de Pearson &,$- 736^{*}$ &,- 049 & ,506 \\
\hline & Sig. (2 extremidades) &, 015 &, 893 & 136 \\
\hline & $\mathrm{N}$ & 10 & 10 & 10 \\
\hline \multirow[t]{3}{*}{ Tempo a $5 \mathrm{~m}$ de Proficiente } & Correlação de Pearson &,- 303 &,- 177 &, $780^{* *}$ \\
\hline & Sig. (2 extremidades) & ,394 &, 624 &, 008 \\
\hline & $\mathrm{N}$ & 10 & 10 & 10 \\
\hline \multirow[t]{3}{*}{ Tempo na caixa } & Correlação de Pearson & ,427 &,- 143 &,- 492 \\
\hline & Sig. (2 extremidades) & ,218 & 694 & 149 \\
\hline & $\mathrm{N}$ & 10 & 10 & 10 \\
\hline \multirow[t]{3}{*}{ Tempo a $2 \mathrm{~m}$} & Correlação de Pearson &,- 539 & ,414 & 260 \\
\hline & Sig. (2 extremidades) &, 108 & ,234 & ,468 \\
\hline & $\mathrm{N}$ & 10 & 10 & 10 \\
\hline
\end{tabular}




\begin{tabular}{|ll|r|}
\hline \multicolumn{2}{c}{ Correlações } \\
\hline & & $\begin{array}{c}\text { Manipulação de } \\
\text { varetas }^{\star \star \star \star}\end{array}$ \\
\hline Inserções observadas & Correlação de Pearson &,- 315 \\
& Sig. (2 extremidades) &, 375 \\
& $\mathrm{~N}$ & 10 \\
\hline Tolerated Scrounging* & Correlação de Pearson &,- 325 \\
& Sig. (2 extremidades) &, 359 \\
& $\mathrm{~N}$ & 10 \\
\hline Tempo na caixa com & Correlação de Pearson &,- 305 \\
Proficiente & Sig. (2 extremidades) &, 392 \\
& $\mathrm{~N}$ & 10 \\
\hline Tempo a 2m de Proficiente & Correlação de Pearson &,- 160 \\
& Sig. (2 extremidades) &, 659 \\
& $\mathrm{~N}$ & 10 \\
\hline Tempo a 5m de Proficiente & Correlação de Pearson &,- 357 \\
& Sig. (2 extremidades) &, 311 \\
& $\mathrm{~N}$ & 10 \\
\hline Tempo na caixa & Correlação de Pearson &, 284 \\
& Sig. (2 extremidades) &, 426 \\
& $\mathrm{~N}$ & 10 \\
\hline Tempo a 2m & Correlação de Pearson &,- 582 \\
& Sig. (2 extremidades) &, 078 \\
& $\mathrm{~N}$ & 10 \\
\hline
\end{tabular}

Page 11 


\begin{tabular}{|ll|r|r|r|}
\hline \multicolumn{1}{|c|}{ Correlações } \\
\hline
\end{tabular}

Page 12 


\begin{tabular}{|c|c|c|c|c|}
\hline \multicolumn{5}{|c|}{ Correlações } \\
\hline & & $\begin{array}{c}\text { Tempo a } 2 \mathrm{~m} \text { de } \\
\text { Proficiente }\end{array}$ & $\begin{array}{c}\text { Tempo a } 5 \mathrm{~m} \text { de } \\
\text { Proficiente }\end{array}$ & $\begin{array}{l}\text { Tempo na } \\
\text { caixa }\end{array}$ \\
\hline \multirow[t]{3}{*}{ Tempo a $5 \mathrm{~m}$} & Correlação de Pearson &,- 032 &,- 209 & ,232 \\
\hline & Sig. (2 extremidades) & ,930 &, 563 &, 519 \\
\hline & $\mathrm{N}$ & 10 & 10 & 10 \\
\hline \multirow{3}{*}{$\begin{array}{l}\text { Retirada de vareta } \\
\text { facilitada }\end{array}$} & Correlação de Pearson &,$- 658^{*}$ &,- 367 & ,513 \\
\hline & Sig. (2 extremidades) & ,039 & 297 & 129 \\
\hline & $\mathrm{N}$ & 10 & 10 & 10 \\
\hline \multirow[t]{3}{*}{ Puxar vareta fixa } & Correlação de Pearson &,$- 736^{\star}$ &,- 303 & ,427 \\
\hline & Sig. (2 extremidades) &, 015 & ,394 & ,218 \\
\hline & $\mathrm{N}$ & 10 & 10 & 10 \\
\hline \multirow[t]{3}{*}{ Explorar caixa ${ }^{* \star}$} & Correlação de Pearson &,- 049 &,- 177 &,- 143 \\
\hline & Sig. (2 extremidades) & 893 & ,624 & ,694 \\
\hline & $\mathrm{N}$ & 10 & 10 & 10 \\
\hline \multirow[t]{3}{*}{ Scrounging $^{\star \star \star}$} & Correlação de Pearson & ,506 &, $780^{* *}$ &,- 492 \\
\hline & Sig. (2 extremidades) &, 136 &, 008 & 149 \\
\hline & $\mathrm{N}$ & 10 & 10 & 10 \\
\hline \multirow[t]{3}{*}{ Manipulação de varetas s $^{\star \star \star \star}$} & Correlação de Pearson &,- 160 &,- 357 & 2,284 \\
\hline & Sig. (2 extremidades) & ,659 &, 311 & ,426 \\
\hline & $\mathrm{N}$ & 10 & 10 & 10 \\
\hline
\end{tabular}

Page 13 


\begin{tabular}{|ll|r|r|r|}
\hline & & & Correlaçães \\
& & Tempo a 2m & Tempo a 5m & $\begin{array}{c}\text { Retirada de } \\
\text { vareta facilitada }\end{array}$ \\
\hline Tempo a 5m & Correlação de Pearson &, 078 & 1 &,- 141 \\
& Sig. (2 extremidades) &, 831 & &, 697 \\
& $\mathrm{~N}$ & 10 & 10 & 10 \\
\hline Retirada de vareta & Correlação de Pearson &,- 487 &,- 141 & 1 \\
facilitada & Sig. (2 extremidades) &, 153 &, 697 & \\
& $\mathrm{~N}$ & 10 & 10 & 10 \\
\hline Puxar vareta fixa & Correlação de Pearson &,- 539 &, 059 &, 797 \\
& Sig. (2 extremidades) &, 108 &, 872 &, 006 \\
& $\mathrm{~N}$ & 10 & 10 & 10 \\
\hline Explorar caixa** & Correlação de Pearson &, 414 &,- 051 &, 114 \\
& Sig. (2 extremidades) &, 234 &, 888 &, 754 \\
& $\mathrm{~N}$ & 10 & 10 & 10 \\
\hline Scrounging*** & Correlação de Pearson &, 260 &,- 232 &,- 288 \\
& Sig. (2 extremidades) &, 468 &, 518 &, 420 \\
& $\mathrm{~N}$ & 10 & 10 & 10 \\
\hline Manipulação de varetas & Correlação de Pearson &,- 582 &,- 033 &,- 116 \\
& Sig. (2 extremidades) &, 078 &, 928 &, 750 \\
& $\mathrm{~N}$ & 10 & 10 & 10 \\
\hline
\end{tabular}

Page 14 


\begin{tabular}{|c|c|c|c|c|}
\hline \multicolumn{5}{|c|}{ Correlações } \\
\hline & & $\begin{array}{l}\text { Puxar vareta } \\
\text { fixa }\end{array}$ & Explorar caixa** & Scrounging ${ }^{\star \star \star}$ \\
\hline \multirow[t]{3}{*}{ Tempo a $5 \mathrm{~m}$} & Correlação de Pearson & 059 &,- 051 &,- 232 \\
\hline & Sig. (2 extremidades) & ,872 & 888 &, 518 \\
\hline & $\mathrm{N}$ & 10 & 10 & 10 \\
\hline \multirow{3}{*}{$\begin{array}{l}\text { Retirada de vareta } \\
\text { facilitada }\end{array}$} & Correlação de Pearson &, $797^{* *}$ & ,114 & -288 \\
\hline & Sig. (2 extremidades) &, 006 &, 754 & , 420 \\
\hline & $\mathrm{N}$ & 10 & 10 & 10 \\
\hline \multirow[t]{3}{*}{ Puxar vareta fixa } & Correlação de Pearson & 1 &,- 292 &,- 299 \\
\hline & Sig. (2 extremidades) & &, 413 & ,401 \\
\hline & $\mathrm{N}$ & 10 & 10 & 10 \\
\hline \multirow[t]{3}{*}{ Explorar caixa ${ }^{\star \star}$} & Correlação de Pearson &,- 292 & 1 &,- 399 \\
\hline & Sig. (2 extremidades) & , 413 & & ,254 \\
\hline & $\mathrm{N}$ & 10 & 10 & 10 \\
\hline \multirow[t]{3}{*}{ Scrounging ${ }^{\star \star \star}$} & Correlação de Pearson &,- 299 &,- 399 & 1 \\
\hline & Sig. (2 extremidades) & ,401 & ,254 & \\
\hline & $\mathrm{N}$ & 10 & 10 & 10 \\
\hline \multirow[t]{3}{*}{ Manipulação de varetas ${ }^{\star \star \star \star}$} & Correlação de Pearson &,- 132 &,- 089 &,- 361 \\
\hline & Sig. (2 extremidades) &, 716 & ,808 & ,306 \\
\hline & $\mathrm{N}$ & 10 & 10 & 10 \\
\hline
\end{tabular}

Page 15 


\begin{tabular}{|ll|r|}
\multicolumn{2}{|c|}{ Correlaçães } \\
\hline & Correlação de Pearson & $\begin{array}{c}\text { Manipulação de } \\
\text { varetas }\end{array}$ \\
\hline Sig. (2 extremidades) &,- 033 \\
& $\mathrm{~N}$ &, 928 \\
& Correlação de Pearson & 10 \\
\hline Retirada de vareta & Sig. (2 extremidades) &,- 116 \\
facilitada & $\mathrm{N}$ &, 750 \\
& Correlação de Pearson & 10 \\
\hline Puxar vareta fixa & Sig. (2 extremidades) &,- 132 \\
& $\mathrm{~N}$ &, 716 \\
& Correlação de Pearson & 10 \\
\hline Explorar caixa &,- 089 \\
& Sig. (2 extremidades) &, 808 \\
$\mathrm{~N}$ & 10 \\
\hline Scrounging &,- 361 \\
& Correlação de Pearson &, 306 \\
& Sig. (2 extremidades) & 10 \\
\hline $\mathrm{N}$ & 1 \\
\hline Manipulação de varetas & Correlação de Pearson & 10 \\
\hline & Sig. (2 extremidades) & \\
& $\mathrm{N}$ & \\
\hline
\end{tabular}

**. A correlação é significativa no nível 0,01 (2 extremidades).

*. A correlação é significativa no nível 0,05 (2 extremidades).

\section{Correlações 1 e 3}




\begin{tabular}{|c|c|c|c|c|}
\hline \multicolumn{5}{|c|}{ Correlações } \\
\hline & & $\begin{array}{l}\text { Inserções } \\
\text { observadas }\end{array}$ & $\begin{array}{l}\text { Tolerated } \\
\text { Scrounging* }\end{array}$ & $\begin{array}{l}\text { Tempo na } \\
\text { caixa com } \\
\text { Proficiente }\end{array}$ \\
\hline \multirow[t]{3}{*}{ Inserções observadas } & Correlação de Pearson & $\overline{1}$ &, $970^{\star \star}$ &, $967^{\star \star}$ \\
\hline & Sig. (2 extremidades) & &, 000 &, 000 \\
\hline & $\mathrm{N}$ & 10 & 10 & 10 \\
\hline \multirow[t]{3}{*}{ Tolerated Scrounging* } & Correlação de Pearson &, $970^{* \star}$ & 1 &, $964^{* \star}$ \\
\hline & Sig. (2 extremidades) &, 000 & &, 000 \\
\hline & $\mathrm{N}$ & 10 & 10 & 10 \\
\hline \multirow{3}{*}{$\begin{array}{l}\text { Tempo na caixa com } \\
\text { Proficiente }\end{array}$} & Correlação de Pearson &, $967^{\star \star}$ &, $964^{\star \star}$ & 1 \\
\hline & Sig. (2 extremidades) &, 000 &, 000 & \\
\hline & $\mathrm{N}$ & 10 & 10 & 10 \\
\hline \multirow[t]{3}{*}{ Tempo a $2 \mathrm{~m}$ de Proficiente } & Correlação de Pearson & ,257 & ,295 & ,233 \\
\hline & Sig. (2 extremidades) & ,474 & ,408 &, 516 \\
\hline & $\mathrm{N}$ & 10 & 10 & 10 \\
\hline \multirow[t]{3}{*}{ Tempo a $5 \mathrm{~m}$ de Proficiente } & Correlação de Pearson &,- 539 &,- 486 &,- 532 \\
\hline & Sig. (2 extremidades) & , 108 & ,154 &, 114 \\
\hline & $\mathrm{N}$ & 10 & 10 & 10 \\
\hline \multirow[t]{3}{*}{ Tempo na caixa } & Correlação de Pearson &,- 147 &,- 016 &,- 061 \\
\hline & Sig. (2 extremidades) & ,685 & ,965 & ,866 \\
\hline & $\mathrm{N}$ & 10 & 10 & 10 \\
\hline \multirow[t]{3}{*}{ Tempo a $2 \mathrm{~m}$} & Correlação de Pearson &,- 111 &,- 118 &,- 188 \\
\hline & Sig. (2 extremidades) & ,760 & ,745 & ,603 \\
\hline & $\mathrm{N}$ & 10 & 10 & 10 \\
\hline \multirow[t]{3}{*}{ Tempo a $5 \mathrm{~m}$} & Correlação de Pearson & ,350 & ,271 & ,380 \\
\hline & Sig. (2 extremidades) & ,322 & ,450 & ,279 \\
\hline & $\mathrm{N}$ & 10 & 10 & 10 \\
\hline \multirow{3}{*}{$\begin{array}{l}\text { Retirada de vareta } \\
\text { facilitada }\end{array}$} & Correlação de Pearson & , 197 &, 171 &, 170 \\
\hline & Sig. (2 extremidades) &, 586 & ,637 & ,639 \\
\hline & $\mathrm{N}$ & 10 & 10 & 10 \\
\hline \multirow[t]{3}{*}{ Puxar vareta fixa } & Correlação de Pearson &,- 228 &,- 296 &,- 160 \\
\hline & Sig. (2 extremidades) &, 527 & ,406 & ,658 \\
\hline & $\mathrm{N}$ & 10 & 10 & 10 \\
\hline \multirow[t]{3}{*}{ Explorar caixa ${ }^{\star *}$} & Correlação de Pearson &,- 353 &,- 362 &,- 324 \\
\hline & Sig. (2 extremidades) & ,318 & ,304 & ,361 \\
\hline & $\mathrm{N}$ & 10 & 10 & 10 \\
\hline \multirow[t]{3}{*}{ Scrounging ${ }^{\star \star \star}$} & Correlação de Pearson & ,350 & ,291 & ,262 \\
\hline & Sig. (2 extremidades) & ,322 & ,415 & ,464 \\
\hline & $\mathrm{N}$ & 10 & 10 & 10 \\
\hline
\end{tabular}

Page 17 


\begin{tabular}{|c|c|c|c|c|}
\hline \multicolumn{5}{|c|}{ Correlações } \\
\hline & & $\begin{array}{c}\text { Tempo a } 2 \mathrm{~m} \text { de } \\
\text { Proficiente }\end{array}$ & $\begin{array}{c}\text { Tempo a } 5 \mathrm{~m} \text { de } \\
\text { Proficiente }\end{array}$ & $\begin{array}{l}\text { Tempo na } \\
\text { caixa }\end{array}$ \\
\hline \multirow[t]{3}{*}{ Inserções observadas } & Correlação de Pearson & ,257 &,- 539 &,- 147 \\
\hline & Sig. (2 extremidades) & ,474 & ,108 & ,685 \\
\hline & $\mathrm{N}$ & 10 & 10 & 10 \\
\hline \multirow[t]{3}{*}{ Tolerated Scrounging* } & Correlação de Pearson & ,295 &,- 486 &,- 016 \\
\hline & Sig. (2 extremidades) & ,408 & 154 & ,965 \\
\hline & $\mathrm{N}$ & 10 & 10 & 10 \\
\hline \multirow{3}{*}{$\begin{array}{l}\text { Tempo na caixa com } \\
\text { Proficiente }\end{array}$} & Correlação de Pearson & ,233 &,- 532 &,- 061 \\
\hline & Sig. (2 extremidades) &, 516 &, 114 & ,866 \\
\hline & $\mathrm{N}$ & 10 & 10 & 10 \\
\hline \multirow[t]{3}{*}{ Tempo a $2 \mathrm{~m}$ de Proficiente } & Correlação de Pearson & 1 & ,494 &,- 312 \\
\hline & Sig. (2 extremidades) & & 147 & ,381 \\
\hline & $\mathrm{N}$ & 10 & 10 & 10 \\
\hline \multirow[t]{3}{*}{ Tempo a $5 \mathrm{~m}$ de Proficiente } & Correlação de Pearson & ,494 & 1 &,- 186 \\
\hline & Sig. (2 extremidades) & 147 & & ,607 \\
\hline & $\mathrm{N}$ & 10 & 10 & 10 \\
\hline \multirow[t]{3}{*}{ Tempo na caixa } & Correlação de Pearson &,- 312 &,- 186 & 1 \\
\hline & Sig. (2 extremidades) & ,381 & ,607 & \\
\hline & $\mathrm{N}$ & 10 & 10 & 10 \\
\hline \multirow[t]{3}{*}{ Tempo a $2 \mathrm{~m}$} & Correlação de Pearson &,- 091 & ,252 &,- 390 \\
\hline & Sig. (2 extremidades) & ,803 & ,483 & ,265 \\
\hline & $\mathrm{N}$ & 10 & 10 & 10 \\
\hline \multirow[t]{3}{*}{ Tempo a $5 \mathrm{~m}$} & Correlação de Pearson &,- 592 &,$- 655^{\star}$ & ,389 \\
\hline & Sig. (2 extremidades) & ,072 &, 040 & ,266 \\
\hline & $\mathrm{N}$ & 10 & 10 & 10 \\
\hline \multirow{3}{*}{$\begin{array}{l}\text { Retirada de vareta } \\
\text { facilitada }\end{array}$} & Correlação de Pearson &,- 087 & ,001 &,- 100 \\
\hline & Sig. (2 extremidades) & ,811 & ,999 & ,783 \\
\hline & $\mathrm{N}$ & 10 & 10 & 10 \\
\hline \multirow[t]{3}{*}{ Puxar vareta fixa } & Correlação de Pearson &,- 078 & ,327 & ,205 \\
\hline & Sig. (2 extremidades) & ,830 & ,356 &, 570 \\
\hline & $\mathrm{N}$ & 10 & 10 & 10 \\
\hline \multirow[t]{3}{*}{ Explorar caixa ${ }^{\star *}$} & Correlação de Pearson & ,216 & ,226 &,- 259 \\
\hline & Sig. (2 extremidades) &, 550 & ,529 & , 470 \\
\hline & $\mathrm{N}$ & 10 & 10 & 10 \\
\hline \multirow[t]{3}{*}{ Scrounging $^{\star * *}$} & Correlação de Pearson &, $703^{*}$ & 104 &,- 562 \\
\hline & Sig. (2 extremidades) & ,023 & ,776 & ,091 \\
\hline & $\mathrm{N}$ & 10 & 10 & 10 \\
\hline
\end{tabular}

Page 18 


\begin{tabular}{|c|c|c|c|c|}
\hline \multicolumn{5}{|c|}{ Correlações } \\
\hline & & Tempo a $2 m$ & Tempo a $5 \mathrm{~m}$ & $\begin{array}{c}\text { Retirada de } \\
\text { vareta facilitada }\end{array}$ \\
\hline \multirow[t]{3}{*}{ Inserções observadas } & Correlação de Pearson &,- 111 & ,350 & ,197 \\
\hline & Sig. (2 extremidades) & ,760 & ,322 &, 586 \\
\hline & $\mathrm{N}$ & 10 & 10 & 10 \\
\hline \multirow[t]{3}{*}{ Tolerated Scrounging ${ }^{*}$} & Correlação de Pearson &,- 118 & ,271 & ,171 \\
\hline & Sig. (2 extremidades) & ,745 & ,450 & ,637 \\
\hline & $\mathrm{N}$ & 10 & 10 & 10 \\
\hline \multirow{3}{*}{$\begin{array}{l}\text { Tempo na caixa com } \\
\text { Proficiente }\end{array}$} & Correlação de Pearson &,- 188 & ,380 & , 170 \\
\hline & Sig. (2 extremidades) & ,603 & ,279 & ,639 \\
\hline & $\mathrm{N}$ & 10 & 10 & 10 \\
\hline \multirow[t]{3}{*}{ Tempo a $2 \mathrm{~m}$ de Proficiente } & Correlação de Pearson &,- 091 &,- 592 &,- 087 \\
\hline & Sig. (2 extremidades) & 803 & ,072 & 811 \\
\hline & $\mathrm{N}$ & 10 & 10 & 10 \\
\hline \multirow[t]{3}{*}{ Tempo a 5m de Proficiente } & Correlação de Pearson & ,252 &,$- 655^{\star}$ & 001 \\
\hline & Sig. (2 extremidades) & ,483 &, 040 & ,999 \\
\hline & $\mathrm{N}$ & 10 & 10 & 10 \\
\hline \multirow[t]{3}{*}{ Tempo na caixa } & Correlação de Pearson &,- 390 & ,389 &,- 100 \\
\hline & Sig. (2 extremidades) & ,265 & ,266 & ,783 \\
\hline & $\mathrm{N}$ & 10 & 10 & 10 \\
\hline \multirow[t]{3}{*}{ Tempo a $2 \mathrm{~m}$} & Correlação de Pearson & 1 &,- 383 & , 180 \\
\hline & Sig. (2 extremidades) & & ,274 & 619 \\
\hline & $\mathrm{N}$ & 10 & 10 & 10 \\
\hline \multirow[t]{3}{*}{ Tempo a $5 \mathrm{~m}$} & Correlação de Pearson &,- 383 & 1 & ,331 \\
\hline & Sig. (2 extremidades) & ,274 & & 351 \\
\hline & $\mathrm{N}$ & 10 & 10 & 10 \\
\hline \multirow{3}{*}{$\begin{array}{l}\text { Retirada de vareta } \\
\text { facilitada }\end{array}$} & Correlação de Pearson & ,180 & ,331 & 1 \\
\hline & Sig. (2 extremidades) & ,619 & ,351 & \\
\hline & $\mathrm{N}$ & 10 & 10 & 10 \\
\hline \multirow[t]{3}{*}{ Puxar vareta fixa } & Correlação de Pearson &,- 367 & ,299 &,- 132 \\
\hline & Sig. (2 extremidades) & ,296 & ,402 & ,716 \\
\hline & $\mathrm{N}$ & 10 & 10 & 10 \\
\hline \multirow[t]{3}{*}{ Explorar caixa** } & Correlação de Pearson & 069 &,- 247 & 023 \\
\hline & Sig. (2 extremidades) & ,851 & ,492 & 949 \\
\hline & $\mathrm{N}$ & 10 & 10 & 10 \\
\hline \multirow[t]{3}{*}{ Scrounging ${ }^{\star \star \star}$} & Correlação de Pearson &,- 145 &,- 351 &,- 327 \\
\hline & Sig. (2 extremidades) & 690 & ,320 & 357 \\
\hline & $\mathrm{N}$ & 10 & 10 & 10 \\
\hline
\end{tabular}

Page 19 


\begin{tabular}{|c|c|c|c|c|}
\hline \multicolumn{5}{|c|}{ Correlações } \\
\hline & & $\begin{array}{c}\text { Puxar vareta } \\
\text { fixa }\end{array}$ & Explorar caixa** & Scrounging ${ }^{\star \star \star}$ \\
\hline \multirow[t]{3}{*}{ Inserções observadas } & Correlação de Pearson &,- 228 &,- 353 & 350 \\
\hline & Sig. (2 extremidades) &, 527 &, 318 & ,322 \\
\hline & $\mathrm{N}$ & 10 & 10 & 10 \\
\hline \multirow[t]{3}{*}{ Tolerated Scrounging ${ }^{*}$} & Correlação de Pearson &,- 296 &,- 362 & ,291 \\
\hline & Sig. (2 extremidades) & ,406 & ,304 & , 415 \\
\hline & $\mathrm{N}$ & 10 & 10 & 10 \\
\hline \multirow{3}{*}{$\begin{array}{l}\text { Tempo na caixa com } \\
\text { Proficiente }\end{array}$} & Correlação de Pearson &,- 160 &,- 324 & ,262 \\
\hline & Sig. (2 extremidades) & 658 &, 361 & ,464 \\
\hline & $\mathrm{N}$ & 10 & 10 & 10 \\
\hline \multirow[t]{3}{*}{ Tempo a $2 \mathrm{~m}$ de Proficiente } & Correlação de Pearson &,- 078 & ,216 &, $703^{*}$ \\
\hline & Sig. (2 extremidades) & 830 &, 550 &, 023 \\
\hline & $\mathrm{N}$ & 10 & 10 & 10 \\
\hline \multirow[t]{3}{*}{ Tempo a $5 \mathrm{~m}$ de Proficiente } & Correlação de Pearson & ,327 & ,226 & ,104 \\
\hline & Sig. (2 extremidades) & ,356 &, 529 & ,776 \\
\hline & $\mathrm{N}$ & 10 & 10 & 10 \\
\hline \multirow[t]{3}{*}{ Tempo na caixa } & Correlação de Pearson & ,205 &,- 259 &,- 562 \\
\hline & Sig. (2 extremidades) &, 570 &, 470 & 091 \\
\hline & $\mathrm{N}$ & 10 & 10 & 10 \\
\hline \multirow[t]{3}{*}{ Tempo a $2 m$} & Correlação de Pearson &,- 367 & 069 &,- 145 \\
\hline & Sig. (2 extremidades) & ,296 & 851 & ,690 \\
\hline & $\mathrm{N}$ & 10 & 10 & 10 \\
\hline \multirow[t]{3}{*}{ Tempo a $5 \mathrm{~m}$} & Correlação de Pearson & ,299 &,- 247 &,- 351 \\
\hline & Sig. (2 extremidades) & ,402 & ,492 & ,320 \\
\hline & $\mathrm{N}$ & 10 & 10 & 10 \\
\hline \multirow{3}{*}{$\begin{array}{l}\text { Retirada de vareta } \\
\text { facilitada }\end{array}$} & Correlação de Pearson &,- 132 & 023 &,- 327 \\
\hline & Sig. (2 extremidades) &, 716 & 949 & ,357 \\
\hline & $\mathrm{N}$ & 10 & 10 & 10 \\
\hline \multirow[t]{3}{*}{ Puxar vareta fixa } & Correlação de Pearson & 1 &,- 303 &,- 183 \\
\hline & Sig. (2 extremidades) & & ,395 & ,612 \\
\hline & $\mathrm{N}$ & 10 & 10 & 10 \\
\hline \multirow[t]{3}{*}{ Explorar caixa ${ }^{* \star}$} & Correlação de Pearson &,- 303 & 1 & ,364 \\
\hline & Sig. (2 extremidades) & ,395 & & ,301 \\
\hline & $\mathrm{N}$ & 10 & 10 & 10 \\
\hline \multirow[t]{3}{*}{ Scrounging $^{\star \star \star}$} & Correlação de Pearson &,- 183 & ,364 & 1 \\
\hline & Sig. (2 extremidades) & ,612 & 301 & \\
\hline & $\mathrm{N}$ & 10 & 10 & 10 \\
\hline
\end{tabular}

Page 20 


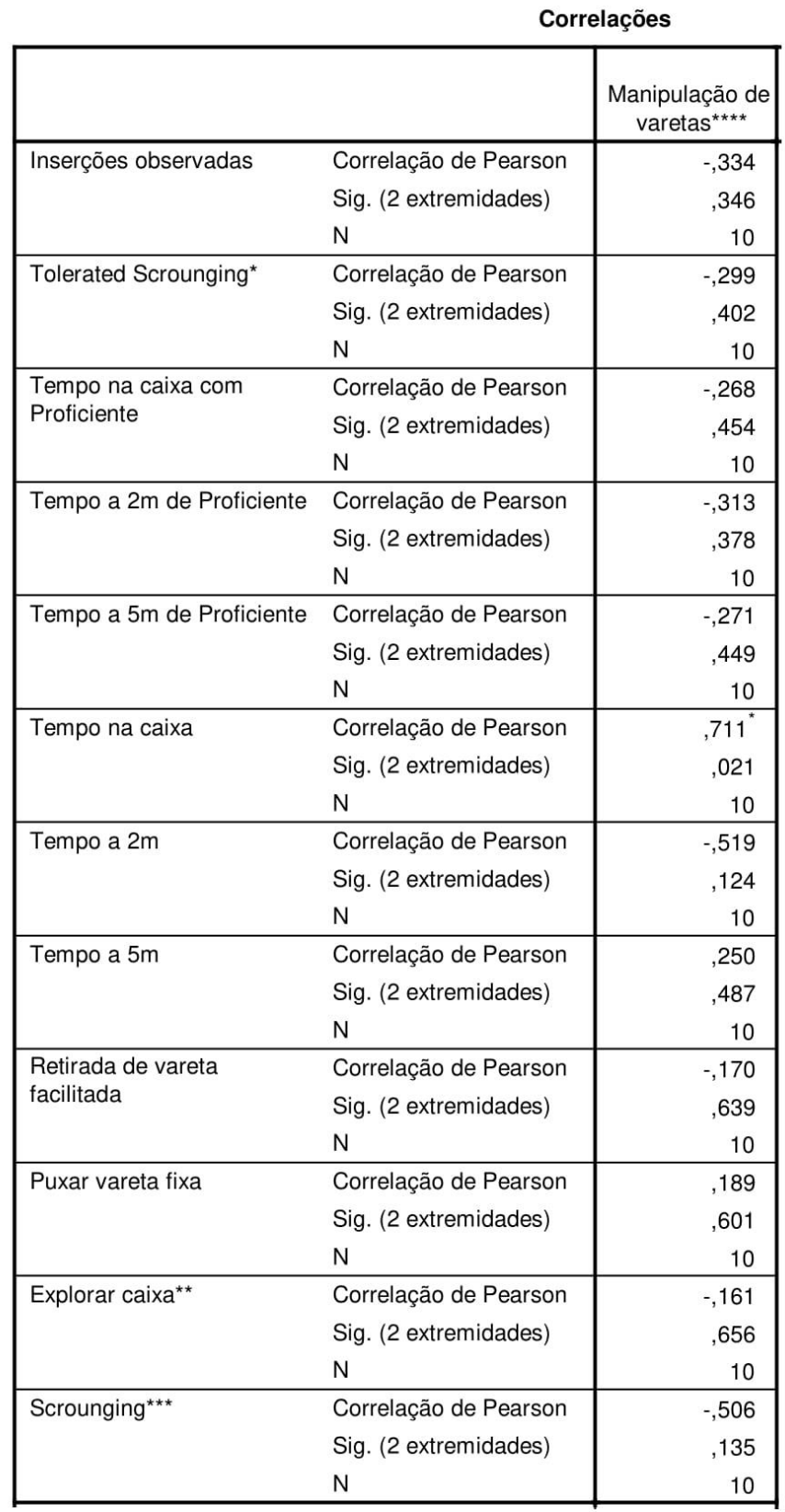




\begin{tabular}{|ll|r|r|r|}
\hline \multicolumn{1}{|c|}{ Correlações } \\
\hline & & $\begin{array}{c}\text { Inserções } \\
\text { observadas }\end{array}$ & $\begin{array}{c}\text { Tolerated } \\
\text { Scrounging }\end{array}$ & $\begin{array}{c}\text { Tempo na } \\
\text { caixa com } \\
\text { Proficiente }\end{array}$ \\
\hline Manipulação de varetas $^{\star \star * \star}$ & Correlação de Pearson &,- 334 &,- 299 &,- 268 \\
& Sig. (2 extremidades) &, 346 &, 402 &, 454 \\
& $\mathrm{~N}$ & 10 & 10 & 10 \\
\hline
\end{tabular}

Correlações

\begin{tabular}{|ll|r|r|r|}
\hline & & $\begin{array}{c}\text { Tempo a 2m de } \\
\text { Proficiente }\end{array}$ & $\begin{array}{c}\text { Tempo a 5m de } \\
\text { Proficiente }\end{array}$ & $\begin{array}{c}\text { Tempo na } \\
\text { caixa }\end{array}$ \\
\hline Manipulação de varetas $^{* \star \star *}$ Correlação de Pearson &,- 313 &,- 271 &, $711^{*}$ \\
& Sig. (2 extremidades) &, 378 &, 449 &, 021 \\
& $\mathrm{~N}$ & 10 & 10 & 10 \\
\hline
\end{tabular}

Correlações

\begin{tabular}{|c|c|c|c|c|}
\hline & & Tempo a $2 \mathrm{~m}$ & Tempo a $5 \mathrm{~m}$ & $\begin{array}{c}\text { Retirada de } \\
\text { vareta facilitada }\end{array}$ \\
\hline \multirow[t]{3}{*}{ Manipulação de varetas ${ }^{* \star \star \star}$} & Correlação de Pearson &,- 519 & ,250 &,- 170 \\
\hline & Sig. (2 extremidades) & 124 & 487 & 639 \\
\hline & $\mathrm{N}$ & 10 & 10 & 10 \\
\hline
\end{tabular}

Correlações

\begin{tabular}{|ll|r|r|r|}
\hline & $\begin{array}{c}\text { Puxar vareta } \\
\text { fixa }\end{array}$ & Explorar caixa** & Scrounging \\
\hline Manipulação de varetas $^{* * * *}$ \\
& Correlação de Pearson &, 189 &,- 161 &,- 506 \\
& Sig. (2 extremidades) &, 601 &, 656 &, 135 \\
$\mathrm{~N}$ & 10 & 10 & 10 \\
\hline
\end{tabular}

Correlações

\begin{tabular}{|ll|r|}
\hline & & $\begin{array}{c}\text { Manipulação de } \\
\text { varetas }^{* * * *}\end{array}$ \\
\hline Manipulação de varetas $^{* * * *}$ & $\begin{array}{l}\text { Correlação de Pearson } \\
\text { Sig. (2 extremidades) } \\
\mathrm{N}\end{array}$ & 1 \\
\hline
\end{tabular}

**. A correlação é significativa no nível 0,01 (2 extremidades).

*. A correlação é significativa no nível 0,05 (2 extremidades).

Correlações 2 e 3 
[Conjunto_de_dados2]

Correlações

\begin{tabular}{|c|c|c|c|c|}
\hline & & $\begin{array}{l}\text { Inserções } \\
\text { observadas }\end{array}$ & $\begin{array}{c}\text { Tolerated } \\
\text { Scrounging }\end{array}$ & $\begin{array}{l}\text { Tempo na } \\
\text { caixa com } \\
\text { Proficiente }\end{array}$ \\
\hline \multirow[t]{3}{*}{ Inserções observadas } & Correlação de Pearson & 1 &, $907^{\star *}$ &, $979^{* *}$ \\
\hline & Sig. (2 extremidades) & & ,000 & ,000 \\
\hline & $\mathrm{N}$ & 10 & 10 & 10 \\
\hline \multirow[t]{3}{*}{ Tolerated Scrounging ${ }^{*}$} & Correlação de Pearson &, $907^{\star \star}$ & 1 &, 920 ** \\
\hline & Sig. (2 extremidades) & ,000 & & ,000 \\
\hline & $\mathrm{N}$ & 10 & 10 & 10 \\
\hline \multirow{3}{*}{$\begin{array}{l}\text { Tempo na caixa com } \\
\text { Proficiente }\end{array}$} & Correlação de Pearson & $979^{\star \star}$ &, $920^{\star \star}$ & 1 \\
\hline & Sig. (2 extremidades) & ,000 & ,000 & \\
\hline & $\mathrm{N}$ & 10 & 10 & 10 \\
\hline \multirow[t]{3}{*}{ Tempo a $2 m$ de Proficiente } & Correlação de Pearson & ,578 &, 574 & , 556 \\
\hline & Sig. (2 extremidades) & ,080 & ,083 & ,095 \\
\hline & $\mathrm{N}$ & 10 & 10 & 10 \\
\hline \multirow[t]{3}{*}{ Tempo a $5 \mathrm{~m}$ de Proficiente } & Correlação de Pearson &,- 265 &,- 210 &,- 262 \\
\hline & Sig. (2 extremidades) & , 460 &, 560 & ,464 \\
\hline & $\mathrm{N}$ & 10 & 10 & 10 \\
\hline \multirow[t]{3}{*}{ Tempo na caixa } & Correlação de Pearson &,- 095 & , 107 & ,002 \\
\hline & Sig. (2 extremidades) & ,793 & ,768 & ,996 \\
\hline & $\mathrm{N}$ & 10 & 10 & 10 \\
\hline \multirow[t]{3}{*}{ Tempo a $2 \mathrm{~m}$} & Correlação de Pearson & ,444 & ,631 & ,393 \\
\hline & Sig. (2 extremidades) & , 199 & 051 & ,262 \\
\hline & $\mathrm{N}$ & 10 & 10 & 10 \\
\hline \multirow[t]{3}{*}{ Tempo a $5 \mathrm{~m}$} & Correlação de Pearson & ,273 & ,281 & ,333 \\
\hline & Sig. (2 extremidades) & ,446 & ,432 & ,348 \\
\hline & $\mathrm{N}$ & 10 & 10 & 10 \\
\hline \multirow{3}{*}{$\begin{array}{l}\text { Retirada de vareta } \\
\text { facilitada }\end{array}$} & Correlação de Pearson &,- 432 &,- 438 &,- 388 \\
\hline & Sig. (2 extremidades) & ,212 & ,206 & ,267 \\
\hline & $\mathrm{N}$ & 10 & 10 & 10 \\
\hline \multirow[t]{3}{*}{ Puxar vareta fixa } & Correlação de Pearson &,- 542 &,- 446 &,- 456 \\
\hline & Sig. (2 extremidades) & , 106 & , 196 & , 186 \\
\hline & $\mathrm{N}$ & 10 & 10 & 10 \\
\hline \multirow[t]{3}{*}{ Explorar caixa** } & Correlação de Pearson &,- 425 &,- 311 &,- 409 \\
\hline & Sig. (2 extremidades) & ,221 & ,381 & ,241 \\
\hline & $\mathrm{N}$ & 10 & 10 & 10 \\
\hline \multirow[t]{3}{*}{ Scrounging ${ }^{* * *}$} & Correlação de Pearson & ,332 & , 120 & ,255 \\
\hline & Sig. (2 extremidades) & ,349 & ,742 & , 478 \\
\hline & $\mathrm{N}$ & 10 & 10 & 10 \\
\hline
\end{tabular}

Page 23 


\begin{tabular}{|c|c|c|c|c|}
\hline \multicolumn{5}{|c|}{ Correlações } \\
\hline & & $\begin{array}{c}\text { Tempo a } 2 \mathrm{~m} \text { de } \\
\text { Proficiente }\end{array}$ & $\begin{array}{c}\text { Tempo a } 5 \mathrm{~m} \text { de } \\
\text { Proficiente }\end{array}$ & $\begin{array}{l}\text { Tempo na } \\
\text { caixa }\end{array}$ \\
\hline \multirow[t]{3}{*}{ Inserções observadas } & Correlação de Pearson &, 578 &,- 265 &,- 095 \\
\hline & Sig. (2 extremidades) & 080 &, 460 & ,793 \\
\hline & $\mathrm{N}$ & 10 & 10 & 10 \\
\hline \multirow[t]{3}{*}{ Tolerated Scrounging* } & Correlação de Pearson & ,574 &,- 210 &, 107 \\
\hline & Sig. (2 extremidades) & ,083 &, 560 &, 768 \\
\hline & $\mathrm{N}$ & 10 & 10 & 10 \\
\hline \multirow{3}{*}{$\begin{array}{l}\text { Tempo na caixa com } \\
\text { Proficiente }\end{array}$} & Correlação de Pearson & ,556 &,- 262 &, 002 \\
\hline & Sig. (2 extremidades) & ,095 & ,464 & ,996 \\
\hline & $\mathrm{N}$ & 10 & 10 & 10 \\
\hline \multirow[t]{3}{*}{ Tempo a $2 \mathrm{~m}$ de Proficiente } & Correlação de Pearson & 1 & ,443 &,- 357 \\
\hline & Sig. (2 extremidades) & & 199 & ,311 \\
\hline & $\mathrm{N}$ & 10 & 10 & 10 \\
\hline \multirow[t]{3}{*}{ Tempo a $5 \mathrm{~m}$ de Proficiente } & Correlação de Pearson & ,443 & 1 &,- 236 \\
\hline & Sig. (2 extremidades) & , 199 & &, 511 \\
\hline & $\mathrm{N}$ & 10 & 10 & 10 \\
\hline \multirow[t]{3}{*}{ Tempo na caixa } & Correlação de Pearson &,- 357 &,- 236 & 1 \\
\hline & Sig. (2 extremidades) & ,311 &, 511 & \\
\hline & $\mathrm{N}$ & 10 & 10 & 10 \\
\hline \multirow[t]{3}{*}{ Tempo a $2 \mathrm{~m}$} & Correlação de Pearson & ,245 &,- 032 &,- 058 \\
\hline & Sig. (2 extremidades) & ,495 & ,931 & ,873 \\
\hline & $\mathrm{N}$ & 10 & 10 & 10 \\
\hline \multirow[t]{3}{*}{ Tempo a $5 \mathrm{~m}$} & Correlação de Pearson &,- 390 &,$- 680^{*}$ & , 173 \\
\hline & Sig. (2 extremidades) & ,265 & ,030 & ,632 \\
\hline & $\mathrm{N}$ & 10 & 10 & 10 \\
\hline \multirow{3}{*}{$\begin{array}{l}\text { Retirada de vareta } \\
\text { facilitada }\end{array}$} & Correlação de Pearson &,- 583 &,- 269 &, 534 \\
\hline & Sig. (2 extremidades) & ,077 & ,453 &, 112 \\
\hline & $\mathrm{N}$ & 10 & 10 & 10 \\
\hline \multirow[t]{3}{*}{ Puxar vareta fixa } & Correlação de Pearson &,- 455 &,- 064 &, $707^{*}$ \\
\hline & Sig. (2 extremidades) & , 186 & ,861 & ,022 \\
\hline & $\mathrm{N}$ & 10 & 10 & 10 \\
\hline \multirow[t]{3}{*}{ Explorar caixa ${ }^{\star *}$} & Correlação de Pearson &,- 065 &,- 075 &,- 284 \\
\hline & Sig. (2 extremidades) & ,858 & ,836 & , 426 \\
\hline & $\mathrm{N}$ & 10 & 10 & 10 \\
\hline \multirow[t]{3}{*}{ Scrounging ${ }^{\star \star \star}$} & Correlação de Pearson & 600 & ,330 &,- 413 \\
\hline & Sig. (2 extremidades) &, 067 & ,352 & ,235 \\
\hline & $\mathrm{N}$ & 10 & 10 & 10 \\
\hline
\end{tabular}

Page 24 


\begin{tabular}{|c|c|c|c|c|}
\hline \multicolumn{5}{|c|}{ Correlações } \\
\hline & & Tempo a $2 \mathrm{~m}$ & Tempo a $5 \mathrm{~m}$ & $\begin{array}{c}\text { Retirada de } \\
\text { vareta facilitada }\end{array}$ \\
\hline \multirow[t]{3}{*}{ Inserções observadas } & Correlação de Pearson & ,444 & 273 &,- 432 \\
\hline & Sig. (2 extremidades) & , 199 & ,446 & ,212 \\
\hline & $\mathrm{N}$ & 10 & 10 & 10 \\
\hline \multirow[t]{3}{*}{ Tolerated Scrounging ${ }^{*}$} & Correlação de Pearson & 631 & ,281 &,- 438 \\
\hline & Sig. (2 extremidades) & ,051 & ,432 & 206 \\
\hline & $\mathrm{N}$ & 10 & 10 & 10 \\
\hline \multirow{3}{*}{$\begin{array}{l}\text { Tempo na caixa com } \\
\text { Proficiente }\end{array}$} & Correlação de Pearson & ,393 & ,333 &,- 388 \\
\hline & Sig. (2 extremidades) & ,262 & ,348 & ,267 \\
\hline & $\mathrm{N}$ & 10 & 10 & 10 \\
\hline \multirow[t]{3}{*}{ Tempo a $2 \mathrm{~m}$ de Proficiente } & Correlação de Pearson & ,245 &,- 390 &,- 583 \\
\hline & Sig. (2 extremidades) & ,495 & ,265 & ,077 \\
\hline & $\mathrm{N}$ & 10 & 10 & 10 \\
\hline \multirow[t]{3}{*}{ Tempo a 5m de Proficiente } & Correlação de Pearson &,- 032 &,$- 680^{*}$ &,- 269 \\
\hline & Sig. (2 extremidades) & ,931 &, 030 & ,453 \\
\hline & $\mathrm{N}$ & 10 & 10 & 10 \\
\hline \multirow[t]{3}{*}{ Tempo na caixa } & Correlação de Pearson &,- 058 & ,173 &, 534 \\
\hline & Sig. (2 extremidades) & ,873 & ,632 & ,112 \\
\hline & $\mathrm{N}$ & 10 & 10 & 10 \\
\hline \multirow[t]{3}{*}{ Tempo a $2 \mathrm{~m}$} & Correlação de Pearson & 1 & ,352 &,- 538 \\
\hline & Sig. (2 extremidades) & & ,319 & , 109 \\
\hline & $\mathrm{N}$ & 10 & 10 & 10 \\
\hline \multirow[t]{3}{*}{ Tempo a $5 \mathrm{~m}$} & Correlação de Pearson & ,352 & 1 &,- 101 \\
\hline & Sig. (2 extremidades) & ,319 & & ,782 \\
\hline & $\mathrm{N}$ & 10 & 10 & 10 \\
\hline \multirow{3}{*}{$\begin{array}{l}\text { Retirada de vareta } \\
\text { facilitada }\end{array}$} & Correlação de Pearson &,- 538 &,- 101 & 1 \\
\hline & Sig. (2 extremidades) & ,109 & ,782 & \\
\hline & $\mathrm{N}$ & 10 & 10 & 10 \\
\hline \multirow[t]{3}{*}{ Puxar vareta fixa } & Correlação de Pearson &,- 588 &,- 185 &, $875^{* \star}$ \\
\hline & Sig. (2 extremidades) & 074 &, 610 & ,001 \\
\hline & $\mathrm{N}$ & 10 & 10 & 10 \\
\hline \multirow[t]{3}{*}{ Explorar caixa** } & Correlação de Pearson &,- 048 & ,151 &,- 115 \\
\hline & Sig. (2 extremidades) & ,896 & 676 & ,751 \\
\hline & $\mathrm{N}$ & 10 & 10 & 10 \\
\hline \multirow[t]{3}{*}{ Scrounging ${ }^{\star \star \star}$} & Correlação de Pearson &,- 208 &,- 411 &,- 497 \\
\hline & Sig. (2 extremidades) &, 564 & 238 & 144 \\
\hline & $\mathrm{N}$ & 10 & 10 & 10 \\
\hline
\end{tabular}

Page 25 


\begin{tabular}{|c|c|c|c|c|}
\hline \multicolumn{5}{|c|}{ Correlações } \\
\hline & & $\begin{array}{l}\text { Puxar vareta } \\
\text { fixa }\end{array}$ & Explorar caixa** & Scrounging $^{\star \star *}$ \\
\hline \multirow[t]{3}{*}{ Inserções observadas } & Correlação de Pearson &,- 542 &,- 425 & ,332 \\
\hline & Sig. (2 extremidades) & , 106 & ,221 & ,349 \\
\hline & $\mathrm{N}$ & 10 & 10 & 10 \\
\hline \multirow[t]{3}{*}{ Tolerated Scrounging* } & Correlação de Pearson &,- 446 &,- 311 & 120 \\
\hline & Sig. (2 extremidades) & 196 & 381 & ,742 \\
\hline & $\mathrm{N}$ & 10 & 10 & 10 \\
\hline \multirow{3}{*}{$\begin{array}{l}\text { Tempo na caixa com } \\
\text { Proficiente }\end{array}$} & Correlação de Pearson &,- 456 &,- 409 & ,255 \\
\hline & Sig. (2 extremidades) & , 186 & ,241 & , 478 \\
\hline & $\mathrm{N}$ & 10 & 10 & 10 \\
\hline \multirow[t]{3}{*}{ Tempo a $2 \mathrm{~m}$ de Proficiente } & Correlação de Pearson &,- 455 &,- 065 & 600 \\
\hline & Sig. (2 extremidades) & 186 & 858 & ,067 \\
\hline & $\mathrm{N}$ & 10 & 10 & 10 \\
\hline \multirow[t]{3}{*}{ Tempo a $5 \mathrm{~m}$ de Proficiente } & Correlação de Pearson &,- 064 &,- 075 & ,330 \\
\hline & Sig. (2 extremidades) & ,861 & ,836 & ,352 \\
\hline & $\mathrm{N}$ & 10 & 10 & 10 \\
\hline \multirow[t]{3}{*}{ Tempo na caixa } & Correlação de Pearson &, $707^{*}$ &,- 284 &,- 413 \\
\hline & Sig. (2 extremidades) & ,022 & ,426 & ,235 \\
\hline & $\mathrm{N}$ & 10 & 10 & 10 \\
\hline \multirow[t]{3}{*}{ Tempo a $2 m$} & Correlação de Pearson &,- 588 &,- 048 &,- 208 \\
\hline & Sig. (2 extremidades) &, 074 & ,896 &, 564 \\
\hline & $\mathrm{N}$ & 10 & 10 & 10 \\
\hline \multirow[t]{3}{*}{ Tempo a $5 \mathrm{~m}$} & Correlação de Pearson &,- 185 & ,151 &,- 411 \\
\hline & Sig. (2 extremidades) & ,610 & ,676 & ,238 \\
\hline & $\mathrm{N}$ & 10 & 10 & 10 \\
\hline \multirow{3}{*}{$\begin{array}{l}\text { Retirada de vareta } \\
\text { facilitada }\end{array}$} & Correlação de Pearson & $875^{\star *}$ &,- 115 &,- 497 \\
\hline & Sig. (2 extremidades) &, 001 &, 751 &, 144 \\
\hline & $\mathrm{N}$ & 10 & 10 & 10 \\
\hline \multirow[t]{3}{*}{ Puxar vareta fixa } & Correlação de Pearson & 1 & 045 &,- 344 \\
\hline & Sig. (2 extremidades) & & ,901 & ,331 \\
\hline & $\mathrm{N}$ & 10 & 10 & 10 \\
\hline \multirow[t]{3}{*}{ Explorar caixa** } & Correlação de Pearson &, 045 & 1 &,- 041 \\
\hline & Sig. (2 extremidades) & ,901 & & 911 \\
\hline & $\mathrm{N}$ & 10 & 10 & 10 \\
\hline \multirow[t]{3}{*}{ Scrounging $^{\star \star *}$} & Correlação de Pearson &,- 344 &,- 041 & 1 \\
\hline & Sig. (2 extremidades) & ,331 & ,911 & \\
\hline & $\mathrm{N}$ & 10 & 10 & 10 \\
\hline
\end{tabular}

Page 26 


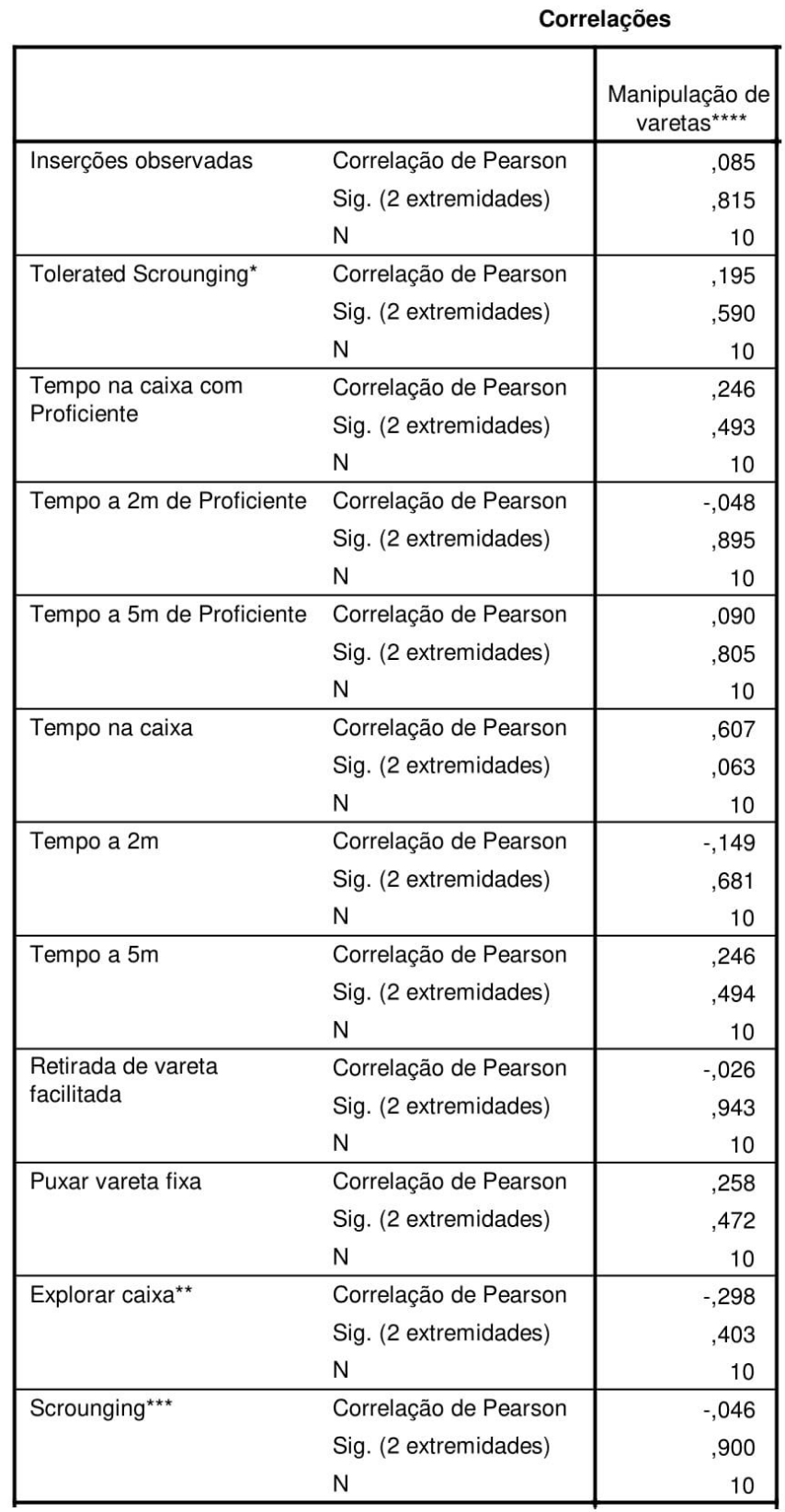




\begin{tabular}{|c|c|c|c|c|}
\hline \multicolumn{5}{|c|}{ Correlações } \\
\hline & & $\begin{array}{l}\text { Inserções } \\
\text { observadas }\end{array}$ & $\begin{array}{l}\text { Tolerated } \\
\text { Scrounging* }\end{array}$ & $\begin{array}{l}\text { Tempo na } \\
\text { caixa com } \\
\text { Proficiente }\end{array}$ \\
\hline \multirow[t]{3}{*}{ Manipulação de varetas ${ }^{\star \star \star \star}$} & Correlação de Pearson & ,085 & ,195 & ,246 \\
\hline & Sig. (2 extremidades) & ,815 &, 590 & ,493 \\
\hline & $\mathrm{N}$ & 10 & 10 & 10 \\
\hline
\end{tabular}

Correlações

\begin{tabular}{|ll|r|r|r|}
\hline & & $\begin{array}{c}\text { Tempo a 2m de } \\
\text { Proficiente }\end{array}$ & $\begin{array}{c}\text { Tempo a 5m de } \\
\text { Proficiente }\end{array}$ & $\begin{array}{c}\text { Tempo na } \\
\text { caixa }\end{array}$ \\
\hline Manipulação de varetas $^{* \star \star *}$ Correlação de Pearson &,- 048 &, 090 &, 607 \\
& Sig. (2 extremidades) &, 895 &, 805 &, 063 \\
$\mathrm{~N}$ & 10 & 10 & 10 \\
\hline
\end{tabular}

Correlações

\begin{tabular}{|c|c|c|c|c|}
\hline & & Tempo a $2 m$ & Tempo a $5 \mathrm{~m}$ & $\begin{array}{c}\text { Retirada de } \\
\text { vareta facilitada }\end{array}$ \\
\hline \multirow[t]{3}{*}{ Manipulação de varetas ${ }^{* \star * \star}$} & Correlação de Pearson &,- 149 & ,246 &,- 026 \\
\hline & Sig. (2 extremidades) & 681 & 494 & ,943 \\
\hline & $\mathrm{N}$ & 10 & 10 & 10 \\
\hline
\end{tabular}

Correlações

\begin{tabular}{|ll|r|r|r|}
\hline & $\begin{array}{c}\text { Puxar vareta } \\
\text { fixa }\end{array}$ & Explorar caixa** & Scrounging \\
\hline Manipulação de varetas $^{* * * *}$ \\
& Correlação de Pearson &, 258 &,- 298 &,- 046 \\
& Sig. (2 extremidades) &, 472 &, 403 &, 900 \\
$\mathrm{~N}$ & 10 & 10 & 10 \\
\hline
\end{tabular}

Correlações

\begin{tabular}{|ll|r|}
\hline & & $\begin{array}{c}\text { Manipulação de } \\
\text { varetas }^{* * * *}\end{array}$ \\
\hline Manipulação de varetas $^{* * * *}$ Correlação de Pearson & 1 \\
& Sig. (2 extremidades) \\
$\mathrm{N}$ & 10 \\
\hline
\end{tabular}

**. A correlação é significativa no nível 0,01 (2 extremidades).

*. A correlação é significativa no nível 0,05 (2 extremidades). 
APÊNDICE E - TESTES ESTATÍSTICOS NÃO PARAMÉTRICOS (DADOS BRUTOS)

Testes de NPar

Teste Kruskal-Wallis - BRUTO

\begin{tabular}{|c|c|c|c|}
\hline \multicolumn{4}{|c|}{ Classificações } \\
\hline & Sucesso & $\mathrm{N}$ & $\begin{array}{l}\text { Postos de } \\
\text { média }\end{array}$ \\
\hline \multirow[t]{4}{*}{ Inserções observadas } & 1,00 & 5 & 8,50 \\
\hline & 2,00 & 5 & 9,90 \\
\hline & 3,00 & 5 & 5,60 \\
\hline & Total & 15 & \\
\hline \multirow[t]{4}{*}{ Tolerated Scrounging* } & 1,00 & 5 & 8,00 \\
\hline & 2,00 & 5 & 10,80 \\
\hline & 3,00 & 5 & 5,20 \\
\hline & Total & 15 & \\
\hline \multirow{4}{*}{$\begin{array}{l}\text { Tempo na caixa com } \\
\text { Proficiente }\end{array}$} & 1,00 & 5 & 9,40 \\
\hline & 2,00 & 5 & 10,00 \\
\hline & 3,00 & 5 & 4,60 \\
\hline & Total & 15 & \\
\hline \multirow[t]{4}{*}{ Tempo a $2 \mathrm{~m}$ de Proficiente } & 1,00 & 5 & 11,00 \\
\hline & 2,00 & 5 & 9,40 \\
\hline & 3,00 & 5 & 3,60 \\
\hline & Total & 15 & \\
\hline \multirow[t]{4}{*}{ Tempo a 5m de Proficiente } & 1,00 & 5 & 10,20 \\
\hline & 2,00 & 5 & 9,60 \\
\hline & 3,00 & 5 & 4,20 \\
\hline & Total & 15 & \\
\hline \multirow[t]{4}{*}{ Tempo na caixa } & 1,00 & 5 & 11,00 \\
\hline & 2,00 & 5 & 10,00 \\
\hline & 3,00 & 5 & 3,00 \\
\hline & Total & 15 & \\
\hline \multirow[t]{4}{*}{ Tempo a 2m } & 1,00 & 5 & 10,20 \\
\hline & 2,00 & 5 & 10,80 \\
\hline & 3,00 & 5 & 3,00 \\
\hline & Total & 15 & \\
\hline \multirow[t]{4}{*}{ Tempo a 5m } & 1,00 & 5 & 10,60 \\
\hline & 2,00 & 5 & 10,00 \\
\hline & 3,00 & 5 & 3,40 \\
\hline & Total & 15 & \\
\hline
\end{tabular}




\begin{tabular}{|c|c|c|c|}
\hline \multicolumn{4}{|c|}{ Classificações } \\
\hline & Sucesso & $\mathrm{N}$ & $\begin{array}{l}\text { Postos de } \\
\text { média }\end{array}$ \\
\hline \multirow{4}{*}{$\begin{array}{l}\text { Retirada de vareta } \\
\text { facilitada }\end{array}$} & 1,00 & 5 & 10,60 \\
\hline & 2,00 & 5 & 7,00 \\
\hline & 3,00 & 5 & 6,40 \\
\hline & Total & 15 & \\
\hline \multirow[t]{4}{*}{ Puxar vareta fixa } & 1,00 & 5 & 10,20 \\
\hline & 2,00 & 5 & 8,00 \\
\hline & 3,00 & 5 & 5,80 \\
\hline & Total & 15 & \\
\hline \multirow[t]{4}{*}{ Explorar caixa ${ }^{\star \star}$} & 1,00 & 5 & 10,80 \\
\hline & 2,00 & 5 & 10,20 \\
\hline & 3,00 & 5 & 3,00 \\
\hline & Total & 15 & \\
\hline \multirow[t]{4}{*}{ Scrounging ${ }^{* * *}$} & 1,00 & 5 & 5,60 \\
\hline & 2,00 & 5 & 11,60 \\
\hline & 3,00 & 5 & 6,80 \\
\hline & Total & 15 & \\
\hline \multirow[t]{4}{*}{ Manipulação de varetas ${ }^{\star \star \star \star ~}$} & 1,00 & 5 & 12,60 \\
\hline & 2,00 & 5 & 8,40 \\
\hline & 3,00 & 5 & 3,00 \\
\hline & Total & 15 & \\
\hline
\end{tabular}

Estatísticas de teste ${ }^{a, b}$

\begin{tabular}{|l|r|r|r|r|r|}
\hline & $\begin{array}{c}\text { Inserções } \\
\text { observadas }\end{array}$ & $\begin{array}{c}\text { Tolerated } \\
\text { Scrounging* }\end{array}$ & $\begin{array}{l}\text { Tempo na } \\
\text { caixa com } \\
\text { Proficiente }\end{array}$ & $\begin{array}{c}\text { Tempo a 2m de } \\
\text { Proficiente }\end{array}$ & $\begin{array}{c}\text { Tempo a 5m de } \\
\text { Proficiente }\end{array}$ \\
\hline Qui-quadrado & 2,409 & 3,920 & 4,380 & 7,580 & 5,460 \\
df & 2 & 2 & 2 & 2 & 2 \\
Significância Sig. &, 300 &, 141 &, 112 &, 023 &, 065 \\
\hline
\end{tabular}

Estatísticas de teste $\mathrm{e}^{\mathrm{a}, \mathrm{b}}$

\begin{tabular}{|l|r|r|r|r|r|}
\hline & $\begin{array}{c}\text { Tempo na } \\
\text { caixa }\end{array}$ & Tempo a 2m & Tempo a 5m & $\begin{array}{c}\text { Retirada de } \\
\text { vareta facilitada }\end{array}$ & $\begin{array}{c}\text { Puxar vareta } \\
\text { fixa }\end{array}$ \\
\hline Qui-quadrado & 9,500 & 9,420 & 7,980 & 2,585 & 2,437 \\
df & 2 & 2 & 2 & 2 & 2 \\
Significância Sig. &, 009 &, 009 &, 018 &, 275 &, 296 \\
\hline
\end{tabular}


Estatísticas de teste ${ }^{a, b}$

\begin{tabular}{|l|r|r|r|}
\hline & Explorar caixa** & Scrounging & $\begin{array}{c}\text { Manipulação de } \\
\text { varetas }^{\star * \star *}\end{array}$ \\
\hline Qui-quadrado & 9,420 & 5,085 & 11,601 \\
df & 2 & 2 & 2 \\
Significância Sig. &, 009 &, 079 &, 003 \\
\hline
\end{tabular}

a. Teste Kruskal Wallis

b. Variável de Agrupamento: Sucesso

Testes de NPar

Teste Mann-Whitney 12 BRUTO

\begin{tabular}{|c|c|c|c|c|}
\hline \multicolumn{5}{|c|}{ Classificações } \\
\hline & Sucesso & $\mathrm{N}$ & $\begin{array}{l}\text { Postos de } \\
\text { média }\end{array}$ & $\begin{array}{c}\text { Soma de } \\
\text { Classificações }\end{array}$ \\
\hline \multirow[t]{3}{*}{ Inserções observadas } & 1,00 & 5 & 4,90 & 24,50 \\
\hline & 2,00 & 5 & 6,10 & 30,50 \\
\hline & Total & 10 & & \\
\hline \multirow[t]{3}{*}{ Tolerated Scrounging* } & 1,00 & 5 & 4,60 & 23,00 \\
\hline & 2,00 & 5 & 6,40 & 32,00 \\
\hline & Total & 10 & & \\
\hline \multirow{3}{*}{$\begin{array}{l}\text { Tempo na caixa com } \\
\text { Proficiente }\end{array}$} & 1,00 & 5 & 5,20 & 26,00 \\
\hline & 2,00 & 5 & 5,80 & 29,00 \\
\hline & Total & 10 & & \\
\hline \multirow[t]{3}{*}{ Tempo a $2 \mathrm{~m}$ de Proficiente } & 1,00 & 5 & 6,00 & 30,00 \\
\hline & 2,00 & 5 & 5,00 & 25,00 \\
\hline & Total & 10 & & \\
\hline \multirow[t]{3}{*}{ Tempo a $5 \mathrm{~m}$ de Proficiente } & 1,00 & 5 & 5,80 & 29,00 \\
\hline & 2,00 & 5 & 5,20 & 26,00 \\
\hline & Total & 10 & & \\
\hline \multirow[t]{3}{*}{ Tempo na caixa } & 1,00 & 5 & 6,00 & 30,00 \\
\hline & 2,00 & 5 & 5,00 & 25,00 \\
\hline & Total & 10 & & \\
\hline \multirow[t]{3}{*}{ Tempo a $2 \mathrm{~m}$} & 1,00 & 5 & 5,20 & 26,00 \\
\hline & 2,00 & 5 & 5,80 & 29,00 \\
\hline & Total & 10 & & \\
\hline
\end{tabular}




\begin{tabular}{|c|c|c|c|c|}
\hline \multicolumn{5}{|c|}{ Classificações } \\
\hline & Sucesso & $\mathrm{N}$ & $\begin{array}{l}\text { Postos de } \\
\text { média }\end{array}$ & $\begin{array}{c}\text { Soma de } \\
\text { Classificações }\end{array}$ \\
\hline \multirow[t]{3}{*}{ Tempo a $5 \mathrm{~m}$} & 1,00 & 5 & 6,00 & 30,00 \\
\hline & 2,00 & 5 & 5,00 & 25,00 \\
\hline & Total & 10 & & \\
\hline \multirow{3}{*}{$\begin{array}{l}\text { Retirada de vareta } \\
\text { facilitada }\end{array}$} & 1,00 & 5 & 6,00 & 30,00 \\
\hline & 2,00 & 5 & 5,00 & 25,00 \\
\hline & Total & 10 & & \\
\hline \multirow[t]{3}{*}{ Puxar vareta fixa } & 1,00 & 5 & 6,00 & 30,00 \\
\hline & 2,00 & 5 & 5,00 & 25,00 \\
\hline & Total & 10 & & \\
\hline \multirow[t]{3}{*}{ Explorar caixa** } & 1,00 & 5 & 5,80 & 29,00 \\
\hline & 2,00 & 5 & 5,20 & 26,00 \\
\hline & Total & 10 & & \\
\hline \multirow[t]{3}{*}{ Scrounging ${ }^{\star * *}$} & 1,00 & 5 & 3,60 & 18,00 \\
\hline & 2,00 & 5 & 7,40 & 37,00 \\
\hline & Total & 10 & & \\
\hline \multirow[t]{3}{*}{ Manipulação de varetas ${ }^{\star * \star *}$} & 1,00 & 5 & 7,60 & 38,00 \\
\hline & 2,00 & 5 & 3,40 & 17,00 \\
\hline & Total & 10 & & \\
\hline
\end{tabular}

Estatísticas de teste ${ }^{a}$

\begin{tabular}{|l|r|r|r|r|}
\hline & $\begin{array}{c}\text { Inserções } \\
\text { observadas }\end{array}$ & $\begin{array}{c}\text { Tolerated } \\
\text { Scrounging }^{*}\end{array}$ & $\begin{array}{c}\text { Tempo na } \\
\text { caixa com } \\
\text { Proficiente }\end{array}$ & $\begin{array}{c}\text { Tempo a 2m de } \\
\text { Proficiente }\end{array}$ \\
\hline U de Mann-Whitney & 9,500 & 8,000 & 11,000 & 10,000 \\
Wilcoxon W & 24,500 & 23,000 & 26,000 & 25,000 \\
Z &,- 629 &,- 940 &,- 313 &,- 522 \\
$\begin{array}{l}\text { Significância Sig. (2 } \\
\text { extremidades) }\end{array}$ &, 530 &, 347 &, 754 &, 602 \\
$\begin{array}{l}\text { Sig exata [2*(Sig. de 1 } \\
\text { extremidade)] }\end{array}$ &, $548^{\mathrm{b}}$ &, $421^{\mathrm{b}}$ &, $841^{\mathrm{b}}$ &, $690^{\mathrm{b}}$ \\
\hline
\end{tabular}


Estatísticas de teste ${ }^{a}$

\begin{tabular}{|l|r|r|r|r|}
\hline & $\begin{array}{c}\text { Tempo a 5m de } \\
\text { Proficiente }\end{array}$ & $\begin{array}{c}\text { Tempo na } \\
\text { caixa }\end{array}$ & Tempo a 2m & Tempo a 5m \\
\hline U de Mann-Whitney & 11,000 & 10,000 & 11,000 & 10,000 \\
Wilcoxon W & 26,000 & 25,000 & 26,000 & 25,000 \\
Z &,- 313 &,- 522 &,- 313 &,- 522 \\
Significância Sig. (2 &, 754 &, 602 &, 754 &, 602 \\
extremidades) &, $841^{\mathrm{b}}$ &, $690^{\mathrm{b}}$ &, $841^{\mathrm{b}}$ &, $690^{\mathrm{b}}$ \\
$\begin{array}{l}\text { Sig exata [2*(Sig. de 1 } \\
\text { extremidade)] }\end{array}$ & & & & \\
\hline
\end{tabular}

Estatísticas de teste ${ }^{a}$

\begin{tabular}{|l|r|r|r|r|}
\hline & $\begin{array}{c}\text { Retirada de } \\
\text { vareta facilitada }\end{array}$ & $\begin{array}{c}\text { Puxar vareta } \\
\text { fixa }\end{array}$ & Explorar caixa** $^{* *}$ & Scrounging $^{* * *}$ \\
\hline U de Mann-Whitney & 10,000 & 10,000 & 11,000 & 3,000 \\
Wilcoxon W & 25,000 & 25,000 & 26,000 & 18,000 \\
Z &,- 524 &,- 522 &,- 313 & $-2,015$ \\
Significância Sig. (2 &, 600 &, 602 &, 754 &, 044 \\
extremidades) &, $690^{\mathrm{b}}$ &, $690^{\mathrm{b}}$ &, $841^{\mathrm{b}}$ &, $056^{\mathrm{b}}$ \\
$\begin{array}{l}\text { Sig exata [2*(Sig. de 1 } \\
\text { extremidade)] }\end{array}$ & & & \\
\hline
\end{tabular}

Estatísticas de teste ${ }^{a}$

\begin{tabular}{|l|r|}
\hline & $\begin{array}{c}\text { Manipulação de } \\
\text { varetas }^{\star \star \star *}\end{array}$ \\
\hline U de Mann-Whitney & 2,000 \\
Wilcoxon W & 17,000 \\
Z & $-2,193$ \\
Significância Sig. (2 &, 028 \\
extremidades) &, $032^{\mathrm{b}}$ \\
Sig exata [2*(Sig. de 1 &,${ }^{\text {extremidade)] }}$ \\
\hline
\end{tabular}

a. Variável de Agrupamento: Sucesso

b. Não corrigido para vínculos.

\section{Testes de NPar}

Teste Mann-Whitney 13 BRUTO 


\begin{tabular}{|c|c|c|c|c|}
\hline \multicolumn{5}{|c|}{ Classificações } \\
\hline & Sucesso & $\mathrm{N}$ & $\begin{array}{l}\text { Postos de } \\
\text { média }\end{array}$ & $\begin{array}{c}\text { Soma de } \\
\text { Classificações }\end{array}$ \\
\hline \multirow[t]{3}{*}{ Inserções observadas } & 1,00 & 5 & 6,60 & 33,00 \\
\hline & 3,00 & 5 & 4,40 & 22,00 \\
\hline & Total & 10 & & \\
\hline \multirow[t]{3}{*}{ Tolerated Scrounging* } & 1,00 & 5 & 6,40 & 32,00 \\
\hline & 3,00 & 5 & 4,60 & 23,00 \\
\hline & Total & 10 & & \\
\hline \multirow{3}{*}{$\begin{array}{l}\text { Tempo na caixa com } \\
\text { Proficiente }\end{array}$} & 1,00 & 5 & 7,20 & 36,00 \\
\hline & 3,00 & 5 & 3,80 & 19,00 \\
\hline & Total & 10 & & \\
\hline \multirow[t]{3}{*}{ Tempo a $2 \mathrm{~m}$ de Proficiente } & 1,00 & 5 & 8,00 & 40,00 \\
\hline & 3,00 & 5 & 3,00 & 15,00 \\
\hline & Total & 10 & & \\
\hline \multirow[t]{3}{*}{ Tempo a 5m de Proficiente } & 1,00 & 5 & 7,40 & 37,00 \\
\hline & 3,00 & 5 & 3,60 & 18,00 \\
\hline & Total & 10 & & \\
\hline \multirow[t]{3}{*}{ Tempo na caixa } & 1,00 & 5 & 8,00 & 40,00 \\
\hline & 3,00 & 5 & 3,00 & 15,00 \\
\hline & Total & 10 & & \\
\hline \multirow[t]{3}{*}{ Tempo a $2 \mathrm{~m}$} & 1,00 & 5 & 8,00 & 40,00 \\
\hline & 3,00 & 5 & 3,00 & 15,00 \\
\hline & Total & 10 & & \\
\hline \multirow[t]{3}{*}{ Tempo a $5 \mathrm{~m}$} & 1,00 & 5 & 7,60 & 38,00 \\
\hline & 3,00 & 5 & 3,40 & 17,00 \\
\hline & Total & 10 & & \\
\hline \multirow{3}{*}{$\begin{array}{l}\text { Retirada de vareta } \\
\text { facilitada }\end{array}$} & 1,00 & 5 & 7,60 & 38,00 \\
\hline & 3,00 & 5 & 3,40 & 17,00 \\
\hline & Total & 10 & & \\
\hline \multirow[t]{3}{*}{ Puxar vareta fixa } & 1,00 & 5 & 7,20 & 36,00 \\
\hline & 3,00 & 5 & 3,80 & 19,00 \\
\hline & Total & 10 & & \\
\hline \multirow[t]{3}{*}{ Explorar caixa** } & 1,00 & 5 & 8,00 & 40,00 \\
\hline & 3,00 & 5 & 3,00 & 15,00 \\
\hline & Total & 10 & & \\
\hline \multirow[t]{3}{*}{ Scrounging ${ }^{\star * *}$} & 1,00 & 5 & 5,00 & 25,00 \\
\hline & 3,00 & 5 & 6,00 & 30,00 \\
\hline & Total & 10 & & \\
\hline
\end{tabular}




\begin{tabular}{|ll|r|r|r|}
\hline \multicolumn{1}{|c|}{ Classificações } \\
\hline Sucesso & N & $\begin{array}{c}\text { Postos de } \\
\text { média }\end{array}$ & $\begin{array}{c}\text { Soma de } \\
\text { Classificações }\end{array}$ \\
\hline Manipulação de varetas $^{* * * *}$ & 1,00 & 5 & 8,00 & 40,00 \\
& 3,00 & 5 & 3,00 & 15,00 \\
Total & 10 & & \\
\hline
\end{tabular}

Estatísticas de teste ${ }^{a}$

\begin{tabular}{|l|r|r|r|r|}
\hline & \multicolumn{1}{|c|}{$\begin{array}{c}\text { Inserções } \\
\text { observadas }\end{array}$} & $\begin{array}{c}\text { Tolerated } \\
\text { Scrounging }\end{array}$ & $\begin{array}{c}\text { Tempo na } \\
\text { caixa com } \\
\text { Proficiente }\end{array}$ & $\begin{array}{c}\text { Tempo a 2m de } \\
\text { Proficiente }\end{array}$ \\
\hline U de Mann-Whitney & 7,000 & 8,000 & 4,000 &, 000 \\
Wilcoxon W & 22,000 & 23,000 & 19,000 & 15,000 \\
Z & $-1,149$ &,- 940 & $-1,776$ & $-2,611$ \\
$\begin{array}{l}\text { Significância Sig. (2 } \\
\text { extremidades) }\end{array}$ &, 251 &, 347 &, 076 &, 009 \\
$\begin{array}{l}\text { Sig exata [2*(Sig. de 1 } \\
\text { extremidade)] }\end{array}$ &, $310^{\mathrm{b}}$ &, $421^{\mathrm{b}}$ &, $095^{\mathrm{b}}$ &, $008^{\mathrm{b}}$ \\
\hline
\end{tabular}

Estatísticas de teste ${ }^{a}$

\begin{tabular}{|l|r|r|r|r|}
\hline & $\begin{array}{c}\text { Tempo a 5m de } \\
\text { Proficiente }\end{array}$ & $\begin{array}{c}\text { Tempo na } \\
\text { caixa }\end{array}$ & Tempo a 2m & Tempo a 5m \\
\hline U de Mann-Whitney & 3,000 &, 000 &, 000 & 2,000 \\
Wilcoxon W & 18,000 & 15,000 & 15,000 & 17,000 \\
Z & $-1,984$ & $-2,611$ & $-2,611$ & $-2,193$ \\
Significância Sig. (2 &, 047 &, 009 &, 009 &, 028 \\
extremidades) &, $056^{\text {b }}$ &, $008^{\mathrm{b}}$ &, $008^{\mathrm{b}}$ &, $032^{\mathrm{b}}$ \\
$\begin{array}{l}\text { Sig exata [2*(Sig. de 1 } \\
\text { extremidade)] }\end{array}$ & & & \\
\hline
\end{tabular}

Estatísticas de teste ${ }^{a}$

\begin{tabular}{|l|r|r|r|r|}
\hline & $\begin{array}{c}\text { Retirada de } \\
\text { vareta facilitada }\end{array}$ & $\begin{array}{c}\text { Puxar vareta } \\
\text { fixa }\end{array}$ & Explorar caixa** & Scrounging $^{* \star *}$ \\
\hline U de Mann-Whitney & 2,000 & 4,000 &, 000 & 10,000 \\
Wilcoxon W & 17,000 & 19,000 & 15,000 & 25,000 \\
Z & $-2,193$ & $-1,781$ & $-2,611$ &,- 524 \\
Significância Sig. (2 &, 028 &, 075 &, 009 &, 600 \\
extremidades) &, $032^{\mathrm{b}}$ &, $095^{\mathrm{b}}$ &, $008^{\mathrm{b}}$ &, $690^{\mathrm{b}}$ \\
Sig exata [2*(Sig. de 1 & & & & \\
extremidade)] & & &
\end{tabular}


Estatísticas de teste ${ }^{a}$

\begin{tabular}{|l|r|}
\hline & $\begin{array}{c}\text { Manipulação de } \\
\text { varetas**** }^{* * *}\end{array}$ \\
\hline U de Mann-Whitney &, 000 \\
Wilcoxon W & 15,000 \\
Z & $-2,619$ \\
Significância Sig. (2 \\
extremidades) &, 009 \\
Sig exata [2*(Sig. de 1 \\
extremidade)]
\end{tabular}

a. Variável de Agrupamento: Sucesso

b. Não corrigido para vínculos.

\section{Testes de NPar}

\section{Teste Mann-Whitney 23 BRUTO}

\begin{tabular}{|c|c|c|c|c|}
\hline \multicolumn{5}{|c|}{ Classificações } \\
\hline & Sucesso & $\mathrm{N}$ & $\begin{array}{l}\text { Postos de } \\
\text { média }\end{array}$ & $\begin{array}{c}\text { Soma de } \\
\text { Classificações }\end{array}$ \\
\hline \multirow[t]{3}{*}{ Inserçōes observadas } & 2,00 & 5 & 6,80 & 34,00 \\
\hline & 3,00 & 5 & 4,20 & 21,00 \\
\hline & Total & 10 & & \\
\hline \multirow[t]{3}{*}{ Tolerated Scrounging* } & 2,00 & 5 & 7,40 & 37,00 \\
\hline & 3,00 & 5 & 3,60 & 18,00 \\
\hline & Total & 10 & & \\
\hline \multirow{3}{*}{$\begin{array}{l}\text { Tempo na caixa com } \\
\text { Proficiente }\end{array}$} & 2,00 & 5 & 7,20 & 36,00 \\
\hline & 3,00 & 5 & 3,80 & 19,00 \\
\hline & Total & 10 & & \\
\hline \multirow[t]{3}{*}{ Tempo a $2 \mathrm{~m}$ de Proficiente } & 2,00 & 5 & 7,40 & 37,00 \\
\hline & 3,00 & 5 & 3,60 & 18,00 \\
\hline & Total & 10 & & \\
\hline \multirow[t]{3}{*}{ Tempo a $5 \mathrm{~m}$ de Proficiente } & 2,00 & 5 & 7,40 & 37,00 \\
\hline & 3,00 & 5 & 3,60 & 18,00 \\
\hline & Total & 10 & & \\
\hline \multirow[t]{3}{*}{ Tempo na caixa } & 2,00 & 5 & 8,00 & 40,00 \\
\hline & 3,00 & 5 & 3,00 & 15,00 \\
\hline & Total & 10 & & \\
\hline
\end{tabular}




\begin{tabular}{|c|c|c|c|c|}
\hline \multicolumn{5}{|c|}{ Classificações } \\
\hline & Sucesso & $\mathrm{N}$ & $\begin{array}{l}\text { Postos de } \\
\text { média }\end{array}$ & $\begin{array}{l}\text { Soma de } \\
\text { Classificações }\end{array}$ \\
\hline \multirow[t]{3}{*}{ Tempo a $2 \mathrm{~m}$} & 2,00 & 5 & 8,00 & 40,00 \\
\hline & 3,00 & 5 & 3,00 & 15,00 \\
\hline & Total & 10 & & \\
\hline \multirow[t]{3}{*}{ Tempo a $5 \mathrm{~m}$} & 2,00 & 5 & 8,00 & 40,00 \\
\hline & 3,00 & 5 & 3,00 & 15,00 \\
\hline & Total & 10 & & \\
\hline \multirow{3}{*}{$\begin{array}{l}\text { Retirada de vareta } \\
\text { facilitada }\end{array}$} & 2,00 & 5 & 5,00 & 25,00 \\
\hline & 3,00 & 5 & 6,00 & 30,00 \\
\hline & Total & 10 & & \\
\hline \multirow[t]{3}{*}{ Puxar vareta fixa } & 2,00 & 5 & 6,00 & 30,00 \\
\hline & 3,00 & 5 & 5,00 & 25,00 \\
\hline & Total & 10 & & \\
\hline \multirow[t]{3}{*}{ Explorar caixa ${ }^{\star \star}$} & 2,00 & 5 & 8,00 & 40,00 \\
\hline & 3,00 & 5 & 3,00 & 15,00 \\
\hline & Total & 10 & & \\
\hline \multirow[t]{3}{*}{ Scrounging ${ }^{\star \star \star}$} & 2,00 & 5 & 7,20 & 36,00 \\
\hline & 3,00 & 5 & 3,80 & 19,00 \\
\hline & Total & 10 & & \\
\hline \multirow[t]{3}{*}{ Manipulação de varetas } & 2,00 & 5 & 8,00 & 40,00 \\
\hline & 3,00 & 5 & 3,00 & 15,00 \\
\hline & Total & 10 & & \\
\hline
\end{tabular}

Estatísticas de teste $\mathrm{a}^{\mathrm{a}}$

\begin{tabular}{|l|r|r|r|r|}
\hline & $\begin{array}{c}\text { Inserções } \\
\text { observadas }\end{array}$ & $\begin{array}{c}\text { Tolerated } \\
\text { Scrounging }^{*}\end{array}$ & $\begin{array}{c}\text { Tempo na } \\
\text { caixa com } \\
\text { Proficiente }\end{array}$ & $\begin{array}{c}\text { Tempo a 2m de } \\
\text { Proficiente }\end{array}$ \\
\hline U de Mann-Whitney & 6,000 & 3,000 & 4,000 & 3,000 \\
Wilcoxon W & 21,000 & 18,000 & 19,000 & 18,000 \\
Z & $-1,358$ & $-1,984$ & $-1,776$ & $-1,984$ \\
$\begin{array}{l}\text { Significância Sig. (2 } \\
\text { extremidades) }\end{array}$ &, 175 &, 047 &, 076 &, 047 \\
$\begin{array}{l}\text { Sig exata [2*(Sig. de 1 } \\
\text { extremidade)] }\end{array}$ &, $222^{\text {b }}$ &, $056^{\text {b }}$ &, $095^{\text {b }}$ &, $056^{\text {b }}$ \\
\hline
\end{tabular}


Estatísticas de teste ${ }^{\mathrm{a}}$

\begin{tabular}{|l|r|r|r|r|}
\hline & $\begin{array}{c}\text { Tempo a 5m de } \\
\text { Proficiente }\end{array}$ & $\begin{array}{c}\text { Tempo na } \\
\text { caixa }\end{array}$ & Tempo a 2m & Tempo a 5m \\
\hline U de Mann-Whitney & 3,000 &, 000 &, 000 &, 000 \\
Wilcoxon W & 18,000 & 15,000 & 15,000 & 15,000 \\
Z & $-1,984$ & $-2,611$ & $-2,611$ & $-2,611$ \\
Significância Sig. (2 &, 047 &, 009 &, 009 &, 009 \\
extremidades) &, $056^{\mathrm{b}}$ &, $008^{\mathrm{b}}$ &, $008^{\mathrm{b}}$ &, $008^{\mathrm{b}}$ \\
Sig exata [2*(Sig. de 1 & & & \\
extremidade)] & & &
\end{tabular}

Estatísticas de teste ${ }^{a}$

\begin{tabular}{|l|r|r|r|r|}
\hline & $\begin{array}{c}\text { Retirada de } \\
\text { vareta facilitada }\end{array}$ & $\begin{array}{c}\text { Puxar vareta } \\
\text { fixa }\end{array}$ & Explorar caixa** $^{* *}$ & Scrounging $^{* * *}$ \\
\hline U de Mann-Whitney & 10,000 & 10,000 &, 000 & 4,000 \\
Wilcoxon W & 25,000 & 25,000 & 15,000 & 19,000 \\
Z &,- 524 &,- 529 & $-2,611$ & $-1,781$ \\
$\begin{array}{l}\text { Significância Sig. (2 } \\
\text { extremidades) }\end{array}$ &, 600 &, 597 &, 009 &, 075 \\
$\begin{array}{l}\text { Sig exata [2*(Sig. de 1 } \\
\text { extremidade)] }\end{array}$ &, $690^{\mathrm{b}}$ &, $690^{\mathrm{b}}$ &, $008^{\mathrm{b}}$ &, $095^{\mathrm{b}}$ \\
\hline
\end{tabular}

Estatísticas de teste ${ }^{a}$

\begin{tabular}{|l|r|}
\hline & $\begin{array}{c}\text { Manipulação de } \\
\text { varetas }^{* * * *}\end{array}$ \\
\hline U de Mann-Whitney &, 000 \\
Wilcoxon W & 15,000 \\
Z & $-2,619$ \\
Significância Sig. (2 &, 009 \\
extremidades) &, $008^{\text {b }}$ \\
Sig exata [2*(Sig. de 1 & \\
extremidade)] & \\
\hline
\end{tabular}

a. Variável de Agrupamento: Sucesso

b. Não corrigido para vínculos. 


\section{APÊNDICE F - TESTES ESTATÍSTICOS NÃO PARAMÉTRICOS (DADOS CORRIGIDOS)}

Teste Kruskal-Wallis 123 RAZAO

\begin{tabular}{|c|c|c|c|}
\hline \multicolumn{4}{|c|}{ Classificações } \\
\hline & Sucesso & $\mathrm{N}$ & $\begin{array}{l}\text { Postos de } \\
\text { média }\end{array}$ \\
\hline \multirow[t]{4}{*}{ Inserções observadas } & 1,00 & 5 & 6,60 \\
\hline & 2,00 & 5 & 9,00 \\
\hline & 3,00 & 5 & 8,40 \\
\hline & Total & 15 & \\
\hline \multirow[t]{4}{*}{ Tolerated Scrounging ${ }^{\star}$} & 1,00 & 5 & 6,20 \\
\hline & 2,00 & 5 & 9,60 \\
\hline & 3,00 & 5 & 8,20 \\
\hline & Total & 15 & \\
\hline \multirow{4}{*}{$\begin{array}{l}\text { Tempo na caixa com } \\
\text { Proficiente }\end{array}$} & 1,00 & 5 & 7,10 \\
\hline & 2,00 & 5 & 9,40 \\
\hline & 3,00 & 5 & 7,50 \\
\hline & Total & 15 & \\
\hline \multirow[t]{4}{*}{ Tempo a $2 \mathrm{~m}$ de Proficiente } & 1,00 & 5 & 7,70 \\
\hline & 2,00 & 5 & 7,30 \\
\hline & 3,00 & 5 & 9,00 \\
\hline & Total & 15 & \\
\hline \multirow[t]{4}{*}{ Tempo a 5m de Proficiente } & 1,00 & 5 & 8,40 \\
\hline & 2,00 & 5 & 8,40 \\
\hline & 3,00 & 5 & 7,20 \\
\hline & Total & 15 & \\
\hline \multirow[t]{4}{*}{ Tempo na caixa } & 1,00 & 5 & 11,00 \\
\hline & 2,00 & 5 & 10,00 \\
\hline & 3,00 & 5 & 3,00 \\
\hline & Total & 15 & \\
\hline \multirow[t]{4}{*}{ Tempo a $2 m$} & 1,00 & 5 & 6,00 \\
\hline & 2,00 & 5 & 10,00 \\
\hline & 3,00 & 5 & 8,00 \\
\hline & Total & 15 & \\
\hline \multirow[t]{4}{*}{ Tempo a $5 \mathrm{~m}$} & 1,00 & 5 & 8,20 \\
\hline & 2,00 & 5 & 9,20 \\
\hline & 3,00 & 5 & 6,60 \\
\hline & Total & 15 & \\
\hline \multirow{4}{*}{$\begin{array}{l}\text { Retirada de vareta } \\
\text { facilitada }\end{array}$} & 1,00 & 5 & 7,40 \\
\hline & 2,00 & 5 & 7,00 \\
\hline & 3,00 & 5 & 9,60 \\
\hline & Total & 15 & \\
\hline \multirow[t]{2}{*}{ Puxar vareta fixa } & 1,00 & 5 & 8,80 \\
\hline & 2,00 & 5 & 8,00 \\
\hline
\end{tabular}




\begin{tabular}{|c|c|c|c|}
\hline \multicolumn{4}{|c|}{ Classificações } \\
\hline & Sucesso & $\mathrm{N}$ & $\begin{array}{l}\text { Postos de } \\
\text { média }\end{array}$ \\
\hline & 3,00 & 5 & 7,20 \\
\hline & Total & 15 & \\
\hline \multirow[t]{4}{*}{ Explorar caixa ${ }^{\star \star}$} & 1,00 & 5 & 7,80 \\
\hline & 2,00 & 5 & 7,00 \\
\hline & 3,00 & 5 & 9,20 \\
\hline & Total & 15 & \\
\hline \multirow[t]{4}{*}{ Scrounging ${ }^{\star \star *}$} & 1,00 & 5 & 5,00 \\
\hline & 2,00 & 5 & 10,00 \\
\hline & 3,00 & 5 & 9,00 \\
\hline & Total & 15 & \\
\hline \multirow[t]{4}{*}{ Manipulação de varetas ${ }^{\star \star \star \star}$} & 1,00 & 5 & 12,80 \\
\hline & 2,00 & 5 & 7,80 \\
\hline & 3,00 & 5 & 3,40 \\
\hline & Total & 15 & \\
\hline
\end{tabular}

Estatísticas de teste ${ }^{a, b}$

\begin{tabular}{|l|r|r|r|r|r|}
\hline & $\begin{array}{c}\text { Inserções } \\
\text { observadas }\end{array}$ & $\begin{array}{c}\text { Tolerated } \\
\text { Scrounging* }\end{array}$ & $\begin{array}{c}\text { Tempo na } \\
\text { caixa com } \\
\text { Proficiente }\end{array}$ & $\begin{array}{c}\text { Tempo a 2m de } \\
\text { Proficiente }\end{array}$ & $\begin{array}{c}\text { Tempo a 5m de } \\
\text { Proficiente }\end{array}$ \\
\hline Qui-quadrado &, 780 & 1,460 &, 758 &, 397 &, 243 \\
df & 2 & 2 & 2 & 2 & 2 \\
Significância Sig. &, 677 &, 482 &, 685 &, 820 &, 886 \\
\hline
\end{tabular}

Estatísticas de teste ${ }^{a, b}$

\begin{tabular}{|l|r|r|r|r|r|}
\hline & $\begin{array}{c}\text { Tempo na } \\
\text { caixa }\end{array}$ & Tempo a 2m & Tempo a 5m & $\begin{array}{c}\text { Retirada de } \\
\text { vareta facilitada }\end{array}$ & $\begin{array}{c}\text { Puxar vareta } \\
\text { fixa }\end{array}$ \\
\hline Qui-quadrado & 9,500 & 2,000 &, 860 &, 982 &, 322 \\
df & 2 & 2 & 2 & 2 & 2 \\
Significância Sig. &, 009 &, 368 &, 651 &, 612 &, 851 \\
\hline
\end{tabular}

Estatísticas de teste ${ }^{a, b}$

\begin{tabular}{|l|r|r|r|}
\hline & Explorar caixa** & Scrounging & $\begin{array}{c}\text { Manipulação de } \\
\text { varetas }^{* * * *}\end{array}$ \\
\hline Qui-quadrado &, 620 & 3,500 & 11,060 \\
df & 2 & 2 & 2 \\
Significância Sig. &, 733 &, 174 &, 004 \\
\hline
\end{tabular}

a. Teste Kruskal Wallis

b. Variável de Agrupamento: Sucesso 
Teste Mann-Whitney 1 E 2 RAZAO

\begin{tabular}{|c|c|c|c|c|}
\hline \multicolumn{5}{|c|}{ Classificações } \\
\hline & Sucesso & $\mathrm{N}$ & $\begin{array}{l}\text { Postos de } \\
\text { média }\end{array}$ & $\begin{array}{l}\text { Soma de } \\
\text { Classificações }\end{array}$ \\
\hline \multirow[t]{3}{*}{ Inserções observadas } & 1,00 & 5 & 4,80 & 24,00 \\
\hline & 2,00 & 5 & 6,20 & 31,00 \\
\hline & Total & 10 & & \\
\hline \multirow[t]{3}{*}{ Tolerated Scrounging ${ }^{*}$} & 1,00 & 5 & 4,40 & 22,00 \\
\hline & 2,00 & 5 & 6,60 & 33,00 \\
\hline & Total & 10 & & \\
\hline \multirow{3}{*}{$\begin{array}{l}\text { Tempo na caixa com } \\
\text { Proficiente }\end{array}$} & 1,00 & 5 & 4,60 & 23,00 \\
\hline & 2,00 & 5 & 6,40 & 32,00 \\
\hline & Total & 10 & & \\
\hline \multirow[t]{3}{*}{ Tempo a $2 \mathrm{~m}$ de Proficiente } & 1,00 & 5 & 5,80 & 29,00 \\
\hline & 2,00 & 5 & 5,20 & 26,00 \\
\hline & Total & 10 & & \\
\hline \multirow[t]{3}{*}{ Tempo a $5 \mathrm{~m}$ de Proficiente } & 1,00 & 5 & 5,60 & 28,00 \\
\hline & 2,00 & 5 & 5,40 & 27,00 \\
\hline & Total & 10 & & \\
\hline \multirow[t]{3}{*}{ Tempo na caixa } & 1,00 & 5 & 6,00 & 30,00 \\
\hline & 2,00 & 5 & 5,00 & 25,00 \\
\hline & Total & 10 & & \\
\hline \multirow[t]{3}{*}{ Tempo a $2 m$} & 1,00 & 5 & 4,40 & 22,00 \\
\hline & 2,00 & 5 & 6,60 & 33,00 \\
\hline & Total & 10 & & \\
\hline \multirow[t]{3}{*}{ Tempo a $5 \mathrm{~m}$} & 1,00 & 5 & 5,20 & 26,00 \\
\hline & 2,00 & 5 & 5,80 & 29,00 \\
\hline & Total & 10 & & \\
\hline \multirow{3}{*}{$\begin{array}{l}\text { Retirada de vareta } \\
\text { facilitada }\end{array}$} & 1,00 & 5 & 6,00 & 30,00 \\
\hline & 2,00 & 5 & 5,00 & 25,00 \\
\hline & Total & 10 & & \\
\hline \multirow[t]{3}{*}{ Puxar vareta fixa } & 1,00 & 5 & 6,00 & 30,00 \\
\hline & 2,00 & 5 & 5,00 & 25,00 \\
\hline & Total & 10 & & \\
\hline \multirow[t]{3}{*}{ Explorar caixa ${ }^{\star *}$} & 1,00 & 5 & 5,60 & 28,00 \\
\hline & 2,00 & 5 & 5,40 & 27,00 \\
\hline & Total & 10 & & \\
\hline
\end{tabular}




\begin{tabular}{|ll|r|r|c|}
\hline & Classificações \\
\hline & Sucesso & $\mathrm{N}$ & $\begin{array}{c}\text { Postos de } \\
\text { média }\end{array}$ & $\begin{array}{c}\text { Soma de } \\
\text { Classificações }\end{array}$ \\
\hline Scrounging $^{\star \star \star}$ & 1,00 & 5 & 3,60 & 18,00 \\
& 2,00 & 5 & 7,40 & 37,00 \\
& Total & 10 & & 39,00 \\
\hline Manipulação de varetas $^{\star \star \star \star}$ & 1,00 & 5 & 7,80 & 16,00 \\
& 2,00 & 5 & 3,20 & \\
& Total & 10 & & \\
\hline
\end{tabular}

Estatísticas de teste ${ }^{a}$

\begin{tabular}{|l|r|r|r|r|}
\hline & \multicolumn{1}{|c|}{$\begin{array}{c}\text { Inserções } \\
\text { observadas }\end{array}$} & $\begin{array}{c}\text { Tolerated } \\
\text { Scrounging }\end{array}$ & $\begin{array}{c}\text { Tempo na } \\
\text { caixa com } \\
\text { Proficiente }\end{array}$ & $\begin{array}{c}\text { Tempo a 2m de } \\
\text { Proficiente }\end{array}$ \\
\hline U de Mann-Whitney & 9,000 & 7,000 & 8,000 & 11,000 \\
Wilcoxon W & 24,000 & 22,000 & 23,000 & 26,000 \\
Z &,- 731 & $-1,149$ &,- 943 &,- 314 \\
$\begin{array}{l}\text { Significância Sig. (2 } \\
\text { extremidades) }\end{array}$ &, 465 &, 251 &, 346 &, 753 \\
$\begin{array}{l}\text { Sig exata [2*(Sig. de 1 } \\
\text { extremidade)] }\end{array}$ &, $548^{\mathrm{b}}$ &, $310^{\mathrm{b}}$ &, $421^{\mathrm{b}}$ &, $841^{\mathrm{b}}$ \\
\hline
\end{tabular}

Estatísticas de teste ${ }^{a}$

\begin{tabular}{|l|r|r|r|r|}
\hline & $\begin{array}{c}\text { Tempo a 5m de } \\
\text { Proficiente }\end{array}$ & $\begin{array}{c}\text { Tempo na } \\
\text { caixa }\end{array}$ & Tempo a 2m & Tempo a 5m \\
\hline U de Mann-Whitney & 12,000 & 10,000 & 7,000 & 11,000 \\
Wilcoxon W & 27,000 & 25,000 & 22,000 & 26,000 \\
Z &,- 105 &,- 522 & $-1,149$ &,- 313 \\
Significância Sig. (2 &, 916 &, 602 &, 251 &, 754 \\
extremidades) & $1,000^{\mathrm{b}}$ &, $690^{\mathrm{b}}$ &, $310^{\mathrm{b}}$ &, $841^{\mathrm{b}}$ \\
$\begin{array}{l}\text { Sig exata [2*(Sig. de 1 } \\
\text { extremidade)] }\end{array}$ & & & & \\
\hline
\end{tabular}


Estatísticas de teste ${ }^{a}$

\begin{tabular}{|l|r|r|r|r|}
\hline & $\begin{array}{c}\text { Retirada de } \\
\text { vareta facilitada }\end{array}$ & $\begin{array}{c}\text { Puxar vareta } \\
\text { fixa }\end{array}$ & Explorar caixa** & Scrounging $^{* * *}$ \\
\hline U de Mann-Whitney & 10,000 & 10,000 & 12,000 & 3,000 \\
Wilcoxon W & 25,000 & 25,000 & 27,000 & 18,000 \\
Z &,- 524 &,- 522 &,- 104 & $-1,984$ \\
Significância Sig. (2 &, 600 &, 602 &, 917 &, 047 \\
extremidades) &, $690^{\mathrm{b}}$ &, $690^{\mathrm{b}}$ & $1,000^{\mathrm{b}}$ &, $056^{\mathrm{b}}$ \\
$\begin{array}{l}\text { Sig exata [2*(Sig. de 1 } \\
\text { extremidade)] }\end{array}$ & & & & \\
\hline
\end{tabular}

Estatísticas de teste ${ }^{a}$

\begin{tabular}{|l|r|}
\hline & $\begin{array}{c}\text { Manipulação de } \\
\text { varetas }^{* * * *}\end{array}$ \\
\hline U de Mann-Whitney & 1,000 \\
Wilcoxon W & 16,000 \\
Z & $-2,402$ \\
Significância Sig. (2 &, 016 \\
extremidades) &, $016^{\mathrm{b}}$ \\
Sig exata [2*(Sig. de 1 \\
extremidade)]
\end{tabular}

a. Variável de Agrupamento: Sucesso

b. Não corrigido para vínculos.

Teste Mann-Whitney 1 E 3 RAZAO 


\begin{tabular}{|c|c|c|c|c|}
\hline \multicolumn{5}{|c|}{ Classificações } \\
\hline & Sucesso & $\mathrm{N}$ & $\begin{array}{l}\text { Postos de } \\
\text { média }\end{array}$ & $\begin{array}{l}\text { Soma de } \\
\text { Classificações }\end{array}$ \\
\hline \multirow[t]{3}{*}{ Inserções observadas } & 1,00 & 5 & 4,80 & 24,00 \\
\hline & 3,00 & 5 & 6,20 & 31,00 \\
\hline & Total & 10 & & \\
\hline \multirow[t]{3}{*}{ Tolerated Scrounging ${ }^{*}$} & 1,00 & 5 & 4,80 & 24,00 \\
\hline & 3,00 & 5 & 6,20 & 31,00 \\
\hline & Total & 10 & & \\
\hline \multirow{3}{*}{$\begin{array}{l}\text { Tempo na caixa com } \\
\text { Proficiente }\end{array}$} & 1,00 & 5 & 5,50 & 27,50 \\
\hline & 3,00 & 5 & 5,50 & 27,50 \\
\hline & Total & 10 & & \\
\hline \multirow[t]{3}{*}{ Tempo a $2 \mathrm{~m}$ de Proficiente } & 1,00 & 5 & 4,90 & 24,50 \\
\hline & 3,00 & 5 & 6,10 & 30,50 \\
\hline & Total & 10 & & \\
\hline \multirow[t]{3}{*}{ Tempo a 5m de Proficiente } & 1,00 & 5 & 5,80 & 29,00 \\
\hline & 3,00 & 5 & 5,20 & 26,00 \\
\hline & Total & 10 & & \\
\hline \multirow[t]{3}{*}{ Tempo na caixa } & 1,00 & 5 & 8,00 & 40,00 \\
\hline & 3,00 & 5 & 3,00 & 15,00 \\
\hline & Total & 10 & & \\
\hline \multirow[t]{3}{*}{ Tempo a $2 \mathrm{~m}$} & 1,00 & 5 & 4,60 & 23,00 \\
\hline & 3,00 & 5 & 6,40 & 32,00 \\
\hline & Total & 10 & & \\
\hline \multirow[t]{3}{*}{ Tempo a $5 \mathrm{~m}$} & 1,00 & 5 & 6,00 & 30,00 \\
\hline & 3,00 & 5 & 5,00 & 25,00 \\
\hline & Total & 10 & & \\
\hline \multirow{3}{*}{$\begin{array}{l}\text { Retirada de vareta } \\
\text { facilitada }\end{array}$} & 1,00 & 5 & 4,40 & 22,00 \\
\hline & 3,00 & 5 & 6,60 & 33,00 \\
\hline & Total & 10 & & \\
\hline \multirow[t]{3}{*}{ Puxar vareta fixa } & 1,00 & 5 & 5,80 & 29,00 \\
\hline & 3,00 & 5 & 5,20 & 26,00 \\
\hline & Total & 10 & & \\
\hline \multirow[t]{3}{*}{ Explorar caixa** } & 1,00 & 5 & 5,20 & 26,00 \\
\hline & 3,00 & 5 & 5,80 & 29,00 \\
\hline & Total & 10 & & \\
\hline \multirow[t]{3}{*}{ Scrounging ${ }^{\star \star \star}$} & 1,00 & 5 & 4,40 & 22,00 \\
\hline & 3,00 & 5 & 6,60 & 33,00 \\
\hline & Total & 10 & & \\
\hline
\end{tabular}




\begin{tabular}{|ll|r|r|r|}
\hline \multicolumn{1}{|c|}{ Classificações } \\
\hline Sucesso & N & $\begin{array}{c}\text { Postos de } \\
\text { média }\end{array}$ & $\begin{array}{c}\text { Soma de } \\
\text { Classificações }\end{array}$ \\
\hline Manipulação de varetas $^{* * * *}$ & 1,00 & 5 & 8,00 & 40,00 \\
& 3,00 & 5 & 3,00 & 15,00 \\
Total & 10 & & \\
\hline
\end{tabular}

Estatísticas de teste ${ }^{a}$

\begin{tabular}{|l|r|r|r|r|}
\hline & $\begin{array}{c}\text { Inserções } \\
\text { observadas }\end{array}$ & $\begin{array}{c}\text { Tolerated } \\
\text { Scrounging }^{*}\end{array}$ & $\begin{array}{c}\text { Tempo na } \\
\text { caixa com } \\
\text { Proficiente }\end{array}$ & $\begin{array}{c}\text { Tempo a 2m de } \\
\text { Proficiente }\end{array}$ \\
\hline U de Mann-Whitney & 9,000 & 9,000 & 12,500 & 9,500 \\
Wilcoxon W & 24,000 & 24,000 & 27,500 & 24,500 \\
Z &,- 731 &,- 731 &, 000 &,- 631 \\
$\begin{array}{l}\text { Significância Sig. (2 } \\
\text { extremidades) }\end{array}$ &, 465 &, 465 & 1,000 &, 528 \\
$\begin{array}{l}\text { Sig exata [2*(Sig. de 1 } \\
\text { extremidade)] }\end{array}$ &, $548^{\mathrm{b}}$ &, $548^{\mathrm{b}}$ & $1,000^{\mathrm{b}}$ &, $548^{\mathrm{b}}$ \\
\hline
\end{tabular}

Estatísticas de teste ${ }^{a}$

\begin{tabular}{|l|r|r|r|r|}
\hline & $\begin{array}{c}\text { Tempo a 5m de } \\
\text { Proficiente }\end{array}$ & $\begin{array}{c}\text { Tempo na } \\
\text { caixa }\end{array}$ & Tempo a 2m & Tempo a 5m \\
\hline U de Mann-Whitney & 11,000 &, 000 & 8,000 & 10,000 \\
Wilcoxon W & 26,000 & 15,000 & 23,000 & 25,000 \\
Z &,- 317 & $-2,611$ &,- 940 &,- 522 \\
Significância Sig. (2 &, 751 &, 009 &, 347 &, 602 \\
extremidades) &, $841^{\mathrm{b}}$ &, $008^{\mathrm{b}}$ &, $421^{\mathrm{b}}$ &, $690^{\mathrm{b}}$ \\
$\begin{array}{l}\text { Sig exata [2*(Sig. de 1 } \\
\text { extremidade)] }\end{array}$ & & & \\
\hline
\end{tabular}

Estatísticas de teste ${ }^{a}$

\begin{tabular}{|l|r|r|r|r|}
\hline & $\begin{array}{c}\text { Retirada de } \\
\text { vareta facilitada }\end{array}$ & $\begin{array}{c}\text { Puxar vareta } \\
\text { fixa }\end{array}$ & Explorar caixa** & Scrounging $^{* \star *}$ \\
\hline U de Mann-Whitney & 7,000 & 11,000 & 11,000 & 7,000 \\
Wilcoxon W & 22,000 & 26,000 & 26,000 & 22,000 \\
Z & $-1,149$ &,- 314 &,- 313 & $-1,149$ \\
Significância Sig. (2 &, 251 &, 753 &, 754 &, 251 \\
extremidades) &, $310^{\mathrm{b}}$ &, $841^{\mathrm{b}}$ &, $841^{\mathrm{b}}$ &, $310^{\mathrm{b}}$ \\
Sig exata [2*(Sig. de 1 & & & & \\
extremidade)] & & &
\end{tabular}


Estatísticas de teste ${ }^{a}$

\begin{tabular}{|l|r|}
\hline & $\begin{array}{c}\text { Manipulação de } \\
\text { varetas**** }^{* * *}\end{array}$ \\
\hline U de Mann-Whitney &, 000 \\
Wilcoxon W & 15,000 \\
Z & $-2,611$ \\
Significância Sig. (2 \\
extremidades) &, 009 \\
Sig exata [2*(Sig. de 1 \\
extremidade)]
\end{tabular}

a. Variável de Agrupamento: Sucesso

b. Não corrigido para vínculos.

Teste Mann-Whitney 2 E 3 RAZAO

\begin{tabular}{|c|c|c|c|c|}
\hline \multicolumn{5}{|c|}{ Classificações } \\
\hline & Sucesso & $\mathrm{N}$ & $\begin{array}{l}\text { Postos de } \\
\text { média }\end{array}$ & $\begin{array}{c}\text { Soma de } \\
\text { Classificações }\end{array}$ \\
\hline \multirow[t]{3}{*}{ Inserções observadas } & 2,00 & 5 & 5,80 & 29,00 \\
\hline & 3,00 & 5 & 5,20 & 26,00 \\
\hline & Total & 10 & & \\
\hline \multirow[t]{3}{*}{ Tolerated Scrounging ${ }^{*}$} & 2,00 & 5 & 6,00 & 30,00 \\
\hline & 3,00 & 5 & 5,00 & 25,00 \\
\hline & Total & 10 & & \\
\hline \multirow{3}{*}{$\begin{array}{l}\text { Tempo na caixa com } \\
\text { Proficiente }\end{array}$} & 2,00 & 5 & 6,00 & 30,00 \\
\hline & 3,00 & 5 & 5,00 & 25,00 \\
\hline & Total & 10 & & \\
\hline \multirow[t]{3}{*}{ Tempo a $2 \mathrm{~m}$ de Proficiente } & 2,00 & 5 & 5,10 & 25,50 \\
\hline & 3,00 & 5 & 5,90 & 29,50 \\
\hline & Total & 10 & & \\
\hline \multirow[t]{3}{*}{ Tempo a $5 \mathrm{~m}$ de Proficiente } & 2,00 & 5 & 6,00 & 30,00 \\
\hline & 3,00 & 5 & 5,00 & 25,00 \\
\hline & Total & 10 & & \\
\hline \multirow[t]{3}{*}{ Tempo na caixa } & 2,00 & 5 & 8,00 & 40,00 \\
\hline & 3,00 & 5 & 3,00 & 15,00 \\
\hline & Total & 10 & & \\
\hline \multirow[t]{3}{*}{ Tempo a $2 \mathrm{~m}$} & 2,00 & 5 & 6,40 & 32,00 \\
\hline & 3,00 & 5 & 4,60 & 23,00 \\
\hline & Total & 10 & & \\
\hline
\end{tabular}




\begin{tabular}{|c|c|c|c|c|}
\hline \multicolumn{5}{|c|}{ Classificações } \\
\hline & Sucesso & $\mathrm{N}$ & $\begin{array}{l}\text { Postos de } \\
\text { média }\end{array}$ & $\begin{array}{c}\text { Soma de } \\
\text { Classificações }\end{array}$ \\
\hline \multirow[t]{3}{*}{ Tempo a $5 \mathrm{~m}$} & 2,00 & 5 & 6,40 & 32,00 \\
\hline & 3,00 & 5 & 4,60 & 23,00 \\
\hline & Total & 10 & & \\
\hline \multirow{3}{*}{$\begin{array}{l}\text { Retirada de vareta } \\
\text { facilitada }\end{array}$} & 2,00 & 5 & 5,00 & 25,00 \\
\hline & 3,00 & 5 & 6,00 & 30,00 \\
\hline & Total & 10 & & \\
\hline \multirow[t]{3}{*}{ Puxar vareta fixa } & 2,00 & 5 & 6,00 & 30,00 \\
\hline & 3,00 & 5 & 5,00 & 25,00 \\
\hline & Total & 10 & & \\
\hline \multirow[t]{3}{*}{ Explorar caixa** } & 2,00 & 5 & 4,60 & 23,00 \\
\hline & 3,00 & 5 & 6,40 & 32,00 \\
\hline & Total & 10 & & \\
\hline \multirow[t]{3}{*}{ Scrounging ${ }^{\star * *}$} & 2,00 & 5 & 5,60 & 28,00 \\
\hline & 3,00 & 5 & 5,40 & 27,00 \\
\hline & Total & 10 & & \\
\hline \multirow[t]{3}{*}{ Manipulação de varetas ${ }^{\star * \star *}$} & 2,00 & 5 & 7,60 & 38,00 \\
\hline & 3,00 & 5 & 3,40 & 17,00 \\
\hline & Total & 10 & & \\
\hline
\end{tabular}

Estatísticas de teste ${ }^{a}$

\begin{tabular}{|l|r|r|r|r|}
\hline & $\begin{array}{c}\text { Inserções } \\
\text { observadas }\end{array}$ & $\begin{array}{c}\text { Tolerated } \\
\text { Scrounging }^{*}\end{array}$ & $\begin{array}{c}\text { Tempo na } \\
\text { caixa com } \\
\text { Proficiente }\end{array}$ & $\begin{array}{c}\text { Tempo a 2m de } \\
\text { Proficiente }\end{array}$ \\
\hline U de Mann-Whitney & 11,000 & 10,000 & 10,000 & 10,500 \\
Wilcoxon W & 26,000 & 25,000 & 25,000 & 25,500 \\
Z &,- 313 &,- 522 &,- 522 &,- 419 \\
$\begin{array}{l}\text { Significância Sig. (2 } \\
\text { extremidades) }\end{array}$ &, 754 &, 602 &, 602 &, 675 \\
$\begin{array}{l}\text { Sig exata [2*(Sig. de 1 } \\
\text { extremidade)] }\end{array}$ &, $841^{\mathrm{b}}$ &, $690^{\mathrm{b}}$ &, $690^{\mathrm{b}}$ &, $690^{\mathrm{b}}$ \\
\hline
\end{tabular}


Estatísticas de teste ${ }^{\mathrm{a}}$

\begin{tabular}{|l|r|r|r|r|}
\hline & $\begin{array}{c}\text { Tempo a 5m de } \\
\text { Proficiente }\end{array}$ & $\begin{array}{c}\text { Tempo na } \\
\text { caixa }\end{array}$ & Tempo a 2m & Tempo a 5m \\
\hline U de Mann-Whitney & 10,000 &, 000 & 8,000 & 8,000 \\
Wilcoxon W & 25,000 & 15,000 & 23,000 & 23,000 \\
Z &,- 524 & $-2,611$ &,- 940 &,- 940 \\
Significância Sig. (2 &, 600 &, 009 &, 347 &, 347 \\
extremidades) &, $690^{\mathrm{b}}$ &, $008^{\mathrm{b}}$ &, $421^{\mathrm{b}}$ &, $421^{\mathrm{b}}$ \\
$\begin{array}{l}\text { Sig exata [2*(Sig. de 1 } \\
\text { extremidade)] }\end{array}$ & & & &
\end{tabular}

Estatísticas de teste ${ }^{a}$

\begin{tabular}{|l|r|r|r|r|}
\hline & $\begin{array}{c}\text { Retirada de } \\
\text { vareta facilitada }\end{array}$ & $\begin{array}{c}\text { Puxar vareta } \\
\text { fixa }\end{array}$ & Explorar caixa**$^{* *}$ & Scrounging $^{* * *}$ \\
\hline U de Mann-Whitney & 10,000 & 10,000 & 8,000 & 12,000 \\
Wilcoxon W & 25,000 & 25,000 & 23,000 & 27,000 \\
Z &,- 524 &,- 529 &,- 940 &,- 104 \\
$\begin{array}{l}\text { Significância Sig. (2 } \\
\text { extremidades) }\end{array}$ &, 600 &, 597 &, 347 &, 917 \\
$\begin{array}{l}\text { Sig exata [2*(Sig. de 1 } \\
\text { extremidade)] }\end{array}$ &, $690^{\mathrm{b}}$ &, $690^{\mathrm{b}}$ &, $421^{\mathrm{b}}$ & $1,000^{\mathrm{b}}$ \\
\hline
\end{tabular}

Estatísticas de teste ${ }^{a}$

\begin{tabular}{|l|r|}
\hline & $\begin{array}{c}\text { Manipulação de } \\
\text { varetas }^{* * * *}\end{array}$ \\
\hline U de Mann-Whitney & 2,000 \\
Wilcoxon W & 17,000 \\
Z & $-2,193$ \\
Significância Sig. (2 &, 028 \\
extremidades) &, $032^{\mathrm{b}}$ \\
Sig exata [2*(Sig. de 1 & \\
extremidade)] & \\
\hline
\end{tabular}

a. Variável de Agrupamento: Sucesso

b. Não corrigido para vínculos.

Testes de NPar 